Thiago de Paula Alonso

\title{
CONDUTIVIDADE HIDRÁULICA DE SOLOS COMPACTADOS EM ENSAIOS COM PERMEÂMETRO DE PAREDE FLEXÍVEL
}

\begin{abstract}
Dissertação apresentada à Escola de Engenharia de São Carlos da Universidade de São Paulo, como parte dos requisitos para obtenção do título de Mestre em Geotecnia.
\end{abstract}

Orientador: Professor Dr. Orencio Monje Vilar

São Carlos, Agosto de 2005 
FOLHA DE JULGAMENTO

Candidato: Engenheiro THIAGO DE PAULA ALONSO

Dissertação defendida e julgada em 16-09-2005 perante a Comissão Julgadora:

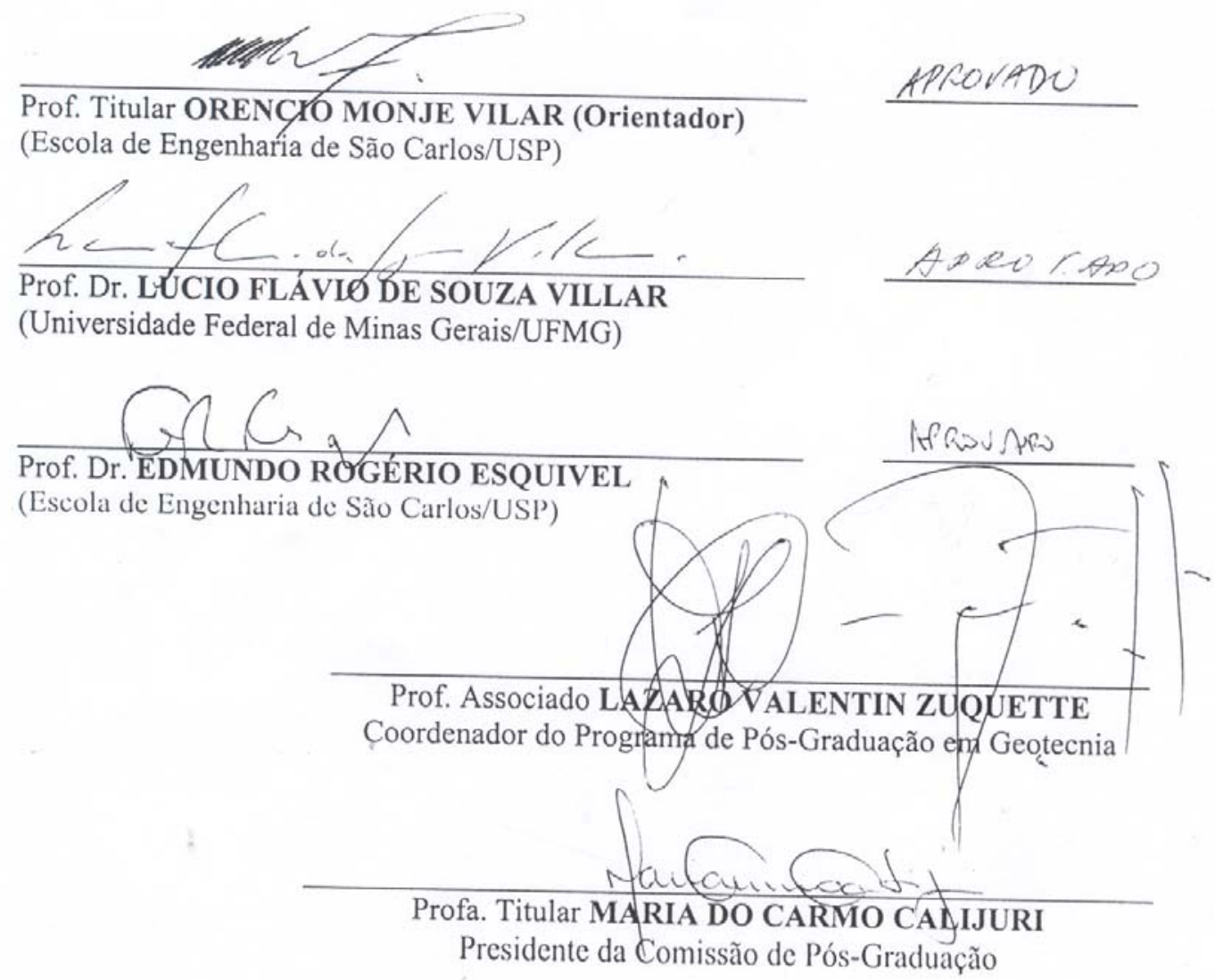


"Nada é tão implacável e cruel quanto a inveja; $e$, no entanto, estamos sempre empenhados em suscitá-la com todas as forças!” (Arthur Schopenhauer) 
Aos meus Pais Valdemar e Vilma, exemplos de sabedoria e sacrificio

e aos meus irmãos, Daniel e Matheus, Amigos de copo e de cruz. 


\section{AGRADECIMENTOS}

À todos os amigos da turma de mestrado de 2002 do Departamento de Geotecnia - EESC, com afeição à Wanessa pelo apoio, cumplicidade e paciência.

Ao Professor Orencio pela orientação, ajuda e compreensão.

Aos Professores, funcionários e amigos do Departamento de Geotecnia da Escola de Engenharia de São Carlos, em especial para Oscar e Zé Luís pela ajuda e ensinamentos.

Aos Amigos de Laboratório China, Heraldo, Josiele, Lolo e Roger pela agradável convivência e presteza de todas as horas.

À todos os moradores, ex-moradores e agregados da República Rodox especialmente à Ana Lídia, Alemão, Carol, Charles Guerreiro, Dodói, Gerção, Gordo, Jaca, Lock's, Nair Bala, Ney, Paty Balão, Samuca, Turco, Tubo, Zini e Zola pela amizade de hoje e sempre.

À Universidade de São Paulo e a CNPq, Conselho Nacional de Desenvolvimento Científico e Tecnológico, pela estrutura e pelo apoio financeiro fornecido. 
Sumário

LISTA DE FIGURAS ........................................................................................

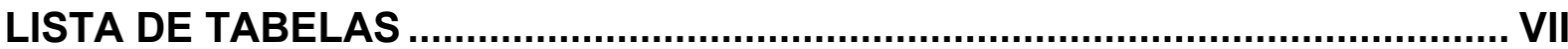

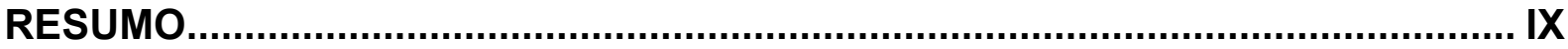

ABSTRACT

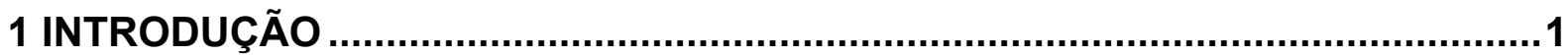

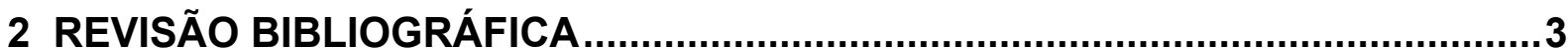

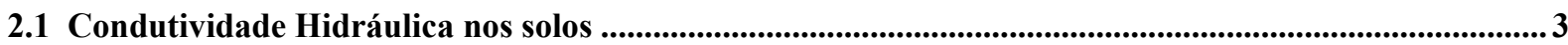

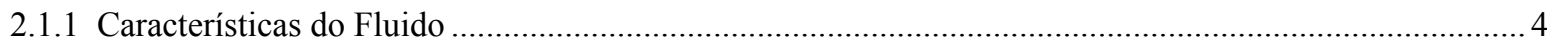

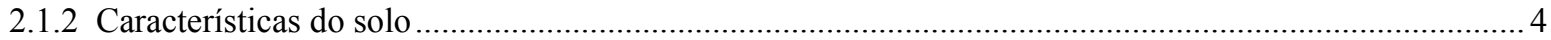

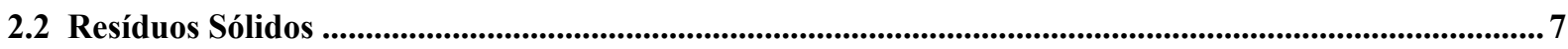

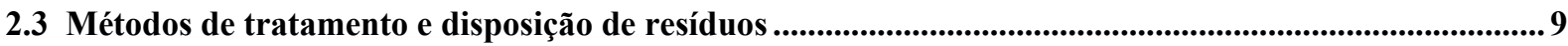

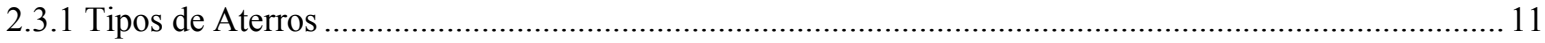

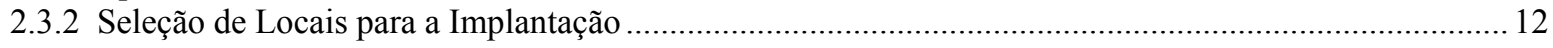

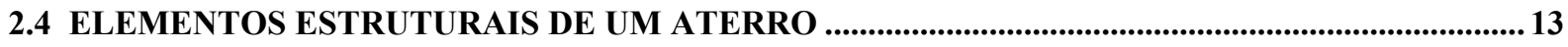

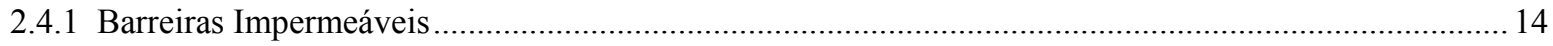

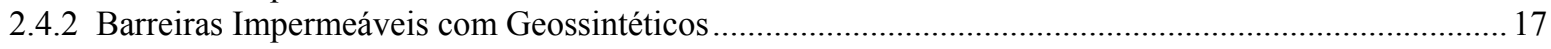

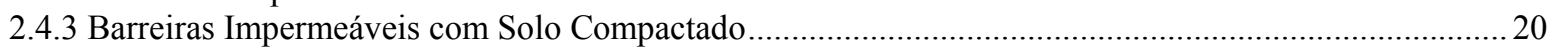

2.5 Comportamento Hidráulico Dos Solos Compactados ..................................................................................22

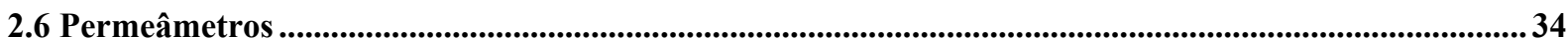

3 MATERIAIS E MÉTODOS ...........................................................................39

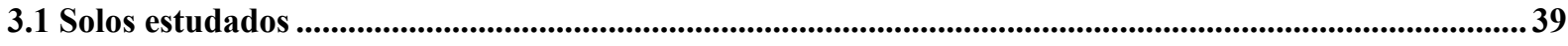

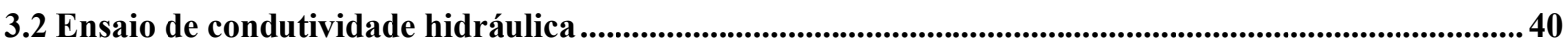

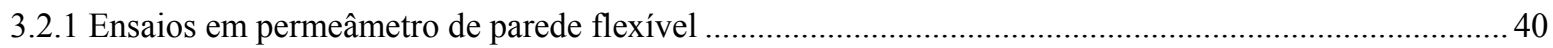

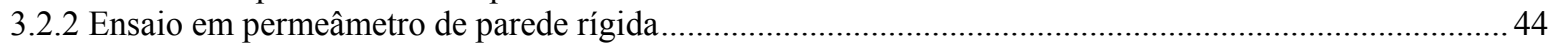

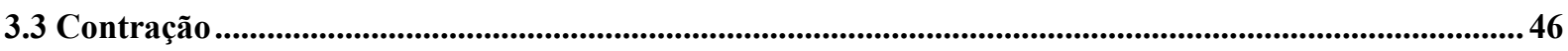

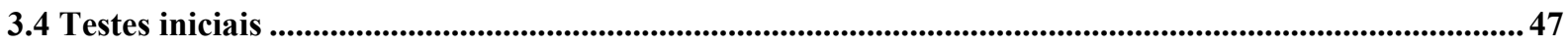

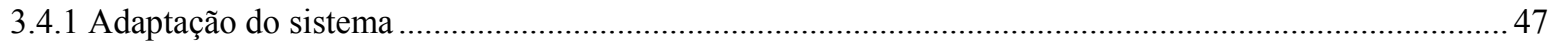

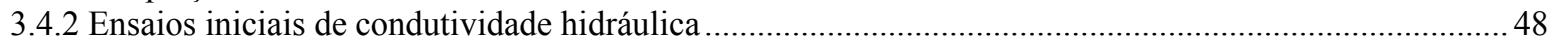

4 APRESENTAÇÃO E ANÁLISES DOS RESULTADOS.....................................50

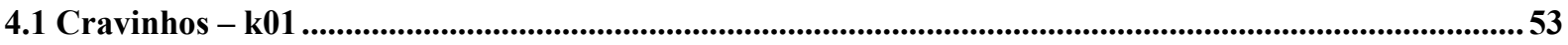

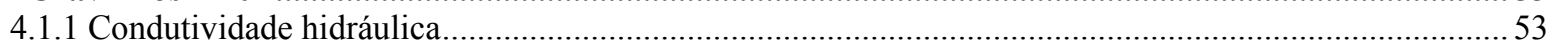

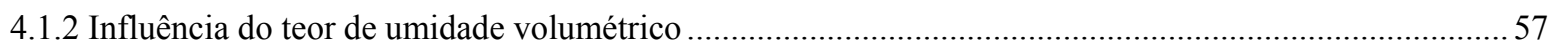

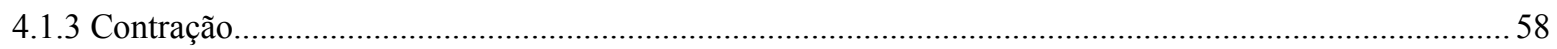


4.1.4 Ensaios com permeâmetro de parede rígida .

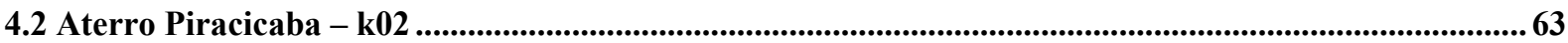

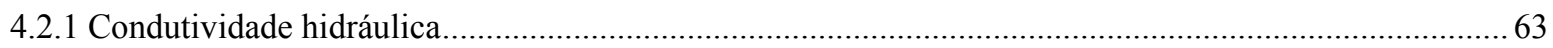

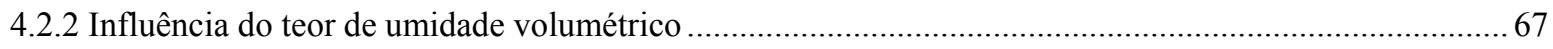

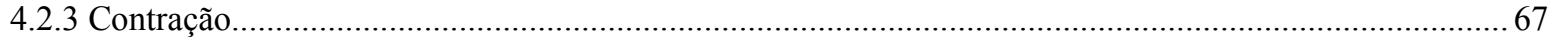

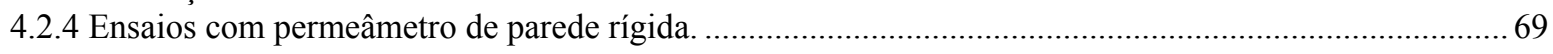

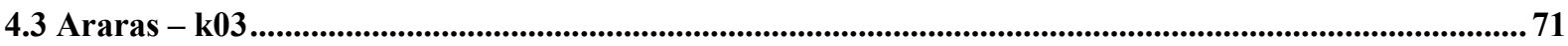

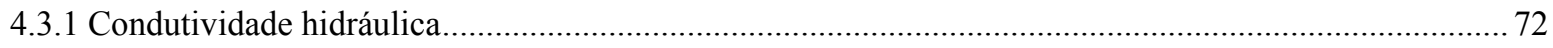

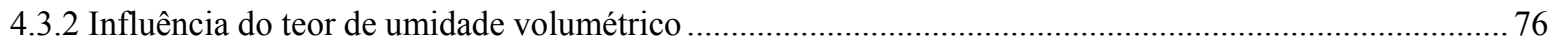

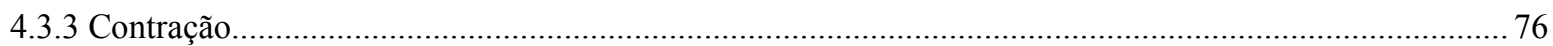

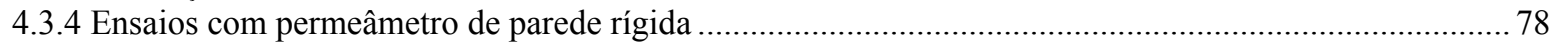

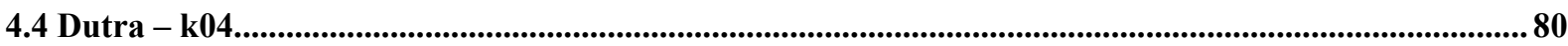

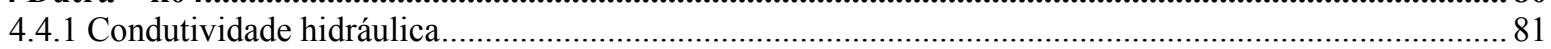

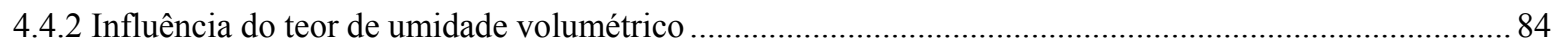

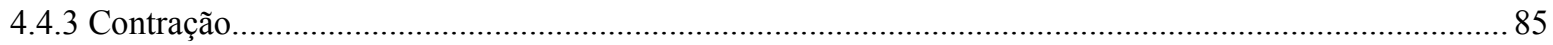

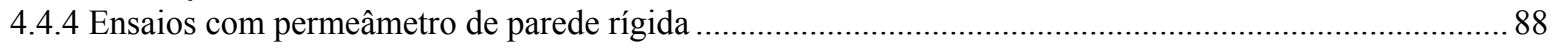

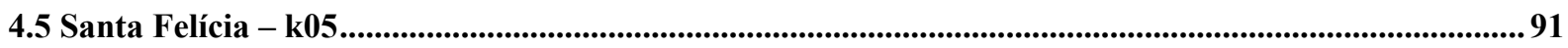

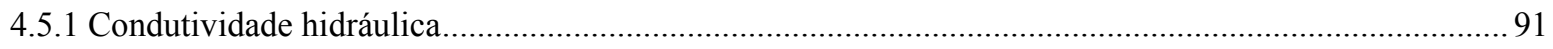

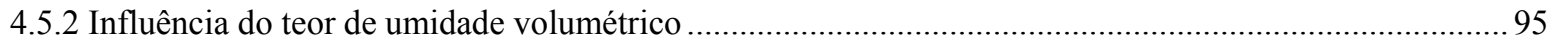

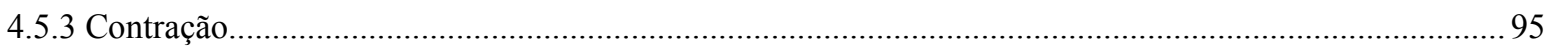

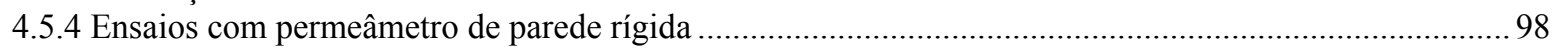

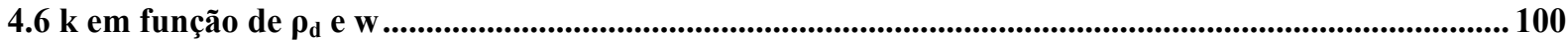

4.7 Correlações com outras características dos solos .........................................................................101

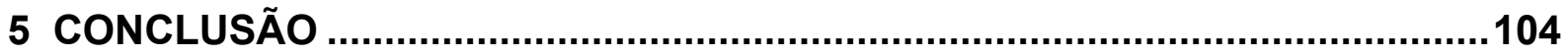

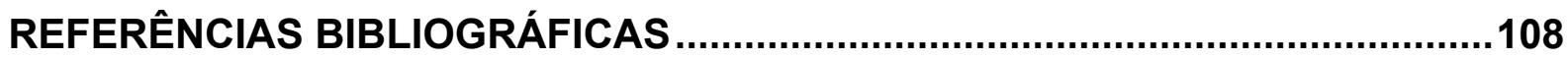

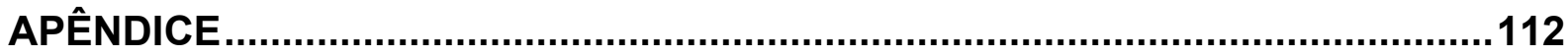


LISTA DE FIGURAS

FIGURA 2.1 - VARIAÇÃO DA CONDUTIVIDADE HIDRÁULICA COM A MODIFICAÇÃO DE ÍNDICE DE VAZIOS PARA ALGUNS SOLOS, MODIFICADO DE LAMBE AND WHITMAN (1969).

FIGURA 2.2 - CONDUTIVIDADE HIDRÁULICA VERSUS GRAU DE SATURAÇÃO PARA ARGILA COMPACTADA. (OLSON AND DANIEL, 1981).

FIGURA 2.3 - ESTRUTURA FINAL DO ATERRO SANITÁRIO. 10

FIGURA 2.5 - CETESB (1993), CONDIÇÕES DE FUNDAÇÃO DE ATERROS SANITÁRIOS. 16

FIGURA 2.6 - PERFIL TÍPICO DE IMPERMEABILIZAÇÃO COM O USO DE MATERIAIS SINTÉTICOS E SOLO, SHARMA\& LEWIS (1994).

FIGURA 2.7 - EFEITO DA COMPACTAÇÃO NA ESTRUTURA INTERNA DO SOLO, (LAMBE \& WHITMAN, 1969).

FIGURA 2.8 - RESULTADOS DE CONDUTIVIDADE HIDRÁULICA E MASSA ESPECIFICA SECA X TEOR DE UMIDADE DE MOLDAGEM, MICHELLET AL (1965).... 25

FIGURA 2.9 - VARIAÇÃO DE CONDUTIVIDADE HIDRÁULICA DEVIDO AO AUMENTO DA ENERGIA DE COMPACTAÇÃO, MICHELL ET AL.(1965).

FIGURA 2.10 - TRADICIONAL MÉTODO PARA ESPECIFICAR A ZONA ADMISSÍVEL, (DANIEL \& BENSON, 1990).

FIGURA 2.11 - METODOLOGIA DE DETERMINAÇÃO DA ZONA ADMISSÍVEL PROPOSTA POR BENSON E DANIEL, (1990). (A) CURVA DE COMPACTAÇÃO PARA TRÊS ENERGIAS DIFERENTES; (B) DETERMINAÇÃO DA CONDUTIVIDADE HIDRÁULICA; (C) REPLOTAGEM DA CURVA DE COMPACTAÇÃO, IDENTIFICANDO OS PONTOS COM CONDUTIVIDADE HIDRÁULICA ACEITÁVEIS; (D) ZONA MODIFICADA CONFORME OUTROS FATORES CONDICIONANTES.

FIGURA 2.12 - ZONA ADMISSÍVEL BASEADA EM PARÂMETROS DE CONDUTIVIDADE HIDRÁULICA, CONTRAÇÃO VOLUMÉTRICA E RESISTÊNCIA AO CISALHAMENTO, (DANIEL E WU, 1993).

FIGURA 2.13 - ESCALA DE TRINCAS (TABELA 2.4) EM FUNÇÃO DA CONTRAÇÃO VOLUMÉTRICA, KLEPPE \& OLSON, (1985).

FIGURA 2.14 - VARIAÇÃO DE DA CONTRAÇÃO VOLUMÉTRICA EM FUNÇÃO DO TEOR DE UMIDADE DE MOLDAGEM E ENERGIA DE COMPACTAÇÃO, (ALBRECHT \& BENSON, 2001). 
FIGURA 2.15 - PERMEÂMETRO TIPO MOLDE DE COMPACTAÇÃO COM ANEL DE PROLONGAMENTO, DANIEL (1994).

FIGURA 2.16 - PERMEÂMETRO QUE UTILIZA AMOSTRADOR DE PAREDE FINA, DANIEL (1994).

FIGURA 2.18 - PERMEÂMETRO DE PAREDE FLEXÍVEL, DANIEL ET. AL. (1984). 37

FIGURA 3.1 - PERMEÂMETRO DE PAREDE FLEXÍVEL COM SISTEMA DE CONTROLE HIDRÁULICO, DOURADO, K.A. (2003).

FIGURA 3.2 - ESQUEMA DO SISTEMA DE CONTROLE HIDRÁULICO FECHADO, DOURADO (2003).

FIGURA 3.3 A, B - SEQÜÊNCIA DE MONTAGEM DO ENSAIO EM PERMEÂMETRO DE PAREDE FLEXÍVEL

FIGURA 3.4 - MODELO DE ARRANJO PARA ENSAIO DE CONDUTIVIDADE HIDRÁULICA EM PERMEÂMETRO DE PAREDE RÍGIDA.

FIGURA 3.5 - MATERIAIS UTILIZADOS NO ENSAIO EM PERMEÂMETRO DE PAREDE RÍGIDA.

FIGURA 3.6 - (A) MONTAGEM DO ENSAIO DE CONTRAÇÃO, (B) DETERMINAÇÃO DE ALTURA COM RELÓGIO COMPARADOR.

FIGURA 3.7 - CALIBRAÇÃO DO SISTEMA MODIFICADO. 48

FIGURA 3.8 - COMPARAÇÃO DOS RESULTADOS DE CONDUTIVIDADE HIDRÁULICA OBTIDOS EM ENSAIOS UTILIZANDO O SISTEMA 3 E 4.

FIGURA 3.9 - VALORES DE CONDUTIVIDADE HIDRÁULICA PARA B ENTRE 0,91 E 0,98 .

FIGURA 4.1 - CURVAS GRANULOMÉTRICAS DOS SOLOS ESTUDADOS. 50

FIGURA 4.2 - CARTA DE PLASTICIDADE DOS SOLOS ESTUDADOS. 51

FIGURA 4.3 - CURVAS DE COMPACTAÇÃO CORRESPONDENTES AO ENSAIO COM ENERGIA DO PROCTOR NORMAL DOS SOLOS ESTUDADOS.

FIGURA 4.4A - CONDUTIVIDADE HIDRÁULICA VS TEMPO, AMOSTRA K01, CPS MOLDADOS COM 23\% DE UMIDADE E COM DIFERENTES GRAUS DE COMPACTAÇÃO.

FIGURA 4.4B - CONDUTIVIDADE HIDRÁULICA VS TEMPO, AMOSTRA K01, CPS MOLDADOS COM GC $=100 \%$ E COM DIFERENTES TEORES DE UMIDADE. 
FIGURA 4.5 - EFEITO DO DESVIO DE UMIDADE DE MOLDAGEM NA CONDUTIVIDADE HIDRÁULICA PARA A AMOSTRA K01. 55

FIGURA 4.6 - EFEITO DO GRAU DE COMPACTAÇÃO NA CONDUTIVIDADE HIDRÁULICA PARA A AMOSTRA K01.

FIGURA 4.7 - LIMITANTES INFERIORES DE CONDIÇÕES IDEAIS DE COMPACTAÇÃO E ZONA ADMISSÍVEL, BASEADOS EM PARÂMETROS DE CONDUTIVIDADE HIDRÁULICA, PARA A AMOSTRA K01.

FIGURA 4.8 - CONDUTIVIDADE HIDRÁULICA EM FUNÇÃO DO TEOR DE UMIDADE VOLUMÉTRICO, AMOSTRA K01.

FIGURA 4.9 - CONTRAÇÃO AXIAL E VOLUMÉTRICA EM FUNÇÃO DO TEMPO PARA A MOSTRA K01.

FIGURA 4.10 - CONDIÇÃO DO CP K01-07 APÓS DOIS CICLOS DE UMEDECIMENTO E SECAGEM, (A) VISTA LATERAL, (B) VISTA SUPERIOR.

FIGURA 4.11 - CONDUTIVIDADE HIDRÁULICA VS TEMPO, ENSAIOS EM PERMEÂMETRO DE PAREDE RÍGIDA. AMOSTRA K01, CPS MOLDADOS COM $22,1 \%$ DE UMIDADE E DIFERENTES GRAUS DE COMPACTAÇÃO.

FIGURA 4.12 - COMPARAÇÃO DA CONDUTIVIDADE HIDRÁULICA EM ENSAIOS COM PERMEÂMETROS DE PAREDE FLEXÍVEL E RÍGIDA PARA A AMOSTRA K01. 62

FIGURA 4.13A - CONDUTIVIDADE HIDRÁULICA VS TEMPO, AMOSTRA K02, CPS MOLDADOS W = 24,9\% E DIFERENTES GRAUS DE COMPACTAÇÃO.

FIGURA 4.13B - CONDUTIVIDADE HIDRÁULICA VS TEMPO, AMOSTRA K02, CPS MOLDADOS COM GC $=100 \%$ E DIFERENTES TEORES DE UMIDADE.

FIGURA 4.14 - EFEITO DO DESVIO DE UMIDADE DE MOLDAGEM NA CONDUTIVIDADE HIDRÁULICA PARA A AMOSTRA K02.

FIGURA 4.15 - EFEITO DO GRAU DE COMPACTAÇÃO NA CONDUTIVIDADE HIDRÁULICA PARA A MOSTRA K02.

FIGURA 4.16 - LIMITANTES INFERIORES DE CONDIÇÕES IDEAIS DE COMPACTAÇÃO E ZONA ADMISSÍVEL, BASEADOS EM PARÂMETROS DE CONDUTIVIDADE HIDRÁULICA, PARA A AMOSTRA K02.

FIGURA 4.17 - CONDUTIVIDADE HIDRÁULICA EM FUNÇÃO DO TEOR DE UMIDADE VOLUMÉTRICO, AMOSTRA K02.

FIGURA 4.18 - CONTRAÇÃO AXIAL E VOLUMÉTRICA EM FUNÇÃO DO TEMPO PARA A MOSTRA K02. 
FIGURA 4.19 - CONDIÇÃO DO CP K02-02 APÓS 2 CICLOS DE UMEDECIMENTO E SECAGEM, (A) VISTA LATERAL, (B) VISTA SUPERIOR.

FIGURA 4.20 - CONDUTIVIDADE HIDRÁULICA VS TEMPO, ENSAIOS EM PERMEÂMETRO DE PAREDE RÍGIDA. AMOSTRA K02, CPS MOLDADOS COM $24,3 \%$ DE UMIDADE E COM DIFERENTES GRAUS DE COMPACTAÇÃO.

FIGURA 4.21 - COMPARAÇÃO DA CONDUTIVIDADE HIDRÁULICA EM ENSAIOS COM PERMEÂMETROS DE PAREDE FLEXÍVEL E RÍGIDA PARA A AMOSTRA K02.

FIGURA 4.22A - CONDUTIVIDADE HIDRÁULICA VS TEMPO, AMOSTRA K03, CPS MOLDADOS COM 23,3\% DE UMIDADE E DIFERENTES GRAUS DE COMPACTAÇÃO. 73

FIGURA 4.22B - CONDUTIVIDADE HIDRÁULICA VS TEMPO, AMOSTRA K03, CPS MOLDADOS COM GC $=100 \%$ E DIFERENTES TEORES DE UMIDADE.

FIGURA 4.23 - EFEITO DO DESVIO DE UMIDADE DE MOLDAGEM NA CONDUTIVIDADE HIDRÁULICA PARA A AMOSTRA K03.

FIGURA 4.24 - EFEITO DO GRAU DE COMPACTAÇÃO NA CONDUTIVIDADE HIDRÁULICA PARA A MOSTRA K03.

FIGURA 4.25 - LIMITANTES INFERIORES DE CONDIÇÕES IDEAIS DE COMPACTAÇÃO E ZONA ADMISSÍVEL, BASEADOS EM PARÂMETROS DE CONDUTIVIDADE

HIDRÁULICA, PARA A AMOSTRA K03 75

FIGURA 4.26 - CONDUTIVIDADE HIDRÁULICA EM FUNÇÃO DO TEOR DE UMIDADE VOLUMÉTRICO, AMOSTRA K03.

FIGURA 4.27 - CONTRAÇÃO AXIAL E VOLUMÉTRICA EM FUNÇÃO DO TEMPO PARA A MOSTRA K03.

FIGURA 4.28 - CONDIÇÃO DO CP K03-08 APÓS 3 CICLOS DE UMEDECIMENTO E SECAGEM, (A) VISTA LATERAL, (B) VISTA SUPERIOR.

FIGURA 4.29 - CONDUTIVIDADE HIDRÁULICA VS TEMPO, ENSAIOS EM PERMEÂMETRO DE PAREDE RÍGIDA. AMOSTRA K03, CPS MOLDADOS COM $23,4 \%$ DE UMIDADE E COM DIFERENTES GRAUS DE COMPACTAÇÃO.

FIGURA 4.30 - COMPARAÇÃO DA CONDUTIVIDADE HIDRÁULICA EM ENSAIOS COM PERMEÂMETROS DE PAREDE FLEXÍVEL E RÍGIDA PARA A AMOSTRA K03. 80

FIGURA 4.32A - CONDUTIVIDADE HIDRÁULICA VS TEMPO, AMOSTRA K04, CPS MOLDADOS COM 21,8\% DE UMIDADE E DIFERENTES GRAUS DE COMPACTAÇÃO. 82

FIGURA 4.32B - CONDUTIVIDADE HIDRÁULICA VS TEMPO, AMOSTRA K04, CPS MOLDADOS COM GC $=100 \%$ E DIFERENTES TEORES DE UMIDADE. 
FIGURA 4.33 - EFEITO DO DESVIO DE UMIDADE DE MOLDAGEM NA CONDUTIVIDADE HIDRÁULICA PARA A AMOSTRA K04.

FIGURA 4.34 - EFEITO DO GRAU DE COMPACTAÇÃO NA CONDUTIVIDADE HIDRÁULICA PARA A MOSTRA K04.

FIGURA 4.35 - LIMITANTES INFERIORES DE CONDIÇÕES IDEAIS DE COMPACTAÇÃO E ZONA ADMISSÍVEL, BASEADOS EM PARÂMETROS DE CONDUTIVIDADE HIDRÁULICA, PARA A AMOSTRA K04. 84

FIGURA 4.36 - CONDUTIVIDADE HIDRÁULICA EM FUNÇÃO DO TEOR DE UMIDADE VOLUMÉTRICO, AMOSTRA K04. 85

FIGURA 4.37 - CONTRAÇÃO AXIAL E VOLUMÉTRICA EM FUNÇÃO DO TEMPO PARA A MOSTRA K04.

FIGURA 4.38 - CONDIÇÃO DO CP K04-09 APÓS 1 CICLO DE UMEDECIMENTO E SECAGEM, (A) VISTA LATERAL, (B) VISTA SUPERIOR. 86

FIGURA 4.39 - CONDIÇÃO DO CP K04-09 APÓS O PROCESSO DE UMEDECIMENTO, (A) VISTA LATERAL, (B) VISTA SUPERIOR.

FIGURA 4.40 - CONDUTIVIDADE HIDRÁULICA VS TEMPO, ENSAIOS EM PERMEÂMETRO DE PAREDE RÍGIDA. AMOSTRA K04, CPS MOLDADOS COM 21,8\% DE UMIDADE E COM DIFERENTES GRAUS DE COMPACTAÇÃO.

FIGURA 4.41 - COMPARAÇÃO DA CONDUTIVIDADE HIDRÁULICA EM ENSAIOS COM PERMEÂMETROS DE PAREDE FLEXÍVEL E RÍGIDA PARA A AMOSTRA K04.

FIGURA 4.42A - CONDUTIVIDADE HIDRÁULICA VS TEMPO, AMOSTRA K05, CPS MOLDADOS COM 15,4\% DE UMIDADE E DIFERENTES GRAUS DE COMPACTAÇÃO. 92

FIGURA 4.42B - CONDUTIVIDADE HIDRÁULICA VS TEMPO, AMOSTRA K05, CPS MOLDADOS COM GC $=100 \%$ E DIFERENTES TEORES DE UMIDADE.

FIGURA 4.43 - EFEITO DO DESVIO DE UMIDADE DE MOLDAGEM NA CONDUTIVIDADE HIDRÁULICA PARA A AMOSTRA K05.

FIGURA 4.44 - EFEITO DO GRAU DE COMPACTAÇÃO NA CONDUTIVIDADE HIDRÁULICA PARA A MOSTRA K05.

FIGURA 4.45 - CURVA DE COMPACTAÇÃO, CONDIÇÕES DE COMPACTAÇÃO DOS CORPOS-DE-PROVA E VALORES DE CONDUTIVIDADE HIDRÁULICA PARA A AMOSTRA K05.

FIGURA 4.46 - CONDUTIVIDADE HIDRÁULICA EM FUNÇÃO DO TEOR DE UMIDADE VOLUMÉTRICO, AMOSTRA K05. 
FIGURA 4.47 - CONTRAÇÃO AXIAL E VOLUMÉTRICA EM FUNÇÃO DO TEMPO PARA A MOSTRA K05. 96

FIGURA 4.48 - CONDIÇÃO DO CP K05-03 APÓS TRÊS CICLOS DE UMEDECIMENTO E SECAGEM, (A) VISTA LATERAL, (B) VISTA SUPERIOR.

FIGURA 4.49 - CONDUTIVIDADE HIDRÁULICA VS TEMPO, ENSAIOS EM PERMEÂMETRO DE PAREDE RÍGIDA. AMOSTRA K05, CPS MOLDADOS COM $15,4 \%$ DE UMIDADE E COM DIFERENTES GRAUS DE COMPACTAÇÃO.

FIGURA 4.50 - COMPARAÇÃO DA CONDUTIVIDADE HIDRÁULICA EM ENSAIOS COM PERMEÂMETROS DE PAREDE FLEXÍVEL E RÍGIDA PARA A MOSTRA K05.

FIGURA 4.51 - CURVAS DE COMPACTAÇÃO DOS SOLOS ESTUDADOS E CONJUNTO DE PARÂMETROS DE COMPACTAÇÃO CAPAZES DE PRODUZIR K $\leq 10^{-7} \mathrm{CM} / \mathrm{S} \ldots . . . .100$

FIGURA 4.52 - CONDUTIVIDADE HIDRÁULICA VS \% DE ARGILA, PARA ENSAIOS EM PERMEÂMETRO DE PAREDE FLEXÍVEL E CORPOS-DE-PROVA COM $\mathbf{W}=\mathbf{W}_{\text {отм }} \mathrm{E}$ GC $=$ $100 \%$

FIGURA 4.53 - REGIÃO ONDE É POSSÍVEL ENCONTRAR SOLOS QUE, PRELIMINARMENTE, PODEM SER TOMADOS COM CAPAZES DE APRESENTAR $\mathrm{K} \leq$ $10^{-7} \mathrm{CM} / \mathrm{S}$. 
LISTA DE TABELAS

TABELA 2.2 - DIFERENÇAS ENTRE GCL'S E BARREIRAS DE SOLO COMPACTADO. ADAPTADO DE USEPA (1993) APUD SHARMA \& LEWIS (1994)................................. 19

TABELA 2.3 - CONDUTIVIDADE DOS ARGILOMINERAIS, MERI \& OLSON (1971)...... 22

TABELA 2.4 - CLASSIFICAÇÃO DO APARECIMENTO DE TRINCAS EM SOLO COMPACTADO, KLEPPE \& OLSON, (1985).

TABELA 3.1 - LOCALIZAÇÃO DAS AMOSTRAS. 39

TABELA 4.1 - CARACTERÍSTICAS DOS MATERIAIS ENSAIADOS. 50

TABELA 4.2 - RESULTADOS E CONDIÇÕES DE ENSAIO EM PERMEÂMETRO DE PAREDE FLEXÍVEL PARA A AMOSTRA CRAVINHOS - K01.

TABELA 4.3 - ACRÉSCIMO DA CONDUTIVIDADE HIDRÁULICA DEVIDO A CICLOS DE UMEDECIMENTO E SECAGEM, AMOSTRA K01. 60

TABELA 4.4 - RESULTADOS E CONDIÇÕES DE ENSAIO EM PAREDE RÍGIDA PARA A AMOSTRA CRAVINHOS - K01.

TABELA 4.5 - COMPARAÇÃO DOS RESULTADOS DE CONDUTIVIDADE HIDRÁULICA OBTIDOS EM ENSAIOS COM PERMEÂMETROS DE PAREDE RÍGIDA E FLEXÍVEL..... 62

TABELA 4.6 - RESULTADOS E CONDIÇÕES DE ENSAIO EM PAREDE FLEXÍVEL PARA A AMOSTRA ATERRO PIRACICABA - K02.

TABELA 4.7 - ACRÉSCIMO DA CONDUTIVIDADE HIDRÁULICA DEVIDO A CICLOS DE UMEDECIMENTO E SECAGEM, AMOSTRA K02. 69

TABELA 4.8 - RESULTADOS E CONDIÇÕES DE ENSAIO EM PAREDE RÍGIDA PARA A AMOSTRA ATERRO PIRACICABA - K02.

TABELA 4.9 - COMPARAÇÃO DOS RESULTADOS DE CONDUTIVIDADE HIDRÁULICA OBTIDOS EM ENSAIOS COM PERMEÂMETROS DE PAREDE RÍGIDA E FLEXÍVEL PARA A AMOSTRA K02.

TABELA 4.10 - RESULTADOS E CONDIÇÕES DE ENSAIO EM PAREDE FLEXÍVEL PARA A AMOSTRA ARARAS -K03.

TABELA 4.11 - ACRÉSCIMO DA CONDUTIVIDADE HIDRÁULICA DEVIDO A CICLOS DE UMEDECIMENTO E SECAGEM, AMOSTRA K03. 
TABELA 4.12 - RESULTADOS E CONDIÇÕES DE ENSAIO EM PAREDE RÍGIDA PARA A AMOSTRA ARARAS - K03.

TABELA 4.13 - COMPARAÇÃO DOS RESULTADOS DE CONDUTIVIDADE HIDRÁULICA OBTIDOS EM ENSAIOS COM PERMEÂMETROS DE PAREDE RÍGIDA (R) E FLEXÍVEL

(F) PARA A AMOSTRA K03.

TABELA 4.14 - RESULTADOS E CONDIÇÕES DE ENSAIO EM PAREDE FLEXÍVEL PARA A AMOSTRA DUTRA -K04. 81

TABELA 4.16 - RESULTADOS E CONDIÇÕES DE ENSAIO EM PAREDE RÍGIDA PARA A AMOSTRA DUTRA - K04.

TABELA 4.17 - COMPARAÇÃO DOS RESULTADOS DE CONDUTIVIDADE HIDRÁULICA OBTIDOS EM ENSAIOS COM PERMEÂMETROS DE PAREDE RÍGIDA (R) E FLEXÍVEL

(F) PARA A AMOSTRA K04. 90

TABELA 4.18 - RESULTADOS E CONDIÇÕES DE ENSAIO EM PAREDE FLEXÍVEL PARA A AMOSTRA SANTA FELÍCIA - K05.

TABELA 4.19 - ACRÉSCIMO DA CONDUTIVIDADE HIDRÁULICA DEVIDO A CICLOS DE UMEDECIMENTO E SECAGEM, AMOSTRA K05.

TABELA 4.20 - RESULTADOS E CONDIÇÕES DE COMPACTAÇÃO PARA ENSAIO EM PERMEÂMETRO DE PAREDE RÍGIDA PARA A AMOSTRA ARARAS - K05. 98

TABELA 4.21 - COMPARAÇÃO DOS RESULTADOS DE CONDUTIVIDADE HIDRÁULICA OBTIDOS EM ENSAIOS COM PERMEÂMETROS DE PAREDE RÍGIDA (R) E FLEXÍVEL

(F) PARA A AMOSTRA K05. 99 


\title{
Condutividade Hidráulica de Solos Compactados em Ensaios com Permeâmetro de Parede Flexível
}

\author{
ALONSO, T.P. (2005) "Condutividade hidráulica de solos compactados em ensaios com \\ permeâmetro de parede flexível." São Carlos, dissertação de mestrado. 113p. Escola de \\ Engenharia de São Carlos. Universidade de São Paulo.
}

Resumo: Cincos solos compactados do Estado de São Paulo foram estudados para uso como barreira impermeável de aterros sanitários. Foram realizados ensaios em permeâmetro de parede flexível com utilização do sistema de controle hidráulico de volume constante (sistema fechado), ensaios em permeâmetro de parede rígida e ensaios de contração. Verificou-se que menores valores de condutividade hidráulica estão associados a teores de umidade de moldagem igual ou acima do teor de umidade ótimo fornecida no ensaio de Proctor Normal. Teores de umidade acima do ótimo e graus de compactação superiores a 100\% não causaram significativas reduções na condutividade hidráulica, que tende a se estabilizar a partir destes parâmetros. Foram sugeridas condições de compactação para quatro dos cinco solos analisados, de forma que a condutividade hidráulica não excedesse $1.10^{-7} \mathrm{~cm} / \mathrm{s}$, valor sugerido para barreiras impermeáveis. A contração axial e volumétrica não foi influenciada pelo teor de umidade de moldagem e grau de compactação, para corpos-de-prova compactados nas condições de compactação sugeridas. Os resultados de condutividade hidráulica em ensaios com permeâmetros de parede rígida se mostraram, aproximadamente, uma ordem de grandeza menor se comparados aos resultados obtidos com permeâmetro de parede flexível, porém essa diferença diminuiu com o aumento do grau de compactação dos corpos-de-prova.

Palavras-chave: aterros sanitários; solos compactados; barreiras impermeáveis; condutividade hidráulica; contração; permeâmetro de parede flexível. 


\title{
Hydraulic Conductivity of Compacted Soils in Flexible Wall Permeameter Tests
}

\author{
ALONSO, T.P. (2005) "Hydraulic Conductivity of Compacted Soils in Flexible Wall \\ Permeameter Tests" São Carlos, dissertação de mestrado. 113p. Escola de Engenharia \\ de São Carlos. Universidade de São Paulo.
}

\begin{abstract}
The hydraulic conductivity of five compacted soils from São Paulo State is studied aiming at their use in lining systems. Permeability tests were performed in flexible wall permeameters with constant volume hydraulic control system (closed system), rigid wall permeameters and contraction tests. It was verified that lower values of hydraulic conductivity are associated to molding water content equal or larger than optimum water content of soil as measured in standard Proctor. Molding water content beyond optimum and compaction degree lager than $100 \%$ did not cause significant reduction on hydraulic conductivity, which tends to stabilize when those parameters are reached. It is proposed ideal conditions of compaction for four of five compacted soils studied with hydraulic conductivity not lager than $10^{-7} \mathrm{~cm} / \mathrm{s}$, suggested value for lining systems. The axial and volumetric shrinkage was not influenced by water content and compaction degree, for specimen compacted on ideal conditions suggested here. The hydraulic conductivity results of greatness lower when compared to the results of the flexible wall permeameter, although that difference gets smaller with the rise of compaction degree.
\end{abstract}

Key words: landfills; compacted soils; liners; hydraulic conductivity; shrinkage; flexible wall permeam 
Um dos problemas associados ao crescimento populacional e à expansão urbana e industrial reside na geração de resíduos dos mais variados tipos e na sua disposição segura no meio físico.

Em geral, a degradação dos resíduos origina gases e líquidos que têm em sua composição substâncias capazes de contaminar o solo, a água e a atmosfera causando um enorme prejuízo ao meio ambiente.

A preocupação com esses problemas, principalmente nas duas últimas décadas, tem impulsionado estudos para a disposição segura e adequada destes resíduos, assim como o estabelecimento de normas mais rígidas na implantação de sistemas de disposição.

Existem hoje várias técnicas de tratamento e disposição de resíduos que procuram reduzi-los e dar-lhes destinação final segura. Mesmo com os avanços no conhecimento de técnicas para tal finalidade, o aterro sanitário ainda se apresenta como um método de disposição de resíduos adequado do ponto de vista econômico e ambiental.

Os aterros sanitários possuem elementos estruturais como as barreiras impermeáveis de fundo e cobertura. As barreiras de fundo têm a função de impedir o fluxo de líquido percolado para o meio hidrogeológico subjacente. Já as barreiras de coberturas funcionam como vedação dos resíduos aterrados, além de reduzir a infiltração de águas superficiais e, por sua vez, reduzir a geração de líquido percolado.

Os revestimentos e camadas impermeabilizantes podem ser construídos com solos argilosos, materiais sintéticos ou, ainda, pela associação destes materiais.

Quando se utiliza solo compactado na construção de uma barreira impermeável, é necessário atender a uma série de requisitos no tocante à resistência, à compressibilidade e à permeabilidade. Deve-se garantir estas propriedades em patamares aceitáveis durante a vida útil da obra. Muitos estudos foram realizados com o intuito de aumentar os conhecimentos do comportamento hidráulico de solos compactados para que estes possam ser utilizados em obras de impermeabilização.

O grau de saturação se mostra um importante fator no comportamento hidráulico do solo, visto que este atinge sua maior condutividade hidráulica quando está saturado. Para a 
utilização do solo como material de impermeabilização, fica evidente a importância do estudo da condutividade hidráulica na condição mais crítica, ou seja, saturada.

Este trabalho buscou estudar o comportamento hidráulico de cinco solos típicos do Estado de São Paulo frente a variações de teor de umidade de moldagem e grau de compactação, a partir de amostras deformadas. Realizaram-se ensaios de caracterização, ensaios de contração e observação de aparecimento de trincas frente a ciclos de umedecimento e secagem. Os ensaios de condutividade hidráulica foram conduzidos em permeâmetro de parede flexível e em permeâmetro de parede rígida com o intuito de comparar as duas metodologias de ensaio. 


\section{REVISÃO BIBLIOGRÁFICA}

A condutividade hidráulica é uma das propriedades essenciais dos solos e necessária em todos os estudos que envolvam o fluxo de água neste meio. Trata-se de uma propriedade com enorme faixa de variação, sendo necessária a utilização de ferramental específico para a sua determinação, dependendo dos valores que se deseja medir.

Para a construção de barreiras impermeabilizantes, a condutividade hidráulica é um dos fatores preponderantes na escolha do material, por isso se faz necessário o estudo desta característica.

\subsection{CONDUTIVIDADE HIDRÁULICA NOS SOLOS}

Darcy (1856) dedicou-se ao estudo do fluxo d'água em um filtro de areia, em que estabeleceu uma relação empírica hoje conhecida como lei de Darcy Equação 2.1. A lei de Darcy relaciona a velocidade de descarga $(v)$ de um fluido, através de um meio poroso, com um gradiente hidráulico (i), definido pela Equação 2.2, em uma relação linear. Foi observado também que essa relação seguia uma constante de proporcionalidade $\mathrm{k}$ que foi chamada de condutividade hidráulica.

$$
\begin{aligned}
& \begin{array}{l}
v=k . i \\
i=\frac{\Delta P}{L}
\end{array} \\
& \text { Em que: } \\
& \triangle \mathrm{P}: \quad \text { Perda de carga sobre a distância L; } \\
& \mathrm{L}: \quad \text { Espessura da camada do meio poroso, medida na direção do fluxo. }
\end{aligned}
$$

Quando o fluxo ocorre através de uma seção A, tem-se:

$q=A \cdot v$

Em que:

q : Vazão. 
Portanto pode-se escrever que:

$$
q=k . i . A
$$

onde a condutividade hidráulica $(k)$ é expresso geralmente em $(\mathrm{cm} / \mathrm{s})$.

É importante lembrar que a velocidade (v) da lei de Darcy representa a velocidade de descarga e não a velocidade de percolação ( $v p)$ da água através dos poros do solo.

Sendo que a condutividade hidráulica em solos é dada pela velocidade de descarga $(v)$ através de uma seção (A), sob um gradiente hidráulico (i), pode-se afirmar então que, o valor da condutividade hidráulica em solos dependerá das características do fluido e das características do solo.

\subsubsection{Características do Fluido}

Sabe-se que tanto a viscosidade quanto a massa específica do fluido influenciam na condutividade hidráulica, e que estas propriedades variam em função da temperatura. Entretanto a viscosidade é a mais afetada, fica claro que quanto mais viscoso é o fluido maior é a dificuldade para percolar entre as partículas do meio poroso e, conseqüentemente, menor será a condutividade hidráulica. No entanto, o efeito gravitacional sobre a massa do fluido é um dos fatores que causam do movimento, tendo a massa específica do fluido uma relação direta com a condutividade hidráulica.

Assim podemos reescrever a relação proposta por Darcy da maneira apresentada na Equação 2.5, onde $\mathrm{k}$ é a condutividade hidráulica intrínseca do solo e $\gamma, \mu$ são, respectivamente, o peso específico e viscosidade do percolante.

$$
v=k \cdot \frac{\gamma}{\mu} . i
$$

\subsubsection{Características do solo}

A condutividade hidráulica é afetada por diversos fatores inerentes ao solo. Pode-se destacar, entre eles, o tamanho das partículas, o índice de vazios, a estrutura, a estratificação e o grau de saturação do solo. Fica difícil analisar estes fatores separadamente, já que estão estreitamente relacionados. No entanto, tenta-se neste texto mostrar a importância de cada um deles.

Intuitivamente, quanto menores forem as partículas do solo, menores serão as dimensões dos canais de fluxo, e, portanto menor será a condutividade hidráulica. Assim, solos constituídos de areias finas, por exemplo, apresentam vazios relativamente pequenos, 
acarretando uma baixa permeabilidade e solos constituídos de areias grossas, apresentam vazios relativamente grandes, levando a uma alta condutividade hidráulica.

A partir de numerosos ensaios, vários trabalhos têm sido desenvolvidos no intuito de relacionar a condutividade com o diâmetro das partículas do solo: $k=f(D)$. Porém, todos com amplitudes bastante restritas e valores aproximados de condutividade hidráulica.

Lambe \& Whitman (1969), por meio de dados experimentais demonstraram que a maior influência sobre a condutividade hidráulica se deve à fração mais fina do solo. Entretanto uma relação proposta por Hazen admitiu que a distribuição das partículas deve ser suficientemente extensa para evitar que as partículas menores sejam arrastadas pela força de percolação, ou seja, o solo deve apresentar uma estabilidade interna. Porém, os solos constituídos por partículas grossas uniformes e finas não irão apresentar tal estabilidade, sendo que, a percolação nestes casos poderá produzir um arraste dos finos e provocar um aumento da condutividade hidráulica.

A impossibilidade teórica de estimar a condutividade hidráulica em função do índice de vazios do solo, $\mathrm{k}=\mathrm{f}(\mathrm{e})$, condiciona o uso de análises experimentais para quantificar a influência deste parâmetro. Existem na literatura muitas propostas por investigadores para uma relação entre a permeabilidade e índice de vazios do solo, podemos citar: Taylor (1948), Tavernas et al (1983), Mesri \& Rokhsar (1974), Badillo (1983) entre outros.

A estrutura interna é uma das características mais importantes do solo que influenciam a condutividade hidráulica, especialmente em solos finos (Lambe \& Whitman, 1969).

Quando os autores comparam amostras de solo com o mesmo índice de vazios, verificaram que as amostras que encontram-se com estrutura interna "floculada" apresentam maiores permeabilidades se comparadas à amostras com estrutura interna "dispersa". O fator principal é que em um solo com estrutura interna "floculada" existem grandes canais para o fluxo. Como a percolação através de um canal grande é maior que através de vários canais pequenos, de mesma seção total, Lambe e Whitman (1981) concluíram que quanto maiores forem os canais para um determinado volume de vazios, maior será a permeabilidade.

Segundo Badillo \& Rodriguez (1975), um solo poderá ter permeabilidade diferentes para o estado indeformado e moldado, ainda que o índice de vazios seja o mesmo em ambos os casos. Isto ocorre por uma variação na estrutura e/ou estratificação do solo.

A Figura 2.1 apresenta a variação da condutividade hidráulica com o índice de vazios para alguns solos. 


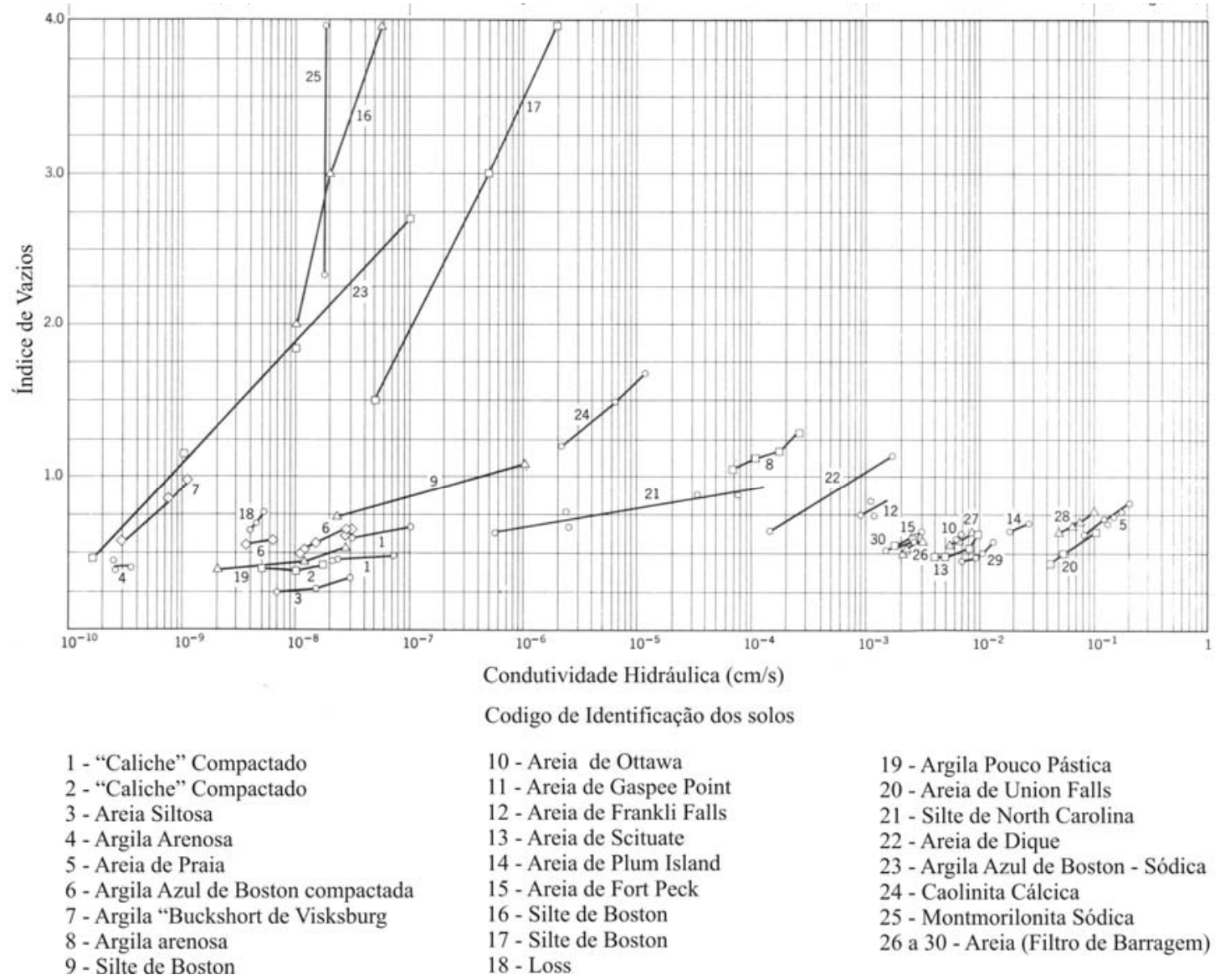

Figura 2.1 - Variação da condutividade hidráulica com a modificação de índice de vazios para alguns solos, modificado de LAMBE AND WHITMAN (1969).

A composição mineralógica é um importante fator na permeabilidade de um solo. Solos argilosos com argilo-minerais como as montmorilonitas apresentam condutividades hidráulicas menores que solos com argilo-minerais como as caulinitas. Dois fatores podem explicar esta diferença, (1) as montmorilonitas apresentam partículas com maior área de superfície específica que as caulinitas, (2) as montmorilonitas apresentam maior capacidade de troca iônica.

O grau de saturação do solo é outro fator que exerce influência direta na condutividade hidráulica. A condutividade hidráulica deve aumentar com o aumento do grau de saturação. Este comportamento foi observado por Olson and Daniel (1981), para uma argila compactada, e é mostrado na Figura 2.2 para uma argila compactada. 


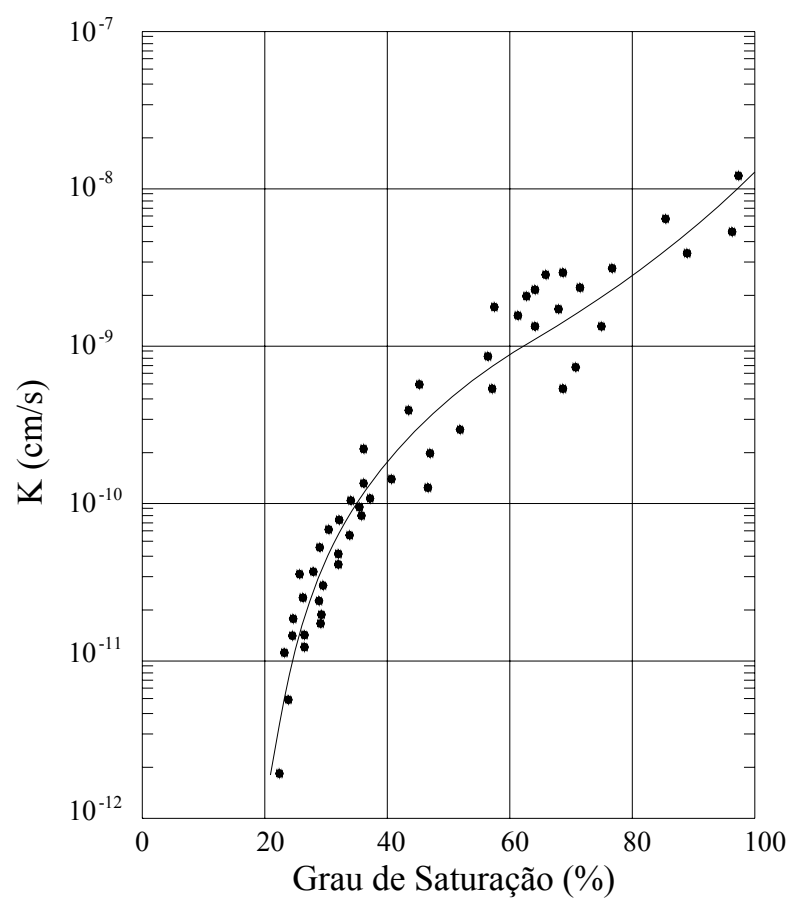

Figura 2.2 - Condutividade hidráulica versus grau de saturação para argila compactada. (Olson and Daniel, 1981)

O estado de saturação se mostra um importante fator no comportamento hidráulico do solo, visto que este atinge sua maior condutividade hidráulica quando está saturado. Para o intuito da utilização do solo com material de impermeabilização, fica clara a importância do estudo de sua condutividade hidráulica no estado crítico, ou seja, saturado.

Posteriormente, neste texto, será discutido o comportamento hidráulico do solo compactado e suas características, assim como, as condições para a obtenção da menor condutividade hidráulica.

\subsection{RESÍDUOS SÓLIDOS}

Toda atividade humana gera algum tipo de resíduo, seja ele doméstico, hospitalar, industrial, proveniente de mineração dentre outras. Os resíduos em geral, principalmente os resíduos sólidos urbanos (RSU), são constituídos de uma parcela significativa de material facilmente a moderadamente degradável por processos físicos, químicos e biológicos. A degradação dá origem a subprodutos dos resíduos como percolados e gases, que apresentam substâncias nocivas ao meio. Estes subprodutos devem ser controlados e tratados de forma a minimizar o impacto ambiental. 
È importante fazer aqui uma distinção dos termos percolado e chorume. O chorume é o termo utilizado para o líquido de alta Demanda Bioquímica de Oxigênio (DBO), com odor desagradável e cor negra produzido pela decomposição da matéria orgânica em lixões e aterros. O termo percolado é utilizado para o líquido que passa através do meio poroso, para a filtração ou extração de substâncias desse meio.

Segundo a ABNT 10.004/87, resíduo sólido é definido como resíduos no estado sólido e semi-sólido que resultam da atividade da comunidade de origem: industrial, doméstica, hospitalar, comercial, agrícola, de serviços e de varrição. Ficam incluídos nesta definição os lodos provenientes de sistemas de tratamento de água, bem como determinados líquidos cujas partículas tornem inviáveis o seu lançamento na rede pública de esgoto ou corpos de água, ou exijam para isso soluções técnicas e/ou economicamente inviáveis em face da tecnologia disponível.

O resíduo pode ser classificado segundo sua periculosidade ao ambiente, conforme a ABNT 10.004/87 os resíduos são classificados em:

- Resíduo Classe I - perigosos: são aqueles que apresentam periculosidade por inflamabilidade, corrosividade, reatividade, toxidade e/ou patogenicidade;

○ Resíduo Classe II - não inertes: são aqueles que não se enquadram na classificação Classe I e III. Os resíduos Classe II pode apresentar propriedades como combustibilidade, biodegradabilidade ou solubilidade em água;

- Resíduo Classe III - abrange os resíduos inertes e não perigosos. Como exemplo, pode-se citar entre outros: rochas, tijolos, vidros, certos tipos de plásticos e borrachas que não são decompostas prontamente.

A CETESB (1993) divide os resíduos sólidos em três categorias: sólidos industriais semi-sólidos e sólidos urbanos, os quais estão definidos a seguir:

○ Resíduos sólidos industriais: são os resíduos sólidos e semi-sólidos resultantes dos processos industriais, assim como determinados resíduos líquidos oriundos dos mesmos processamentos que, por suas características peculiares, não podem ser lançados na rede pública de esgoto ou em corpos de água e não são passíveis de tratamento pelos métodos convencionais. Incluem também os lodos provenientes da estação de tratamento de efluentes; 
○ Resíduos semi-sólidos: materiais, produtos e substâncias resultantes dos processos industriais e de estações de tratamento de efluentes que não são passíveis de reaproveitamento e apresentam características semi-sólidas;

- Resíduos sólidos urbanos: são todos os resíduos sólidos produzidos em edificações residenciais, em estabelecimentos públicos e comerciais, assim como resultantes das diversas atividades de limpeza urbana. Excluem-se os resíduos produzidos em estabelecimentos hospitalares, portos e aeroportos que, por suas características peculiares e conforme a legislação vigente, exigem cuidados especiais quanto ao acondicionamento, coleta e disposição final.

\subsection{MÉTODOS DE TRATAMENTO E DISPOSIÇÃO DE RESÍDUOS}

Existem hoje várias técnicas de tratamentos e disposição de resíduos que visam sua redução de volume e destinação final segura. Entre estas técnicas podemos destacar a incineração, compostagem, reciclagem, compactação e alternativas de trituração e enfardamento. Mesmo com avanços no conhecimento de técnicas para a destinação final do resíduo, o aterro sanitário ainda se apresenta como o melhor método de disposição dos resíduos do ponto de vista econômico e ambiental.

Segundo a ABNT, NBR 8419, “Aterro sanitário é um método de disposição de resíduos sólidos no solo, sem provocar prejuízos ou ameaças à saúde e a segurança, utilizando-se princípios de engenharia, de sorte a confinar o lixo no menor volume possível, cobrindo-o com uma camada de terra, ao fim do trabalho de cada dia, ou mais freqüentemente conforme necessário". A função do aterro sanitário é dispor os resíduos de forma correta e com relativo baixo custo, propiciar uma grande capacidade de armazenamento e condições especiais para a decomposição da matéria orgânica, assegurar a proteção necessária para o meio, de sorte a impedir a contaminação de solos e águas pelos subprodutos da decomposição, e impedir, também, a proliferação de doenças por vetores como ratos, moscas, urubus, baratas, etc. 
O líquido percolado e outros agentes que causam danos à saúde a ao meio ambiente devem ser rigorosamente controlados. Assim um aterro sanitário deve conter os seguintes elementos:

○ Conjunto de células de resíduos recobertas, diariamente, por uma camada de solo para evitar a proliferação de vetores;

- Sistema de drenagem de gás e de líquido percolado;

- Sistema de tratamento de líquido percolado;

- Sistema de drenagem de águas superficiais e nascentes;

- Barreira impermeabilizante de fundo impedindo que o líquido percolado comprometa a qualidade do solo e das águas sub-superficiais;

○ Barreira impermeabilizante de cobertura para diminuir a infiltração no resíduo, e conseqüentemente, diminuição do volume de percolado.

A estrutura final do aterro é constituída por um conjunto de células adjacentes e sobrepostas, como se pode observar na Figura 2.3.

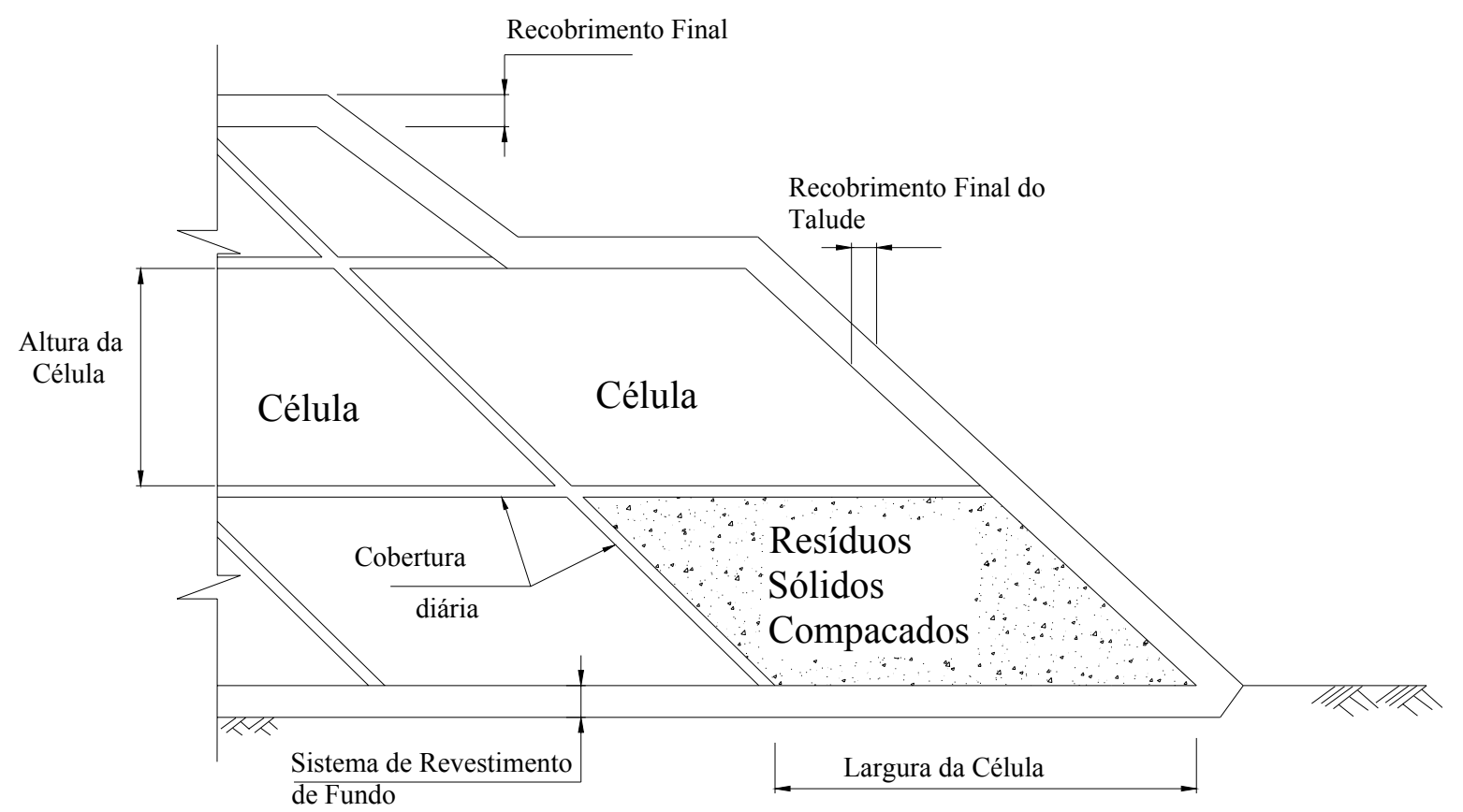

Figura 2.3 - Estrutura final do aterro sanitário.

As limitações da disposição de resíduos em aterros sanitários estão na indisponibilidade de grandes áreas próximas aos grandes centros para viabilizar os custos com transportes, a dificuldade de obter material para o recobrimento diário, as condições 
climáticas e a mão de obra capacitada para o gerenciamento do empreendimento LIMA, (1995).

\subsubsection{Tipos de Aterros}

Com as novas exigências ambientais, novas técnicas de coleta, separação e até mesmo, novas características do resíduo, a concepção dos aterros vem se modificando. Mas pode-se classificar os aterros sob dois aspectos: quanto ao tipo e quanto ao método de aterramento.

- Quanto ao tipo de aterro: tem se os convencionais para resíduos sólidos, para resíduos sólidos triturados e para resíduos especiais. Os aterros convencionais para resíduos sólidos são destinados a resíduos sólidos urbanos e materiais inertes, empregando os processos de compactação. Os aterros para resíduos sólidos triturados são destinados a resíduos sólidos previamente triturados. Desta forma o resíduo adquire altas densidades, cerca de $35 \%$ maior que os aterros convencionais, diminuindo o seu volume e contribuindo com a estabilidade. Além disso, dependendo da legislação local, os resíduos podem ser dispostos sem cobertura diária. Os aterros para resíduos especiais são destinados a resíduos específicos e são conhecidos como monoaterros, pois se destinas a um tipo específico de material (cinzas, amianto, entre outros).

○ Quanto às formas construtivas e operacionais: os aterros podem ser classificados em aterros de trincheiras, de superfície e de depressão. $\mathrm{O}$ aterro de trincheiras se destina às comunidades geradoras de pequenas quantidades de resíduos ou quando a decomposição do resíduo apresenta algum risco para a saúde pública ou ao meio ambiente. As dimensões da trincheira são funções da quantidade de resíduo a ser armazenada e a vida útil do aterro. O fundo da escavação deve ser impermeabilizado com uma barreira impermeável. O nível do lençol freático não deve estar próximo à superfície. $\mathrm{O}$ aterro de superfície se destina a locais de superfície plana e imprópria para a escavação, o resíduo é armazenado em diques de construídos de terra ou com o próprio resíduo. $\mathrm{O}$ aterro de depressão se destina a locais de topografia acidentada, como grotas de fundo de vales, pedreiras extintas e encostas. As técnicas de compactação de 
resíduos neste caso variam com a geometria, hidrologia e geologia do local e com a disponibilidade de material para a cobertura, (TCHOBANOGLOUS et al. 1993).

\subsubsection{Seleção de Locais para a Implantação}

A escolha de locais adequados para a implantação de um aterro sanitário envolve além de fatores ambientais, fatores econômicos, legais e sociais. É necessário o envolvimento de várias áreas da engenharia para assegurar uma disposição segura e economicamente viável. Devem ser investigados condicionantes como topografia, hidrogeologia, geotecnia da área, distância de transporte dos centros geradores de resíduos, capacidade de disposição, condições de acesso e trafegabilidade, susceptibilidade de contaminação do lençol freático, disponibilidade de solos para recobrimento e proteção, entre outros fatores.

A geologia, hidrogeologia e geotecnia são os fatores mais importantes na análise da área, pois a partir destes, dados estabelecem as medidas de projeto e monitoramento do aterro. Os dados geológicos e geotécnicos referem-se aos parâmetros de resistência, deformabilidade e condutividade hidráulica dos terrenos de fundação, e os de hidrogeologia, referem-se ao comportamento das águas superficiais e subterrâneas, dentre outros.

A CETESB (1993) determina as restrições na escolha do local de implantação de um aterro sanitário:

○ Distância mínima de 200m de corpos d'agua superficiais;

○ Distancia mínima de 500m de residências, condicionadas à direção dos ventos;

○ Condutividade hidráulica inferior a $10^{-7} \mathrm{~cm} / \mathrm{s}$;

○ Lençol freático no mínimo a 1,5 metros da cota de fundo do aterro.

$\mathrm{Na}$ literatura são encontradas descrições de diversas formas para a determinação adequada da área para a execução de aterros sanitários. Estes autores recomendam critérios para a seleção segura e econômica de áreas, pode-se citar TIVERON et al. (1995), MELO \& VAL (1994), ZUQUETE et al. (1995), entre outros. 
O Manual de Gerenciamento Integrado do Lixo Municipal (1995) recomenda a utilização dos critérios apresentados na Tabela 2.1 para a avaliação de possíveis áreas para a instalação de aterros sanitários.

Tabela 2.1 - Critérios para a avaliação das áreas para a implantação de aterro sanitário, (Manual de Gerenciamento Integrado do Lixo Municipal, 1995).

\begin{tabular}{cccc}
\hline \multirow{2}{*}{$\begin{array}{c}\text { Dados } \\
\text { Necessários }\end{array}$} & Recomendada & $\begin{array}{c}\text { Recomendada } \\
\text { com Restrições }\end{array}$ & $\begin{array}{c}\text { Não } \\
\text { Recomendada }\end{array}$ \\
\cline { 2 - 4 } Vida Útil & $>10$ anos & $\begin{array}{c}(10 \text { anos, a critério do órgão } \\
\text { ambiental })\end{array}$ \\
\hline $\begin{array}{c}\text { Distância do } \\
\text { centro atendido }\end{array}$ & $>10 \mathrm{Km}$ & $10-20 \mathrm{Km}$ & $>20 \mathrm{Km}$ \\
\hline $\begin{array}{c}\text { Zoneamento } \\
\text { ambiental }\end{array}$ & Áreas sem restrições no zoneamento & $\begin{array}{c}\text { unidades de } \\
\text { conservação } \\
\text { ambiental } \\
\text { correlatas }\end{array}$ \\
\hline $\begin{array}{c}\text { Zoneamento } \\
\text { urbano }\end{array}$ & $\begin{array}{c}\text { Crescimento } \\
\text { mínimo }\end{array}$ & $\begin{array}{c}\text { Crescimento } \\
\text { intermediário }\end{array}$ & $\begin{array}{c}\text { Crescimento } \\
\text { máximo }\end{array}$ \\
\hline $\begin{array}{c}\text { Densidade } \\
\text { populacional }\end{array}$ & Baixa & média & Alta \\
\hline $\begin{array}{c}\text { Uso e ocupação } \\
\text { das terras }\end{array}$ & Áreas devolutas ou pouco utilizadas & Ocupação intensa \\
\hline $\begin{array}{c}\text { Valorização das } \\
\text { terras }\end{array}$ & Boa & Média & Alta \\
\hline $\begin{array}{c}\text { Aceitação da } \\
\text { população e de } \\
\text { entidades } \\
\text { ambientais e não } \\
\text { governamentais }\end{array}$ & Boa & Razoável & Inaceitável \\
\hline $\begin{array}{c}\text { Distância dos } \\
\text { cursos d'agua }\end{array}$ & $>200$ m & $<200$ m, com aprovação do órgão \\
\hline
\end{tabular}

\subsection{ELEMENTOS ESTRUTURAIS DE UM ATERRO}

Para o bom funcionamento de um aterro sanitário, o projeto deve lançar mão de alguns elementos estruturais como tratamento e barreira impermeável de fundação e cobertura, sistemas de drenagens de gases e líquidos percolados, desvio e proteção de cursos e nascentes 
de águas e instrumentação. Neste texto será feito uma breve introdução a estes elementos com o enfoque principal sendo dado às barreiras impermeáveis.

Sistema de Drenagem de Gases e Líquidos Percolados: os aterros sanitários devem possuir um sistema de drenagem interno eficiente para permitir a dissipação de gases e remoção e condução de líquidos percolados, (TIVERON et al. 1995). Os líquidos percolados devem ser interceptados e conduzidos para um local de armazenagem e encaminhados para um tratamento adequado. Esta drenagem é realizada através de drenos internos construídos, geralmente, por brita e tubos perfurados. A impermeabilização de fundo exerce um papel importante neste processo de drenagem.

Sistema de Desvio de Águas e Proteção Superficial: as águas superficiais de cursos d'água e nascentes, assim como águas provenientes de precipitação direta devem ser desviadas e protegidas, pois estas tendem a infiltrar na massa de resíduos aterrados causando erosão e carreando contaminantes. Assim, os aterros são providos de sistemas de drenagem superficial e desvio de nascentes. Estes sistemas são, geralmente, construídos com canaletas e descidas d'água nos taludes. Para evitar a erosão dos taludes, é comum o plantio de vegetação rasteira.

Instrumentação: o monitoramento tem como objetivo avaliar comportamento do aterro sanitário, assim como levantar parâmetros para a elaboração de projetos futuros aliando economia e eficiência. Vários parâmetros são constantemente observados, como pressões internas, deslocamentos horizontais e verticais, nível de água, pressões de gás, movimento de solo de fundação, temperatura etc. $\mathrm{O}$ uso de equipamentos de monitoramento não é prática comum nos aterros do Brasil.

\subsubsection{Barreiras Impermeáveis}

As barreiras impermeáveis são dispositivos utilizados quando se deseja minimizar a infiltração de águas no maciço e resíduos aterrados (como as barreira impermeável de cobertura) e, ou reter ao máximo a percolação de líquidos, de sorte que ele não atinja as águas e solos naturais (como as barreira impermeável de fundo). A barreira de fundo tem como papel principal a interceptação do lixiviado produzidos pela decomposição do resíduo e conduzir à sistemas de coleta de percolado e gases. Desta forma, estes elementos devem 
apresentar características compatíveis para sua função como estanqueidade, durabilidade, resistência mecânica, resistência a intempéries e compatibilidade com os resíduos aterrados.

Os revestimentos e camadas impermeabilizantes podem ser construídos por solos argilosos, materiais sintéticos, ou ainda, pela associação destes materiais (SHARMA \& LEWIS, 1994). A CETESB (1993) apresenta algumas condições mínimas para a disposição do resíduo de classe II, onde se enquadra o resíduo sólido urbano (RSU), observando a não necessidade de impermeabilização de fundo para terrenos em solos naturais com condutividade hidráulica inferior a $10^{-6} \mathrm{~cm} / \mathrm{s}$ e profundidade de nível d'água igual ou maior que $3 \mathrm{~m}$. No primeiro caso apresentado Figura 2.4 a, as condições hidrológicas e climáticas são favoráveis, pois a diferença da evaporação e precipitação é maior que $500 \mathrm{~mm}$. Já no segundo caso apresentado Figura 2.4 b as condições climáticas são desfavoráveis, pois a diferença da evaporação e precipitação é maior que $500 \mathrm{~mm}$. No segundo caso, as chuvas podem ser prejudiciais, pois infiltram no aterro elevando o volume de percolado, aumentando assim o risco de contaminação, para estes casos é indicado uma impermeabilização de cobertura.

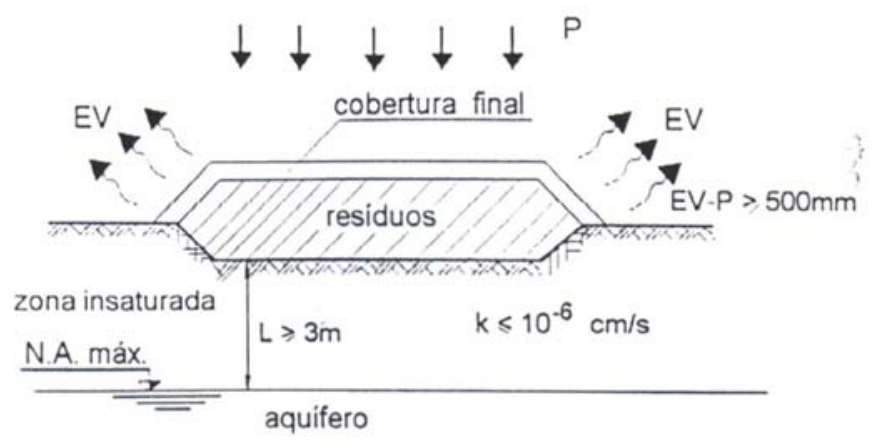

a) Condições climáticas e hidrológicas favoráveis

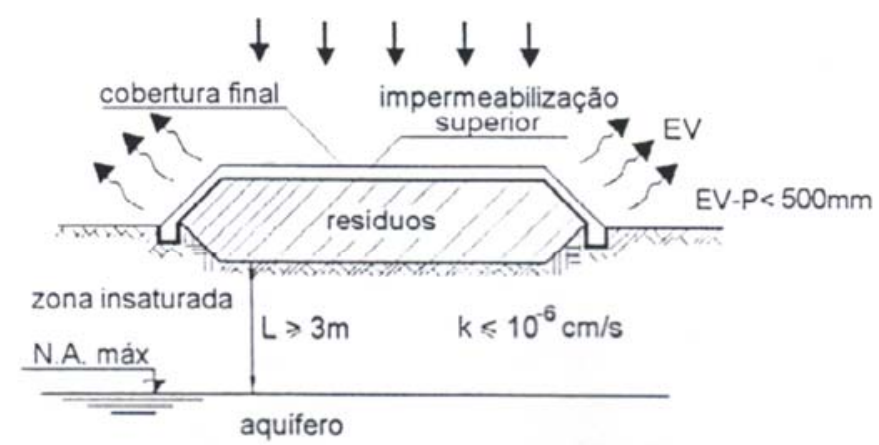

b) Condiçōes climáticas insatisfatórias e hidrológicas favoráveis

Figura 2.4 - CETESB (1993), Condições de fundação de aterros sanitários. 
São apresentados também outros dois casos onde as condições hidrológicas são desfavoráveis, pois a condutividade hidráulica da zona não saturada está entre $10^{-4}$ e $10^{-6} \mathrm{~cm} / \mathrm{s}$ e a profundidade do nível d'água é da ordem de 1,5m. Em ambas as situações são exigidos impermeabilizações de fundo e drenos para o controle de percolados (Figura 2.5). Quanto à impermeabilização de cobertura, as condições são as mesmas dos casos relatados anteriormente.

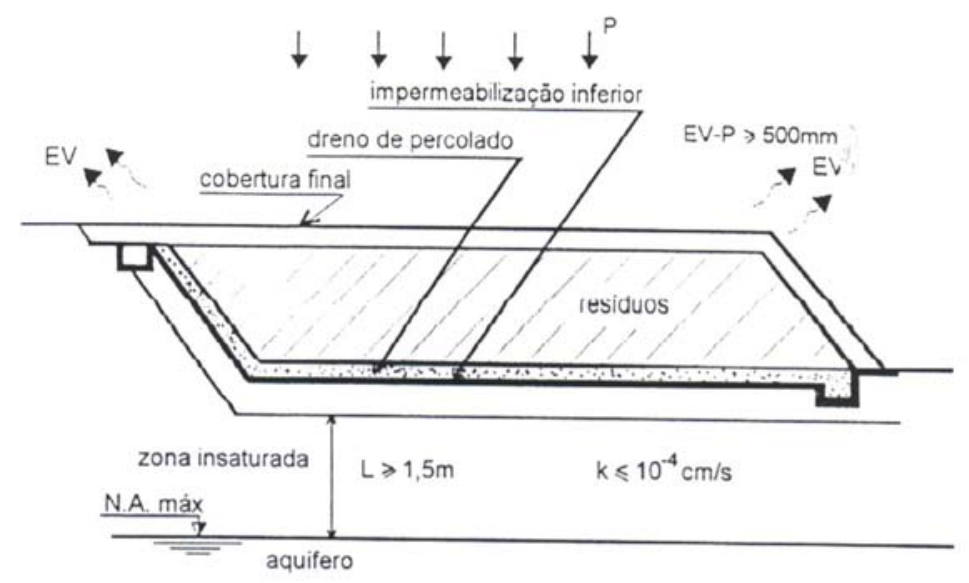

a) Condiçðes climaticas favoráveis e hidrológicas insatisfatórias

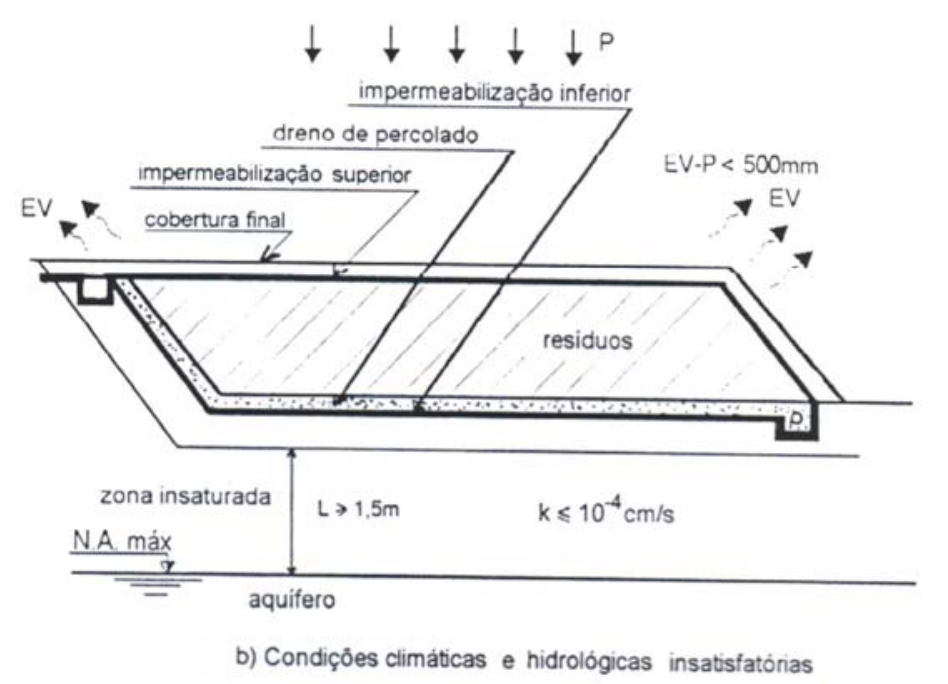

Figura 2.5 - CETESB (1993), Condições de fundação de aterros sanitários. 


\subsubsection{Barreiras Impermeáveis com Geossintéticos}

Com o avanço da tecnologia de industrialização de materiais plásticos, o uso de geossintéticos vem sendo prática comum nas obras de engenharia geotécnica onde se necessita de algum tipo de impermeabilização. No caso de impermeabilização de aterros sanitários, os materiais sintéticos comumente utilizados são as geomembranas e os GCL's (geosynthetic clay liner). Segundo a ASTM D4439, as geomembranas são barreiras construídas de membranas construídas com materiais sintéticos que apresentam permeabilidade baixa, utilizada em obras de engenharia onde se deseja controlar a migração de fluidos.

As geomembranas comumente usadas nas obras de impermeabilização são as de HDPE (polietileno de alta densidade), VLDPE (polietileno de baixa densidade), CSPE (polietileno clorosulfonado), PVC (policloreto de polivinila), e EIA (interpolímero etileno alloy), sendo, atualmente, as mais utilizadas em obras de contenção de resíduos, de polietileno (PE) e polivinil clorado (PVC).

As vantagens do uso da geomembrana de polietileno de alta densidade (HDPE), quando utilizadas como barreira de fundo, estão no fato deste material apresentar alta resistência química à diversas substâncias, apresentar maior durabilidade em longo prazo, além de resistir a elevadas tensões geralmente impostas durante a construção e instalação. Porém quando utilizadas como barreira de recobrimento, o material deve apresentar certa flexibilidade, devido aos grandes recalques que ocorrem nos resíduos. Neste caso, o geomembrana de polietileno de baixa densidade (VLDPE) é mais indicada.

As geomembranas de policloreto de polivinila (PVC) também são utilizadas em obras de impermeabilização. No entanto, devido a aspectos de durabilidade em longo prazo e resistência a ataques químicos, seu uso é indicado para obras de vida útil de 1 à 5 anos. Com o avanço da tecnologia de fabricação e a aplicação de aditivos, as geomembranas vêm apresentando melhorias significativas que podem viabilizar o seu uso em obras de longo prazo. As vantagens de seu uso estão relacionadas à maior trabalhabilidade, facilidades de fabricação em painéis sob medida e baixo custo.

È comum o uso de materiais sintéticos em conjunto com solo natural ou compactado. Nestes casos é necessário o estudo de outros parâmetros como a resistência ao cisalhamento da interface solo geossintéticos. A Figura 2.6 apresenta um típico perfil de sistemas de 
impermeabilização de fundo e cobertura, onde são utilizados materiais sintéticos em conjunto com solo.

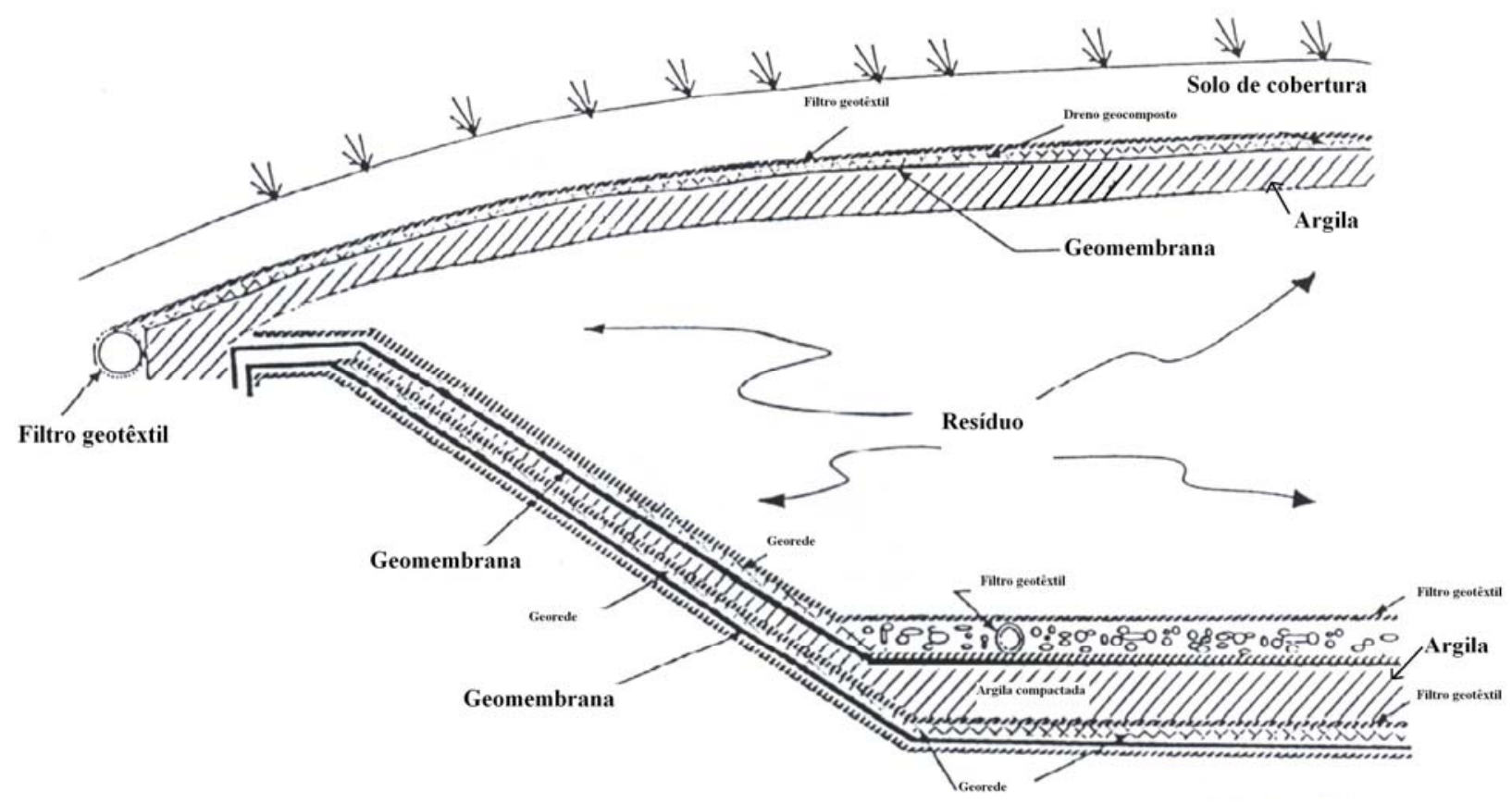

Figura 2.6 - Perfil típico de impermeabilização com o uso de materiais sintéticos e solo, SHARMA\& LEWIS (1994).

Como já citado anteriormente, outro tipo de geossintético utilizado como barreiras impermeáveis é o GCL (geosynthetic clay liner). O GCL é composto por uma fina camada de bentonita seca (material argiloso com elevado potencial expansivo e baixa permeabilidade), com aproximadamente $5 \mathrm{~mm}$, associada a uma geomembrana ou um geotêxtil. A solidarizarão entre a bentonita e o geossintético é feita por aderência mecânica (costura ou agulhamento) ou quimicamente (resina adesiva). Em geral, o GCL é utilizado para substituir barreiras impermeáveis construídas de solo compactado, pois apresenta uma condutividade hidráulica da ordem $1.10^{-8}$ a $1.10^{-10} \mathrm{~cm} / \mathrm{s}$. Uma das configurações mais utilizadas como barreiras impermeáveis, é a composta de uma camada de geotêxtil tecido, uma camada de bentonita e outra camada de geotêxtil não tecido.

Através de ensaios, DANIEL (1996) demonstrou que a percolação do chorume não degrada significativamente o GCL, embora alguns fatores têm se mostrados importantes no comportamento deste material como barreira impermeável. Tais fatores, como tensão de confinamento aplicada, composição química do percolante, principal líquido hidratante 
inicial, entre outros, podem exercer influência no comportamento da GCL. Alguns resultados mostram que a hidratação inicial com chorume (e não água) produz as piores condições.

Os GCLs podem ser uma solução prática e de custo relativamente baixo onde não se dispõe de solos com baixa condutividade hidráulica. Suas vantagens dizem respeito á flexibilidade e facilidade de instalação. No entanto, mais pesquisas devem ser realizadas no comportamento em logo prazo, condições de resistência na interface e desempenho das emendas e uniões entre mantas. A Tabela 2.2 apresenta as diferenças entre o uso de GCL's e solos argilosos como barreiras impermeáveis.

Tabela 2.2 - Diferenças entre GCL's e barreiras de solo compactado. Adaptado de USEPA (1993) ${ }^{1}$ apud SHARMA \& LEWIS (1994).

\begin{tabular}{|c|c|c|}
\hline Características & GCL & Solo Compactado \\
\hline Materiais & $\begin{array}{c}\text { Bentonita, adesivos, geotêxtil e } \\
\text { geomembrana. }\end{array}$ & $\begin{array}{l}\text { Solos naturais ou misturas com } \\
\text { bentonita }\end{array}$ \\
\hline Construção & $\begin{array}{l}\text { Fabricação industrial e então } \\
\text { instalado no campo. }\end{array}$ & Construído em campo \\
\hline Espessura & Aproximadamente $10 \mathrm{~mm}$ & Entre 0,5 e $1 \mathrm{~m}$ \\
\hline $\begin{array}{c}\text { Condutividade } \\
\text { hidráulica }\end{array}$ & $\begin{array}{c}\text { Tipicamente entre } 10^{-8} \text { e } 10^{-10} \\
\mathrm{~cm} / \mathrm{s}\end{array}$ & $\begin{array}{c}\text { Tipicamente entre } 10^{-7} \text { e } 10^{-8} \\
\mathrm{~cm} / \mathrm{s}\end{array}$ \\
\hline $\begin{array}{l}\text { Facilidade e tempo de } \\
\text { construção }\end{array}$ & Instalação rápida e simples. & Baixa e de complicada construção \\
\hline $\begin{array}{l}\text { Teor de umidade } \\
\text { durante a construção }\end{array}$ & $\begin{array}{l}\text { Inicialmente seca, durante a } \\
\text { construção não pode ser } \\
\text { umedecida. }\end{array}$ & $\begin{array}{l}\text { Próximo à saturação, pode secar e } \\
\text { trincar. Pode haver consolidação } \\
\text { da camada argilosa }\end{array}$ \\
\hline
\end{tabular}

\footnotetext{
${ }^{1}$ U.S. Environmental Protection Agency (USEPA) Report of Workshop on geosynthetic clay liners, USEPA, Washington, D.C., August (1993).
} 


\subsubsection{Barreiras Impermeáveis com Solo Compactado}

$\mathrm{Na}$ literatura é apontado um tipo de barreira impermeável constituída de solo em condições naturais. Este maciço deve apresentar condutividade hidráulica inferior a $10^{-6} \mathrm{~cm} / \mathrm{s}$ e estar isento de imperfeições como falhas, trincas ou qualquer descontinuidade que propicie um caminho preferencial de fluxo.

Para a utilização de barreiras impermeáveis com solo em condições naturais, é necessária a verificação de suas características por estudos geotécnicos de campo e laboratório. Deve-se lembrar que os furos de prospecção e os destinados à instalação de equipamento de medida causam danos e comprometem o bom funcionamento da barreira. Estes furos e perturbações ao maciço devem ser apropriadamente reparados.

É difícil e caro assegurar que uma barreira impermeável com o solo, em condições naturais, tenha uma baixa e uniforme condutividade hidráulica. Por isso esta prática não é comumente utilizada. Portanto, a engenharia geotécnica lança mão da compactação dos solos como método de melhoria do desempenho deste material. É apresentado a seguir algumas peculiaridades de construção e escolha do solo a ser utilizado como barreira impermeabilizante.

\section{Quanto à construção}

A construção de barreiras impermeáveis utilizando solo compactado deve seguir alguns requisitos de execução para garantir o seu bom funcionamento. As camadas do fundo do aterro são compactadas em faixas horizontais. Já nos taludes é recomendado que as camadas de solo sejam compactadas em faixas paralelas ao talude, pois desta forma, diminuise a área de materiais mal selecionados e eventuais imperfeições nas ligações das camadas não representem caminhos preferenciais de fluxo, (McBEAN et al., 1995).

Quanto ao estado do material, este não pode apresentar torrões e/ou material grosseiro, portanto deve ser processado para promover o destorroamento e peneirado para a separação da fração grossa do solo. O solo pode ser secado ou umedecido cerca de 2 a $3 \%$ da sua umidade natural, e espalhado em camada de $30 \mathrm{~cm}$ para a homogeneização da umidade, utilizando grades de discos, até atingir a umidade desejada para a compactação.

A compactação deve ser realizada utilizando equipamentos adequados as características do solo. Os equipamentos estáticos são preferidos frente aos vibratórios, por perturbar menos a camada de solo a ser compactada. A superfície de uma camada 
previamente compactada deve ser escarificada para a melhor aderência com a próxima sobrejacente. Após a compactação, a superfície deve ser protegida contra o ressecamento, que pode causar trincas de contração no solo e formar caminhos preferenciais de fluxo, prejudicando o bom funcionamento da barreira. Esta proteção pode ser realizada com lona plástica, desde que não absorva calor e resseque o solo, ou molhando o solo periodicamente.

Assim como é realizado com aterros em barragens, pode ser construída uma barreira experimental. Segundo DANIEL (1993) a construção de uma barreira experimental oferece muitas informações, onde são realizados testes de controle de qualidade e principalmente de condutividade hidráulica. Com este artifício, podem ser determinados equipamentos a serem utilizados, assim como, número de passadas, espessura da camada, etc.

\section{Quanto à escolha do material}

O solo selecionado para a construção de uma barreira impermeável deve apresentar características que atendam as necessidades desta função, principalmente quando a condutividade hidráulica. Geralmente solos argilosos apresentam as melhores características. A CETESB (1993) sugere a adoção de um critério para a escolha do solo a ser utilizado como barreira impermeável:

- Classificação unificada $\mathrm{CL}, \mathrm{CH}, \mathrm{SC}$ ou $\mathrm{OH}$;

- Porcentagem que passa na peneira \#200 maior que 30\%;

○ $\quad$ LP $\geq 30 \%$ e IP $\geq 15$;

○ $\mathrm{PH} \geq 7$;

○ $\mathrm{k} \leq 10^{-7} \mathrm{~cm} / \mathrm{s}$.

Quando o solo com as características necessárias não está disponível, ou quando a área de empréstimo é suficientemente afastada para inviabilizar o uso do material, pode-se lançar mão do uso de aditivos para a melhoria dos solos. Um dos métodos utilizados é a adição de bentonita com o objetivo de obter baixos valores de condutividade hidráulica. Porém, devido à alta plasticidade deste material a trabalhabilidade em campo pode ser dificultada.

Alguns autores têm estudado a utilização de materiais alternativos para o uso como barreiras impermeáveis, Mollamahmutoglu \& Yilmaz , (2001), estudaram o potencial uso de cinza fulcânica em uma mistura de 5 a $30 \%$ de bentonita para a utilização como barreira impermeável. A mistura foi compactada no teor de umidade ótimo e massa específica seca 
máxima. Foram realizados ensaios de permeabilidade e obtidos valores inferiores a $1 \times 10^{-7}$ $\mathrm{cm} / \mathrm{s}$ para a mistura com $20 \%$ (em massa) de bentonita, o que viabiliza o uso para a disposição de resíduos. Os autores observaram também, o aumento da condutividade hidráulica com o tempo quando permeados soluções moderadamente básicas $(20 \%$ de $\mathrm{NaOH})$ e moderadamente acidas $(20 \% \mathrm{de} \mathrm{HCl})$.

\subsection{COMPORTAMENTO HIDRÁULICO DOS SOLOS COMPACTADOS}

O comportamento hidráulico dos solos compactados é função de fatores relacionados á matriz do solo e fatores relacionados aos métodos de compactação. Em um estudo realizado com 67 amostras de solos de aterros sanitários dos Estados Unidos, BENSON et al, (1994), relacionaram a condutividade hidráulica dos solos compactados com fatores como atividade dos argilominerais, grau de compactação, limites de consistência, tipo do compactador, entre outros. Os autores concluíram que a condutividade hidráulica dos solos compactados é função dos seguintes fatores: estrutura dos solos; composição granulométrica e mineralógica; limites de consistência; natureza do líquido percolado.

A composição mineralógica dos solos influencia diretamente a plasticidade do material assim como sua condutividade hidráulica. Há uma tendência de decréscimo do valor da condutividade hidráulica com o aumento da plasticidade. Três argilas com alguns tipo de argilomineral predominante (caulinita, ilita ou monttmorilonita) foram estudas quanto aos seus comportamentos hidráulicos por MESRI \& OLSON (1971). Os resultados são apresentados na Tabela 2.3.

Tabela 2.3 - Condutividade dos argilominerais, MERI \& OLSON (1971).

\begin{tabular}{ccc}
\hline Argilomineral & IP & $\mathrm{k}(\mathrm{cm} / \mathrm{s})$ \\
\hline Caulinita & 20 & $1,5 \times 10^{-6}$ \\
\hline Ilita & 60 & $2 \times 10^{-9}$ \\
\hline Monttmorilonita & 500 & $1 \times 10^{-11}$ \\
\hline
\end{tabular}

Os torrões presentes no solo influenciam diretamente o tamanho dos poros existentes no maciço ou corpo de prova de solo compactado, sendo que, como citado anteriormente, a condutividade hidráulica é função não só da quantidade de vazios existentes no solo, mas 
também do tamanho dos poros. Segundo o estudo de BENSON et al, (1994), a influência dos tamanhos dos poros na condutividade hidráulica foi significativa para solos compactados no ramo seco da curva de compactação e na energia normal. Já para os solos compactados no ramo úmido da curva, o tamanho dos torrões não é importante, pois nesta situação estes torrões se tornam moles e compressíveis.

Em outro estudo realizado, WATABE et al, (2000) analisaram o comportamento hidráulico de um solo não plástico do norte de Quebec, eles observaram que a condutividade foi fortemente afetada pelo grau de saturação e pela compactação. As amostras foram analisadas por microfotografias e evidenciou-se que a condutividade hidráulica é aumentada com o tamanho dos poros e a formação de macroporosidade, quando a amostra é compactada abaixo da umidade ótima.

A prática mostra que valores baixos de condutividade hidráulica para solos compactados são alcançados quando se realiza a compactação próxima ou acima da umidade ótima, ou quando é aumentada a energia de compactação. Esta diferença de condutividade se dá pelo arranjo das partículas, isto é, pela estrutura interna formada no solo causada pela a compactação. Segundo LAMBE \& WHITMAN (1969), quando o solo argiloso é compactado com teor de umidade acima da ótima, as partículas estão arranjadas de forma paralelas (estrutura dispersa), o que dificulta a passagem de fluxo e, conseqüentemente, diminui a condutividade hidráulica. Já quando a compactação é realizada abaixo do teor de umidade ótimo, ramo seco da curva, as partículas se arranjam de forma floculada (estrutura floculada), o que facilita a passagem de fluxo. A Figura 2.7 mostra o efeito da energia de compactação e o teor de umidade de moldagem na estrutura interna do solo compactado. Na condição A da Figura 2.7, o solo se apresenta com uma estrutura interna chamada de estrutura flocolada, com o aumento da umidade de moldagem, o solo tende a uma estrutura interna chamada de estrutura dispersa, condição E. O mesmo acontece com o aumento da energia de compactação. 


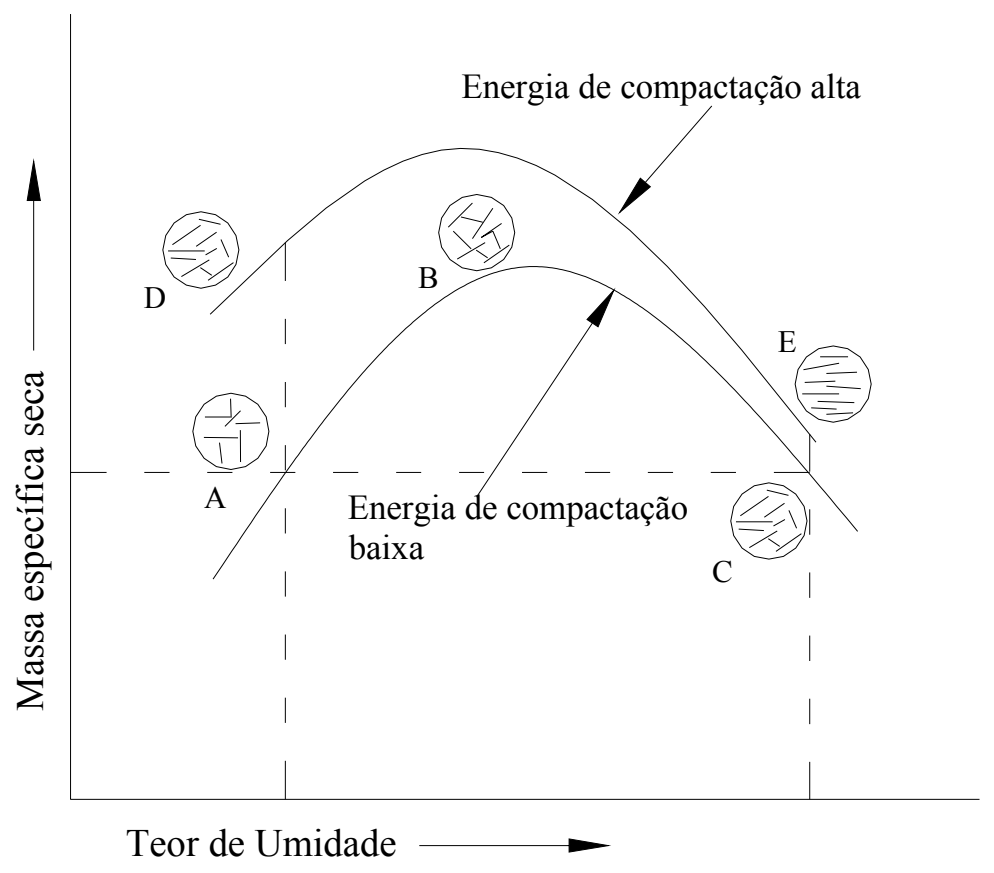

Figura 2.7 - Efeito da compactação na estrutura interna do solo, (LAMBE \& WHITMAN, 1969).

MITCHELL et al, (1965) analisaram fatores como estrutura do solo, condições de compactação, método de compactação, entre outros. Para a analise, foi escolhida uma argila siltosa com $L L=37 \%$ e IP $=23 \%$, compactada de forma dinâmica, com variação de umidade de moldagem e massa específica variável e constante. A Figura 2.8 mostra os resultados obtidos da condutividade hidráulica e massa específica seca em função do teor de umidade. 


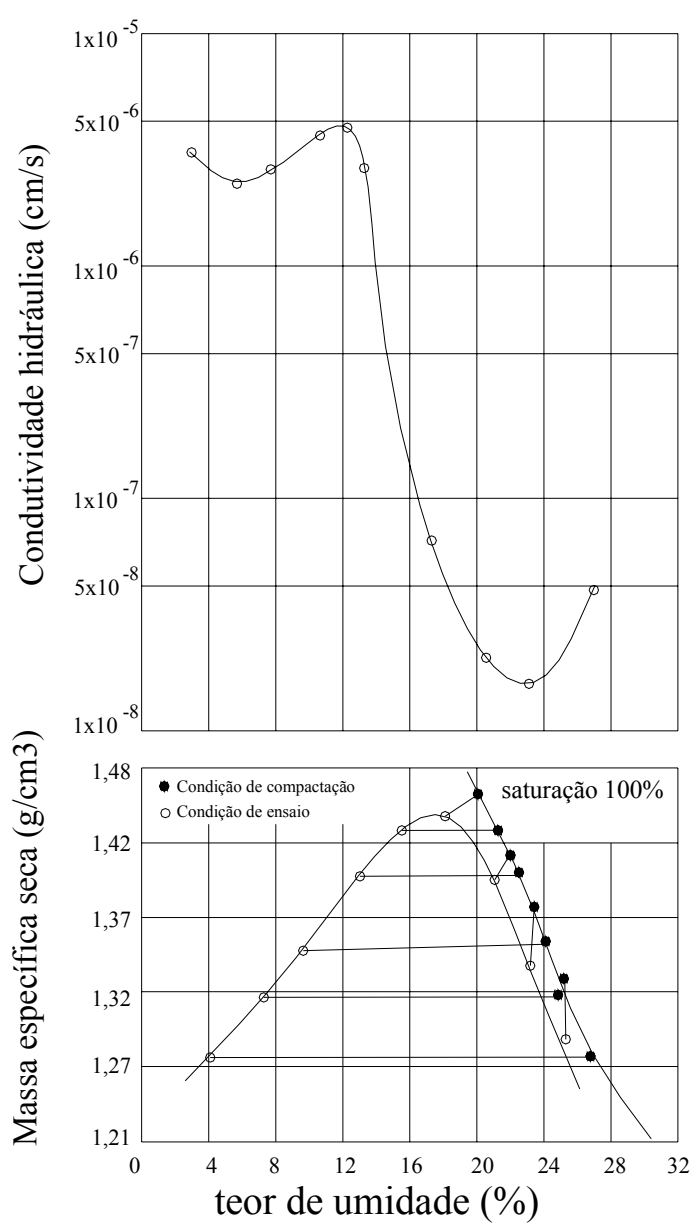

Figura 2.8 - Resultados de condutividade hidráulica e massa especifica seca $x$ teor de umidade de moldagem, MICHELLet al (1965).

Observa-se também que a condutividade hidráulica diminui bruscamente quando a compactação é realizada acima do teor de umidade ótimo, comportamento que se assemelha com os estudos realizados por LAMBE \& WITMAN (1969). Outro fator analisado por MICHELL et al, (1965), foi o efeito do aumento da energia de compactação na condutividade hidráulica. Para os pontos mais secos não se observou significativa variação e, após o teor de umidade ótima, a diminuição da condutividade hidráulica foi bastante pronunciada. Além disso, com o aumento da energia de compactação, a diminuição da condutividade hidráulica foi da ordem de 100 vezes, principalmente nos pontos próximo a umidade ótima. A Figura 2.9 mostra os resultados obtidos por MICHELL et al. (1965). 


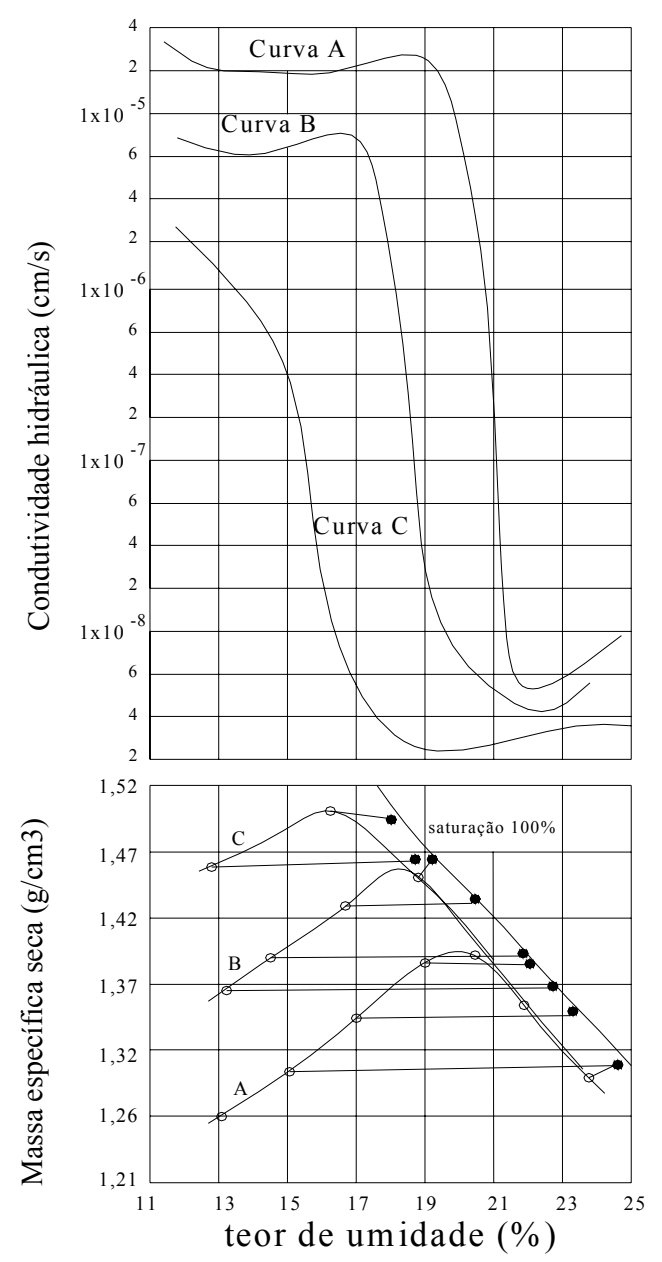

Figura 2.9 - Variação de condutividade hidráulica devido ao aumento da energia de compactação, MICHELL et al.(1965).

\section{Quanto ao método de compactação}

Como visto nos estudos apresentados anteriormente, a especificação de uma faixa de teor de umidade e massa específica seca, com uma determinada energia de compactação, são fatores importantes na condutividade do solo compactado. BENSON \& DANIEL (1990) estudaram fatores limitantes para a obtenção de valores aceitáveis de condutividade hidráulica em solos compactados para o uso como barreiras impermeáveis. Os autores utilizaram a metodologia proposta por MUNDELL \& BAILEY (1985) e BOUTWELL \& HEDGES (1989), onde é recomendada a utilização da curva de compactação do solo obtida pelo ensaio de Proctor Normal. A metodologia proposta é a determinação de uma zona admissível na curva de compactação do solo, Figura 2.10, em que a combinação de massa específíca seca e teor de umidade leve a condições ideais para o uso do solo principalmente como barreira 
impermeável de aterro sanitário. A faixa de massa específica seca requerida é uma porcentagem "P" da massa específica seca máxima do ensaio de compactação. A porcentagem "P" é usualmente de 95\% da massa específica seca máxima do ensaio de Proctor Normal (ASTM D698), ou 90\% da massa específica seca máxima do ensaio de Proctor Modificado (ASTM D1557). A faixa de teor de umidade varia de acordo com as características do solo. Para solos argilosos utilizados como barreiras impermeáveis, esta variação está, tipicamente, entre $0-4 \%$ do teor de umidade ótimo do ensaio de Proctor Normal ou modificado. Esta zona admissível tem como limite superior a curva de saturação $100 \%$.

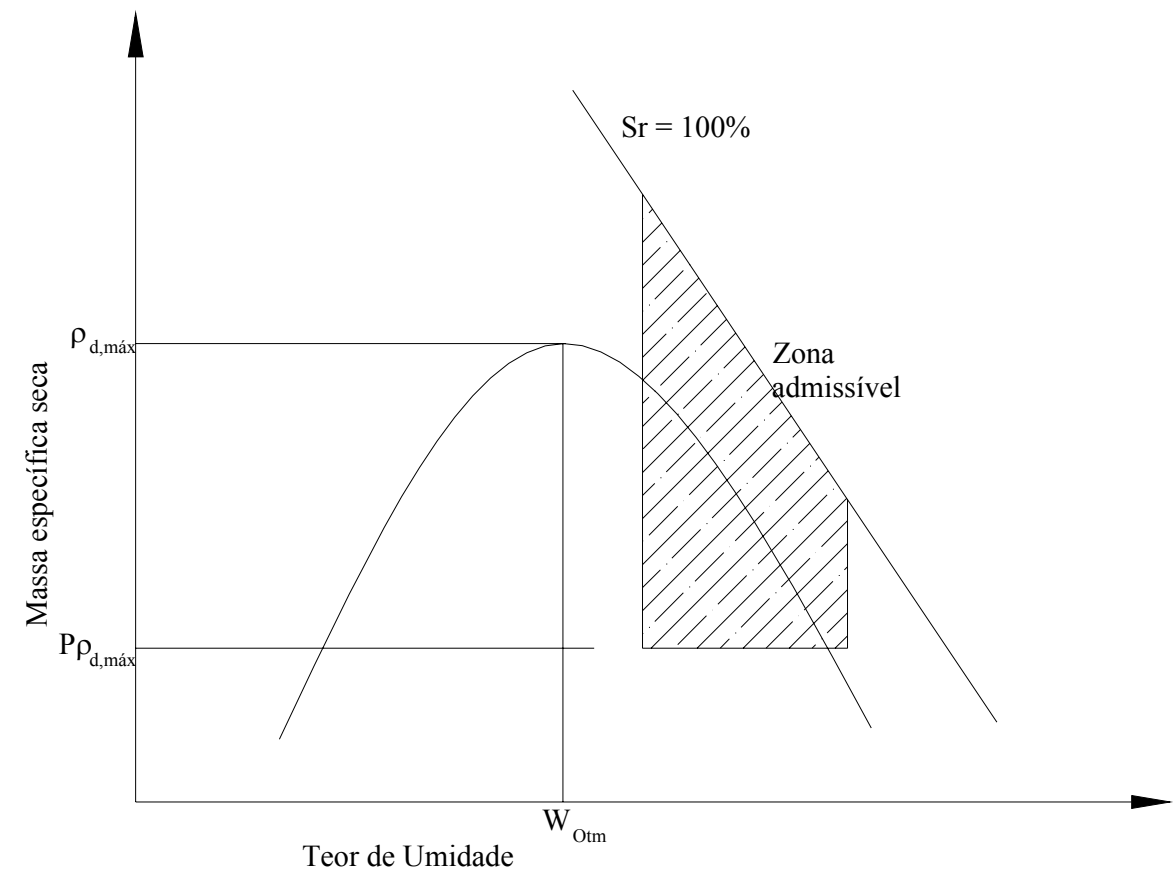

Figura 2.10 - Tradicional método para especificar a zona admissível, (DANIEL \& BENSON, 1990).

A zona admissível, mostrada na Figura 2.10, envolve conhecimentos empíricos da prática de construção de base de estradas, barragens de terra, e outros tipos de aterros. As especificações foram determinadas no intuito de atender as condições necessárias de resistência ao cisalhamento, compressibilidade e condutividade hidráulica para a execução de barreiras impermeáveis. No entanto, DANIEL \& BENSON (1990) utilizaram os dados de MICHELL et al (1965) e BOUTWELL \& HEDGES (1989) para a determinação da área admissível pelo método tradicional. Os autores perceberam algumas deficiências do método. Algumas amostras compactadas com massa específica seca e teor de umidade que se enquadravam dentro da área admissível, apresentavam condutividade hidráulica superior a $1 \times 10^{-7} \mathrm{~cm} / \mathrm{s}$, que é o valor limite aceitável para o uso do material como barreira impermeável. 
Como mostrado em estudos anteriores de MICHELL et al. (1965), a energia de compactação exerce influência direta na condutividade hidráulica do solo compactado, sendo que o aumento da energia de compactação resulta no decréscimo da condutividade hidráulica para solos argilosos. Desta forma, DANIEL \& BENSON (1990) recomendam uma nova metodologia para a determinação da zona admissível, incluindo ensaios de permeabilidade. Os autores recomendam os seguintes procedimentos:

i. Realizar as curvas de compactação em três energias, Proctor reduzido, normal e modificado, compactando cinco a seis corpos de prova por energia. Figura 2.11 a.

ii. As amostras devem ter suas condutividades hidráulicas, este procedimento deve ser executado com o monitoramento do grau de saturação e tensão confinante. Os dados devem ser plotados em um gráfico de condutividade hidráulica $\mathrm{x}$ teor de umidade de moldagem (Figura $2.11 \mathrm{~b}$ ).

iii. As amostras que apresentarem a condutividade hidráulica igual ou inferior a $1 \times 10^{-7}$ devem ser plotadas com símbolos diferenciados, a zona admissível deve ser determinada de forma a incluir os valores de permeabilidade aceitável $\left(\geq 10^{-7} \mathrm{~cm} / \mathrm{s}\right)$. Figura $2.11 \mathrm{c}$.

iv. A zona admissível deve ser modificada incluindo parâmetros de resistência ao cisalhamento, atrito interfacial com geotêxtil, considerações de umedecimento e secagem, interesses construtivos e práticas locais (Figura $2.11 \mathrm{~d}$ ). 


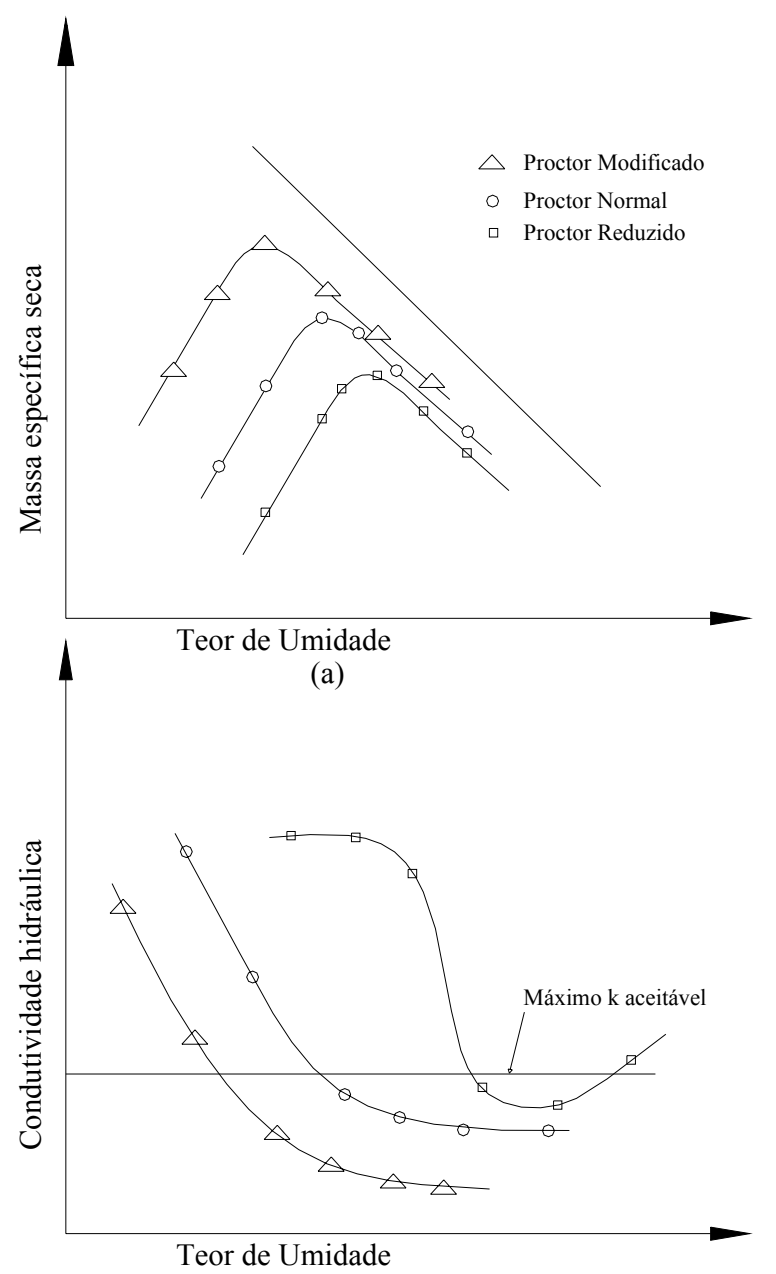

(b)

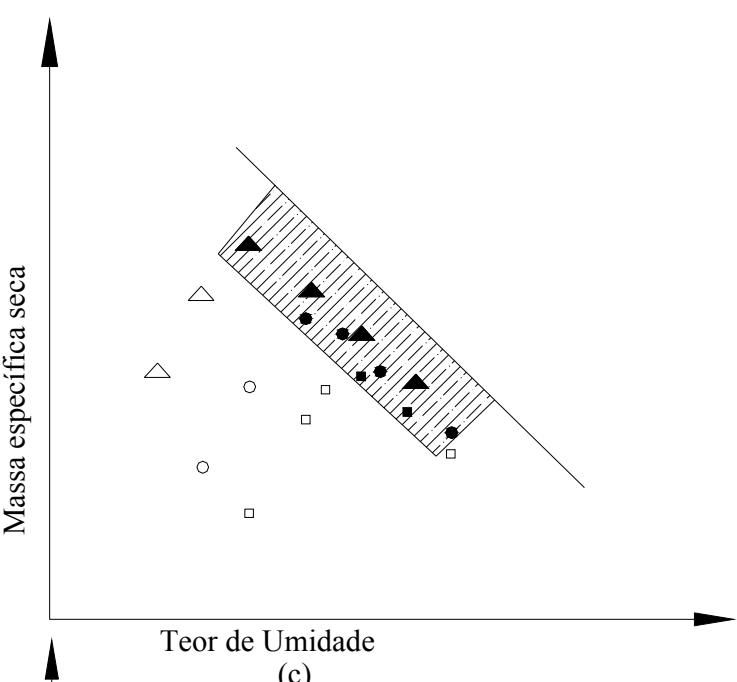

(c)

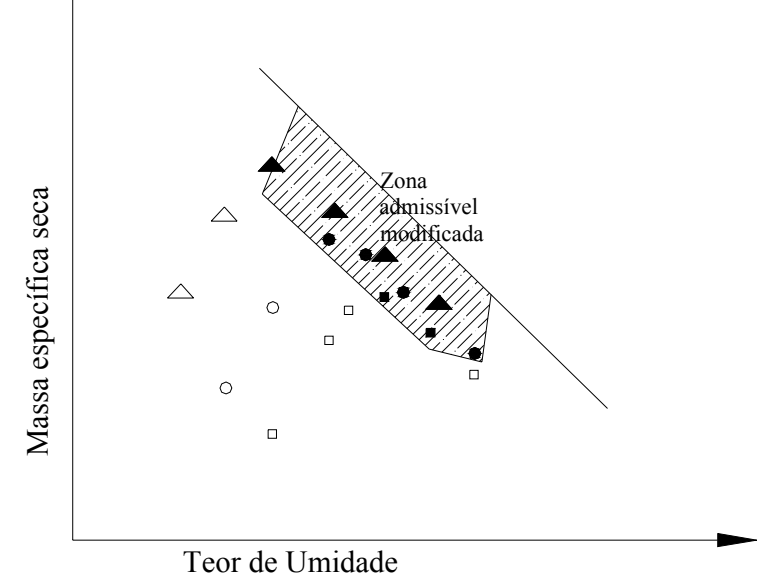

(d)

Figura 2.11 - Metodologia de determinação da zona admissível proposta por BENSON e DANIEL, (1990). (a) curva de compactação para três energias diferentes; (b) determinação da condutividade hidráulica; (c) replotagem da curva de compactação, identificando os pontos com condutividade hidráulica aceitáveis; (d) zona modificada conforme outros fatores condicionantes.

DANIEL e WU (1993), ao considerarem a idéia de estabelecer as condições de compactação para solos usados na construção de barreiras impermeáveis, introduziram mais dois parâmetros para a determinação da zona admissível. Estes dois parâmetros são relacionados à contração e resistência ao cisalhamento. Os limites propostos pelos autores são de $4 \%$ para a contração volumétrica e $200 \mathrm{kPa}$ para a resistência ao cisalhamento, além de $1 \times 10^{-7} \mathrm{~cm} / \mathrm{s}$ para a condutividade hidráulica. Pela proposta recomendada pelos autores, a área admissível é dada pela sobreposição das áreas limites segundo os parâmetros citados acima, como mostra a Figura 2.12. 


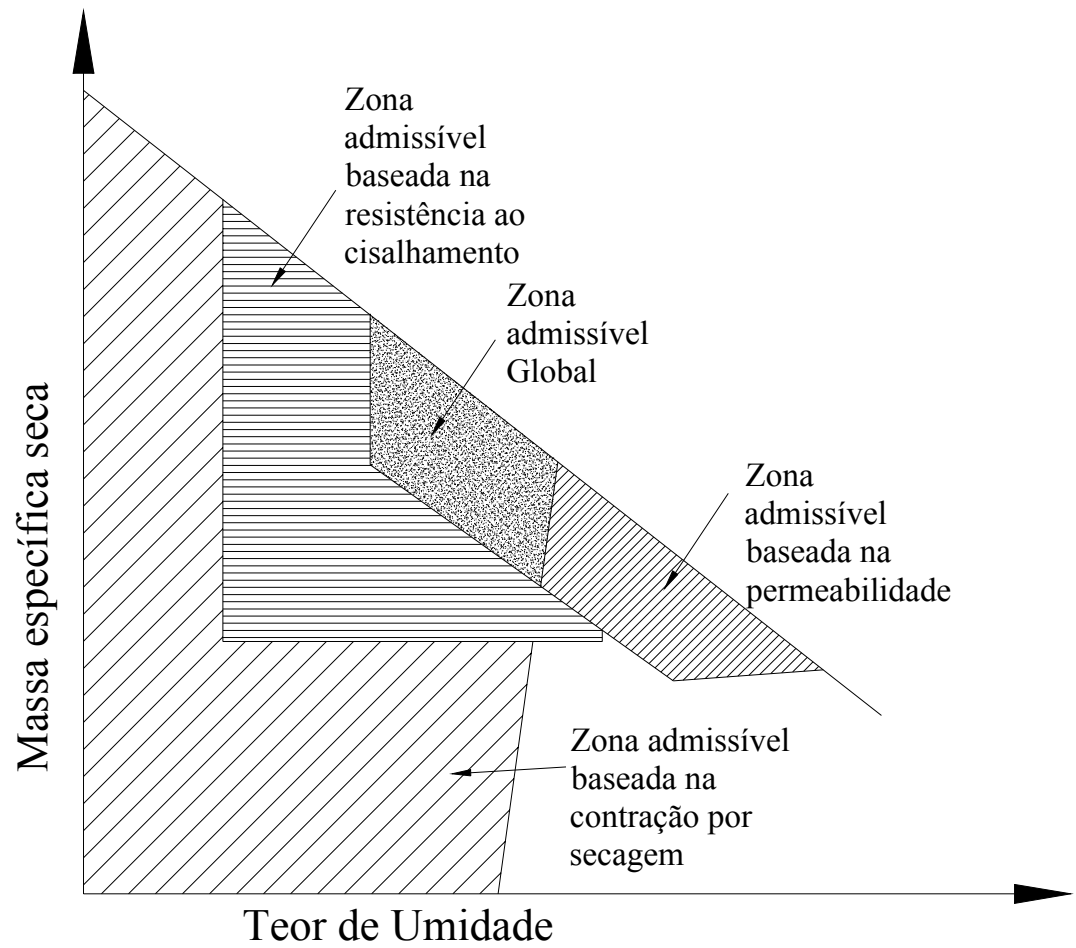

Figura 2.12 - Zona admissível baseada em parâmetros de condutividade hidráulica, contração volumétrica e resistência ao cisalhamento, (DANIEL e WU, 1993).

\section{Quanto à contração}

É comum o aparecimento de trincas na superfície do solo compactado. Estas trincas estão relacionadas com a contração volumétrica sofrida pelo solo, quando este é submetido à secagem. O aparecimento de trincas pode causar um caminho preferencial de fluxo, aumentando a condutividade hidráulica e prejudicando o bom funcionamento da impermeabilização.

Alguns autores estudaram contração de solos compactados quando submetidos a secagens, SEED \& CHAN (1959), fazeram um estudo sobre a contração axial de argilas compactadas. Neste trabalho, os autores relacionam a contração axial ao teor de umidade na moldagem dos copos de prova de solo compactado. Os autores explicam o fenômeno de contração como conseqüência do grau de saturação do solo na compactação. Desta forma as maiores contrações foram observadas para os solos compactados no ramo úmido da curva de compactação. Tal fato pode ser relacionado com a estrutura interna do solo compactado, conforme sugerido por LAMBE (1958).

$\mathrm{Na}$ tentativa de estabelecer limites de contração volumétrica para garantir a segurança em barreiras impermeáveis, KLEPPE \& OLSON (1985), analisaram o comportamento de solo 
naturais e misturados. A intenção dos autores foi relacionar a abertura de trincas com a contração volumétrica. Os ensaios realizados foram de contração volumétrica, abertura de trincas e condutividade hidráulica. Nos ensaios de contração volumétrica, os corpos-de-prova foram compactados com $38 \mathrm{~mm}$ de diâmetro e $76 \mathrm{~mm}$ de altura. Para o ensaio de condutividade hidráulica, os CPs foram moldados com $82 \mathrm{~mm}$ de diâmetro e $25 \mathrm{~mm}$ de altura. Já para o ensaio de trincamento, na tentativa de melhor representar as condições de campo, os CPs foram moldados em blocos com dimensões de $150 \mathrm{~mm}$ por $300 \mathrm{~mm}$ de largura e $50 \mathrm{~mm}$ de espessura.

KLEPPE \& OLSON, (1985), padronizaram o aparecimento de trincas em cinco níveis, como é mostrado na Tabela 2.4. Utilizando a escala adotada, os autores plotam o aparecimento de trincas em função da contração volumétrica, como é mostrado na Figura 2.13 .

Tabela 2.4 - Classificação do aparecimento de trincas em solo compactado, KLEPPE \& OLSON, (1985).

\begin{tabular}{cc}
\hline Número & Descrição \\
\hline 0 & Não há aparecimento de trincas \\
\hline 1 & Trincamento mínimo, trincas menores que $1 \mathrm{~mm}$ de espessura e $5 \mathrm{~mm}$ de \\
& profundidade. \\
\hline 2 & Trincamento moderado, abertura de trincas variando de 3 a 10 mm de espessura \\
& e 30 mm de profundidade. \\
\hline 3 & Trincamento maior, mais do que 10 mm de espessura e/ou penetração através \\
& do corpo de prova. \\
\hline 4 & Trincamento elevado, mais do que 20 mm de espessura, possivelmente em \\
&
\end{tabular}




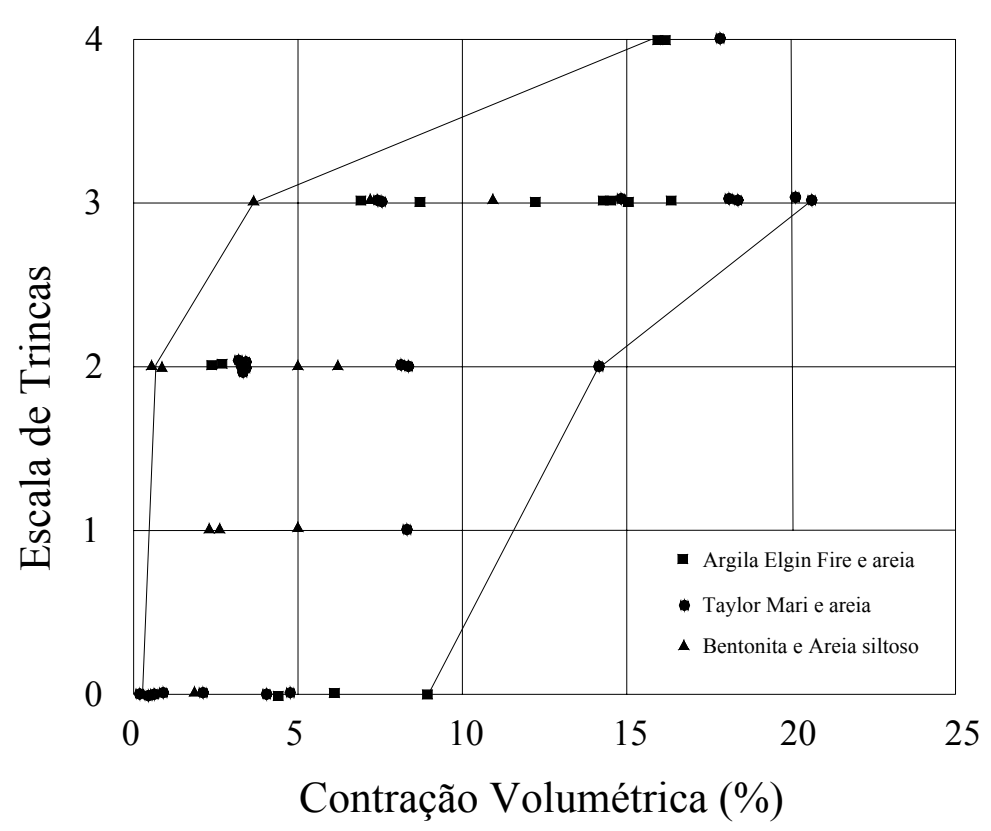

Figura 2.13 - Escala de trincas (tabela 2.4) em função da contração volumétrica, KLEPPE \& OLSON, (1985).

Os autores sugerem que para contrações volumétricas menores que 5\% o aparecimento de trincas causam pequenos danos ao solo, e para contrações volumétricas superiores a 10\%, são, geralmente, prejudiciais ao solo. Desta forma, com limitação de contração volumétrica de 5\%, é admitido o aparecimento de trincas de classes 1 e 2. DANIEL E WU, (1993), adotam um limite de $4 \%$ de contração volumétrica, o que admite também o aparecimento de trincas de classes 1 e 2 .

ALBERCHT \& BENSON, (2001), estudaram os fatores que influenciam a contração e o aparecimento de trincas em solos compactados. Os autores analisaram os efeitos do número de ciclos (umedecimento e secagem), condições de compactação e composição mineralógica do solo. Foram selecionados solos utilizados em barreiras de fundo e cobertura de aterros sanitários dos Estados Unidos. Os solos foram classificados como CL e CH. As amostras foram compactadas em três energias diferentes, Proctor normal, reduzido e modificado, e induzidos à saturação. As amostras foram submetidas, também, a ciclos de secagem e umedecimento com duração de duas semanas cada ciclo, em ambiente com temperatura de aproximadamente $20^{\circ} \mathrm{C}$ e baixa umidade relativa do ar.

As amostram foram submetidas a quatro ciclos e foi observado que, após os dez primeiros dias de secagem, não ocorreram mudanças significativas de volume e massa dos corpos de prova. Ao final do período de secagem as amostram eram levadas à saturação novamente e submetidas a mais um período de secagem. 
Para os corpos de prova moldados com teor de umidade ótimo, as contrações volumétricas foram menores, já para os corpos de prova moldados com teor de umidade aproximadamente $5 \%$ acima do ótimo, as contrações volumétricas foram significativas, maiores que $30 \%$. A Figura 2.14 mostra o efeito da energia de compactação e teor de umidade de moldagem na contração volumétrica. Medidas de condutividade hidráulica foram realizadas a cada ciclo.
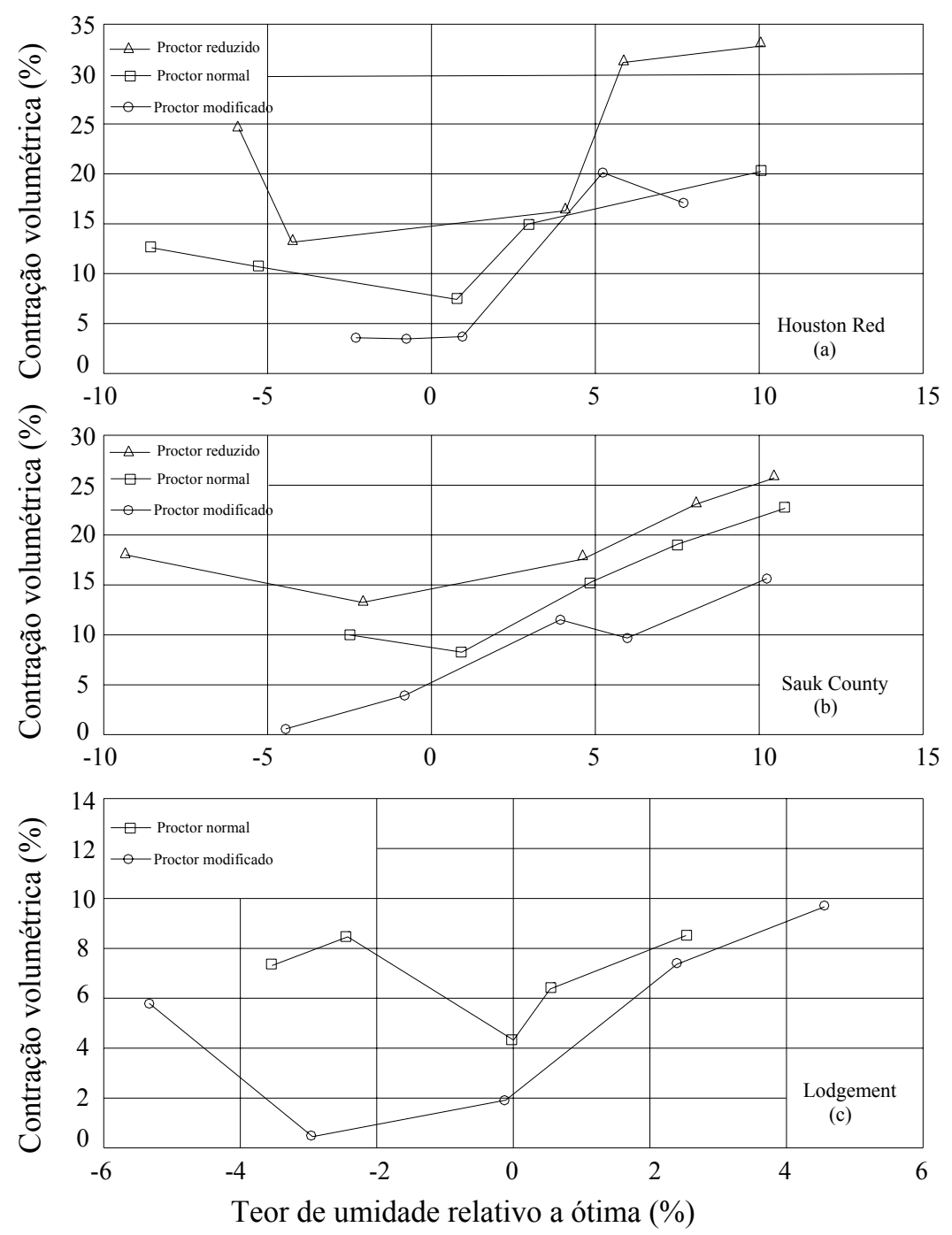

Figura 2.14 - Variação de da contração volumétrica em função do teor de umidade de moldagem e energia de compactação, (ALBRECHT \& BENSON, 2001).

Pode ser observado que o aparecimento de trincas está diretamente relacionado com valores de contrações volumétricas elevadas (aproximadamente 30\%). Os valores de contração volumétrica são mais acentuados em argilas mais plásticas, a condutividade hidráulica aumenta com o aumento do número de ciclos, devido ao aparecimento de trincas na 
superfície do solo. Segundo os autores, a contração volumétrica está diretamente ligada ao teor de umidade de moldagem, a energia de compactação, a porcentagem de argila e ao índice de plasticidade do solo.

\subsection{PERMEÂMETROS}

O conhecimento da condutividade hidráulica dos materiais é de interesse para diversas áreas da engenharia, em especial para a engenharia geotécnica.

Nos materiais inconsolidados, a condutividade hidráulica apresenta enorme variação. Encontram-se valores desde $10^{+2} \mathrm{~cm} / \mathrm{s}$, para matérias de alta condutividade como pedregulhos, até $10^{-12} \mathrm{~cm} / \mathrm{s}$, geralmente para solos com presença de argilas de alta atividade. Existem várias técnicas para a determinação deste parâmetro, abrangendo ensaios de campo e laboratório.

Os ensaios de laboratórios, quando comparados com ensaios de campo, apresentam algumas vantagens: controle nas condições de contorno (saturação, nível de tensões efetivas, carga hidráulica e direção de fluxo), possibilidade de medidas de anisotropia, tempo de ensaio e custo. Por outro lado, os ensaios de campo sofrem um menor efeito escala, pois o volume de solo ensaiado é maior que em laboratório. Existem variações nas determinações de campo e em laboratório, causadas principalmente por problemas de amostragem (DANIEL, 1987).

A condutividade hidráulica em laboratório pode ser medida por diversos procedimentos e empregando diferentes equipamentos. Normalmente utiliza-se algum tipo de permeâmetro. Existem, de um modo geral, dois tipos de permeâmetros: permeâmetro de parede rígida e permeâmetro de parede flexível, contando com diversas variações para cada um deles. A escolha do equipamento a ser utilizado depende das condições de contorno a serem adotadas, assim como do tipo de material a ser ensaiado, das condições de pressão e do fluido percolante.

$\mathrm{O}$ permeâmetro de parede rígida é composto por um corpo de prova $(\mathrm{CP})$ cilíndrico contido em uma caixa ou tubo rígido, onde o fluido percolante atravessa o $\mathrm{CP}$ ao longo do seu eixo. Daniel (1994) descreve quatro tipos de permeâmetro de parede rígida e variações de modelos em cada tipo: 
a) Os permeâmetros tipo cilindro de compactação têm como característica o fato do solo a ser ensaiado ser compactado no próprio tubo em que se realizará a percolação. $\mathrm{Na}$ maioria destes permeâmetros o molde de compactação é encaixado entre placas (não permite a expansão do corpo de prova), ou entre uma placa e um anel de prolongamento que tem o mesmo diâmetro interno do molde (permite a expansão do corpo de prova). O fluxo preferencial entre a parede do permeâmetro e o $\mathrm{CP}$, é minimizado devido à compactação do material no próprio corpo do permeâmetro. A vedação entre os encaixes é garantida por anéis do tipo O'rings. Figura 2.15.

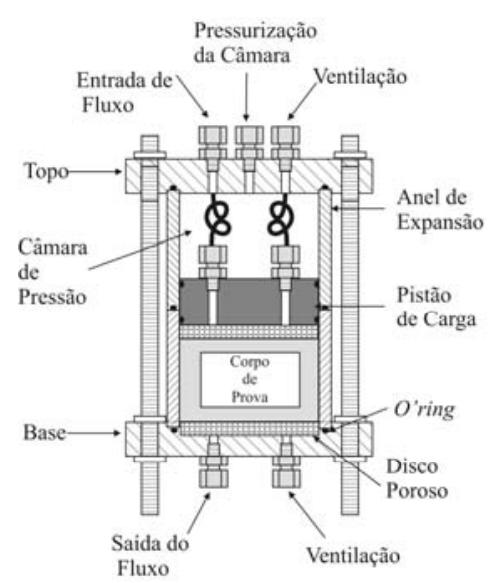

Figura 2.15 - Permeâmetro tipo molde de compactação com anel de prolongamento, DANIEL (1994).

b) Os permeâmetros tipo célula de consolidação permitem o controle de tensões no CP e são usados somente para solos argilosos que não contenham pedregulhos ou areia grossa.

c) Os permeâmetros tipo tubo de amostragem são utilizados para a determinação da condutividade hidráulica de materiais indeformados. O CP é obtido por puncionamento do tubo de parede fina no solo e este tubo é encaixado diretamente no permeâmetro. Um problema freqüente neste ensaio é o fluxo preferencial entre a parede do permeâmetro e o $\mathrm{CP}$, o que pode levar a resultados não reais de condutividade hidráulica. Figura 2.16. 


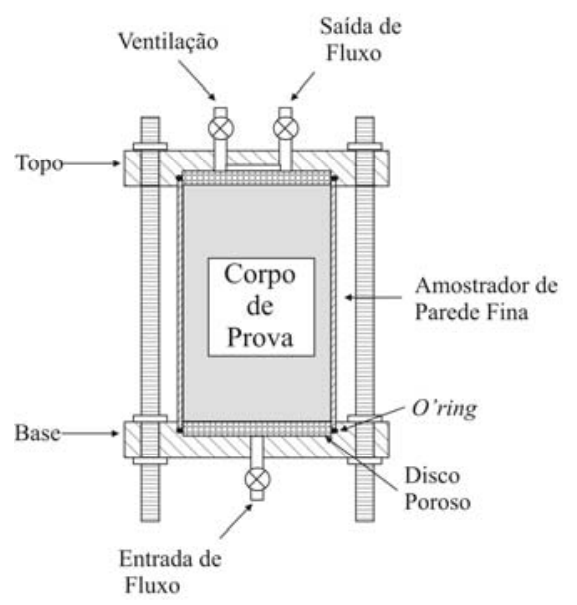

Figura 2.16 - Permeâmetro que utiliza amostrador de parede fina, DANIEL (1994).

d) Outros permeâmetro têm como característica básica o fato da parede do permeâmetro não estar em contato com o CP. O material a ser ensaiado é colocado no centro do permeâmetro e o espaço entre a parede e o CP é preenchido com material selante, normalmente bentonita. Cuidados especiais devem ser tomados no preenchimento do material selante para não influenciar os resultados. Figura 2.17.

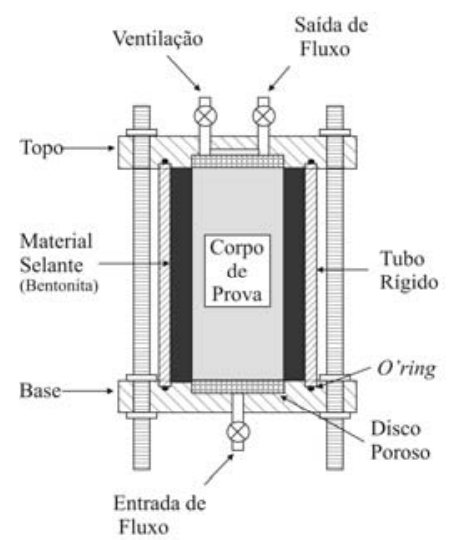

Figura 2.17 - Permeâmetro que utiliza material selante entre o CP e a parede, DANIEL (1994).

De acordo com a ASTM D5084 - 90 (1990), o permeâmetro de parede flexível é um equipamento utilizado para a determinação da condutividade hidráulica de materiais porosos, cujo valor seja menor ou igual a $10^{-3} \mathrm{~cm} / \mathrm{s}$. Existem três diferentes procedimentos para este método de ensaio: carga constante, carga variável ou fluxo constante. Através destes sistemas, podem-se medir parâmetros necessários para o cálculo da condutividade hidráulica. Com este método de ensaio, o fluxo preferencial nas paredes do permeâmetro é eliminado, diminui o tempo de saturação da amostra e a saturação é mantida durante todo o ensaio. 
Os ensaios de permeabilidade com permeâmetro de parede flexível são utilizados por serem rápidos e econômicos. Porém, devem ser conhecidas suas limitações: (1) a amostra ensaiada nem sempre representa a real situação de campo (efeito escala), (2) durante o ensaio, pode-se introduzir alguns erros, entre eles: introduzir ar na amostra saturada, adensamento do corpo-de-prova, crescimento de microorganismos em ensaios de longa duração, entre outros.

Este tipo de permeâmetro é composto por uma câmara que no interior é posicionado o $\mathrm{CP}$ entre duas pedras porosas envolto em uma membrana flexível, conforme ilustra a Figura 2.18. A dupla drenagem no cabeçote e no pedestal tem como finalidade facilitar a saturação das pedras porosas e das linhas condutoras de fluxo. Após a montagem descrita acima, faz-se o enchimento da câmara e aplicação da pressão confinante no seu interior que pressiona a membrana flexível contra o $\mathrm{CP}$, de forma que durante o ensaio não ocorra fluxo entre a membrana e o CP. Ao mesmo tempo em que se aumenta a pressão na câmara aplica-se uma pressão interna no $\mathrm{CP}$, denominada contra-pressão, sendo que a diferença entre a pressão interna e externa do CP constitui a tensão efetiva durante o ensaio.

Este procedimento de aumento da pressão confinante e contra-pressão tem como objetivo a saturação da amostra e é conhecido como saturação por contra-pressão. Assim, o ar ocluso nos poros da amostra ensaiada dissolve-se na fase líquida, em um processo que pode demorar poucas horas ou vários dias, dependendo principalmente da matriz do solo.

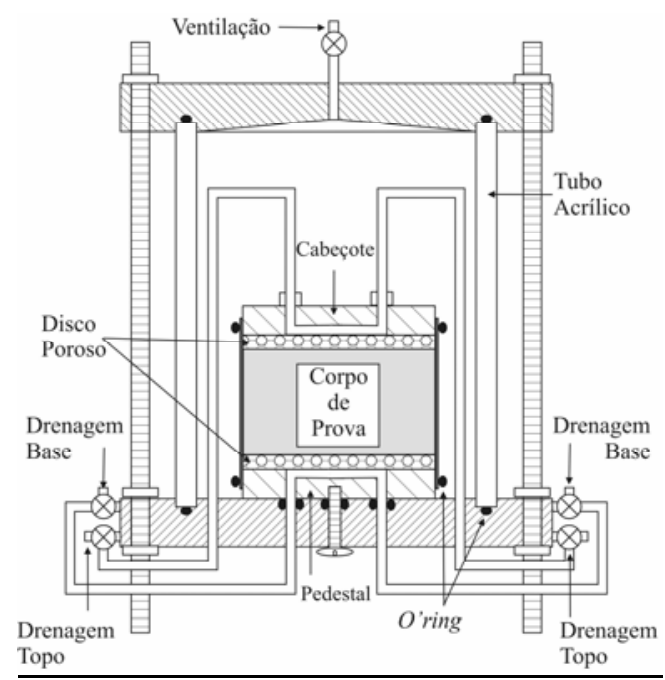

Figura 2.18 - Permeâmetro de parede flexível, DANIEL et. al. (1984). 
A realização de ensaios em permeâmetros de parede flexível propicia a determinação de baixas condutividades hidráulicas com um tempo de ensaio reduzido, viabilizando o estudo de solos compactados com condutividades hidráulicas iguais ou menores que $10^{-7} \mathrm{~cm} / \mathrm{s}$. Outro fator importante deste ensaio é a possibilidade da determinação da condutividade hidráulica saturada, pois como visto anteriormente, neste estado, o solo apresentará o maior valor de condutividade hidráulica. 


\subsection{SOLOS ESTUDADOS}

Estuda-se o comportamento hidráulico de cinco solos compactados do Estado de São Paulo por meio de ensaios de permeabilidade de carga variável em permeâmetros de parede flexível, parede rígida e ensaios de contração.

A identificação das amostras e sua procedência encontram-se na Tabela 3.1.

Tabela 3.1 - Localização das amostras.

\begin{tabular}{cccc}
\hline Identificação & Local & Referência & $\begin{array}{c}\text { Coordenadas } \\
\text { UTM }\end{array}$ \\
\hline$K 01$ & Cravinhos-SP & $\begin{array}{c}\text { Aterro } \\
\text { Sanitário }\end{array}$ & $-*$ \\
\hline$K 02$ & Piracicaba-SP & $\begin{array}{c}\text { Aterro } \\
\text { Sanitário }\end{array}$ & $\begin{array}{c}\text { 23k 0239635 } \\
7491630\end{array}$ \\
\hline \multirow{2}{*}{ K03 } & Araras-SP & $\begin{array}{c}\text { SP 330 } \\
\text { Trevo Km } \\
168\end{array}$ & $\begin{array}{c}\text { 23k 0232568 } \\
7523958\end{array}$ \\
\hline \multirow{2}{*}{ K04 } & Rod. Dutra & $\begin{array}{c}\text { Viaduto } \\
\text { Dutra/ D. } \\
\text { Pedro }\end{array}$ & $-*$ \\
\hline \multirow{2}{*}{ K05 } & São Carlos- & USP - \\
SP & CampusII & $-*$ \\
\hline
\end{tabular}

* Não se dispunha de um aparelho georeferenciador (GPS) na ocasião da coleta.

Para a caracterização geotécnica das amostras, foram realizados ensaios segundo a norma ABNT: granulometria conjunta, NBR 7181/84, massa específica dos sólidos, NBR 6508/84, ensaio de compactação Proctor Normal, NBR 7182, limites de liquidez e plasticidade, NBR 6459/84 e NBR 7180/84, e ensaios necessários para a classificação MCT, normatizado pelo DNER norma M-196/89. 


\subsection{ENSAIO DE CONDUTIVIDADE HIDRÁULICA}

\subsubsection{Ensaios em permeâmetro de parede flexível}

Os corpos-de-prova foram compactados dinamicamente, utilizando um compactador de seção plana, a partir de amostras deformadas. As dimensões das amostras foram $40 \pm 1 \mathrm{~mm}$ de altura e $100 \mathrm{~mm}$ de diâmetro. Os corpos-de-prova foram compactados em uma única camada e os parâmetros de compactação foram calculados com base na curva de compactação Proctor Normal de cada solo. Buscou-se a compactação dos corpos-de-prova no ramo úmido das curvas, variando o teor de umidade de moldagem entre 0 a 3 pontos percentuais acima do ótimo. Alguns corpos-de-prova foram compactados no ramo seco. Para cada teor de umidade de moldagem ensaiado, variou-se o grau de compactação entre 95 e 103\%.

Os ensaios foram conduzidos em um permeâmetro de parede flexível construído no Departamento de Geotecnia da Escola de Engenharia de São Carlos da Universidade de São Paulo. O modelo de permeâmetro construído é similar ao descrito por Daniel et al.(1984), e foi desenvolvido por Dourado (2003). O método de ensaio empregado é o sistema de controle hidráulico de volume constante (sistema fechado), concebido originalmente por Bjerrum \& Huder (1957). O permeâmetro dispõe de quatro sistemas de controle hidráulico de volume constante, como mostra a Figura 3.1, que estão ligados a três fontes de pressão, responsáveis pelo confinamento do corpo-de-prova, saturação por contra pressão e imposição do gradiente hidráulico. 


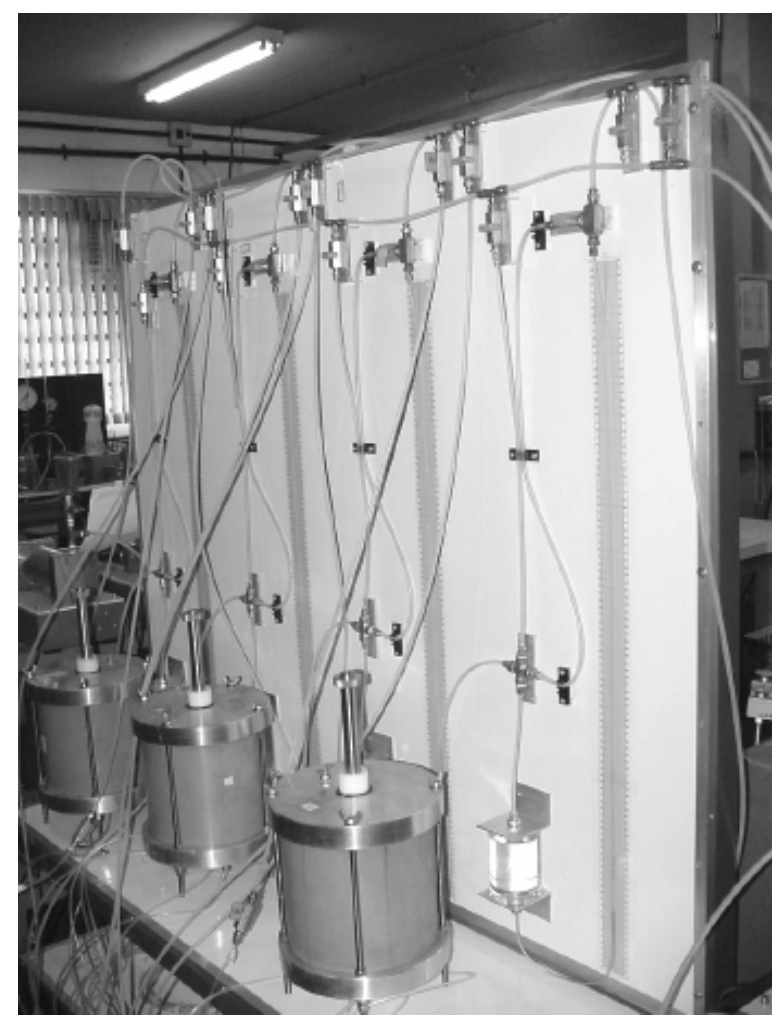

Figura 3.1 - Permeâmetro de parede flexível com sistema de controle hidráulico, DOURADO, K.A. (2003).

O sistema fechado é constituído de um reservatório de interface água-mercúrio ligado a um tubo capilar fixado sobre uma escala milimétrica. $O$ permeâmetro possui quatro acessos ao corpo-de-prova, duas pela base e duas pelo topo. O esquema mostrado na Figura 3.2 apresenta o sistema hidráulico de volume constante (sistema fechado) interligado ao permeâmetro de parede flexível. Os registros apresentados na Figura foram numerados de 1 a 4, sendo que o registro 1 controla o acesso da pressão confinante (linha 1), o registro 2 controla a contrapressão (linha 2), o registro 3 controla a imposição do gradiente hidráulico (linha 3 , incremento de pressão) e o registro 4, quando aberto, equilibra a pressão entre o topo e a base do corpo-de-prova. 


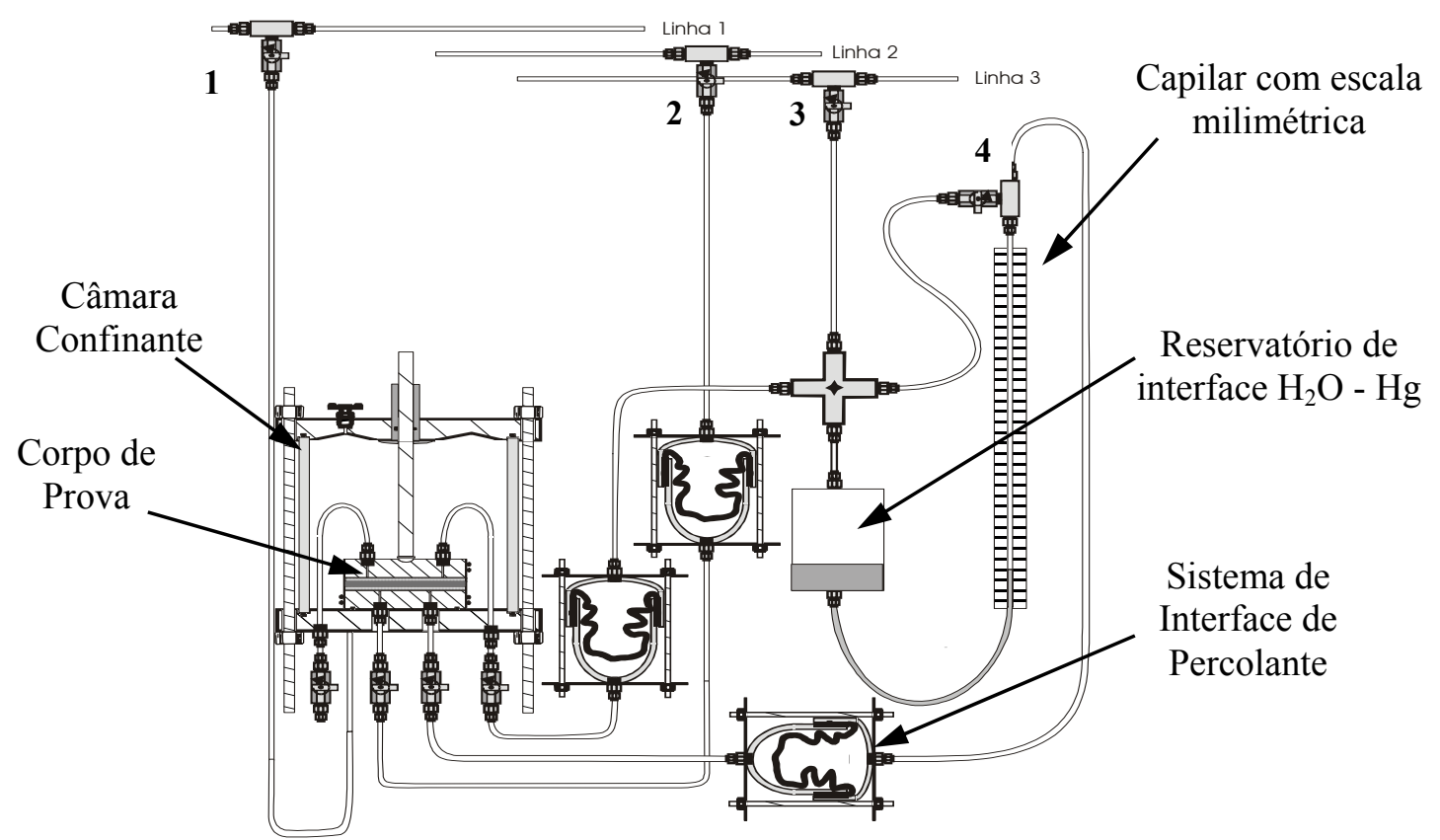

Figura 3.2 - Esquema do sistema de controle hidráulico fechado, Dourado (2003).

O ensaio é montado com o corpo-de-prova dentro da câmara entre um pedestal e um cabeçote de PEAD e duas placas porosas de mesmo diâmetro protegidas com papel filtro, Figura 3.3a. Antes de fechar a câmara, o corpo-de-prova é revestido por uma membrana de látex impermeável, como é mostrado na Figura 3.3b.
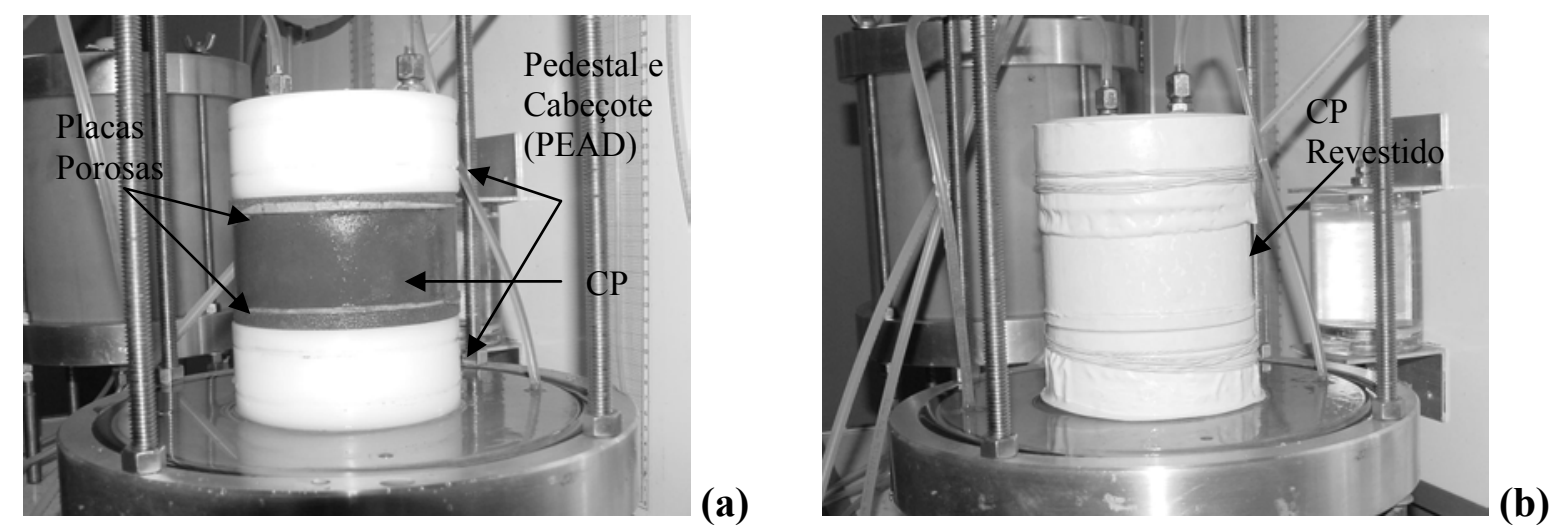

Figura 3.3 a, b - Seqüência de montagem do ensaio em permeâmetro de parede flexível. 
O ensaio é realizado em duas fases, saturação e percolação através do corpo-de-prova. Inicialmente o corpo-de-prova é levado a saturação por contrapressão, neste instante, este encontra-se pressurizado sob o valor ajustado na linha 1 para a pressão confinante e na linha 2 para a contra-pressão. A saturação é atingida por incrementos de pressão confinante e contra pressão como é proposto por Head (1986), e verificada pelo parâmetro B que é definido pela Equação 3.1 .

$B=\frac{\Delta u}{\Delta \sigma_{3}}$

Em que:

$\Delta \mathrm{u}$ - variação da pressão neutra;

$\Delta \sigma_{3}-$ variação da pressão confinante.

Foram realizados incrementos de pressão confinante em estágios de $50 \mathrm{kPa}$. Os ensaios em que os corpos de prova apresentaram B maior ou igual a 0,96 foram considerados saturados.

No início do ensaio (após a saturação) para a medida da condutividade hidráulica, o gradiente hidráulico é imposto por um incremento de pressão na linha 3, o que ocasiona a ascensão da coluna de $\mathrm{Hg}$ no tubo capilar. Esta coluna de $\mathrm{Hg}$ é proporcional à diferença de pressão entre o topo e a base do corpo-de-prova. Neste momento, o sistema é isolado das fontes de pressão externas. A carga hidráulica imposta ao corpo-de-prova é dada pela coluna de $\mathrm{Hg}$ no tubo capilar o que impulsiona o fluxo axialmente através do corpo-de-prova do topo para a base, no mesmo sentido da compactação. Tem-se então um ensaio de carga variável em que no seu decorrer são medidas as variações de altura da coluna de $\mathrm{Hg}$ do tubo capilar, através da escala milimetrada fixada atrás deste tubo. O volume de água percolado pelo corpo-de-prova é calculado multiplicando-se a área interna do tubo capilar pela variação na altura da coluna de $\mathrm{Hg}$.

O cálculo da condutividade hidráulica é realizado com a Equação 3.2.

$k=\frac{a \cdot A}{(a+A) \cdot\left(G_{H g}-G_{H_{2} O}\right)} \cdot \frac{L}{S \cdot \Delta t} \cdot \ln \left(\frac{Y_{i}}{Y_{i+1}}\right)$ 
Em que:

$k$ : $\quad$ condutividade hidráulica entre as leituras i e $\mathrm{i}+1$;

$a: \quad$ área do tubo capilar;

A: $\quad$ área da caneca de mercúrio;

$L: \quad$ altura do $\mathrm{CP}$;

$S: \quad$ área do $\mathrm{CP}$;

$Y_{\mathrm{i}, \mathrm{i}+1}$ : altura da coluna de mercúrio do capilar nos tempos i e $\mathrm{i}+1$;

$\Delta \mathrm{t}: \quad$ intervalo de tempo entre as leituras $\mathrm{Y}_{\mathrm{i}}$ e $\mathrm{Y}_{\mathrm{i}+1}$;

$G_{\mathrm{Hg}}$ : densidade relativa do mercúrio;

$G_{\mathrm{H} 2 \mathrm{O}}$ : densidade relativa da água.

No processo de saturação todos os corpos-de-prova ensaiados foram submetidos à tensão efetiva $\left(\sigma^{\prime}{ }_{3 c}\right)$ igual a $40 \mathrm{kPa}$, isto é, tensão total aplicada na câmara $\left(\sigma_{3 c}\right)$ menos a contra pressão (C.P.) aplicada no topo e na base dos corpos-de-prova. A tensão efetiva utilizada para a realização dos ensaios foi escolhida por apresentar melhor comportamento em ensaios de condutividade hidráulica quando se utilizou solo compactado durante testes do equipamentos realizados por DOURADO (2003).

Foi admitido que o possível adensamento ocorrido na fase de saturação não alterou significativamente o volume de vazios dos corpos-de-prova. Durante as determinações de condutividade hidráulica, os corpos-de-prova foram percolados do topo para a base, com uma diferença inicial de pressão de $20 \mathrm{kPa}$.

\subsubsection{Ensaio em permeâmetro de parede rígida}

Para os ensaios realizados em permeâmetros de parede rígida os corpos-de-prova foram compactados dinamicamente a partir de amostras deformadas. Foi utilizado um compactador de seção plana e cilindros metálicos de $50 \mathrm{~mm}$, de diâmetro e $130 \mathrm{~mm}$ de altura, os mesmos cilindros utilizados na metodologia MCT proposta por NOGAMI e VILLIBOR (1995). As dimensões dos corpos-de-prova foram $50 \pm 1 \mathrm{~mm}$ de altura e $50 \mathrm{~mm}$ de diâmetro. Os corpos-de-prova foram compactados em uma única camada e os parâmetros de 
compactação foram calculados com base na curva de compactação Proctor Normal de cada solo. Buscou-se a compactação dos corpos-de-prova na condição de teor de umidade e grau de compactação semelhantes aos ensaiados em permeâmetro de parede flexível.

A principal modificação da adaptação da metodologia MCT para os ensaios de condutividade hidráulica foi quanto à forma de vedação do corpo de prova. Após a compactação do solo em cilindros metálicos, as extremidades dos cilindros foram preenchidas com uma camada de geotêxtil, pedregulho e vedada com uma rolha de borracha. O modelo para o ensaio de condutividade é mostrado na Figura 3.4.

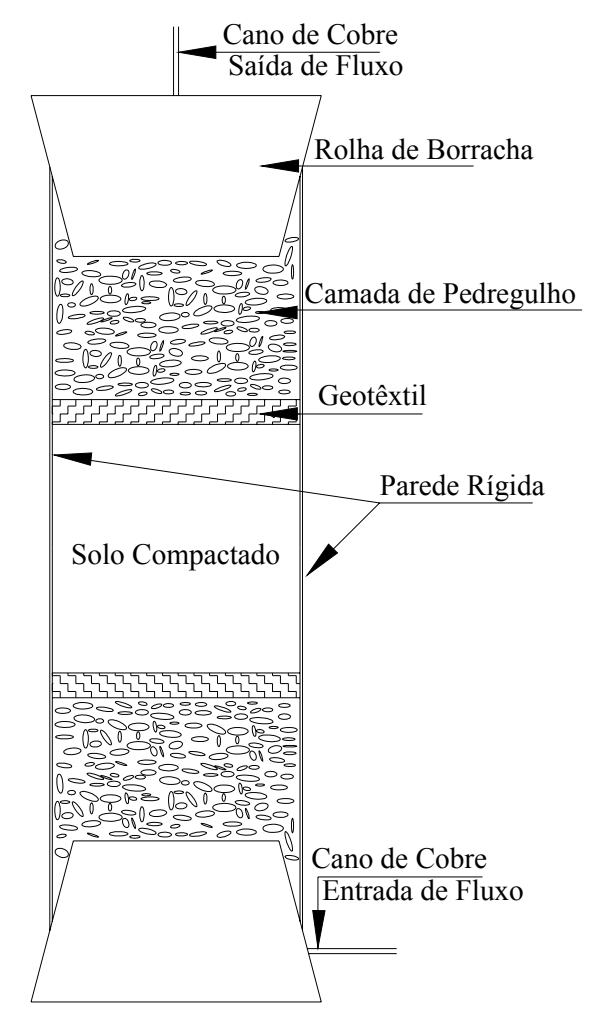

Figura 3.4 - Modelo de arranjo para ensaio de condutividade hidráulica em permeâmetro de parede rígida.

Os detalhes dos materiais utilizados no arranjo montado para o ensaio podem ser observados na Figura 3.5. 


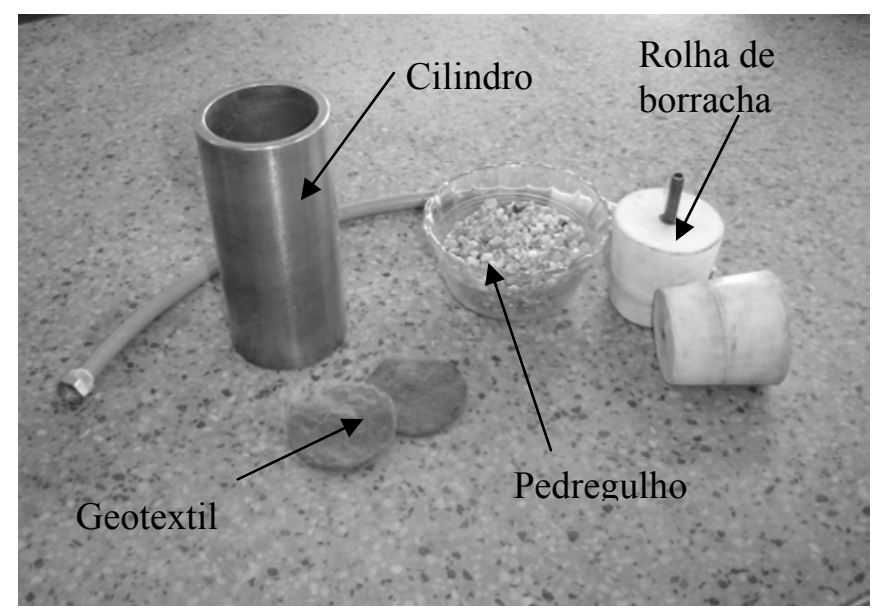

Figura 3.5 - Materiais utilizados no ensaio em permeâmetro de parede rígida.

Os corpos-de-prova foram percolados com água destilada axialmente no sentido da compactação e com direção ascendente, para facilitar a eliminação de bolhas de ar. Foi utilizado o painel de permeabilidade do laboratório do Departamento de Geotecnia, o ensaio foi conduzido à carga variável e o coeficiente de condutividade foi calculado utilizando-se a ley de Darcy. O gradiente hidráulico médio aplicado no início dos ensaios foi de 20 e a saturação foi considerada no instante em que o volume de água percolado através do solo foi constante ao longo do tempo.

\subsection{CONTRAÇÃO}

O ensaio de contração foi realizado com os corpos-de-prova utilizados nos ensaios de condutividade hidráulica em permeâmetro de parede flexível, garantindo assim as mesmas condições de compactação em ambos os ensaios. Buscou-se a análise de corpos-de-prova que atendiam o valor máximo de condutividade hidráulica sugerido para barreiras impermeáveis, $1 \times 10^{-7} \mathrm{~cm} / \mathrm{s}$, em ensaios de parede flexível. Após o ensaio de condutividade hidráulica, para cada corpo-de-prova, foi determinado o diâmetro e a altura em três posições distintas com o auxilio de um paquímetro. Uma quarta determinação de altura foi obtida, no centro do corpode-prova, com o auxilio de um relógio comparador com precisão de 0,01 mm. Os corpos-deprova foram colocados sobre uma placa de granito com suas posições devidamente marcadas. As leituras de variação das dimensões foram realizadas diariamente até a estabilização. Foram realizadas, também, medidas de temperatura e umidade relativa ambiente. A Figura 3.6 mostra o esquema de montagem do ensaio. 


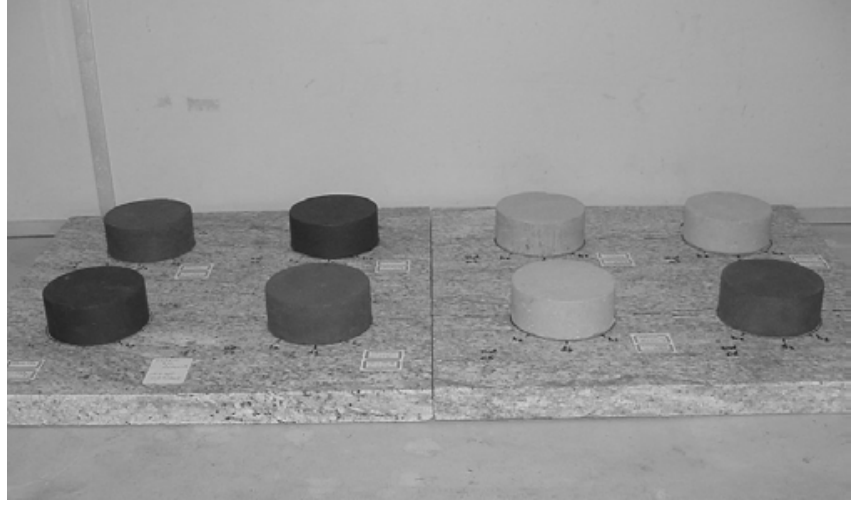

(a)

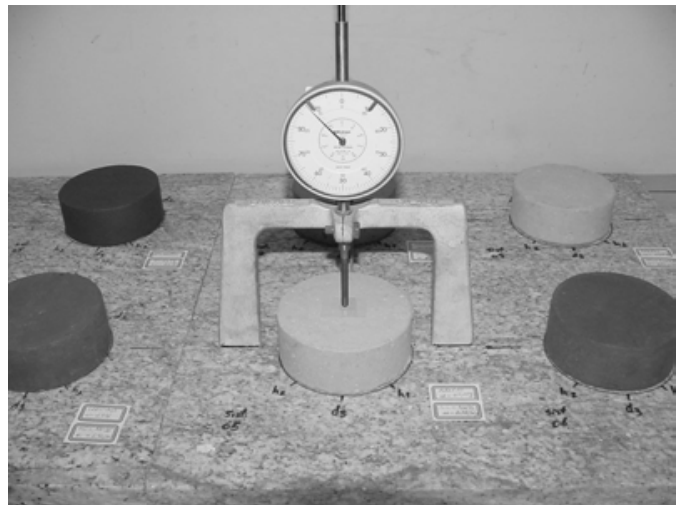

(b)

Figura 3.6 - (a) montagem do ensaio de contração, (b) determinação de altura com relógio comparador.

Para o cálculo da contração axial total foi considerada a média das alturas iniciais e finais do corpo-de-prova, e com a determinação dos diâmetros foi possível verificar a contração volumétrica. Ao final do ensaio de contração, os corpos de prova foram submetidos a ciclos de umedecimento e secagem para a análise do aparecimento de trincas. Após os ciclos, foram realizados novos ensaios de condutividade hidráulica e observado a influência das trincas neste parâmetro.

\subsection{TESTES INICIAIS}

Para o desenvolvimento da pesquisa com a utilização do permeâmetro de parede flexível, algumas adaptações e testes iniciais se fizeram necessários para a validação dos resultados obtidos. Detalhes da adaptação, calibração e comparação dos sistemas são apresentados a seguir.

\subsubsection{Adaptação do sistema}

Foi realizada uma adaptação no permeâmetro de parede flexível para a mensuração da condutividade hidráulica de solos compactados com permeabilidades maiores que $10^{-7} \mathrm{~cm} / \mathrm{s}$. Para tanto foi substituído o tubo capilar de um dos quatro sistemas hidráulicos de volume constante por um tubo de maior diâmetro, garantindo assim maior volume percolado e, consequentemente, maior tempo de ensaio. 
Para a realização da calibração do sistema modificado, foram realizadas leituras de decaimento da coluna de mercúrio no tubo capilar, fixado sobre uma escala milimetrada, e verificado o volume deslocado a cada intervalo de leituras, com o auxílio de um atuador servo controlado.

Foi plotado o volume medido no atuador servo controlado em função das leituras do decaimento da coluna de mercúrio, onde o coeficiente angular da reta obtida com os pares de dados posição da coluna de $\mathrm{Hg}$ vs volume medido é numericamente igual a área da seção transversal do tubo capilar.

A Figura 3.7 mostra a tabela de calibração e o gráfico obtido para a determinação da área da seção transversal do novo tubo utilizado no sistema 4 . Foi adotado $0,7112 \mathrm{~cm}^{2}$ de área.

\begin{tabular}{cc}
\hline Hg (cm) & Vol. (cm3) \\
\hline \hline 12,1 & 0 \\
19,2 & 4,884 \\
33,7 & 15,213 \\
46,5 & 24,35 \\
62 & 35,367 \\
75 & 44,643 \\
84,2 & 51,201 \\
\hline
\end{tabular}

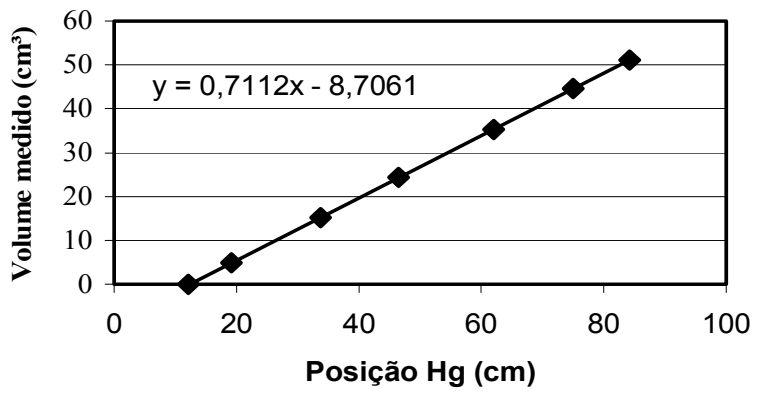

Figura 3.7 - Calibração do sistema modificado.

\subsubsection{Ensaios iniciais de condutividade hidráulica}

Foram realizados ensaios iniciais de condutividade hidráulica para a verificação do sistema modificado. A Figura 3.8 apresenta o comportamento da condutividade hidráulica em função do tempo para a amostra k02 compactada com teor de umidade igual a $24,9 \%$ e grau de compactação igual a 100\%. Foi ensaiado o mesmo corpo-de-prova no sistema 3, que possui tubo capilar com área da seção transversal igual a $0,05762 \mathrm{~cm}^{2}$, e no sistema 4 modificado, que possui tubo com área de $0,7112 \mathrm{~cm}^{2}$. 


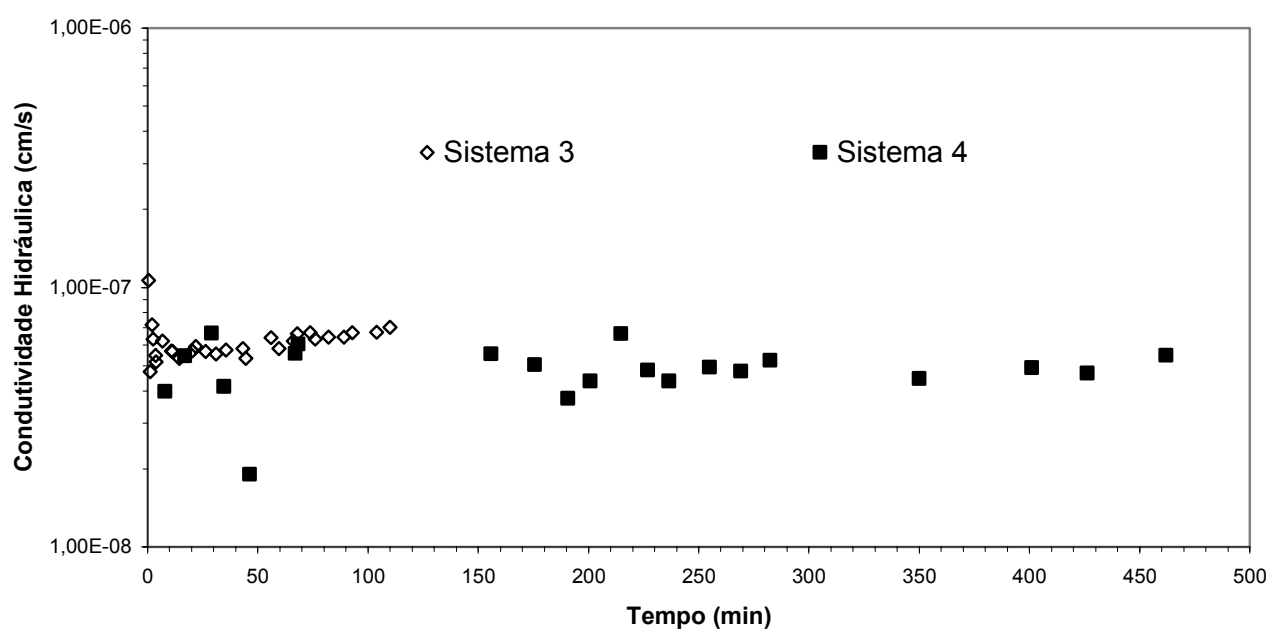

Figura 3.8 - Comparação dos resultados de condutividade hidráulica obtidos em ensaios utilizando o sistema 3 e 4.

Pode-se observar que os resultados de condutividade hidráulica obtidos no ensaio onde se utilizou o sistema 4 apresentam certa dispersão se comparados aos resultados do sistema 3 , porém os dados obtidos nos dois ensaios tendem a valores de condutividade hidráulica próximos.

Com o objetivo de observar a variação da condutividade hidráulica frente a variação de valores do parâmetro $\mathrm{B}$, foram realizados ensaios com a amostra $\mathrm{k} 01$ compactada com $24 \%$ de teor de umidade e $99 \%$ de grau de compactação. Os resultados são apresentados na Figura 3.9.

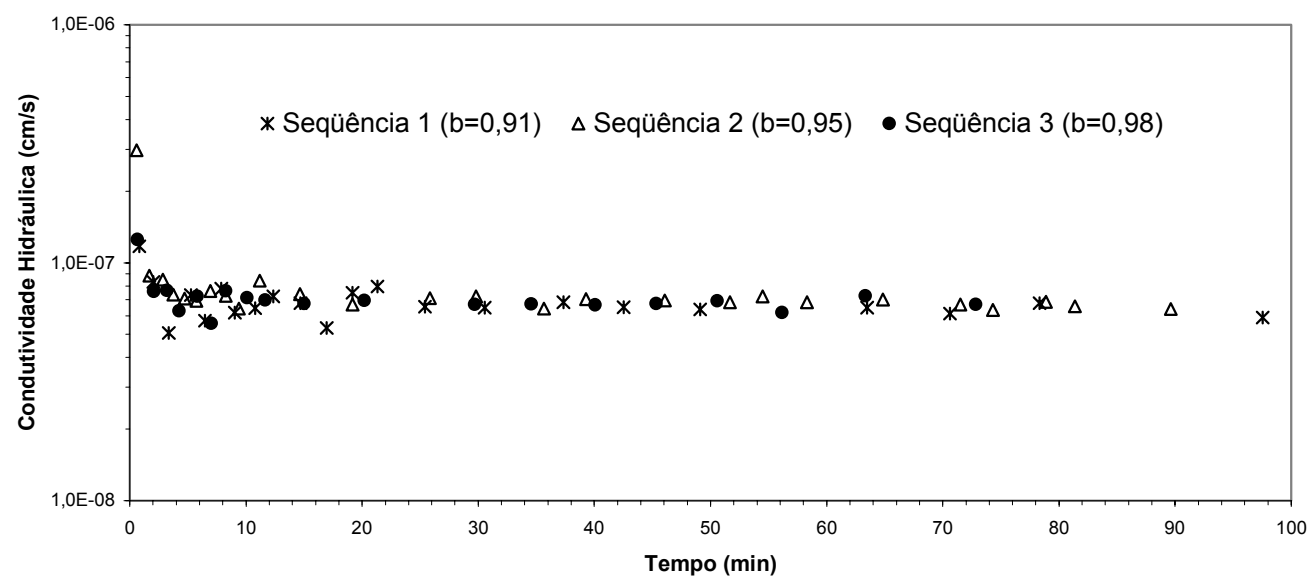

Figura 3.9 - Valores de condutividade hidráulica para B entre 0,91 e 0,98.

Não foram notadas variações significativas de condutividade hidráulica para valores de B entre 0,91 e 0,98 . 
A Tabela 4.1 apresenta os resultados dos ensaios de caracterização dos solos estudados, além de suas classificações Unificada e MCT.

Tabela 4.1 - Características dos materiais ensaiados.

\begin{tabular}{|c|c|c|c|c|c|c|c|}
\hline \multicolumn{3}{|c|}{ Síntese dos resultados } & K01 & K02 & K03 & K04 & K05 \\
\hline \multicolumn{3}{|c|}{$\rho_{\mathrm{s}}\left(\mathrm{g} / \mathrm{cm}^{3}\right)$} & 2,856 & 2,837 & 2,650 & 2,750 & 2,647 \\
\hline \multirow{3}{*}{ Limites de Consistência } & $\mathrm{W}_{\mathrm{L}}$ & $(\%)$ & 37 & 41 & 46 & 51 & 35 \\
\hline & $\mathrm{W}_{\mathrm{p}}$ & $(\%)$ & 31 & 31 & 27 & 30 & 19 \\
\hline & IP & $(\%)$ & 6 & 10 & 19 & 21 & 16 \\
\hline Compactação & $\rho_{\mathrm{dmáx}}$ & $\left(\mathrm{g} / \mathrm{cm}^{3}\right)$ & 1,680 & 1,626 & 1,543 & 1,630 & 1,825 \\
\hline Proctor Normal & $\mathrm{W}_{\text {ótm }}$ & $(\%)$ & 22,0 & 24,3 & 23,3 & 21,8 & 15,4 \\
\hline \multicolumn{3}{|c|}{ Unificada } & $\mathrm{ML}$ & ML & $\mathrm{CL}$ & $\mathrm{MH}$ & $\mathrm{SC}$ \\
\hline \multicolumn{3}{|l|}{ MCT } & $\mathrm{NG}^{\prime}$ & $\mathrm{LG}^{\prime}$ & $\mathrm{NG}^{\prime}$ & $\mathrm{NG}^{\prime}$ & - \\
\hline
\end{tabular}

Para uma melhor visualização da composição granulométrica dos solos estudados, a Figura 4.1 mostra as curvas correspondentes aos ensaios de granulometria conjunta.

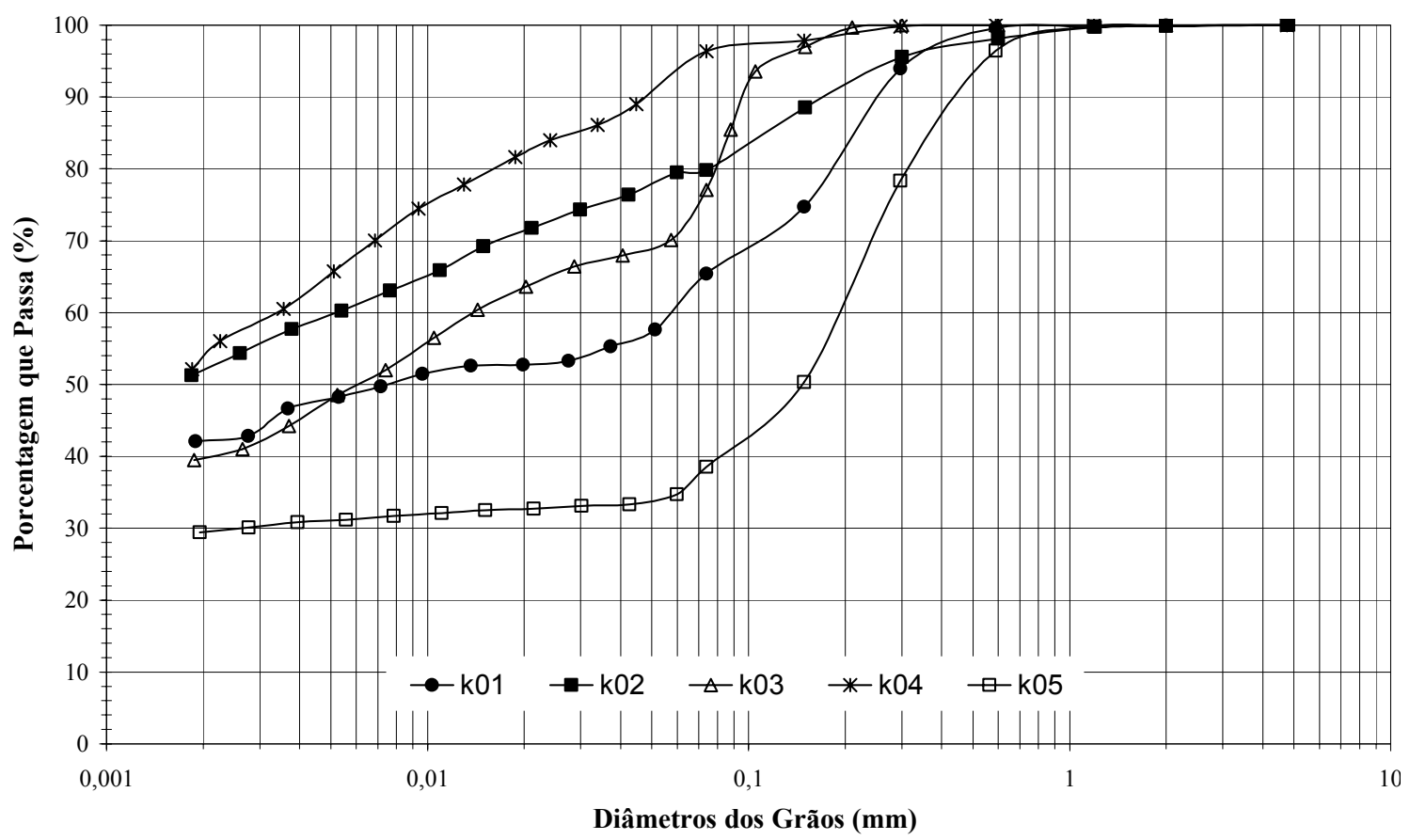

Figura 4.1 - Curvas granulométricas dos solos estudados. 
A Figura 4.2 mostra a carta de plasticidade elaborada a partir dos resultados dos ensaios de limites de consistência.

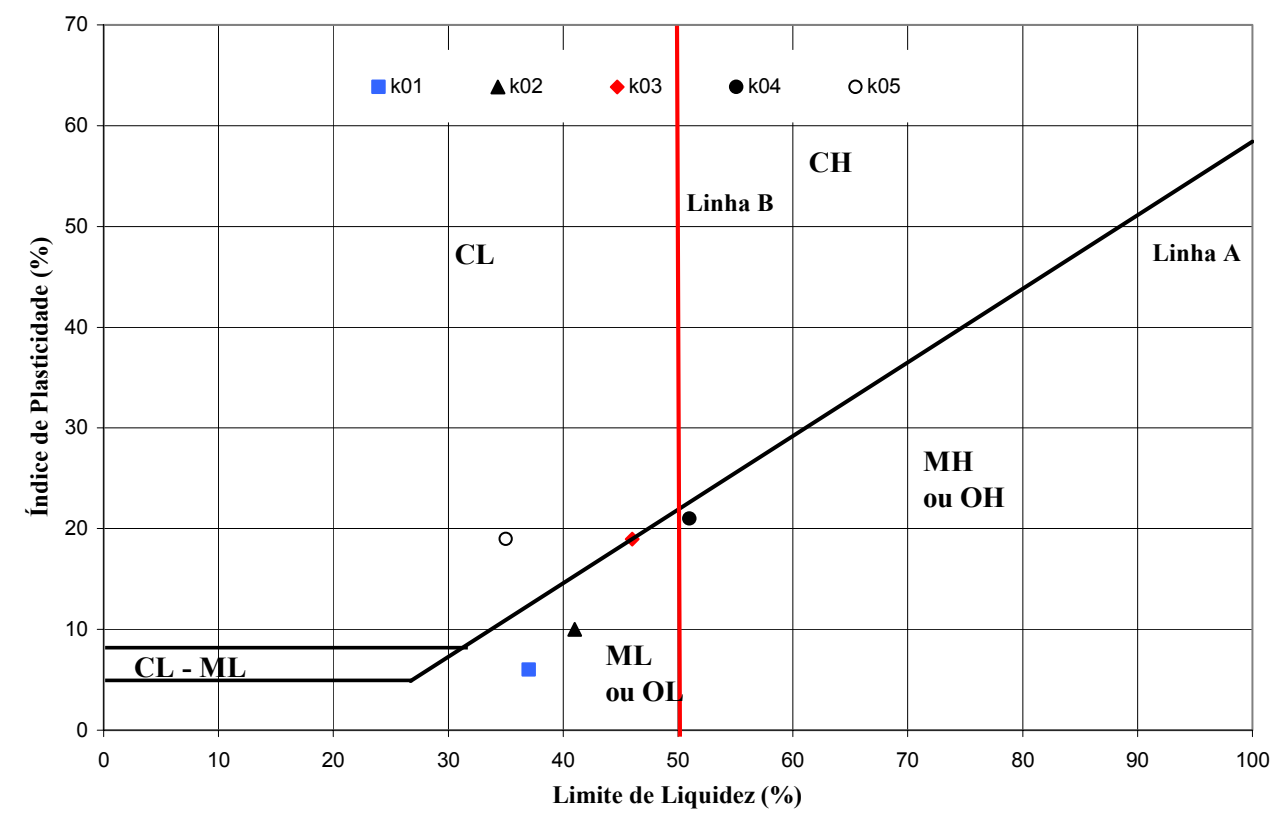

Figura 4.2 - Carta de plasticidade dos solos estudados.

As curvas de compactação referentes ao ensaio de Proctor Normal são mostradas na Figura 4.3. 


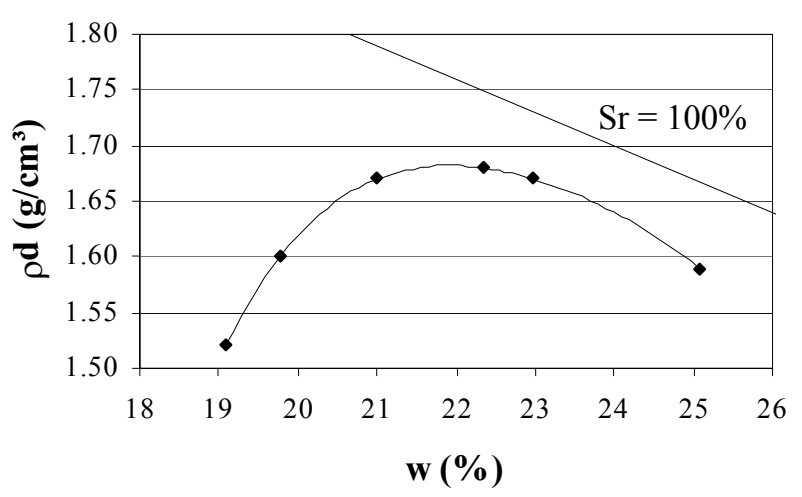

(a) $\mathrm{k} 01$ - Cravinhos

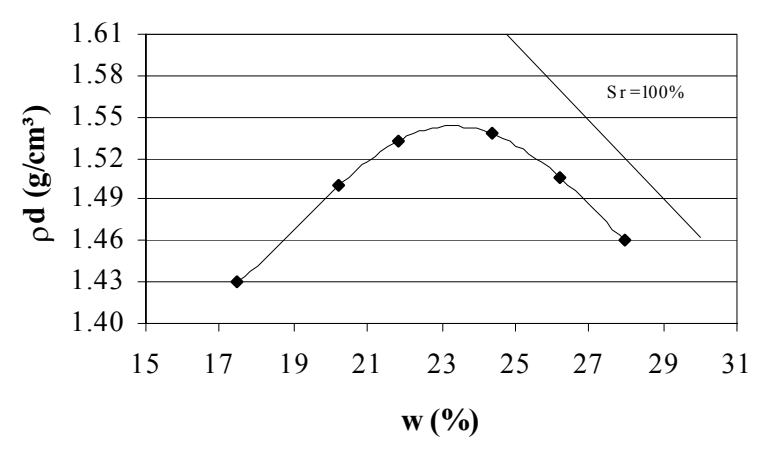

(c) $\mathrm{k} 03$ - Araras

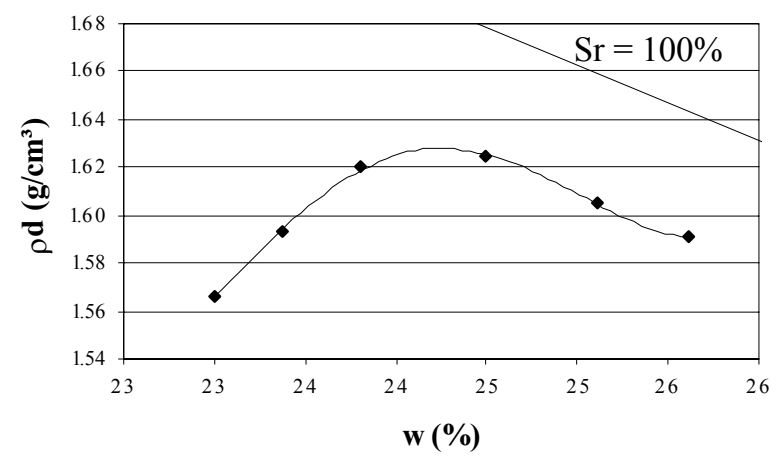

(b) k02 - Aterro Piracicaba

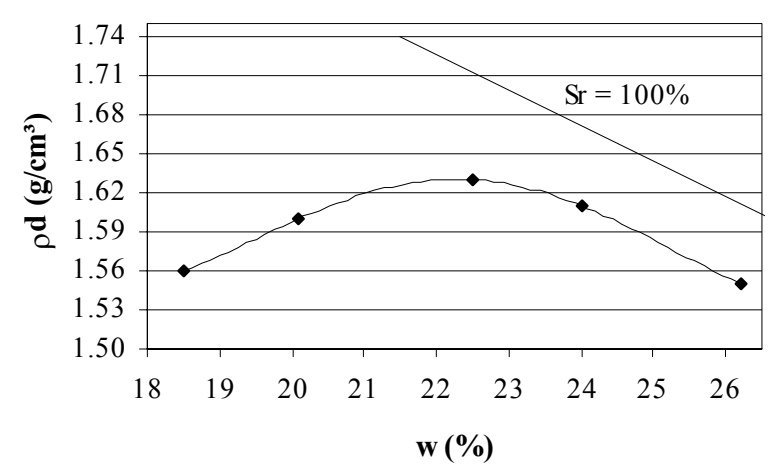

(d) k04 - Dutra

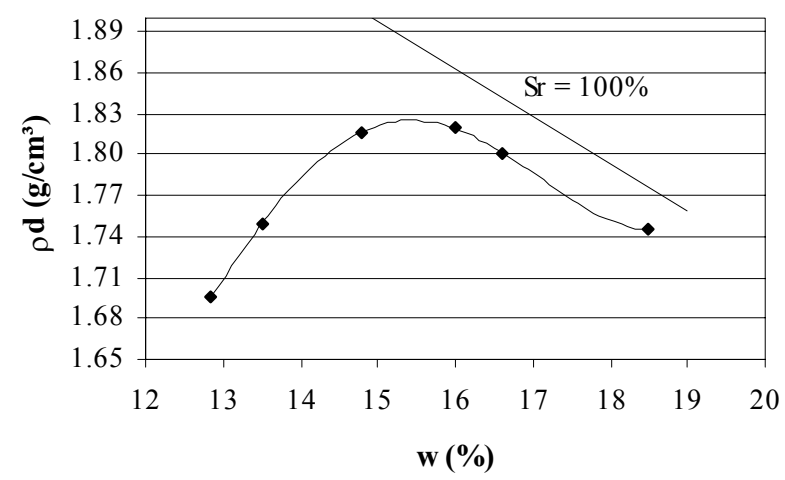

(e) k05 - Santa Felícia

Figura 4.3 - Curvas de compactação correspondentes ao ensaio com energia do Proctor Normal dos solos estudados.

São apresentados a seguir os resultados dos ensaios de condutividade hidráulica em Permeâmetros de Parede Flexível e Rígida, assim como ensaios de contração e ciclagem. Para 
os ensaios de condutividade hidráulica conduzidos em Permeâmetro de Parede Flexível, os corpos-de-prova de solo compactado foram moldados em uma única camada. A compactação objetivou graus de compactação, aproximadamente, entre 95 a 103\%, variando por volta de 2 pontos percentuais entre os corpos-de-prova.

\subsection{CRAVINHOS - K01}

A amostra é de uma argila areno siltosa com mais de $65 \%$ das partículas menores que $0,075 \mathrm{~mm}$. O solo foi classificado como ML, isto é, silte arenoso pela classificação unificada e NG', argiloso não laterítico, pela classificação MCT.

\subsubsection{Condutividade hidráulica}

Foram programados ensaios de condutividade hidráulica utilizando o permeâmetro de parede flexível e o sistema de controle de fluxo fechado, citados anteriormente. A Tabela 4.2 mostra as condições de ensaio de condutividade em permeâmetro de parede flexível e as condições de compactação para cada corpo de prova.

Tabela 4.2 - Resultados e condições de ensaio em permeâmetro de parede flexível para a amostra Cravinhos - k01.

\begin{tabular}{|c|c|c|c|c|c|c|c|c|c|}
\hline \multirow{2}{*}{$\begin{array}{c}\text { Amostra } \\
\text { Cps }\end{array}$} & \multirow{2}{*}{$\begin{array}{c}W_{\text {mold }} \\
(\%)\end{array}$} & \multirow{2}{*}{$\begin{array}{c}\rho d \\
\left(g / \mathrm{cm}^{3}\right)\end{array}$} & \multirow{2}{*}{$\begin{array}{l}\text { GC } \\
(\%)\end{array}$} & \multirow[b]{2}{*}{ e } & \multirow[b]{2}{*}{$\operatorname{Sr}(\%)$} & \multicolumn{2}{|c|}{ Saturação (kPa) } & \multirow[b]{2}{*}{ B } & \multirow[b]{2}{*}{$\mathbf{k}(\mathbf{c m} / \mathbf{s})$} \\
\hline & & & & & & $\sigma 3 c$ & C.P. & & \\
\hline $\mathrm{k} 01-01$ & 22,1 & 1,648 & 98,1 & 0,733 & 86,1 & 550 & 510 & 0,98 & $2,4 \mathrm{E}-07$ \\
\hline $\mathrm{k} 01-02$ & 22,1 & 1,682 & 100,1 & 0,698 & 90,4 & 500 & 460 & 0,99 & $1,1 \mathrm{E}-07$ \\
\hline $\mathrm{k} 01-03$ & 22,1 & 1,73 & 103,0 & 0,651 & 97,0 & 550 & 510 & 0,98 & $5,3 \mathrm{E}-08$ \\
\hline k01-04 & 23,0 & 1,598 & 95,1 & 0,787 & 83,4 & 550 & 510 & 0,99 & $4,5 \mathrm{E}-07$ \\
\hline $\mathrm{k} 01-05$ & 23,0 & 1,648 & 98,1 & 0,733 & 89,6 & 550 & 510 & 0,97 & $1,1 \mathrm{E}-07$ \\
\hline $\mathrm{k} 01-06$ & 23,0 & 1,679 & 99,9 & 0,701 & 93,7 & 500 & 460 & 0,98 & $8,0 \mathrm{E}-08$ \\
\hline $\mathrm{k} 01-07$ & 23,0 & 1,719 & 102,3 & 0,661 & 99,3 & 600 & 560 & 0,98 & $5,7 \mathrm{E}-08$ \\
\hline $\mathrm{k} 01-08$ & 24,3 & 1,596 & 95,0 & 0,789 & 87,9 & 500 & 460 & 0,98 & $3,0 \mathrm{E}-07$ \\
\hline k01-09 & 24,3 & 1,654 & 98,5 & 0,727 & 95,3 & 550 & 510 & 0,98 & $6,8 \mathrm{E}-08$ \\
\hline $\mathrm{k} 01-10$ & 24,3 & 1,678 & 99,9 & 0,702 & 98,9 & 550 & 510 & 0,98 & $5,4 \mathrm{E}-08$ \\
\hline $\mathrm{k} 01-11$ & 25,2 & 1,646 & 98,0 & 0,787 & 91,4 & 550 & 510 & 0,96 & $7,6 \mathrm{E}-08$ \\
\hline k01-12 & 25,2 & 1,596 & 95,0 & 0,746 & 96,5 & 600 & 560 & 0,98 & 2,9E-07 \\
\hline $\mathrm{k} 01-13$ & 20,6 & 1,648 & 98,1 & 0,733 & 80,3 & 600 & 560 & 0,97 & $1,1 \mathrm{E}-05$ \\
\hline $\mathrm{k} 01-14$ & 27,1 & 1,512 & 90,0 & 0,889 & 87,0 & 500 & 460 & 0,97 & $3,1 \mathrm{E}-05$ \\
\hline
\end{tabular}


A Figura 4.4a,b mostra o comportamento típico da condutividade hidráulica em função do tempo. Os resultados apresentados são de corpos-de-prova moldados com teor de umidade igual a $23,0 \%$ e diferentes graus de compactação, assim como para corpos-de-prova moldados com grau de compactação igual a $100 \%$ e diferentes teores de umidade de moldagem.

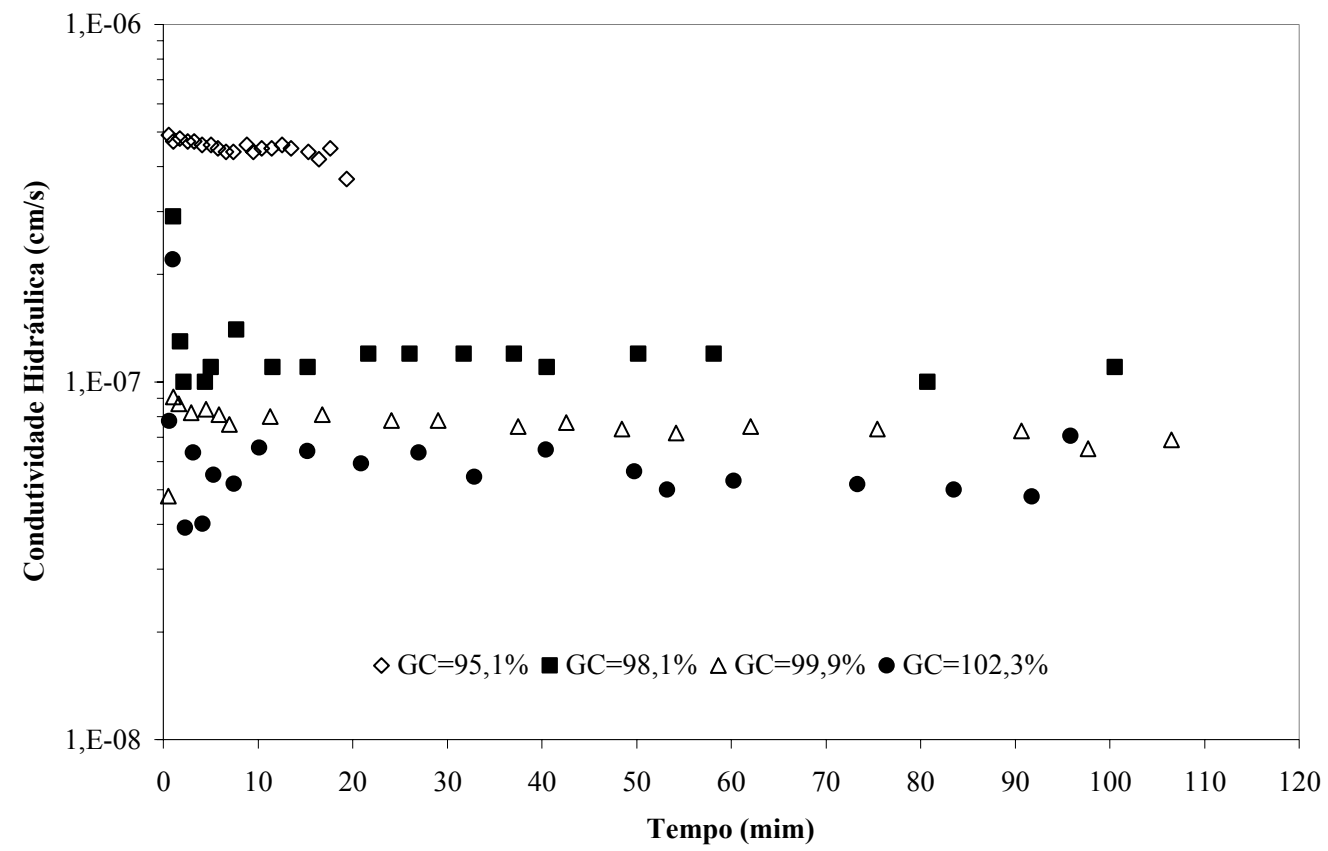

Figura 4.4a - Condutividade hidráulica vs Tempo, amostra k01, CPs moldados com $23 \%$ de umidade e com diferentes graus de compactação.

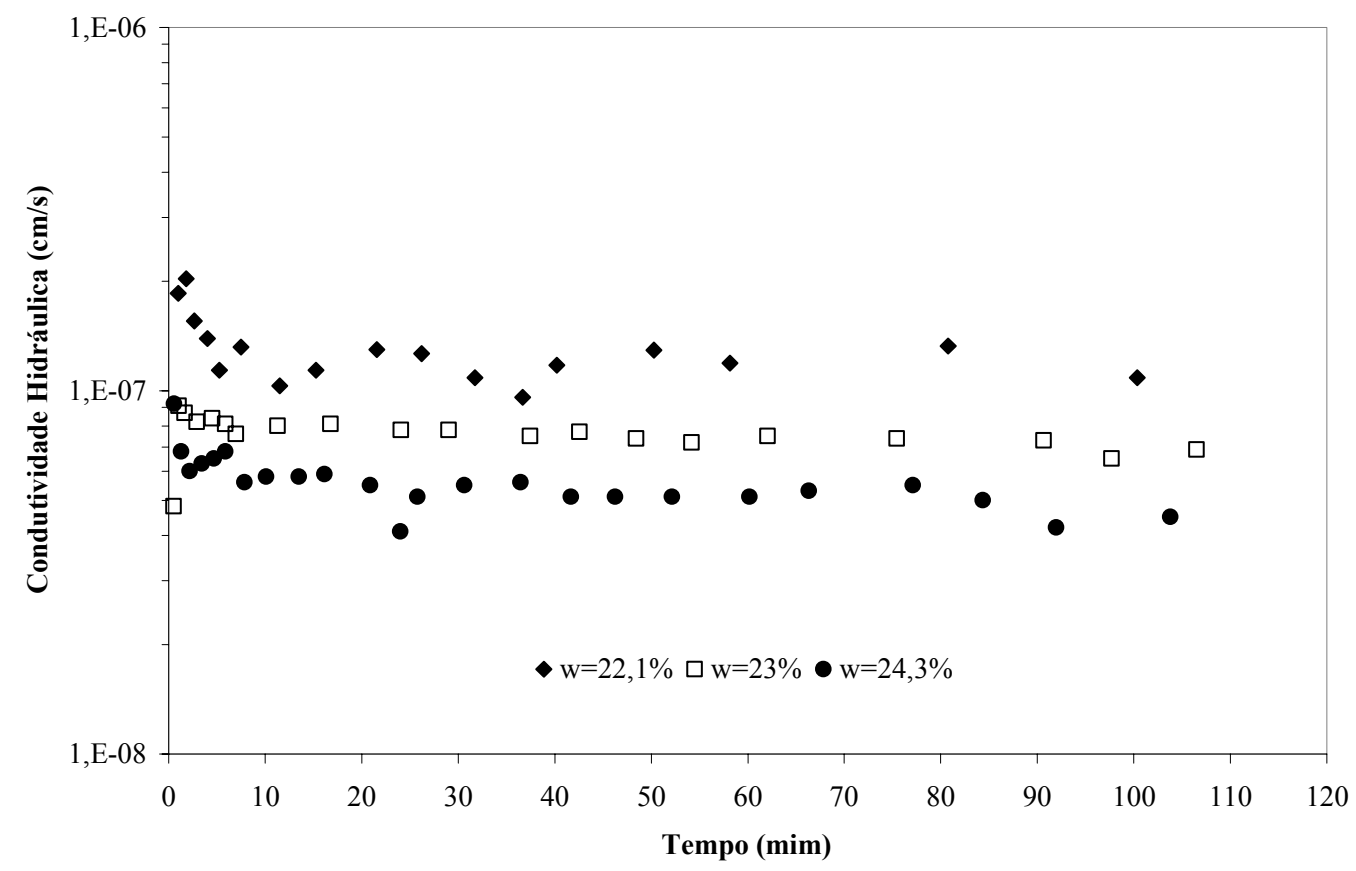

Figura 4.4b - Condutividade hidráulica vs Tempo, amostra k01, CPs moldados com GC $=100 \%$ e com diferentes teores de umidade. 
Os valores de condutividade hidráulica foram determinados a partir de uma reta média dos pontos obtidos nos ensaios para cada corpo-de-prova. Para o ajuste da reta média, foram descartados os pontos de início e do final de cada ensaio que apresentaram certa dispersão. A dispersão apresentada no início de cada ensaio deve-se a imprecisão de leitura, pois o volume percolado nos primeiros minutos de ensaio é muito pequeno.

Para a maior parte dos corpos-de-prova ensaiados, a condutividade hidráulica seguiu uma leve tendência de redução com o tempo. Aparentemente, a mesma tende a diminuir com a redução do gradiente hidráulico médio aplicado, uma vez que este diminui até o final do ensaio. Esse comportamento também foi observado por outros autores que realizaram ensaios de parede flexível e sistema de controle hidráulico fechado, como Wang \& Benson (1999) e Dourado (2003). Porém esta tendência não foi considera significativa pelos autores deste trabalho.

O tempo médio necessário para a fase inicial de saturação do corpo-de-prova foi de 24 horas.

$\mathrm{Na}$ Figura 4.5 pode-se observar a variação da condutividade hidráulica frente à variação do desvio do teor de umidade do solo para diferentes graus de compactação.

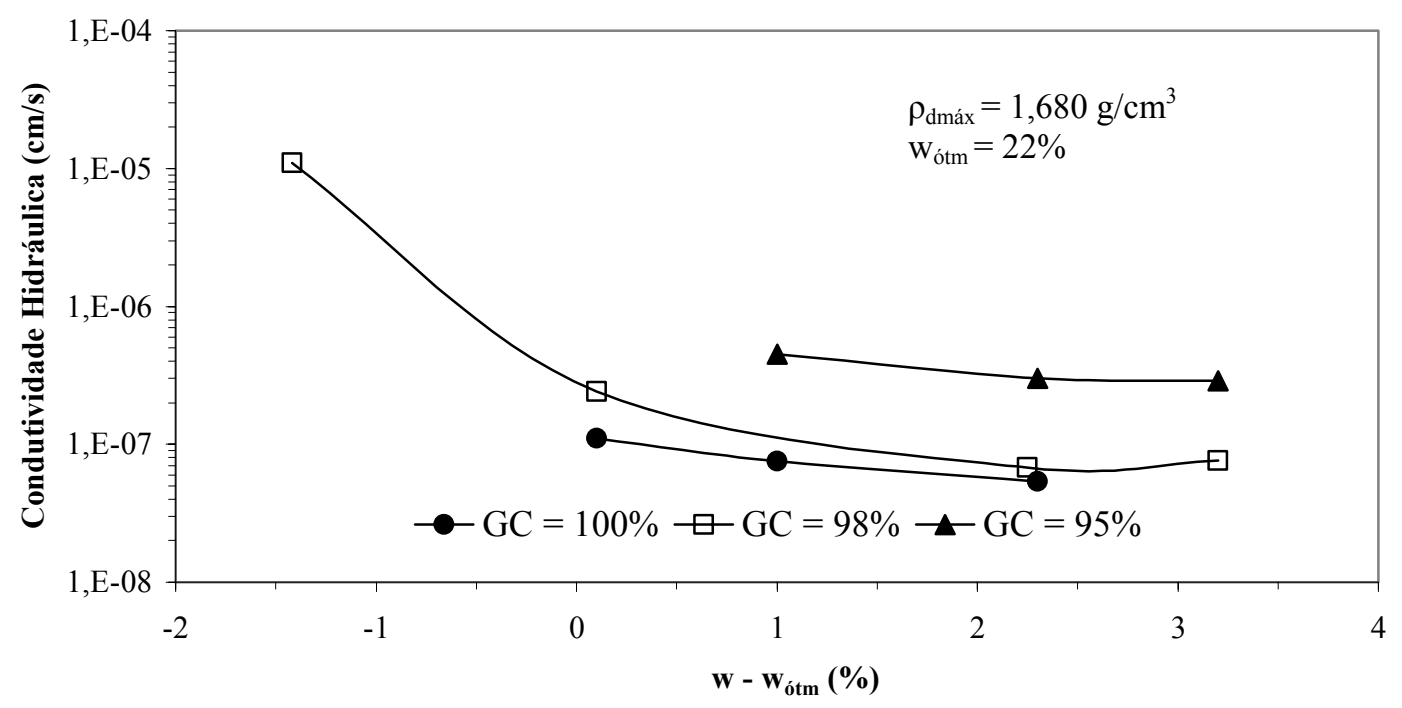

Figura 4.5 - Efeito do desvio de umidade de moldagem na condutividade hidráulica para a amostra k01.

Para a amostra estudada a condutividade hidráulica alcança o valor mínimo quando a compactação é realizada com teor de umidade 2,3 pontos percentuais acima do ótimo, isto é, $\mathrm{w}_{\text {ótm. }}+2,3 \%$, e é significativamente reduzida quando a compactação passa do ramo seco para o ramo úmido. Porém, valores de teor de umidade de compactação maiores que 1 ponto percentual acima do ótimo não causam reduções significativas na condutividade hidráulica. 
Observa-se ainda que a condutividade hidráulica tende a reduzir com o aumento do grau de compactação, o que pode ser melhor apreciado na Figura 4.6, onde mostra-se o comportamento da condutividade hidráulica frente à variação do grau de compactação para diferentes teores de umidade de moldagem.

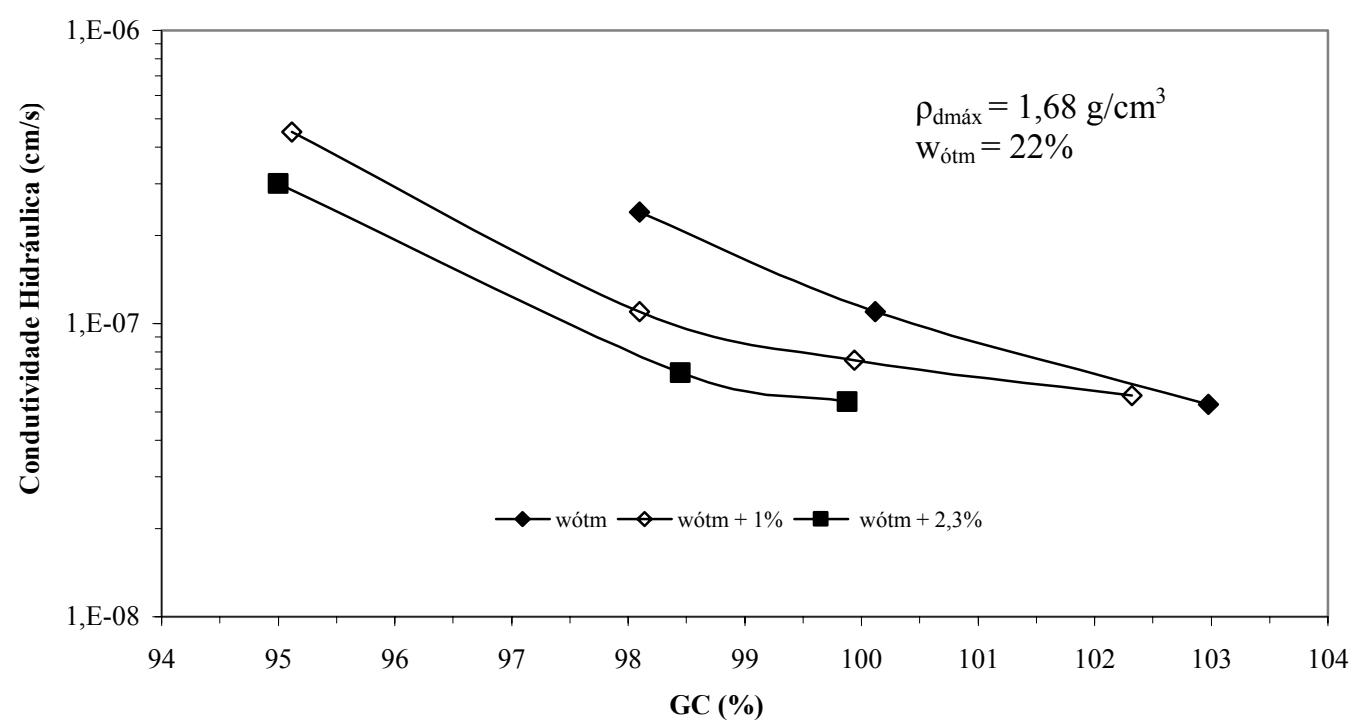

Figura 4.6 - Efeito do grau de compactação na condutividade hidráulica para a amostra k01.

Há uma tendência de redução da condutividade hidráulica com o aumento do grau de compactação para todos os teores de umidade de moldagem estudados. A redução é mais pronunciada em até $98 \%$ de compactação. Graus de compactação maiores que $98 \%$ exercem pouca influência na redução da condutividade hidráulica.

Com o objetivo de utilizar o solo estudado para a construção de barreiras impermeáveis de aterro sanitário, pode-se determinar combinações de valores de peso específico e teor de umidade de forma que a condutividade hidráulica não ultrapasse $1 \times 10^{-7}$ $\mathrm{cm} / \mathrm{s}$. A combinação destes valores e a linha de saturação delimitam uma área, no gráfico $\rho_{\mathrm{d}}$ vs $\mathrm{W}$, em que a condutividade permanece sob valores aceitáveis e é chamada de zona admissível.

Com a intenção de facilitar a prática de compactação, pode-se sugerir também condições ideais de compactação. Estas condições são limitantes inferiores de compactação de forma que a condutividade hidráulica permaneça sob os valores aceitáveis, isto é, $1 \times 10^{-7}$ $\mathrm{cm} / \mathrm{s}$. Naturalmente estas condições ideais de compactação restringem uma área, no gráfico $\rho_{\mathrm{d}}$ $\mathrm{x}$ w, menor que a zona admissível, em que pode-se encontrar valores de condutividade 
hidráulica aceitáveis, porém estas condições ideais de compactação sugeridas são parâmetros práticos para a execução de barreiras impermeáveis com solo compactado.

A Figura 4.7 mostra a curva de compactação referente ao ensaio de Proctor Normal e as condições de compactação dos corpos-de-prova estudados, assim como os valores de condutividade hidráulica obtidos em ensaios com permeâmetro de parede flexível, as condições ideais de compactação (GC $\geq 99 \%$ e w $\geq 22,6 \%$ ) e a zona admissível.

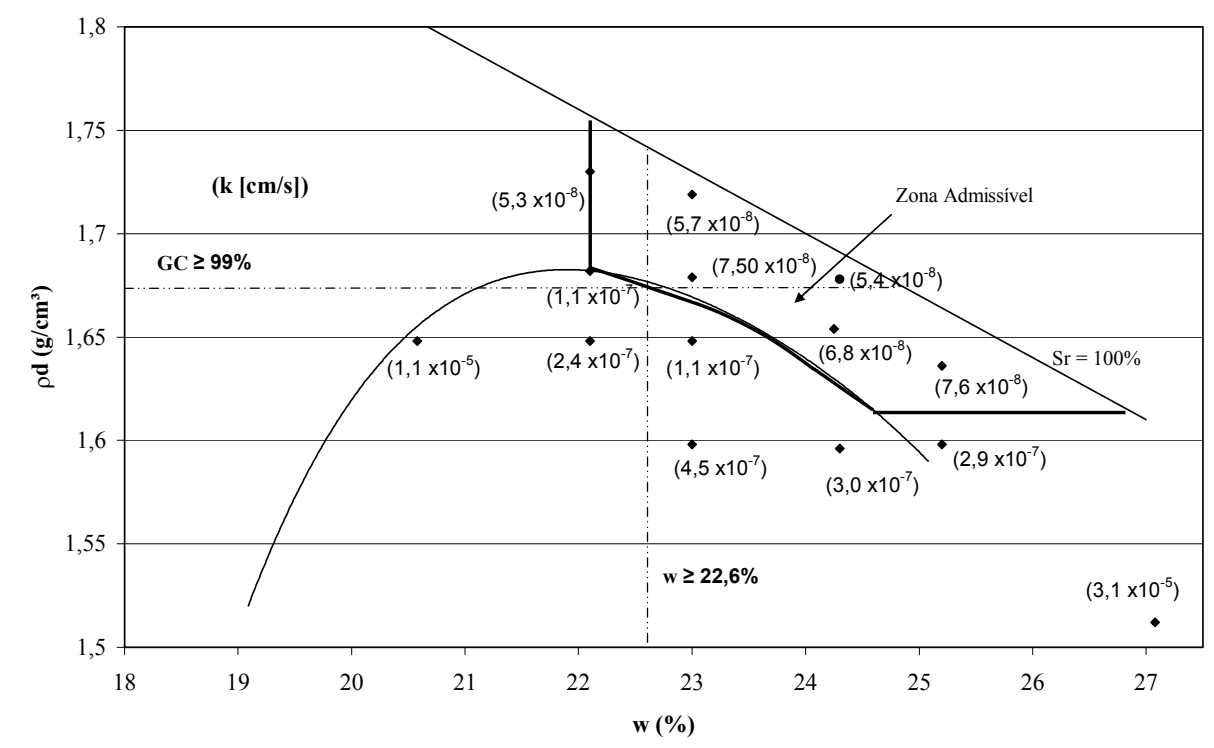

Figura 4.7 - Limitantes inferiores de condições ideais de compactação e zona admissível, baseados em parâmetros de condutividade hidráulica, para a amostra k01.

\subsubsection{Influência do teor de umidade volumétrico}

É de se esperar que o aumento da massa específica seca cause uma redução no valor da condutividade hidráulica, porém corpos-de-prova compactados com a mesma massa específica seca apresentam diferentes valores de condutividade hidráulica se forem compactados no ramo seco ou no ramo úmido da curva de compactação, como pôde ser observado na Figura 4.7. Com a intenção de relacionar essa influência, é mostrado na Figura 4.8 a variação da condutividade hidráulica em função do teor de umidade volumétrico, definido como $\theta_{w}=\frac{V_{w}}{V}$, que também pode ser expresso como $\theta_{w}=\frac{\text { Sr.e }}{1+e}$. 


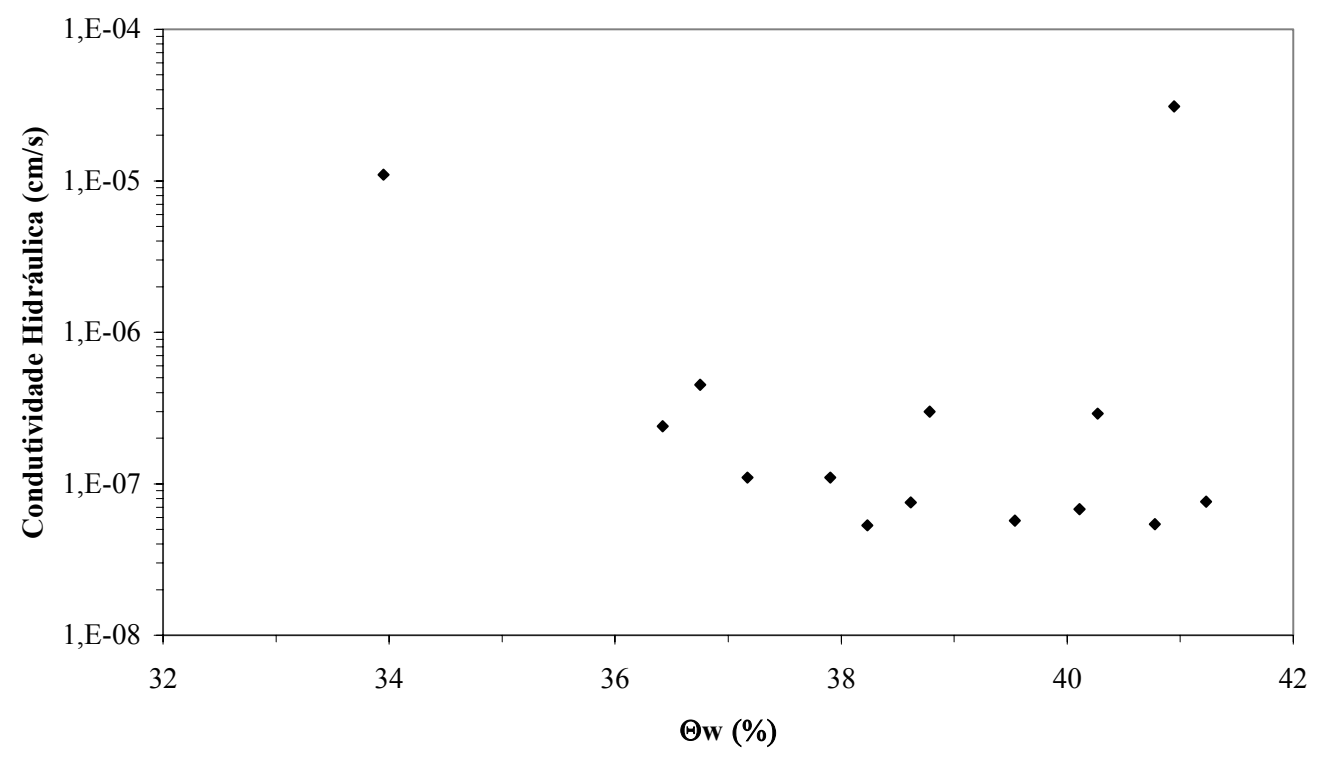

Figura 4.8 - Condutividade hidráulica em função do teor de umidade volumétrico, amostra k01.

Pode-se observar uma tendência de diminuição da condutividade hidráulica com o aumento do teor de umidade volumétrico.

\subsubsection{Contração}

Para a observação do comportamento da amostra no processo de secagem, foram selecionados três corpos-de-prova que atendiam as condições ideais de compactação e submetidos ao ensaio de contração citado anteriormente no item 3.3. Os corpos de prova selecionados foram $\mathrm{k} 01-06\left(\mathrm{w}_{\text {mold. }}=23 \%, \mathrm{GC}=99,9 \%\right), \mathrm{k} 01-07\left(\mathrm{w}_{\text {mold. }}=23 \%, \mathrm{GC}=\right.$ $102,3 \%$ ) e $\mathrm{k} 01-10$ ( $\mathrm{w}_{\text {mold. }}=24,3 \%, \mathrm{GC}=99,9 \%$ ).

A Figura 4.9 mostra a contração axial e volumétrica em função do tempo para estes corpos de prova. 


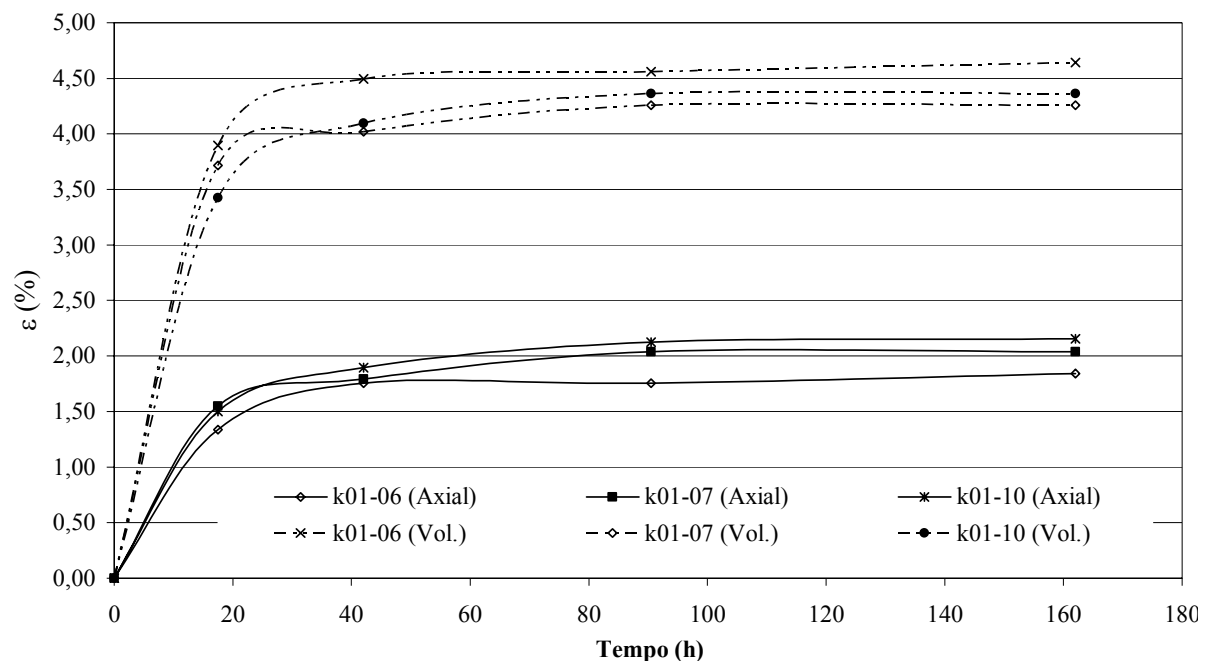

Figura 4.9 - Contração axial e volumétrica em função do tempo para a mostra k01.

Os corpos-de-prova analisados foram compactados no ramo úmido. O grau de compactação e o teor de umidade de moldagem exerceram pouca influência na contração axial e volumétrica. $\mathrm{O}$ processo de contração se estabilizou com 48 horas para todos os corpos-de-prova sem o aparecimento de trincas. Os valores de temperatura ambiente e umidade relativa do ar variaram, respectivamente, entre 22 a $25^{\circ} \mathrm{C}$ e 36 a $40 \%$.

Os mesmo corpos de prova foram submetidos a dois ciclos de umedecimento e secagem para a observação do aparecimento de trincas. Durante o processo de umedecimento, os corpos-deprova não dispunham de confinamento lateral e o umedecimento foi realizado por capilaridade. A Figura 4.10 mostra a condição final do corpo de prova k01-07. As trincas presentes no corpo-de-prova surgiram durante o processo de umedecimento.

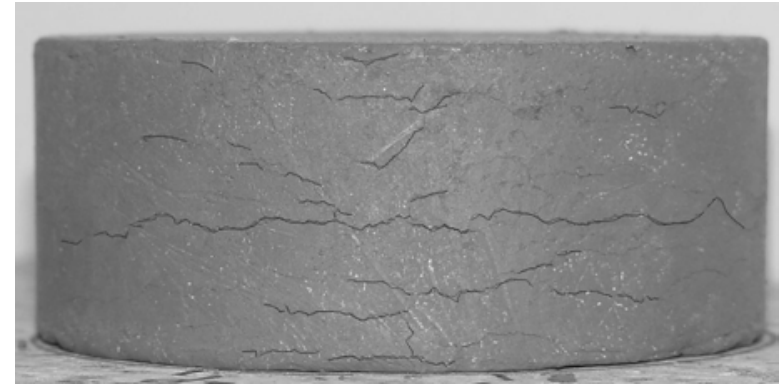

(a)

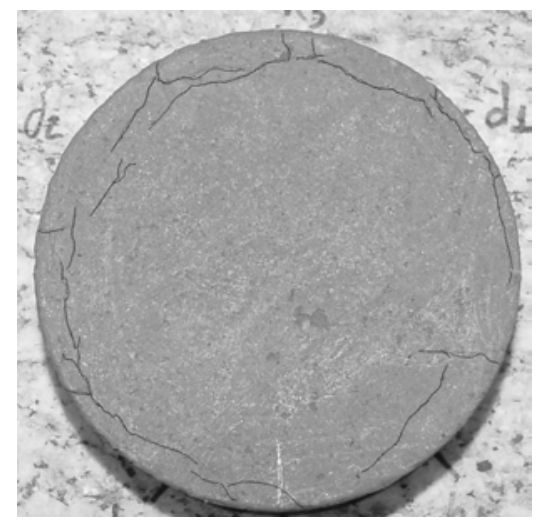

(b)

Figura 4.10 - Condição do Cp k01-07 após dois ciclos de umedecimento e secagem, (a) vista lateral, (b) vista superior. 
A Figura 4.10 foi editada em um programa computacional de edição de imagem para realçar as trincas presentes no corpo-de-prova do solo k01.

Todos os corpos-de-prova submetidos à ciclagem apresentaram um grau de trincamento semelhante ao mostrado na Figura 4.10. Dentre os condicionantes envolvidos, o desconfinamento lateral dos corpos-de-prova durante o processo de umedecimento pode ter exercido forte influência no aparecimento e na quantidade de trincas, pois estas surgiam da periferia para o centro dos corpos-de-prova durante o processo de umedecimento.

Após o último ciclo, os corpos de prova foram submetidos a ensaios de condutividade hidráulica e os resultados são mostrados na Tabela 4.3.

Tabela 4.3 - Acréscimo da condutividade hidráulica devido a ciclos de umedecimento e secagem, amostra k01.

\begin{tabular}{ccc}
\hline $\mathbf{C p s}$ & $\mathbf{k}_{\text {iníc. }}(\mathbf{c m} / \mathbf{s})$ & $\mathbf{k}_{\text {final. }}(\mathbf{c m} / \mathbf{s})$ \\
\hline $\mathrm{k} 01-06$ & $7,5 \cdot 10^{-8}$ & $7,2 \cdot 10^{-6}$ \\
\hline $\mathrm{k} 01-07$ & $5,7.10^{-8}$ & $5,0.10^{-5}$ \\
\hline $\mathrm{k} 01-10$ & $5,4.10^{-8}$ & $2,1.10^{-5}$ \\
\hline
\end{tabular}

Depois de submetidos a ciclos de umedecimento e secagem, os corpos-de-prova não atendem ao valor mínimo de condutividade hidráulica sugerido para barreiras impermeáveis, isto é, $1.10^{-7} \mathrm{~cm} / \mathrm{s}$. Cabe destacar que os fatores externos impostos nos ensaios de ciclagem (umedecimento e secagem) não retratam exatamente as condições encontradas no campo, pois não se considerou o efeito de confinamento. Deste modo, a metodologia adotada pode agir de forma agressiva nos corpos-de-prova, superestimando o surgimento das trincas.

\subsubsection{Ensaios com permeâmetro de parede rígida}

Os ensaios em permeâmetro de parede rígida (r) foram realizados com carga variável e os corpos-de-prova foram confeccionados conforme descrito no item 3.2.2. Com o intuito de comparar os resultados de condutividade hidráulica obtidos nos dois métodos de ensaio, foram estudadas três condições de compactação semelhantes às condições utilizadas nos ensaios em permeâmetro de parede flexível. A Tabela 4.4 apresentadas as condições de compactação dos corpos-de-prova estudados. 
Tabela 4.4 - Resultados e condições de ensaio em parede rígida para a amostra Cravinhos - k01.

\begin{tabular}{ccccccc}
\hline Amostra & $\mathbf{w}_{\text {mold }}(\mathbf{\%})$ & $\begin{array}{c}\rho \mathbf{o d} \\
\left(\mathbf{g} / \mathbf{c m}^{\mathbf{3}}\right)\end{array}$ & $\begin{array}{c}\mathbf{G C} \\
\mathbf{( \% )}\end{array}$ & $\mathbf{e}$ & $\begin{array}{c}\mathbf{S r} \\
\mathbf{( \% )}\end{array}$ & $\mathbf{k} \mathbf{( c m} / \mathbf{s})$ \\
\hline $\mathrm{k} 01-01 \mathrm{r}$ & 22,2 & 1,65 & 98,2 & 0,731 & 86,7 & $1,60 \mathrm{E}-08$ \\
\hline $\mathrm{k} 01-02 \mathrm{r}$ & 22,2 & 1,68 & 100,0 & 0,700 & 90,6 & $1,30 \mathrm{E}-08$ \\
\hline $\mathrm{k} 01-03 \mathrm{r}$ & 22,2 & 1,72 & 102,4 & 0,660 & 96,0 & $9,60 \mathrm{E}-09$ \\
\hline
\end{tabular}

A Figura 4.11 mostra o comportamento da condutividade hidráulica em função do tempo para o ensaio em permeâmetro de parede rígida. Os resultados de condutividade hidráulica são de corpos-de-prova apresentados na Tabela 4.4.

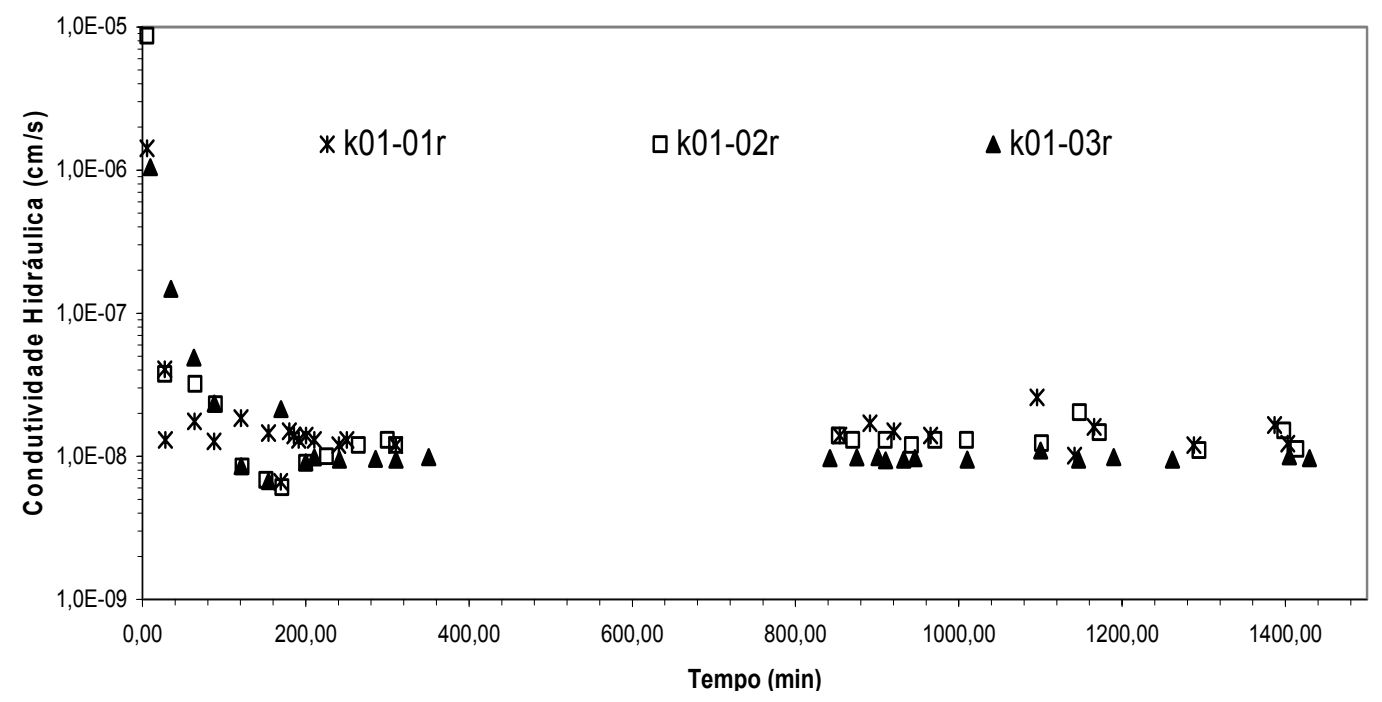

Figura 4.11 - Condutividade hidráulica vs Tempo, ensaios em permeâmetro de parede rígida. Amostra k01, cps moldados com 22,1\% de umidade e diferentes graus de compactação.

$\mathrm{Na}$ fase inicial de ensaio, o tempo médio para a saturação dos corpos-de-prova foi de 72 horas.

A Tabela 4.5 apresenta a comparação dos resultados de condutividade hidráulica obtidos em ensaios com permeâmetro de parede rígida (r) e flexível (f) para corpos-de-prova compactados em condições semelhantes. 
Tabela 4.5 - Comparação dos resultados de condutividade hidráulica obtidos em ensaios com permeâmetros de parede rígida e flexível.

\begin{tabular}{cccccc}
\hline \multirow{2}{*}{ Amostra } & $\begin{array}{c}\mathbf{w}_{\text {mold }} \\
\mathbf{( \% )}\end{array}$ & $\mathbf{e}$ & $\begin{array}{c}\text { Sr } \\
\mathbf{( \% )}\end{array}$ & $\mathbf{k}(\mathbf{c m} / \mathbf{s})$ \\
\hline \multirow{2}{*}{$\mathrm{k} 01-01$} & $\mathrm{r}$ & 22,2 & 0,731 & 86,7 & $1,60 \mathrm{E}-08$ \\
\cline { 2 - 6 } & $\mathrm{f}$ & 22,1 & 0,733 & 86,1 & $2,40 \mathrm{E}-07$ \\
\hline \multirow{2}{*}{$\mathrm{k} 01-02$} & $\mathrm{r}$ & 22,2 & 0,700 & 90,6 & $1,30 \mathrm{E}-08$ \\
\cline { 2 - 6 } & $\mathrm{f}$ & 22,1 & 0,698 & 90,4 & $1,10 \mathrm{E}-07$ \\
\hline \multirow{2}{*}{$\mathrm{k} 01-03$} & $\mathrm{r}$ & 22,2 & 0,660 & 96,0 & $9,60 \mathrm{E}-09$ \\
\cline { 2 - 6 } & $\mathrm{f}$ & 22,1 & 0,651 & 97,0 & $5,30 \mathrm{E}-08$ \\
\hline
\end{tabular}

Os valores de condutividade hidráulica obtidos em ensaios com permeâmetro de parede flexível mostraram-se maiores que os obtidos em permeâmetros de parede rígida. Este comportamento já era esperado, pois em ensaios de parede flexível a saturação é garantida por contra pressão, sendo que o corpo de prova atinge a maior condutividade hidráulica em condição saturada (condição crítica). A saturação do corpo-de-prova não ocorre nos ensaios em permeâmetros de parede rígida, resultando em valores de condutividade hidráulica menores.

A comparação gráfica dos resultados obtidos nos dois métodos de ensaio é mostrada na Figura 4.12.

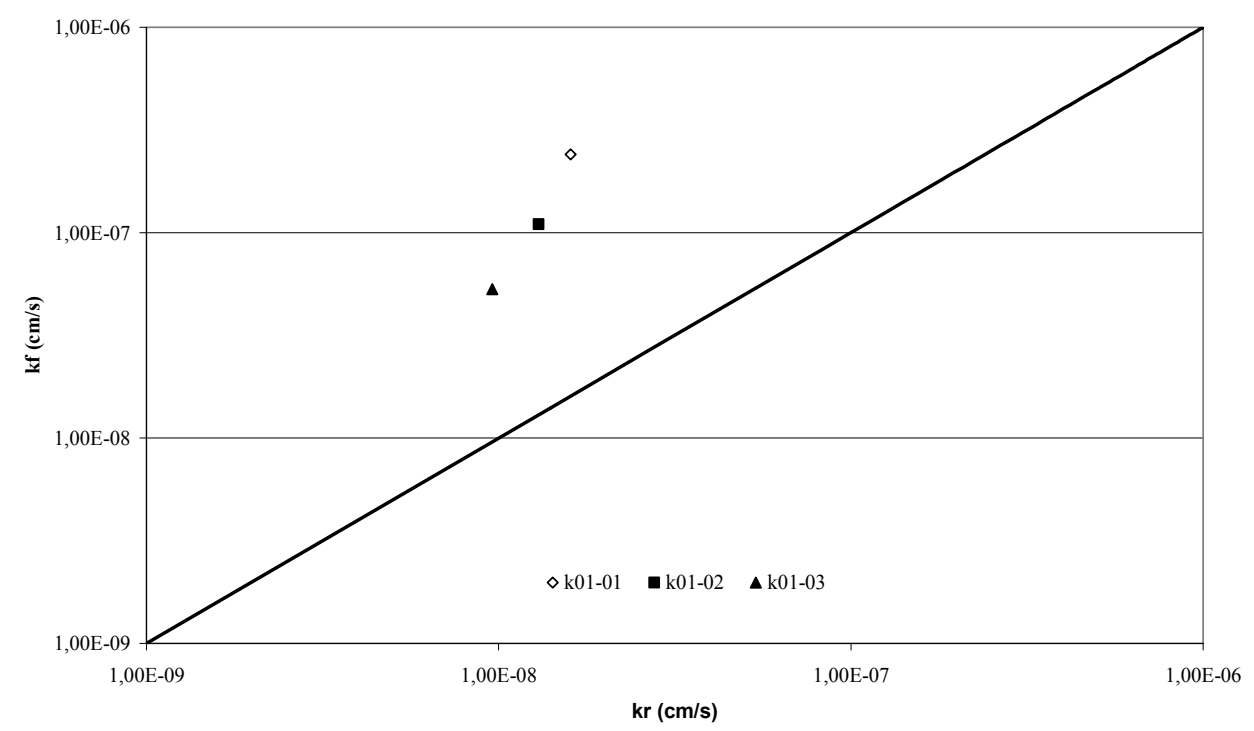

Figura 4.12 - Comparação da condutividade hidráulica em ensaios com permeâmetros de parede flexível e rígida para a amostra k01.

Para corpos-de-prova com índice de vazios por volta de 0,730 , os resultados de condutividade hidráulica em ensaios em permeâmetro de parede flexível foram, 
aproximadamente, uma ordem de grandeza maiores. Esta diferença é reduzida para corpos-deprova com maiores graus de compactação.

O tempo de ensaio foi significativamente reduzido quando se utilizou o permeâmetro de parede flexível. Para os ensaios em permeâmetro de parede flexível, o tempo necessário para a fase inicial de saturação da amostra foi reduzido em, aproximadamente, $70 \%$.

\subsection{ATERRO PIRACICABA - K02}

Trata-se de uma argila silto arenosa contendo mais de 79\% de partículas menores que $0,075 \mathrm{~mm}$. O solo foi classificado como ML, isto é, silte com areia pela classificação unificada e como LG', isto é, argiloso laterítico, pela classificação MCT.

\subsubsection{Condutividade hidráulica}

As condições de compactação dos corpos-de-prova e ensaios de condutividade hidráulica em permeâmetro de parede flexível são mostradas na Tabela 4.6.

Tabela 4.6 - Resultados e condições de ensaio em parede flexível para a amostra Aterro Piracicaba - k02.

\begin{tabular}{|c|c|c|c|c|c|c|c|c|c|}
\hline \multirow{2}{*}{$\begin{array}{c}\text { Amostra } \\
\text { Cps }\end{array}$} & \multirow[b]{2}{*}{$\begin{array}{c}W_{\text {mold }} \\
(\%)\end{array}$} & \multirow{2}{*}{$\begin{array}{c}\rho d \\
(g / c m 3)\end{array}$} & \multirow{2}{*}{$\begin{array}{l}\text { GC } \\
(\%)\end{array}$} & \multirow[b]{2}{*}{$\mathbf{e}$} & \multirow[b]{2}{*}{$\operatorname{Sr}(\%)$} & \multicolumn{2}{|c|}{ Saturação (kPa) } & \multirow[b]{2}{*}{ B } & \multirow[b]{2}{*}{$\mathrm{k}(\mathrm{cm} / \mathrm{s})$} \\
\hline & & & & & & $\sigma_{3 c}$ & C.P. & & \\
\hline $\mathrm{k} 02-01$ & 24,3 & 1,595 & 98,1 & 0,779 & 88,5 & 500 & 460 & 0,98 & $5,3 \mathrm{E}-08$ \\
\hline $\mathrm{k} 02-02$ & 24,3 & 1,631 & 100,3 & 0,739 & 93,2 & 500 & 560 & 0,97 & $2,5 \mathrm{E}-08$ \\
\hline $\mathrm{k} 02-03$ & 24,3 & 1,642 & 101,0 & 0,728 & 94,7 & 500 & 560 & 0,97 & $1,9 \mathrm{E}-08$ \\
\hline k02-04 & 24,3 & 1,671 & 102,8 & 0,698 & 98,8 & 600 & 560 & 0,96 & $1,9 \mathrm{E}-08$ \\
\hline $\mathrm{k} 02-05$ & 24,9 & 1,543 & 94,9 & 0,839 & 84,2 & 550 & 510 & 0,98 & $8,2 \mathrm{E}-06$ \\
\hline $\mathrm{k} 02-06$ & 24,9 & 1,597 & 98,2 & 0,776 & 91,0 & 450 & 410 & 0,97 & $3,2 \mathrm{E}-07$ \\
\hline $\mathrm{k} 02-07$ & 24,9 & 1,63 & 100,2 & 0,740 & 95,4 & 500 & 460 & 0,96 & $6,3 \mathrm{E}-08$ \\
\hline $\mathrm{k} 02-08$ & 24,9 & 1,642 & 101,0 & 0,728 & 97,1 & 500 & 460 & 0,98 & $4,4 \mathrm{E}-08$ \\
\hline $\mathrm{k} 02-09$ & 24,9 & 1,658 & 102,0 & 0,711 & 99,3 & 500 & 460 & 0,97 & $3,8 \mathrm{E}-08$ \\
\hline $\mathrm{k} 02-10$ & 25,9 & 1,549 & 95,3 & 0,832 & 88,4 & 400 & 460 & 0,98 & $8,6 \mathrm{E}-06$ \\
\hline k02-11 & 25,9 & 1,596 & 98,2 & 0,778 & 94,5 & 400 & 460 & 0,97 & $1,4 \mathrm{E}-07$ \\
\hline $\mathrm{k} 02-12$ & 25,9 & 1,627 & 100,1 & 0,744 & 98,8 & 500 & 460 & 0,97 & $3,3 \mathrm{E}-08$ \\
\hline k02-13 & 23,3 & 1,627 & 100,1 & 0,744 & 88,9 & 500 & 460 & 0,97 & $5,0 \mathrm{E}-06$ \\
\hline k02-14 & 23,3 & 1,594 & 98,0 & 0,780 & 84,8 & 500 & 460 & 0,97 & $9,1 \mathrm{E}-06$ \\
\hline
\end{tabular}


A Figura 4.13 mostra o comportamento típico da condutividade hidráulica em função do tempo, para todos os corpos-de-prova ensaiados. Os resultados mostrados na Figura 4.13 são de corpos-de-prova moldados com teor de umidade igual a $24,9 \%$ e diferentes graus de compactação, e também para corpos de prova moldados com grau de compactação igual a $100 \%$ e diferentes teores de umidade de moldagem.

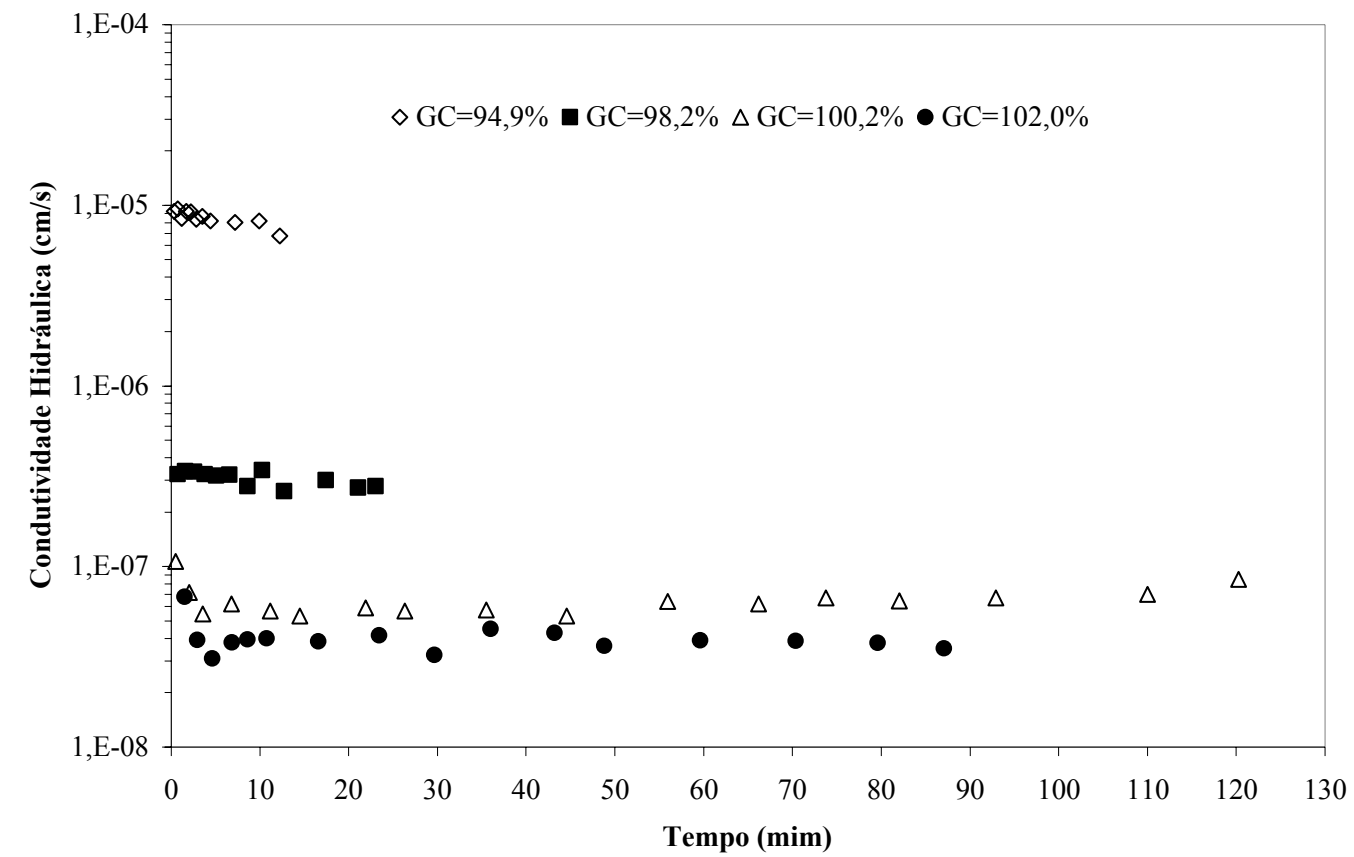

Figura 4.13a - Condutividade hidráulica vs Tempo, amostra k02, CPs moldados $w=$ $\mathbf{2 4 , 9 \%}$ e diferentes graus de compactação.

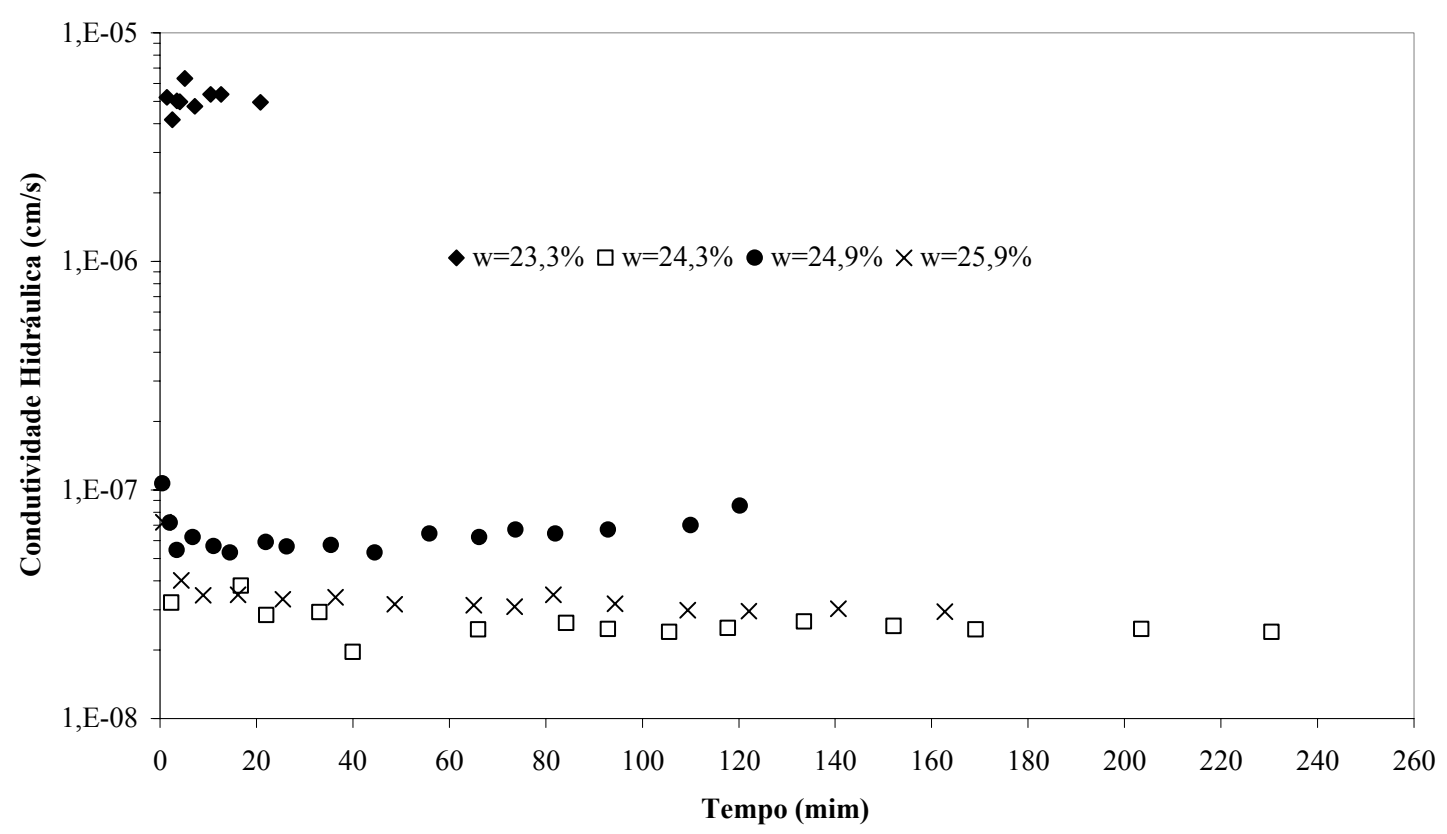

Figura 4.13b - Condutividade hidráulica vs Tempo, amostra k02, CPs moldados com GC $=100 \%$ e diferentes teores de umidade. 
Para a determinação do valor da condutividade hidráulica foi seguido o mesmo critério da reta média descrito no item 3.1.1.

Com exceção do corpo de prova k02-07, em todos os ensaios a condutividade hidráulica seguiu uma leve tendência de diminuição com o tempo, comportamento semelhante ao da amostra k01. Na maior parte dos corpos-de-prova estudados pode-se considerar o fluxo constante em função do tempo a partir dos primeiros 10 minutos de ensaio. $\mathrm{O}$ tempo médio gasto na fase inicial de saturação dos corpos-de-prova foi o mesmo da amostra anterior, isto é, 24 horas.

A Figura 4.14 mostra o comportamento da condutividade hidráulica frente à variação de teor de umidade de moldagem para diferentes graus de compactação. Os valores de teores de umidade estão expressos em relação ao teor de umidade ótima do material.

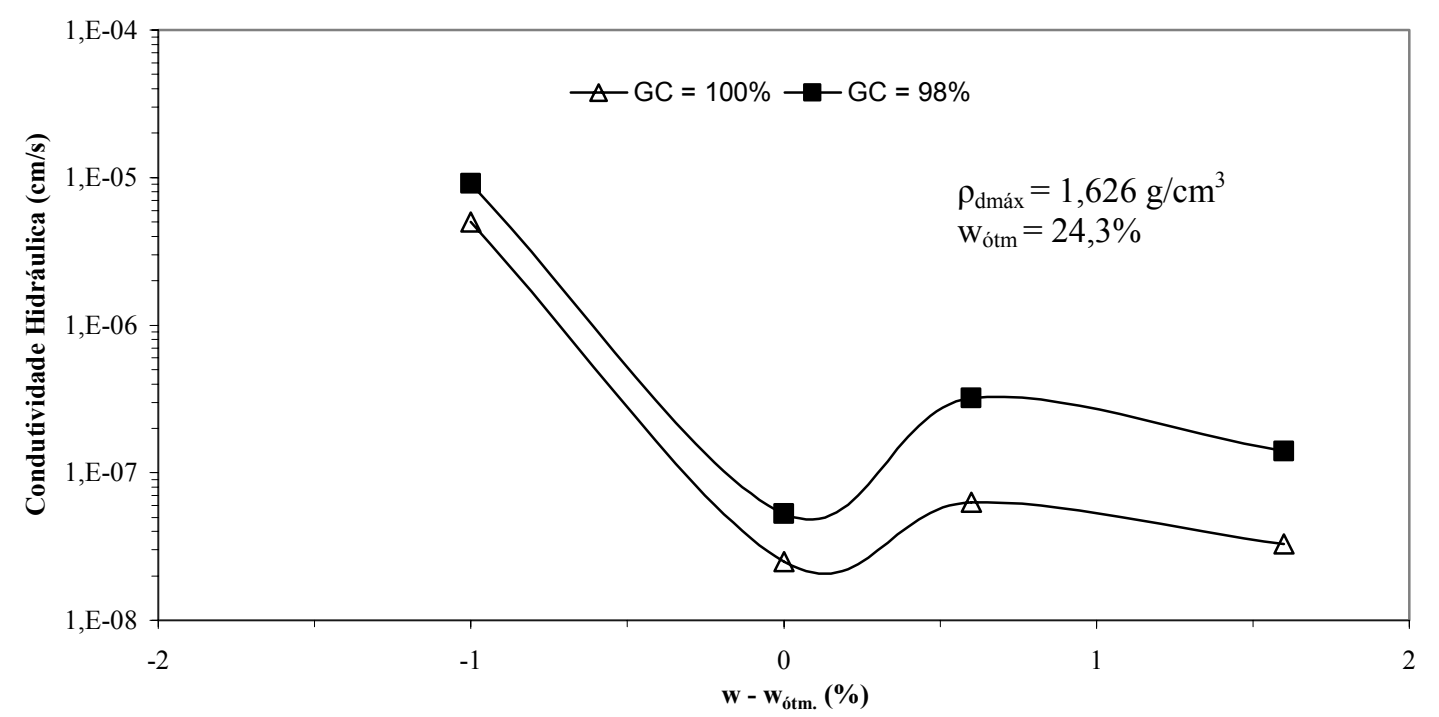

Figura 4.14 - Efeito do desvio de umidade de moldagem na condutividade hidráulica para a amostra k02.

Para a amostra estudada a condutividade hidráulica alcança o valor mínimo quando a compactação é realizada no teor de umidade ótimo. Curiosamente, a condutividade hidráulica apresentou um aumento do seu valor quando o teor de umidade de moldagem cresce para 0,6 pontos percentuais acima do ótimo. Para valores da umidade de moldagem acima de $\mathrm{w}_{\text {ótm }}+$ $0,6 \%$, a condutividade hidráulica volta a diminuir. Esse comportamento também foi observado por Macambira (2002) para alguns solos lateríticos compactados em ensaios de parede rígida. Como esperado, o decréscimo da condutividade hidráulica com o aumento do teor de umidade de moldagem foi mais pronunciado quando se passa do ramo seco para o ramo úmido. Como na amostra anterior, há uma tendência de diminuição da condutividade hidráulica com o aumento do grau de compactação. Este comportamento pode ser melhor observado na Figura 4.15. 


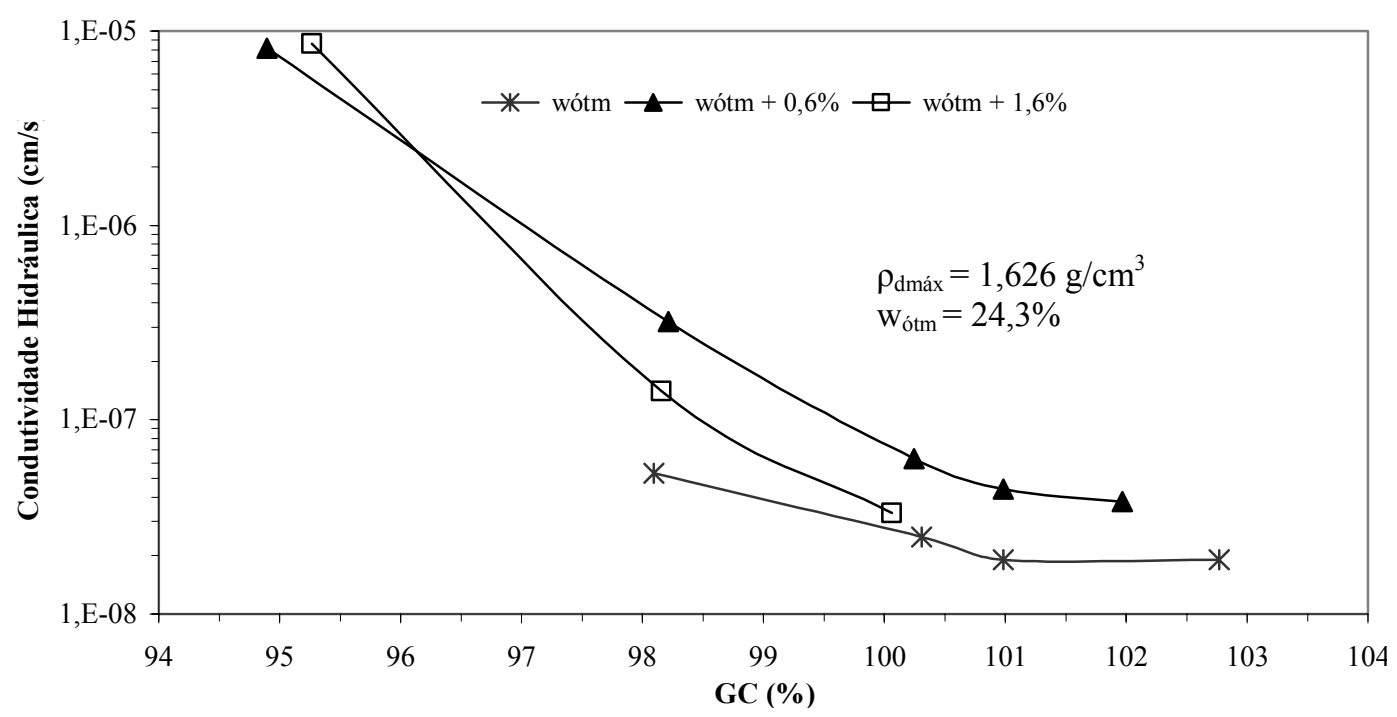

Figura 4.15 - Efeito do grau de compactação na condutividade hidráulica para a mostra k02.

Como é possível observar, a condutividade hidráulica diminuiu com o aumento do grau de compactação para todos os teores de umidade ensaiados. Para grau de compactação superior a $100 \%$, a condutividade hidráulica não sofre significativa redução, de maneira semelhante aos das outras amostras estudadas.

A Figura 4.16 mostra a curva de compactação para a energia do Proctor Normal, as condições de compactação dos corpos-de-prova, os valores da condutividade hidráulica obtidos em ensaios de parede flexível, as condições ideais de compactação (GC $\geq 99 \%$ e w $\geq$ $24,3 \%$ ) e a zona admissível baseada em parâmetros de condutividade hidráulica. Neste caso as condições ideais de compactação coincidem com a zona admissível.

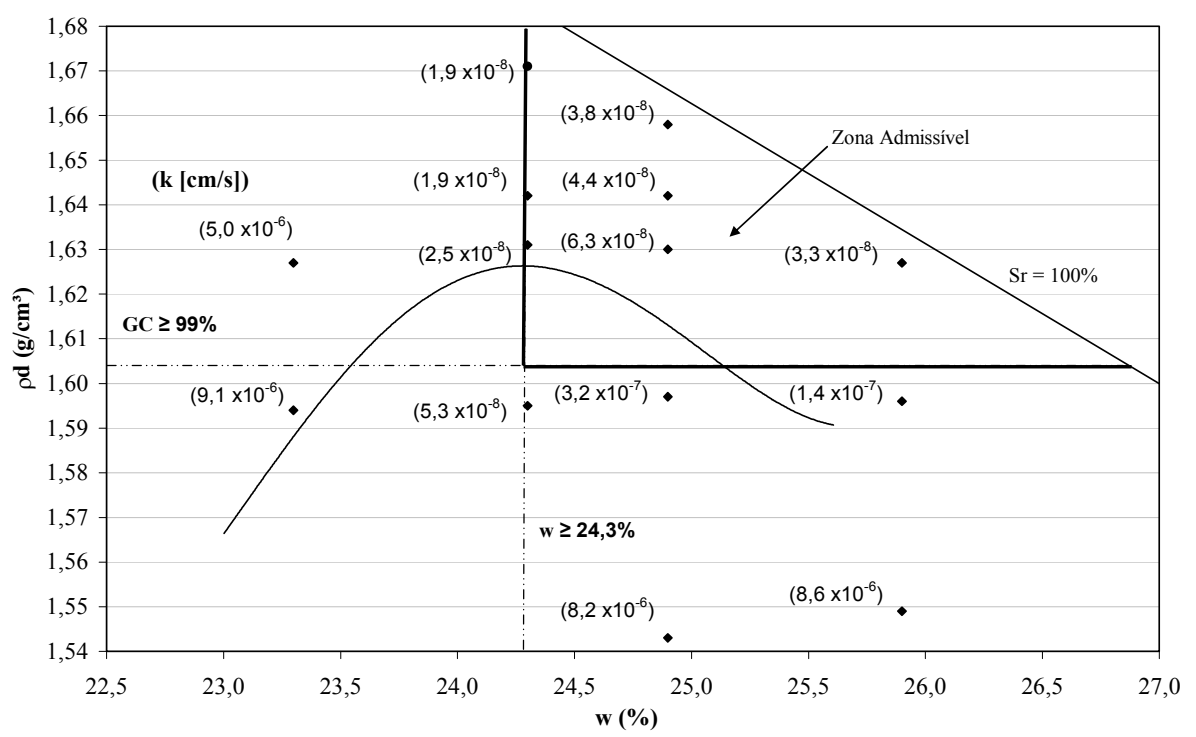

Figura 4.16 - Limitantes inferiores de condições ideais de compactação e zona admissível, baseados em parâmetros de condutividade hidráulica, para a amostra k02. 


\subsubsection{Influência do teor de umidade volumétrico}

A Figura 4.17 apresenta a variação da condutividade hidráulica em função do teor de umidade volumétrico para a amostra k02.

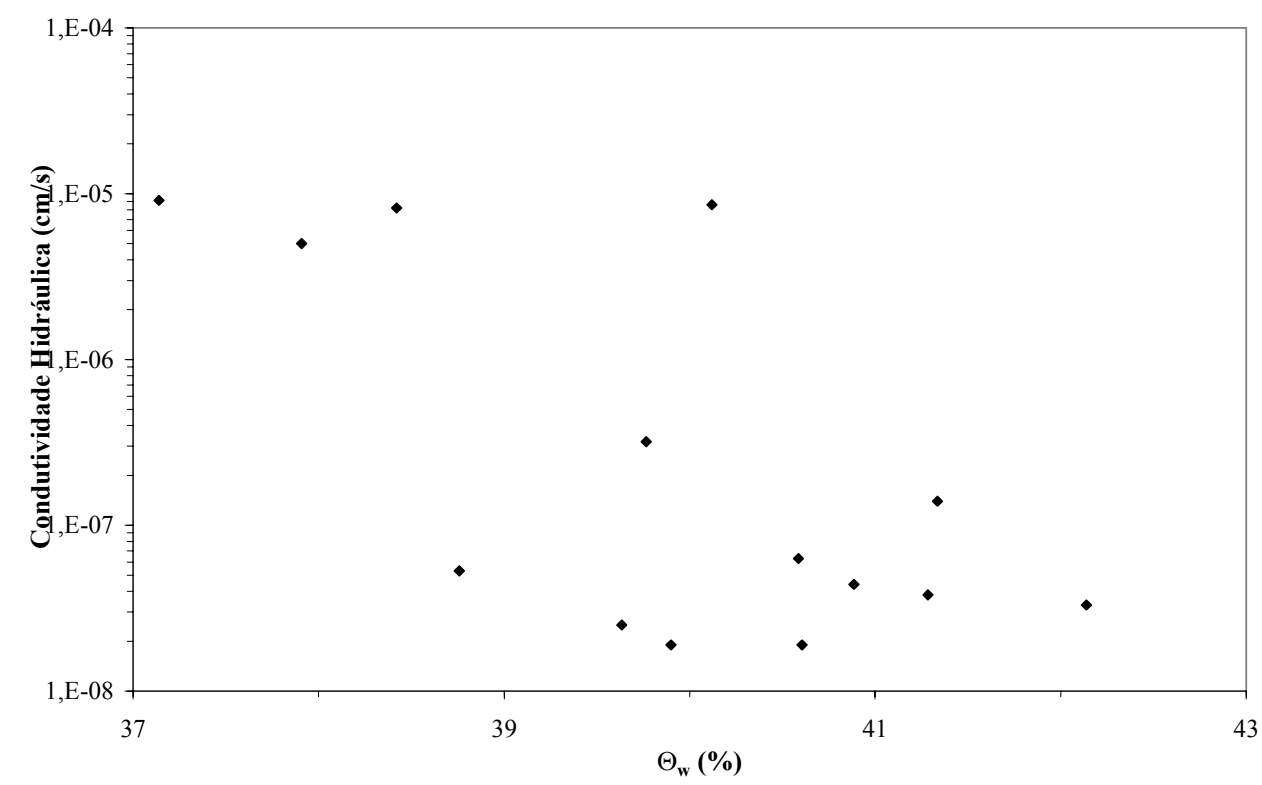

Figura 4.17 - Condutividade hidráulica em função do teor de umidade volumétrico, amostra k02.

Assim como na amostra anterior, os resultados de condutividade hidráulica apresentam uma tendência de diminuição com o aumento do teor de umidade volumétrico.

\subsubsection{Contração}

Os corpos-de-prova selecionados para o ensaio de contração foram k02-02 ( $\mathrm{w}_{\text {mold. }}=$ $24,3 \%, \mathrm{GC}=100,3 \%), \mathrm{k} 02-04 \quad\left(\mathrm{w}_{\text {mold }}=24,3 \%, \mathrm{GC}=102,8 \%\right), \mathrm{k} 02-12 \quad\left(\mathrm{w}_{\text {mold }}=25,9 \%\right.$, $\mathrm{GC}=100,1 \%)$ e $\mathrm{k} 02-07\left(\mathrm{w}_{\text {mold. }}=24,9 \%, \mathrm{GC}=100,2 \%\right)$.

À exemplo da amostra anterior, o ensaio de contração foi realizado conforme citado no item 3.3. A Figura 4.18 mostra a contração axial e volumétrica em função do tempo para estes corpos-de-prova. 


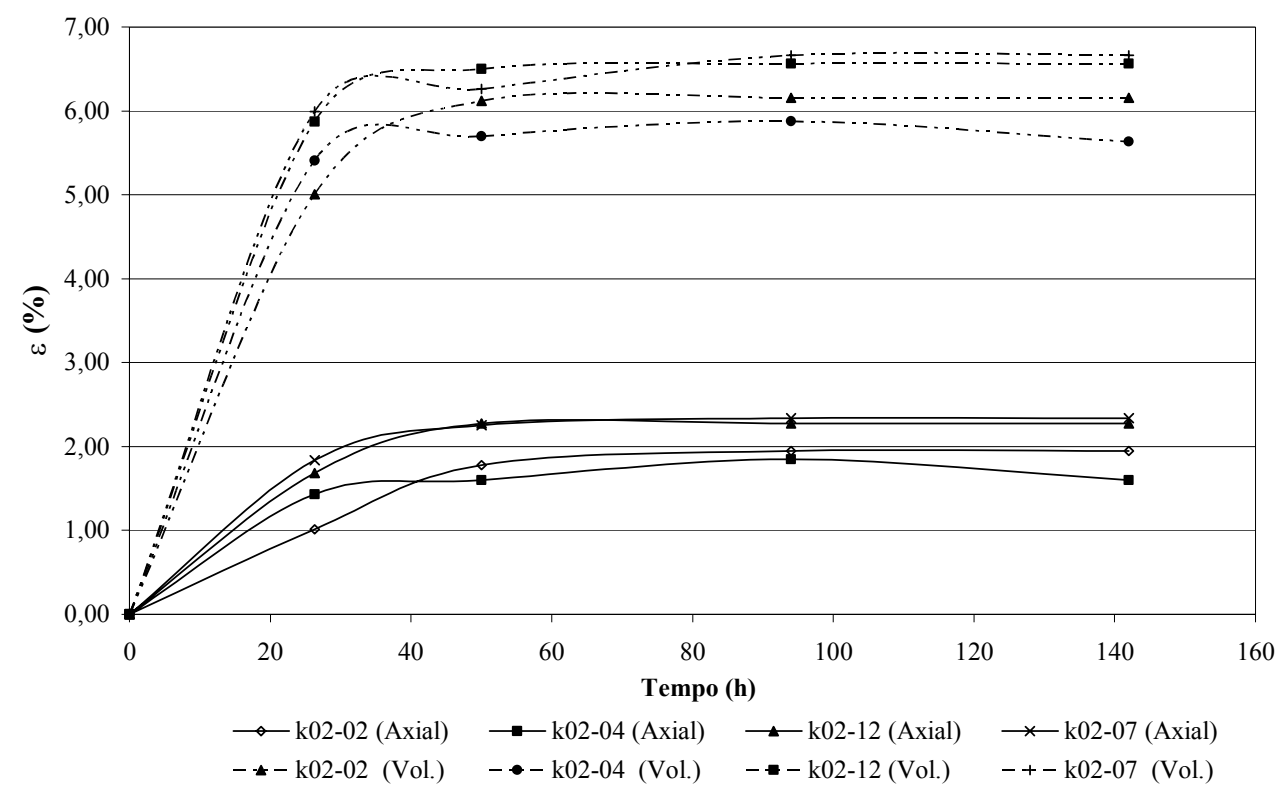

Figura 4.18 - Contração axial e volumétrica em função do tempo para a mostra k02.

O grau de compactação e o teor de umidade de moldagem exerceram pouca influência na contração axial e volumétrica. O processo de contração se estabilizou por volta de 50 horas sem o aparecimento de trincas.

Os valores de temperatura ambiente e umidade relativa do ar variaram, respectivamente, entre 24 a $25^{\circ} \mathrm{C}$ e 36 a $42 \%$.

Os corpos-de-prova foram submetidos a dois ciclos de umedecimento e secagem para a observação do aparecimento de trincas. Ao contrário da amostra anterior, o umedecimento dos corpos-de-prova foi realizado por circulação de água destilada dentro da câmara confinante do permeâmetro de parede flexível, a fím de minimizar o efeito do desconfinamento lateral. A Figura 4.19 mostra a condição final do corpo de prova k02-02.

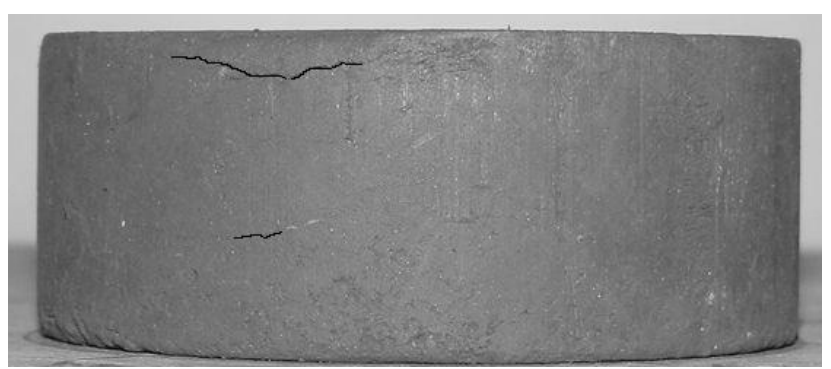

(a)

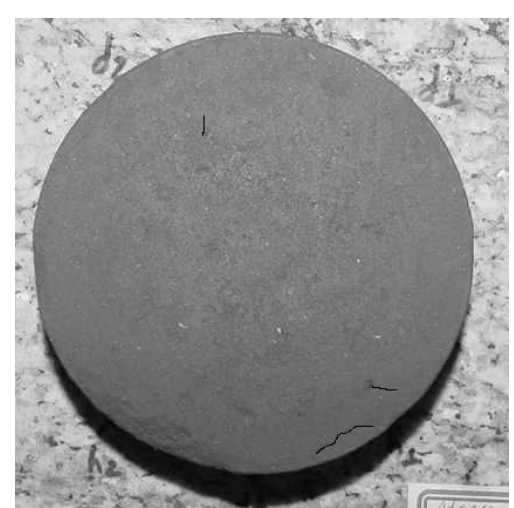

(b)

Figura 4.19 - Condição do Cp k02-02 após 2 ciclos de umedecimento e secagem, (a) vista lateral, (b) vista superior. 
A Figura 4.19 foi editada em um programa computacional de edição de imagem para realçar as trincas presentes no corpo de prova.

Pode-se observar que após os ciclos, os corpos-de-prova apresentaram uma significativa redução no aparecimento de trincas se comparados ao comportamento da amostra k01. O confinamento lateral durante o processo de umedecimento se mostrou importante na redução de trincas.

Após o último ciclo, os corpos-de-prova foram submetidos a ensaios de condutividade hidráulica e os resultados são mostrados na Tabela 4.7.

Tabela 4.7 - Acréscimo da condutividade hidráulica devido a ciclos de umedecimento e secagem, amostra k02.

\begin{tabular}{ccc}
\hline $\mathbf{C p s}$ & $\mathbf{k}_{\text {iníc. }}(\mathbf{c m} / \mathbf{s})$ & $\mathbf{k}_{\text {final. }}(\mathbf{c m} / \mathbf{s})$ \\
\hline $\mathrm{k} 02-02$ & $2,5.10^{-8}$ & $8,5 \cdot 10^{-8}$ \\
\hline $\mathrm{k} 02-04$ & $1,9.10^{-8}$ & $1,1.10^{-7}$ \\
\hline $\mathrm{k} 02-07$ & $6,3 \cdot 10^{-8}$ & $1,9.10^{-7}$ \\
\hline $\mathrm{k} 02-12$ & $3,3.10^{-8}$ & $8,4 \cdot 10^{-8}$ \\
\hline
\end{tabular}

Os corpos-de-prova atenderam o valor mínimo de condutividade hidráulica sugerido para barreiras impermeáveis, com exceção do k02-07 que ficou próximo ao limite. Cabe destacar que apesar dos esforços para minimizar as condições desfavoráveis do ensaio, como o desconfinamento lateral durante o umedecimento, os fatores externos não retratam exatamente as condições de campo, pois o processo de secagem ocorreu sem confinamento lateral.

\subsubsection{Ensaios com permeâmetro de parede rígida.}

Foram estudadas três condições de compactação apresentadas na Tabela 4.8.

Tabela 4.8 - Resultados e condições de ensaio em parede rígida para a amostra Aterro

Piracicaba - k02.

\begin{tabular}{ccccccc}
\hline Amostra & $\begin{array}{c}\mathbf{w}_{\text {mold }} \\
(\mathbf{\% )}\end{array}$ & $\boldsymbol{\rho d}\left(\mathbf{g} / \mathbf{c m}^{\mathbf{3}}\right)$ & $\begin{array}{c}\mathbf{G C} \\
\mathbf{( \% )}\end{array}$ & $\mathbf{e}$ & $\begin{array}{c}\mathbf{S r} \\
\mathbf{( \% )}\end{array}$ & $\mathbf{k} \mathbf{( c m / s )}$ \\
\hline $\mathrm{k} 02-01 \mathrm{r}$ & 24,3 & 1,596 & 98,2 & 0,778 & 88,7 & $4,50 \mathrm{E}-09$ \\
\hline $\mathrm{k} 02-02 \mathrm{r}$ & 24,3 & 1,635 & 100,6 & 0,735 & 93,8 & $3,30 \mathrm{E}-09$ \\
\hline $\mathrm{k} 02-03 \mathrm{r}$ & 24,3 & 1,650 & 101,5 & 0,719 & 95,8 & $3,20 \mathrm{E}-09$ \\
\hline
\end{tabular}


O comportamento da condutividade hidráulica em função do tempo para o ensaio em permeâmetro de parede rígida dos corpos-de-prova apresentados na Tabela 4.8 é mostrado na Figura 4.20.

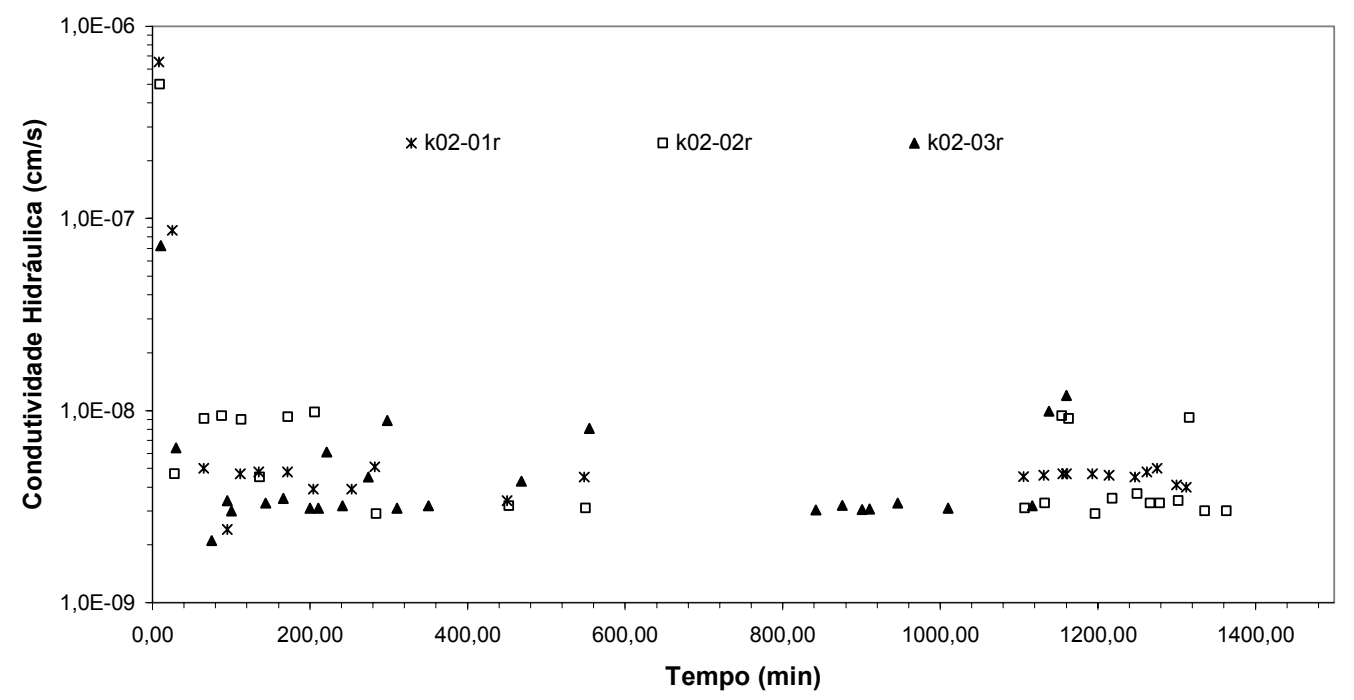

Figura 4.20 - Condutividade hidráulica vs Tempo, ensaios em permeâmetro de parede rígida. Amostra k02, cps moldados com $24,3 \%$ de umidade e com diferentes graus de compactação.

O tempo médio para a fase inicial de saturação dos corpos-de-prova ensaiados em permeâmetro de parede rígida foi de 120 horas.

A Tabela 4.9 apresenta a comparação dos resultados de condutividade hidráulica obtidos em ensaios com permeâmetro de parede rígida (r) e flexível (f) para corpos-de-prova compactados em condições semelhantes.

Tabela 4.9 - Comparação dos resultados de condutividade hidráulica obtidos em ensaios com permeâmetros de parede rígida e flexível para a amostra k02.

\begin{tabular}{cccccc}
\hline \multirow{2}{*}{ Amostra } & \multirow{2}{*}{$\mathbf{w}_{\text {mold }}(\%)$} & e & Sr (\%) & $\mathbf{k}(\mathbf{c m} / \mathbf{s})$ \\
\hline \multirow{2}{*}{$\mathrm{k} 02-01$} & $\mathrm{r}$ & 24,3 & 0,778 & 88,7 & $4,50 \mathrm{E}-09$ \\
\cline { 2 - 6 } & $\mathrm{f}$ & 24,3 & 0,779 & 88,5 & $5,30 \mathrm{E}-08$ \\
\hline \multirow{2}{*}{$\mathrm{k} 02-02$} & $\mathrm{r}$ & 24,3 & 0,735 & 93,8 & $3,30 \mathrm{E}-09$ \\
\cline { 2 - 6 } & $\mathrm{f}$ & 24,3 & 0,739 & 93,2 & $2,50 \mathrm{E}-08$ \\
\hline \multirow{2}{*}{$\mathrm{k} 02-03$} & $\mathrm{r}$ & 24,3 & 0,719 & 95,8 & $3,20 \mathrm{E}-09$ \\
\cline { 2 - 6 } & $\mathrm{f}$ & 24,3 & 0,728 & 94,7 & $1,90 \mathrm{E}-08$ \\
\hline
\end{tabular}


Os resultados de condutividade hidráulica obtidos nos ensaios em permeâmetro de parede rígida se mantiveram menores se comparados com os resultados obtidos em permeâmetro de parede flexível como pode-se observar na Figura 4.21.

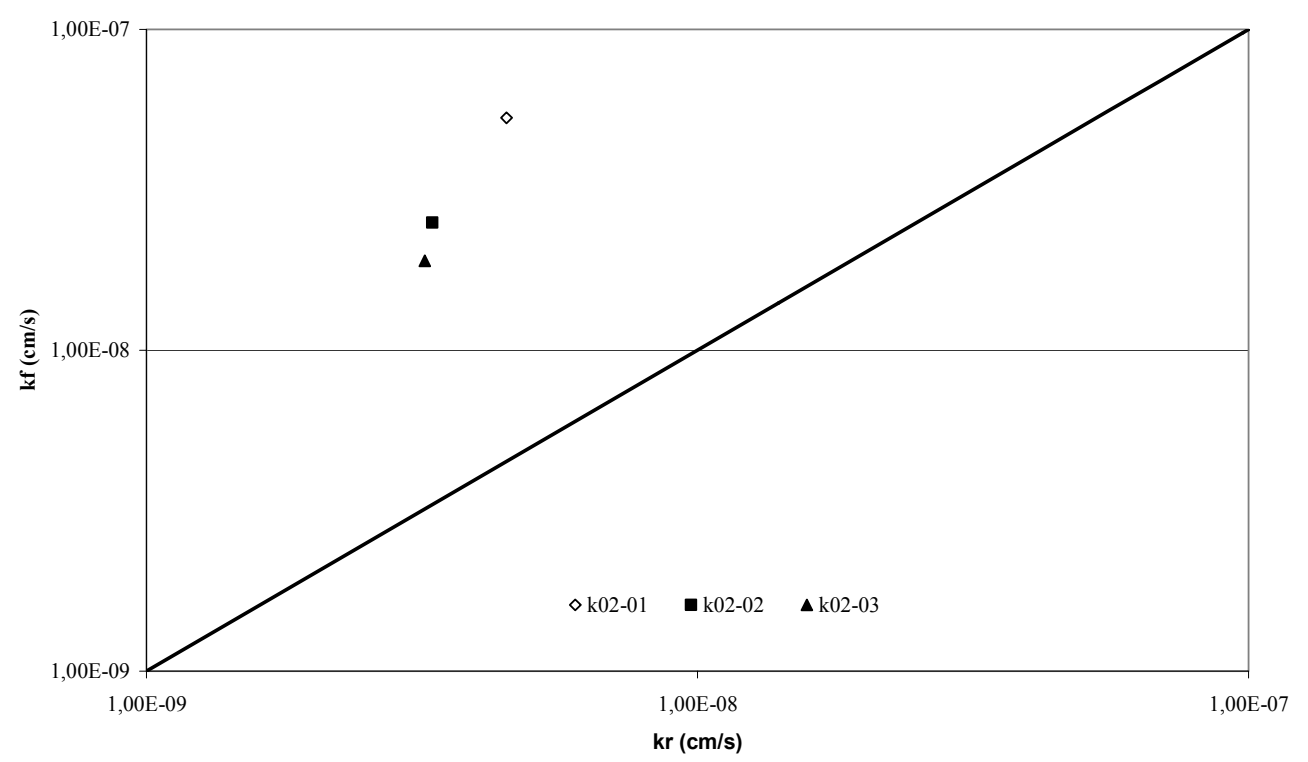

Figura 4.21 - Comparação da condutividade hidráulica em ensaios com permeâmetros de parede flexível e rígida para a amostra k02.

A maior diferença foi alcançada pelo corpo-de-prova com maior índice de vazios, 0,78, e a condutividade hidráulica obtida em permeâmetro de parede flexível foi, aproximadamente, uma ordem de grandeza maior se comparada com o resultado obtido em ensaio com permeâmetro de parede rígida, porém a diferença dos resultados obtidos nos dois métodos de ensaio analisados foi reduzida quando se reduzia o índice de vazios dos corpos de prova.

\subsection{ARARAS - K03}

Trata-se de uma argila silto arenosa contendo $77 \%$ das partículas menores que 0,075 mm. O solo foi classificado como CL, isto é, argila pouco plástica com areia e como NG', isto é argiloso não laterítico pela classificação MCT. 


\subsubsection{Condutividade hidráulica}

A Tabela 4.10 mostra as condições de compactação e de ensaio em permeâmetro de parede flexível para cada corpo-de-prova analisado.

Tabela 4.10 - Resultados e condições de ensaio em parede flexível para a amostra Araras -k03.

\begin{tabular}{|c|c|c|c|c|c|c|c|c|c|}
\hline \multirow{2}{*}{$\begin{array}{c}\text { Amostra } \\
\text { Cps }\end{array}$} & \multirow{2}{*}{$\begin{array}{c}\mathrm{W}_{\text {mold }} \\
(\%)\end{array}$} & \multirow{2}{*}{$\begin{array}{c}\rho d \\
(\mathrm{~g} / \mathrm{cm} 3)\end{array}$} & \multirow{2}{*}{$\begin{array}{l}\mathrm{GC} \\
(\%)\end{array}$} & \multirow[b]{2}{*}{ e } & \multirow[b]{2}{*}{$\operatorname{Sr}(\%)$} & \multicolumn{2}{|c|}{ Saturação $(\mathrm{kPa})$} & \multirow[b]{2}{*}{$\mathrm{B}$} & \multirow[b]{2}{*}{$\mathrm{k}(\mathrm{cm} / \mathrm{s})$} \\
\hline & & & & & & $\sigma_{3 \mathrm{c}}$ & C.P. & & \\
\hline $\mathrm{k} 03-01$ & 23,3 & 1,470 & 95,3 & 0,803 & 76,9 & 450 & 410 & 0,98 & $5,5 \mathrm{E}-06$ \\
\hline k03-02 & 23,3 & 1,514 & 98,1 & 0,750 & 82,3 & 450 & 410 & 0,98 & $2,3 \mathrm{E}-06$ \\
\hline k03-03 & 23,3 & 1,552 & 100,6 & 0,707 & 87,3 & 450 & 410 & 0,99 & $2,1 \mathrm{E}-07$ \\
\hline k03-04 & 23,3 & 1,577 & 102,2 & 0,680 & 90,7 & 500 & 460 & 0,98 & $1,0 \mathrm{E}-07$ \\
\hline $\mathrm{k} 03-05$ & 23,3 & 1,638 & 106,2 & 0,618 & 99,9 & 500 & 460 & 0,98 & $7,9 \mathrm{E}-08$ \\
\hline k03-06 & 24,1 & 1,468 & 95,1 & 0,805 & 79,4 & 400 & 360 & 0,99 & $4,8 \mathrm{E}-06$ \\
\hline $\mathrm{k} 03-07$ & 24,1 & 1,516 & 98,3 & 0,748 & 85,4 & 400 & 360 & 0,98 & $1,6 \mathrm{E}-06$ \\
\hline $\mathrm{k} 03-08$ & 24,1 & 1,542 & 99,9 & 0,719 & 88,9 & 450 & 410 & 0,98 & $1,4 \mathrm{E}-07$ \\
\hline k03-09 & 24,1 & 1,574 & 102,0 & 0,684 & 93,6 & 450 & 410 & 0,98 & $8,5 \mathrm{E}-08$ \\
\hline $\mathrm{k} 03-10$ & 24,1 & 1,601 & 103,8 & 0,655 & 97,6 & 500 & 460 & 0,98 & $5,3 \mathrm{E}-08$ \\
\hline k03-11 & 25,4 & 1,513 & 98,1 & 0,751 & 89,7 & 500 & 460 & 0,98 & $5,2 \mathrm{E}-07$ \\
\hline $\mathrm{k} 03-12$ & 25,4 & 1,546 & 100,2 & 0,714 & 94,4 & 400 & 360 & 0,98 & $2,2 \mathrm{E}-07$ \\
\hline k03-13 & 25,4 & 1,575 & 102,1 & 0,683 & 98,8 & 400 & 360 & 0,98 & $8,9 \mathrm{E}-08$ \\
\hline k03-14 & 21,5 & 1,515 & 98,2 & 0,749 & 76,1 & 550 & 510 & 0,98 & $6,5 \mathrm{E}-06$ \\
\hline $\mathrm{k} 03-15$ & 21,5 & 1,551 & 100,5 & 0,709 & 80,4 & 550 & 510 & 0,98 & $5,1 \mathrm{E}-06$ \\
\hline
\end{tabular}

A Figura 4.22 mostra o comportamento da condutividade hidráulica em função do tempo para corpos de prova moldados com teor de umidade igual a $23,3 \%$ e diferentes graus de compactação, e também para corpos de prova moldados com grau de compactação igual a $100 \%$ e diferentes teores de umidade de moldagem. 


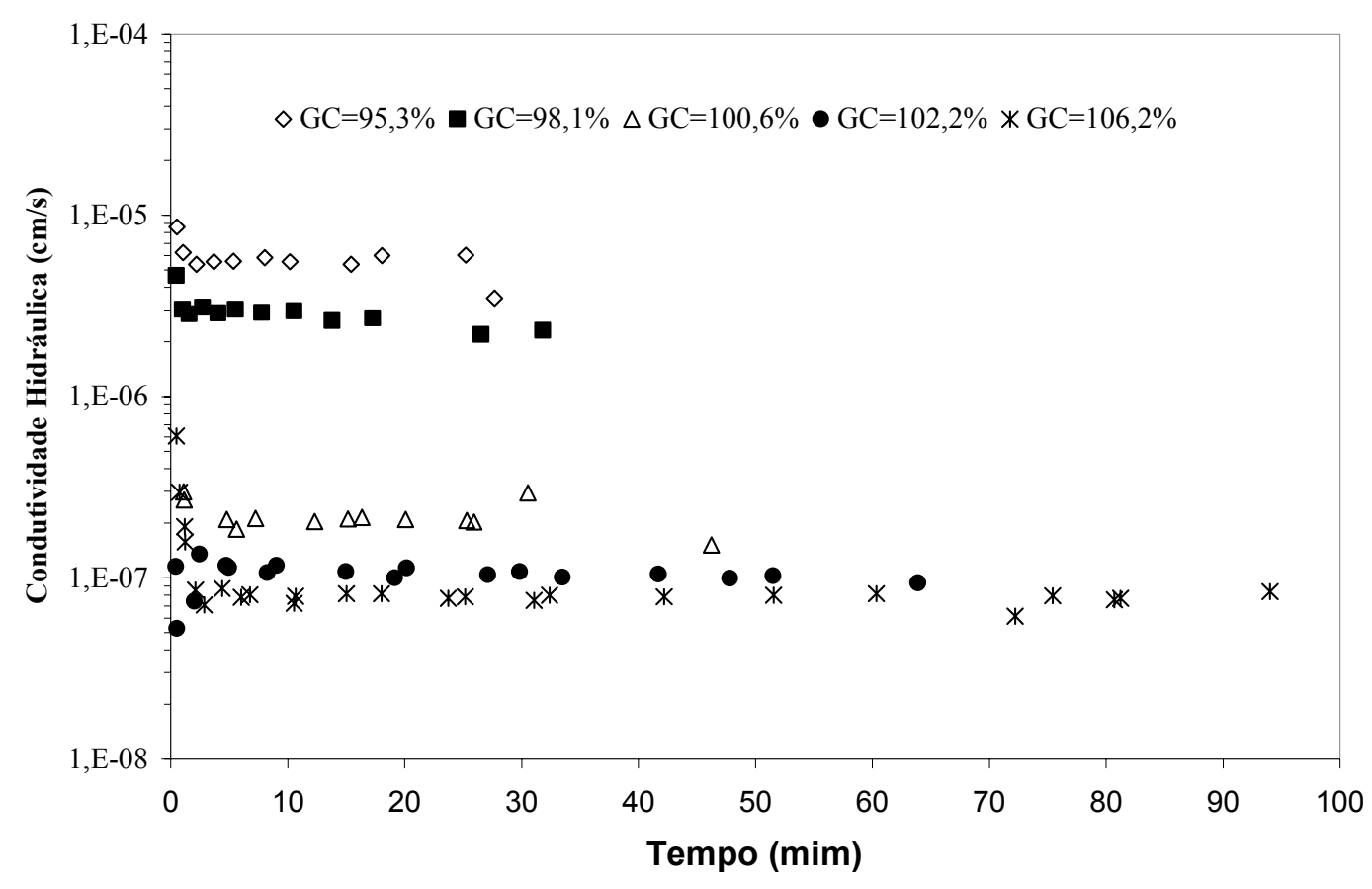

Figura 4.22a - Condutividade hidráulica vs Tempo, amostra k03, CPs moldados com $23,3 \%$ de umidade e diferentes graus de compactação.

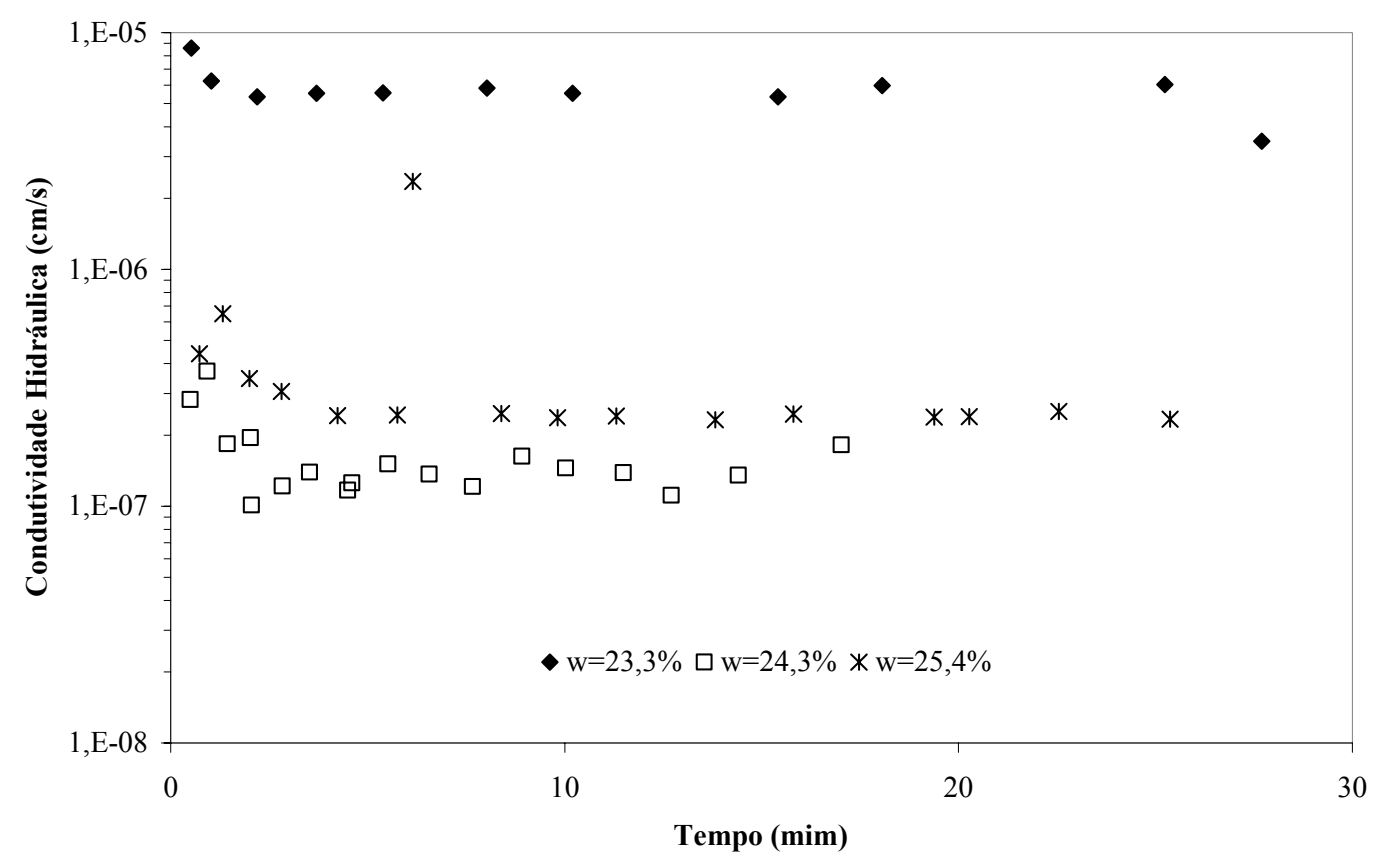

Figura 4.22b - Condutividade hidráulica vs Tempo, amostra k03, CPs moldados com GC $=\mathbf{1 0 0} \%$ e diferentes teores de umidade.

Assim como para as amostras anteriores, o valor da condutividade hidráulica foi determinado a partir de uma reta média dos pontos obtidos no ensaio. O fluxo através dos corpos-de-prova se tornou constante, para maioria dos corpos-de-prova ensaiados, a partir dos 
primeiros 5 minutos de ensaio e o tempo médio para a saturação dos corpos-de-prova foi de 24 horas.

O comportamento da condutividade hidráulica frente à variação de teor de umidade de moldagem para diferentes graus de compactação é mostrado na Figura 4.23.

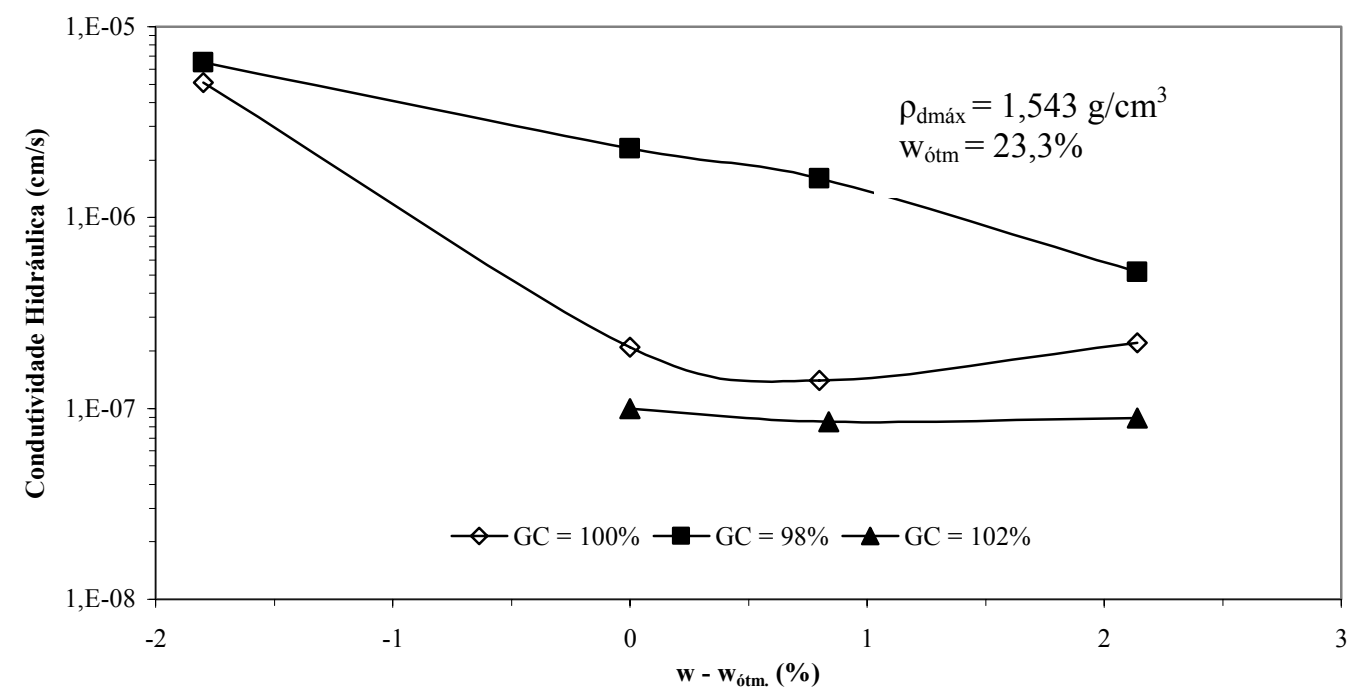

Figura 4.23 - Efeito do desvio de umidade de moldagem na condutividade hidráulica para a amostra k03.

A condutividade hidráulica alcança o mínimo valor quando a compactação é realizada com teor de umidade igual à $\mathrm{w}_{\text {ótm. }}+0,8 \%$, e apresenta uma leve tendência de aumento para teores de umidade de moldagem superiores a este. A redução da condutividade hidráulica não é significativa para teores de umidade de moldagem acima do ótimo. Esse comportamento da condutividade hidráulica no ramo úmido da curva de compactação é similar às outras amostras estudadas. Também para esta amostra, a redução da condutividade hidráulica é mais significativa quando se passa do ramo seco para o ramo úmido.

O comportamento da condutividade hidráulica frente à variação do grau de compactação para diferentes teores de umidade de moldagem é mostrado na Figura 4.24. 


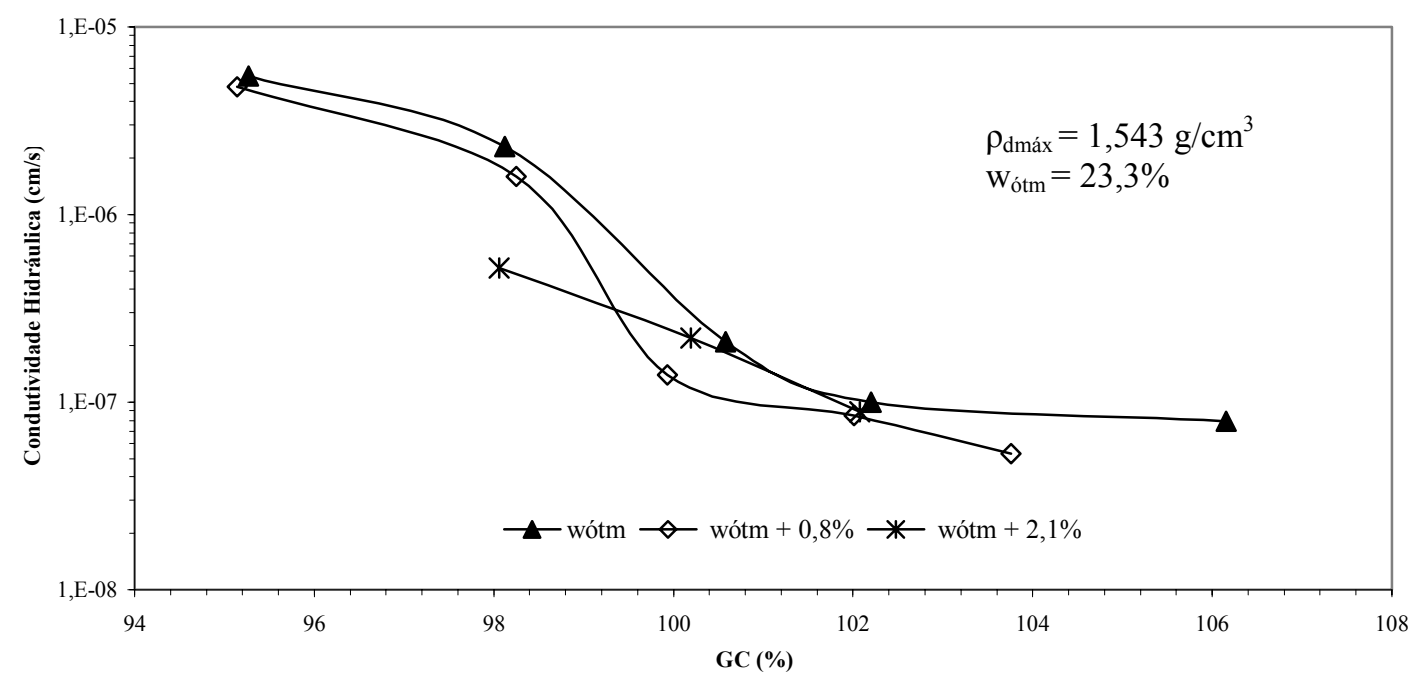

Figura 4.24 - Efeito do grau de compactação na condutividade hidráulica para a mostra k03.

O comportamento da condutividade hidráulica frente às variações de grau de compactação é semelhante aos apresentados pelos outros solos estudados. Neste caso, graus de compactação superiores a 100\% não causam significativa redução na condutividade hidráulica.

A Figura 4.25 mostra a curva de compactação para o ensaio de Proctor Normal, as condições de compactação dos corpos-de-prova, os valores de condutividade hidráulica, as condições ideais de compactação ( $\mathrm{GC} \geq 102 \%$ e w $\geq 23,3 \%$ ) e a zona admissível, baseados em parâmetros de condutividade hidráulica.

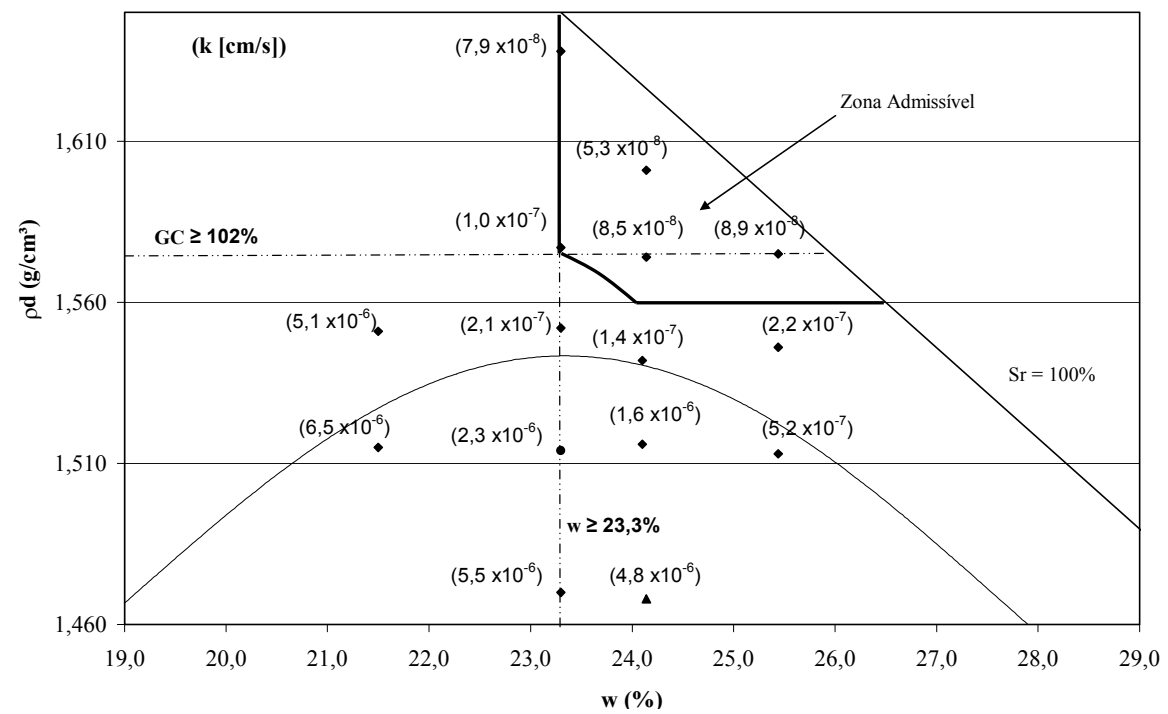

Figura 4.25 - Limitantes inferiores de condições ideais de compactação e zona admissível, baseados em parâmetros de condutividade hidráulica, para a amostra k03. 


\subsubsection{Influência do teor de umidade volumétrico}

Pode-se observar na Figura 4.26 o comportamento da condutividade hidráulica frente a variação do teor de umidade volumétrico.

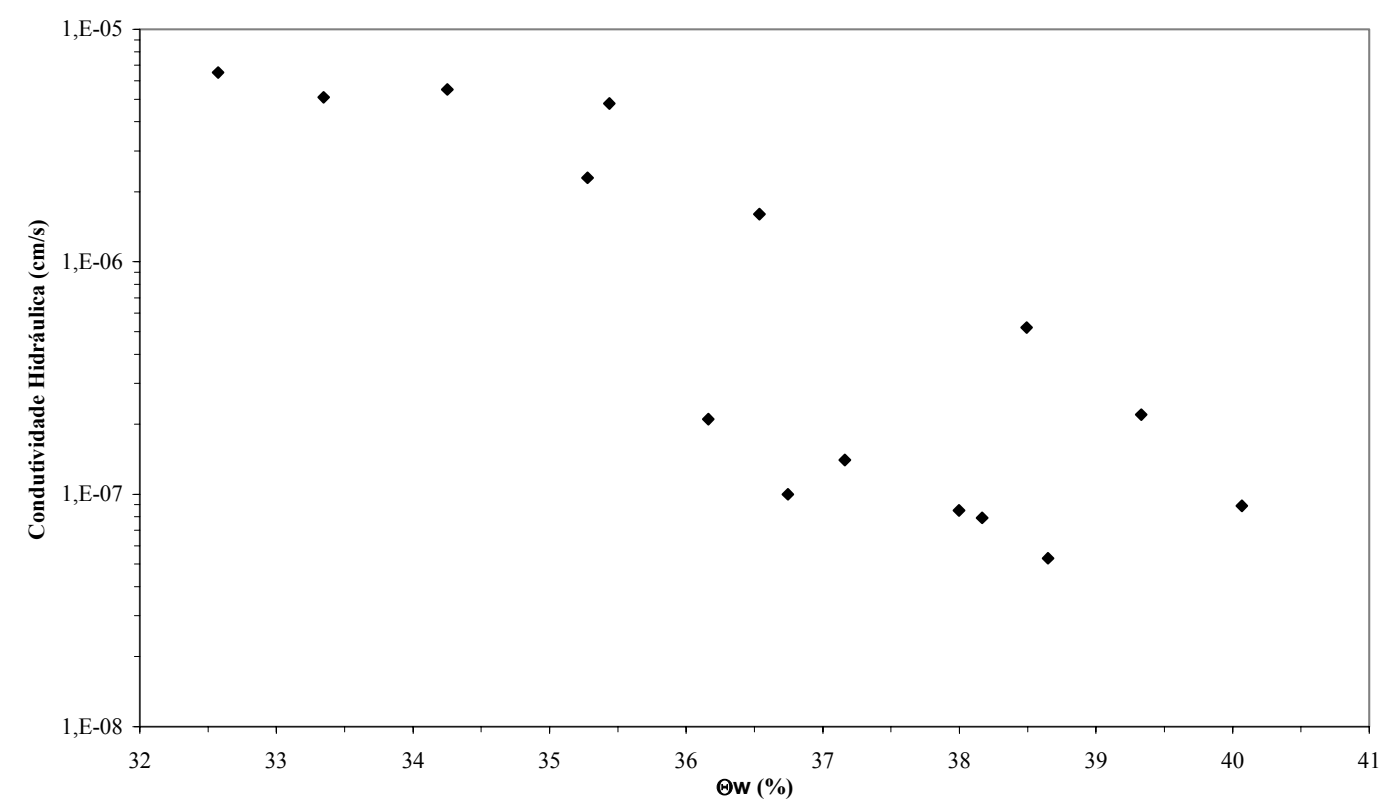

Figura 4.26 - Condutividade hidráulica em função do teor de umidade volumétrico, amostra k03.

A amostra em questão apresenta uma clara tendência de diminuição da condutividade hidráulica com o aumento do teor de umidade volumétrico.

\subsubsection{Contração}

Para a observação da contração na secagem foram selecionados os corpos de prova $\mathrm{k} 03-04\left(\mathrm{w}_{\text {mold. }}=23,3 \%, \mathrm{GC}=102,2 \%\right), \mathrm{k} 03-08\left(\mathrm{w}_{\text {mold. }}=24,1 \%, \mathrm{GC}=99,9 \%\right)$ e $\mathrm{k} 03-09\left(\mathrm{w}_{\text {mold }}\right.$. $=24,1 \%, \mathrm{GC}=102,0 \%)$. O ensaio foi realizado como descrito no item 3.3 .

A Figura 4.27 mostra a contração axial e volumétrica em função do tempo para estes corpos-de-prova. 


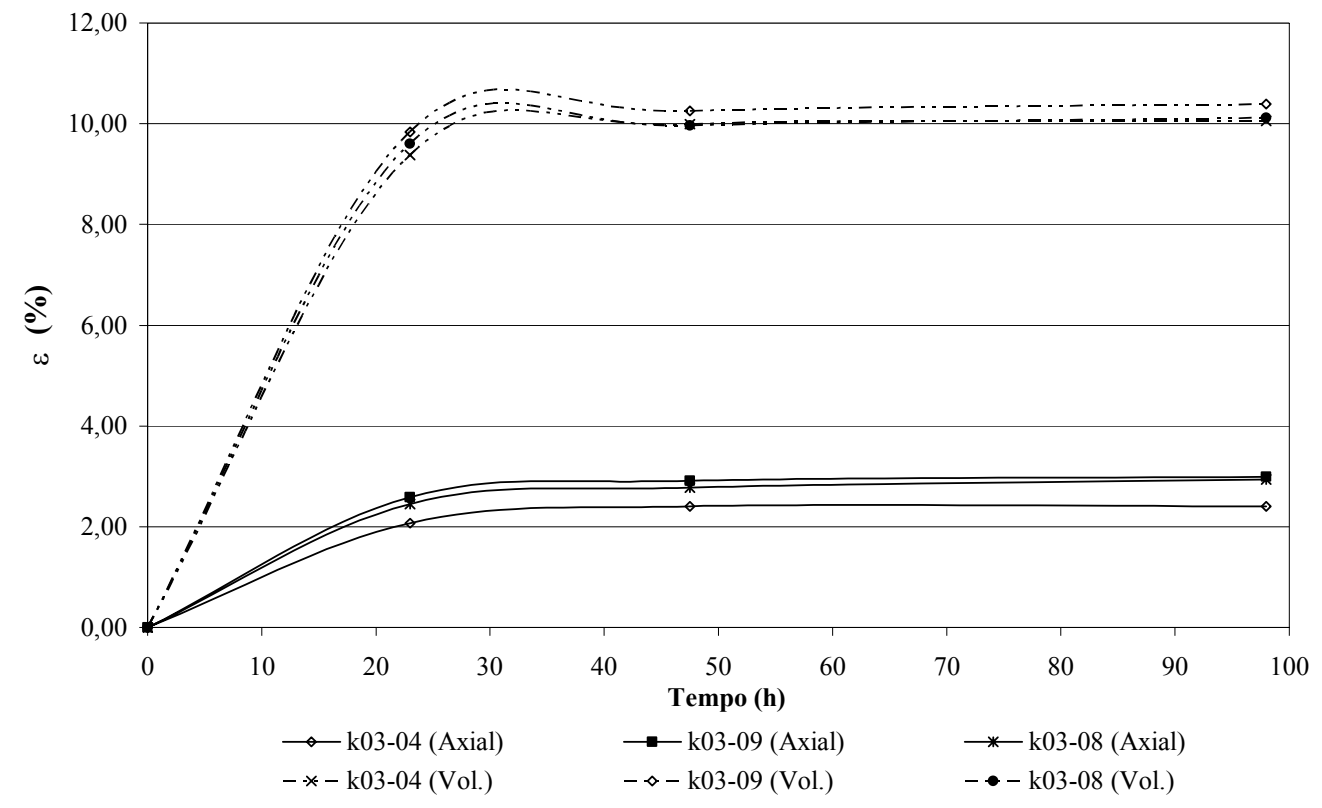

Figura 4.27 - Contração axial e volumétrica em função do tempo para a mostra k03.

A temperatura ambiente e umidade relativa do ar registrada durante a realização do ensaio variaram, respectivamente, entre 26 a $28^{\circ} \mathrm{C}$ e 35 a $38 \%$.

Os valores da contração axial e volumétrica foram relativamente altos se comparados aos das amostras anteriores. Os corpos-de-prova foram submetidos à ciclos de umedecimento e secagem para observar o aparecimento de trincas. $O$ processo de umedecimento foi realizado por circulação de água destilada dentro da câmara confinante do permeâmetro de parede flexível, a fim de minimizar o efeito do desconfinamento lateral. A Figura 4.28 mostra a condição final do corpo de prova k03-08.

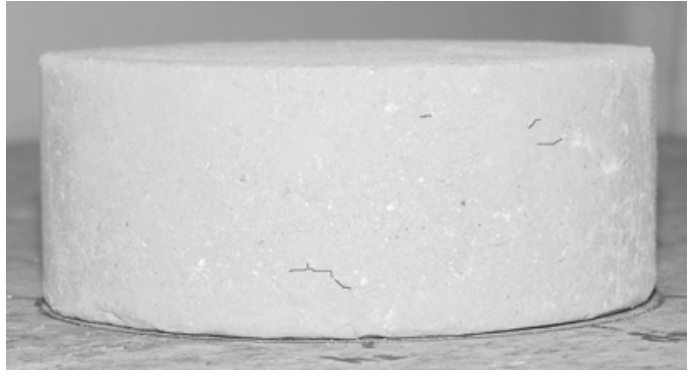

(a)

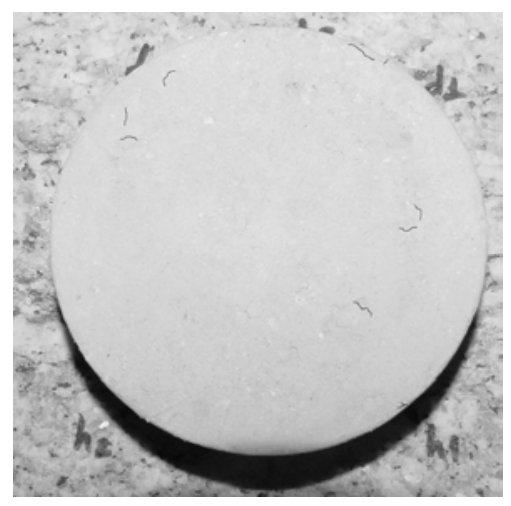

(b)

Figura 4.28 - Condição do Cp k03-08 após 3 ciclos de umedecimento e secagem, (a) vista lateral, (b) vista superior. 
Foi utilizado um programa computacional de edição de imagem para realçar as trincas presentes no corpo de prova da Figura 4.28.

Pode-se observar que após os ciclos, os corpos-de-prova apresentaram uma significativa redução no aparecimento de trincas se comparados ao comportamento da amostra $\mathrm{k} 01$. O confinamento lateral durante o processo de umedecimento se mostrou importante na redução de trincas.

Após o último ciclo, os corpos-de-prova foram submetidos a ensaios de condutividade hidráulica e os resultados são mostrados na Tabela 4.11.

Tabela 4.11 - Acréscimo da condutividade hidráulica devido a ciclos de umedecimento e secagem, amostra k03.

\begin{tabular}{ccc}
\hline $\mathbf{C p s}$ & $\mathbf{k}_{\text {iníc. }}(\mathbf{c m} / \mathbf{s})$ & $\mathbf{k}_{\text {final. }}(\mathbf{c m} / \mathbf{s})$ \\
\hline $\mathrm{k} 03-04$ & $1,0.10^{-7}$ & $4,2 \cdot 10^{-6}$ \\
\hline $\mathrm{k} 03-08$ & $1,4 \cdot 10^{-7}$ & $4,9.10^{-6}$ \\
\hline $\mathrm{k} 03-09$ & $8,5 \cdot 10^{-8}$ & $2,3 \cdot 10^{-7}$ \\
\hline
\end{tabular}

Os corpos-de-prova submetidos a ciclos de umedecimento e secagem não atenderam ao valor mínimo de condutividade hidráulica sugerido para barreiras impermeáveis. Cabe destacar que o processo de secagem ocorreu sem confinamento lateral.

\subsubsection{Ensaios com permeâmetro de parede rígida}

As condições de compactação estudadas e os resultados de condutividade hidráulica obtidas em ensaios com permeâmetro de parede rígida para a amostra Araras - k03 estão apresentadas na Tabela 4.12 .

Tabela 4.12 - Resultados e condições de ensaio em parede rígida para a amostra Araras $-\mathbf{k 0 3}$.

\begin{tabular}{ccccccc}
\hline Amostra & $\begin{array}{c}\mathbf{W}_{\text {mold }} \\
(\mathbf{\%})\end{array}$ & $\boldsymbol{\rho d}\left(\mathbf{g} / \mathbf{c m}^{\mathbf{3}}\right)$ & $\begin{array}{c}\mathbf{G C} \\
\mathbf{( \% )}\end{array}$ & $\mathbf{e}$ & $\begin{array}{c}\mathbf{S r} \\
\mathbf{( \% )}\end{array}$ & $\mathbf{k}(\mathbf{c m} / \mathbf{s})$ \\
\hline $\mathrm{k} 03-02 \mathrm{r}$ & 23,4 & 1,520 & 98,2 & 0,748 & 82,9 & $1,40 \mathrm{E}-07$ \\
\hline $\mathrm{k} 03-03 \mathrm{r}$ & 23,4 & 1,550 & 100,6 & 0,707 & 87,8 & $1,10 \mathrm{E}-07$ \\
\hline $\mathrm{k} 03-04 \mathrm{r}$ & 23,4 & 1,570 & 101,9 & 0,686 & 90,4 & $9,50 \mathrm{E}-08$ \\
\hline
\end{tabular}


O comportamento da condutividade hidráulica em função do tempo para os corpos-deprova apresentados na Tabela 4.12 é mostrado na Figura 4.29.

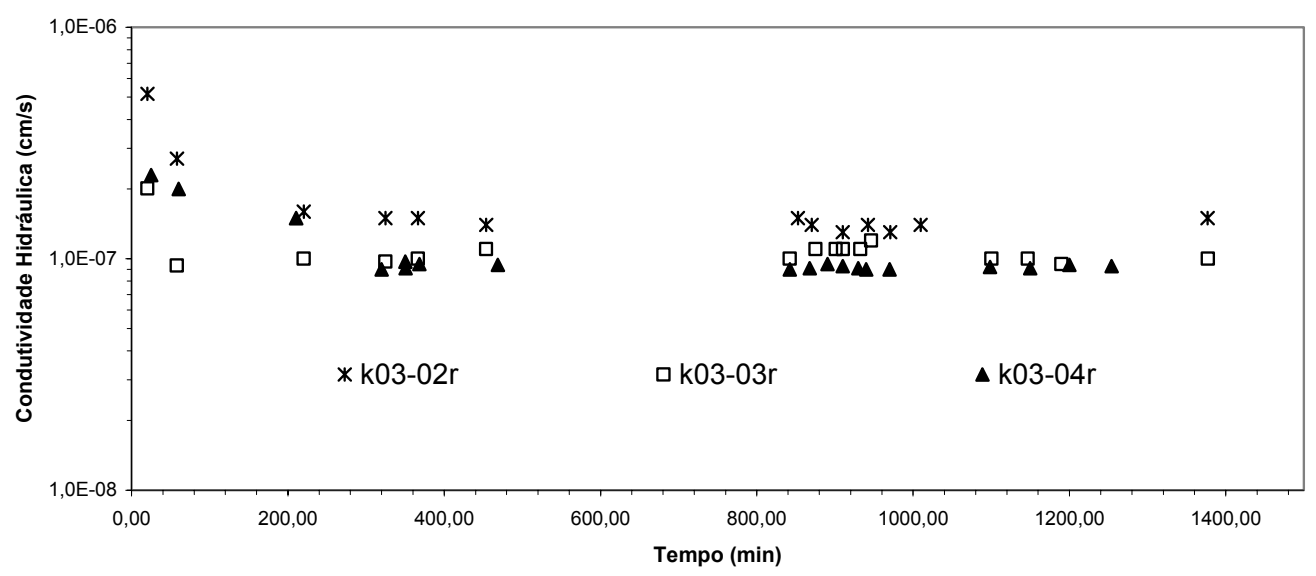

Figura 4.29 - Condutividade hidráulica vs Tempo, ensaios em permeâmetro de parede rígida. Amostra k03, cps moldados com $23,4 \%$ de umidade e com diferentes graus de compactação.

O tempo médio de saturação dos corpos-de-prova ensaiados em permeâmetro de parede rígida foi de 96 horas.

A comparação dos resultados de condutividade hidráulica obtidos em permeâmetros de parede rígida (r) e flexível (f) é apresentada na Tabela 4.13.

Tabela 4.13 - Comparação dos resultados de condutividade hidráulica obtidos em ensaios com permeâmetros de parede rígida (r) e flexível (f) para a amostra k03.

\begin{tabular}{cccccc}
\hline \multirow{2}{*}{ Amostra } & \multirow{2}{*}{$\mathbf{w}_{\text {mold }}(\mathbf{\%})$} & $\mathbf{e}$ & $\mathbf{S r}(\mathbf{\%})$ & $\mathbf{k}(\mathbf{c m} / \mathbf{s})$ \\
\hline \multirow{2}{*}{$\mathrm{k} 03-02$} & $\mathrm{r}$ & 23,4 & 0,748 & 82,9 & $1,40 \mathrm{E}-07$ \\
\cline { 2 - 6 } & $\mathrm{f}$ & 23,3 & 0,750 & 82,3 & $2,30 \mathrm{E}-06$ \\
\hline \multirow{2}{*}{$\mathrm{k} 03-03$} & $\mathrm{r}$ & 23,4 & 0,707 & 87,8 & $1,10 \mathrm{E}-07$ \\
\cline { 2 - 6 } & $\mathrm{f}$ & 23,3 & 0,707 & 87,3 & $2,10 \mathrm{E}-07$ \\
\hline \multirow{2}{*}{$\mathrm{k} 03-04$} & $\mathrm{r}$ & 23,4 & 0,686 & 90,4 & $9,50 \mathrm{E}-08$ \\
\cline { 2 - 6 } & $\mathrm{f}$ & 23,3 & 0,680 & 90,7 & $1,00 \mathrm{E}-07$ \\
\hline
\end{tabular}

Como esperado, os valores de condutividade hidráulica em permeâmetro de parede rígida de mantiveram menores se comparados com o outro método de ensaio testado. A diferença dos de $\mathrm{k}$, obtida pelos dois métodos, também foi reduzida quando se reduziu o índice de vazios dos corpos-de-prova ensaiados. Essa comparação pode ser melhor observada na Figura 4.30. 


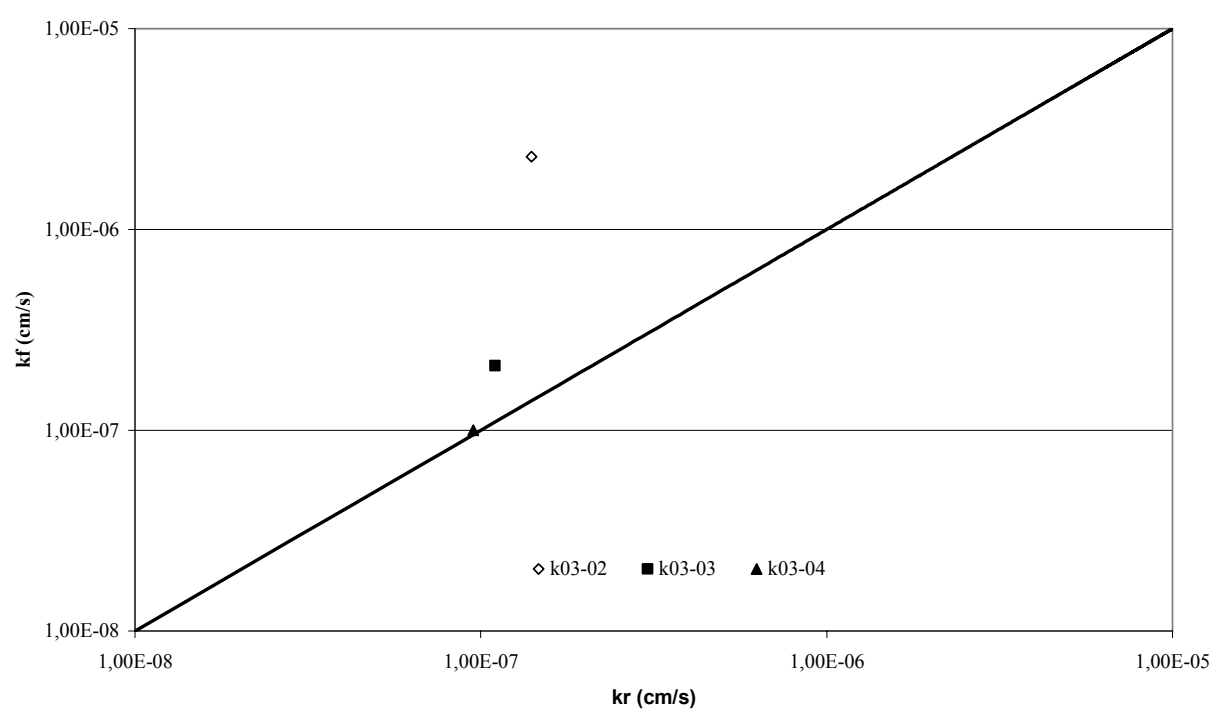

Figura 4.30 - Comparação da condutividade hidráulica em ensaios com permeâmetros de parede flexível e rígida para a amostra k03.

\subsection{DUTRA - K04}

Trata-se de uma argila siltosa contendo $96 \%$ das partículas menores que $0,075 \mathrm{~mm}$. O solo foi classificado como $\mathrm{MH}$, isto é, silte plástico pela classificação unificada e como NG', argiloso não laterítico pela classificação MCT.

O solo em questão apresentou uma peculiaridade durante o processo de preparação de amostra deformada. Quando umedecido, observou-se uma tendência á formação de pequenas porções de solo aglomerado. A Figura 4.31a,b mostra o detalhe do solo destorroado seco e úmido, onde pode-se observar a característica mencionada. Esses aglomerados foram observados mesmo após a moldagem de corpos-de-prova com baixo grau de compactação, como é mostrado na Figura 4.31c. Para corpo-de-prova com graus de compactação superiores a $98 \%$ esta característica foi menos evidente.

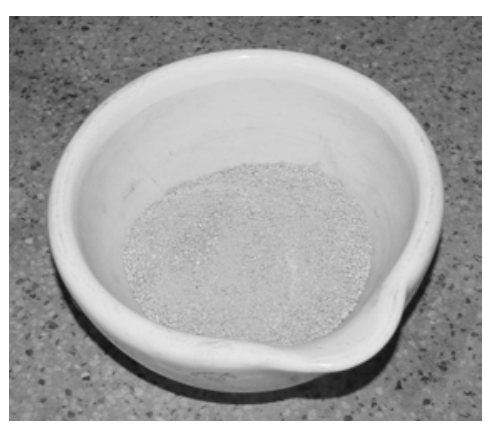

(a)

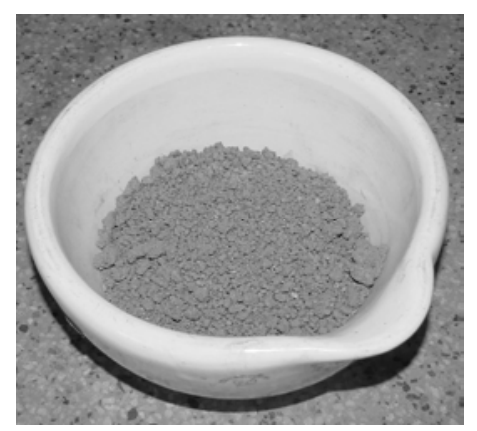

(b)

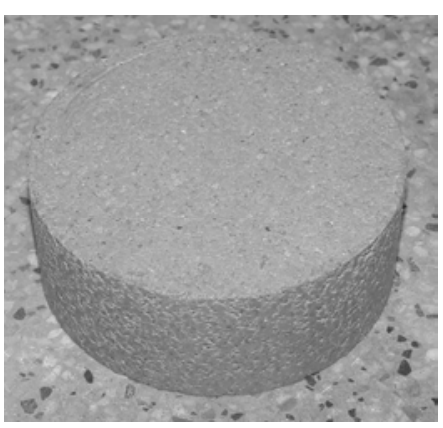

(c)

Figura 4.31 - Amostra k04, (a) solo seco, (b) solo úmido e (c) corpo-de-prova com baixo grau de compactação. 


\subsubsection{Condutividade hidráulica}

A Tabela 4.14 mostra as condições de compactação e de ensaio em permeâmetro de parede flexível para cada corpo-de-prova analisado.

Tabela 4.14 - Resultados e condições de ensaio em parede flexível para a amostra Dutra $-\mathbf{k 0 4}$.

\begin{tabular}{|c|c|c|c|c|c|c|c|c|c|}
\hline \multirow{2}{*}{$\underset{\mathrm{Cps}}{\text { Amostra }}$} & \multirow{2}{*}{$\begin{array}{c}W_{\text {mold }} \\
(\%)\end{array}$} & \multirow{2}{*}{$\begin{array}{c}\rho d \\
\left(\mathrm{~g} / \mathrm{cm}^{3}\right)\end{array}$} & \multirow{2}{*}{$\begin{array}{l}\text { GC } \\
(\%)\end{array}$} & \multirow[b]{2}{*}{$\mathbf{e}$} & \multirow[b]{2}{*}{$\operatorname{Sr}(\%)$} & \multicolumn{2}{|c|}{ Saturação (kPa) } & \multirow[b]{2}{*}{ B } & \multirow[b]{2}{*}{$\mathrm{k}(\mathrm{cm} / \mathrm{s})$} \\
\hline & & & & & & $\sigma 3 c$ & C.P. & & \\
\hline k04-01 & 21,8 & 1,548 & 95,0 & 0,78 & 77,2 & 600 & 540 & 0,97 & $8,20 \mathrm{E}-08$ \\
\hline $\mathrm{k} 04-02$ & 21,8 & 1,597 & 98,0 & 0,72 & 83,0 & 600 & 540 & 0,96 & $2,00 \mathrm{E}-09$ \\
\hline $\mathrm{k} 04-03$ & 21,8 & 1,630 & 100,0 & 0,69 & 87,2 & 650 & 610 & 0,96 & 1,30E-09 \\
\hline k04-04 & 21,8 & 1,662 & 102,0 & 0,65 & 91,6 & 700 & 640 & 0,96 & $1,10 \mathrm{E}-09$ \\
\hline $\mathrm{k} 04-05$ & 21,8 & 1,679 & 103,0 & 0,64 & 94,0 & 700 & 640 & 0,98 & $1,10 \mathrm{E}-09$ \\
\hline k04-06 & 22,5 & 1,545 & 94,8 & 0,78 & 79,3 & 650 & 610 & 0,96 & $8,80 \mathrm{E}-08$ \\
\hline k04-07 & 22,5 & 1,594 & 97,8 & 0,73 & 85,3 & 650 & 610 & 0,97 & $6,00 \mathrm{E}-09$ \\
\hline k04-08 & 22,5 & 1,626 & 99,8 & 0,69 & 89,5 & 650 & 610 & 0,96 & $2,10 \mathrm{E}-09$ \\
\hline k04-09 & 22,5 & 1,663 & 102,0 & 0,65 & 94,7 & 700 & 640 & 0,98 & $1,00 \mathrm{E}-09$ \\
\hline k04-10 & 23,5 & 1,548 & 95,0 & 0,78 & 83,2 & 600 & 540 & 0,98 & $9,00 \mathrm{E}-08$ \\
\hline k04-11 & 23,5 & 1,597 & 98,0 & 0,72 & 89,5 & 650 & 610 & 0,98 & $5,00 \mathrm{E}-09$ \\
\hline k04-12 & 23,5 & 1,63 & 100,0 & 0,69 & 94,1 & 650 & 610 & 0,97 & $3,00 \mathrm{E}-09$ \\
\hline k04-13 & 23,5 & 1,662 & 102,0 & 0,65 & 98,7 & 650 & 610 & 0,97 & $2,30 \mathrm{E}-09$ \\
\hline k04-14 & 20,0 & 1,597 & 98,0 & 0,72 & 76,2 & 650 & 610 & 0,98 & 9,30E-09 \\
\hline $\mathrm{k} 04-15$ & 20,0 & 1,63 & 100,0 & 0,69 & 80,0 & 650 & 610 & 0,97 & $7,80 \mathrm{E}-09$ \\
\hline k04-16 & 21,0 & 1,597 & 98,0 & 0,72 & 80,0 & 650 & 610 & 0,96 & $2,50 \mathrm{E}-09$ \\
\hline k04-17 & 21,0 & 1,63 & 100,0 & 0,69 & 84,0 & 650 & 610 & 0,96 & $2,10 \mathrm{E}-09$ \\
\hline
\end{tabular}

A Figura 4.32 mostra o comportamento da condutividade hidráulica em função do tempo para corpos de prova moldados com teor de umidade igual a $21,8 \%$ e graus de compactação variando entre $95 \%$ e $102 \%$, e também para corpos de prova moldados com grau de compactação igual a $100 \%$ e teores de umidade de moldagem variando entre $20,0 \%$ e $23,5 \%$. O comportamento da condutividade em função do tempo foi semelhante para todos os corpos-de-prova ensaiados. 


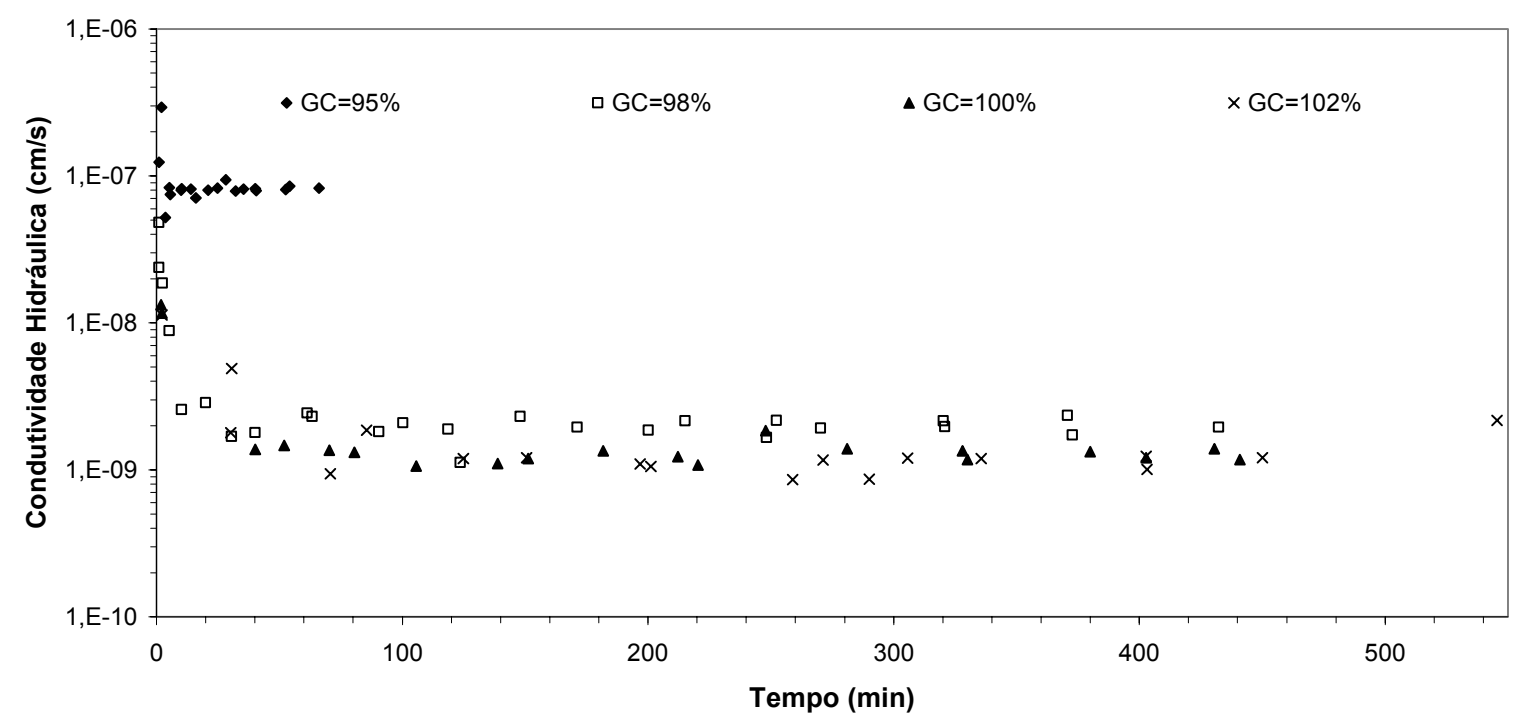

Figura 4.32a - Condutividade hidráulica vs Tempo, amostra k04, CPs moldados com $\mathbf{2 1 , 8 \%}$ de umidade e diferentes graus de compactação.

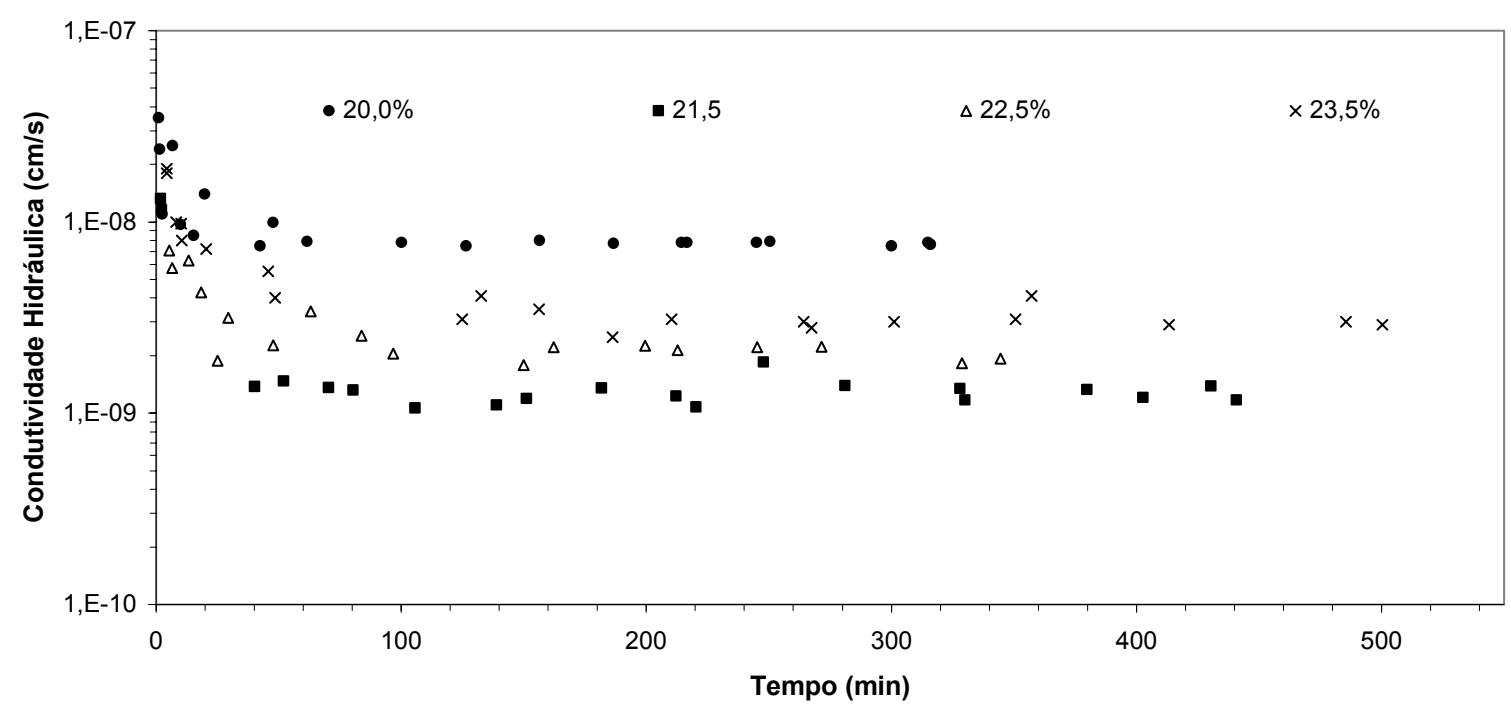

Figura 4.32b - Condutividade hidráulica vs Tempo, amostra k04, CPs moldados com GC $=100 \%$ e diferentes teores de umidade.

Admitindo-se uma reta média dos pontos obtidos, descartando os pontos no início do ensaio que apresentaram certa dispersão devido ao pequeno volume percolado.

Foi necessário 48 horas, em média, para a saturação de cada corpo-de-prova ensaiado.

Pode-se observar na Figura 4.33 o efeito do teor de umidade de moldagem na condutividade hidráulica para corpos-de-prova moldados com diferentes graus de compactação. 


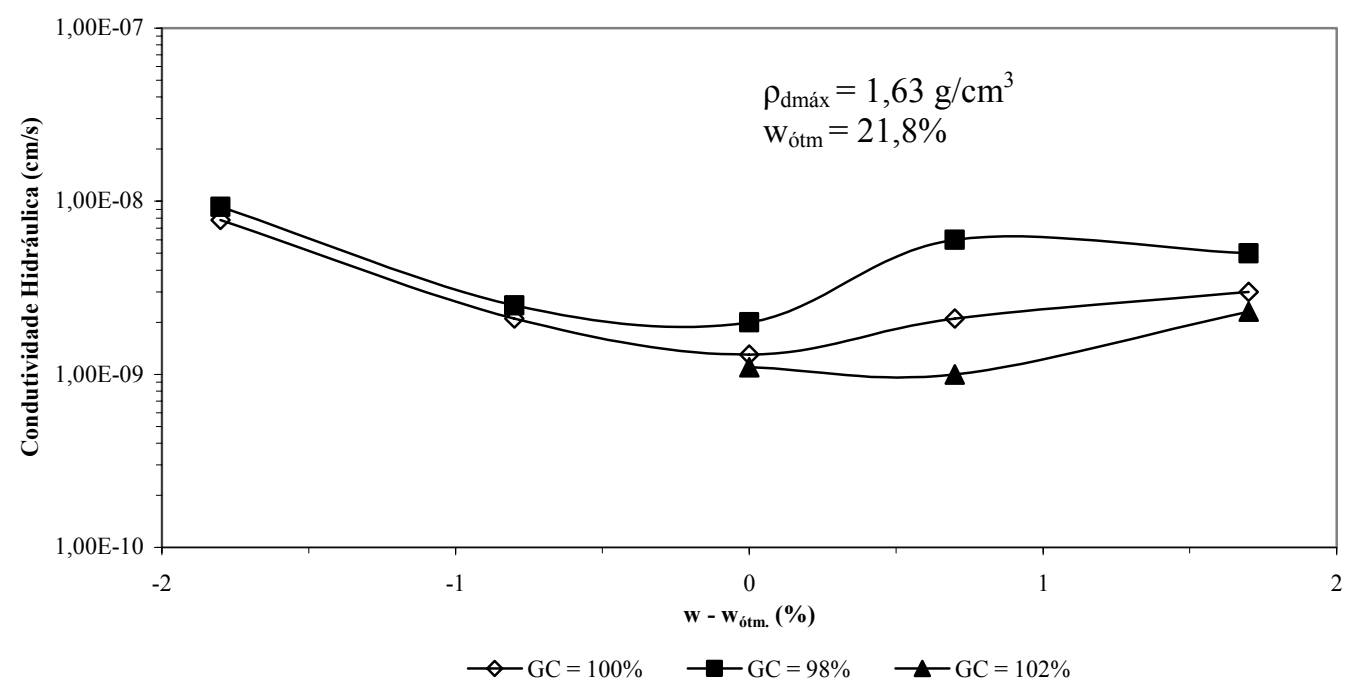

Figura 4.33 - Efeito do desvio de umidade de moldagem na condutividade hidráulica para a amostra k04.

A condutividade hidráulica atinge o valor mínimo quando a compactação é realizada com teor de umidade igual ao teor ótimo, seguindo uma tendência de aumento quando a compactação é realizada com teor de umidade de moldagem acima do teor de umidade ótimo. A redução da condutividade hidráulica quando se passa do ramo seco para o ramo úmido da curva de compactação é proporcionalmente menor se comparada com as amostras anteriores.

O comportamento da condutividade hidráulica frente à variação do grau de compactação para diferentes teores de umidade de moldagem é mostrado na Figura 4.34.

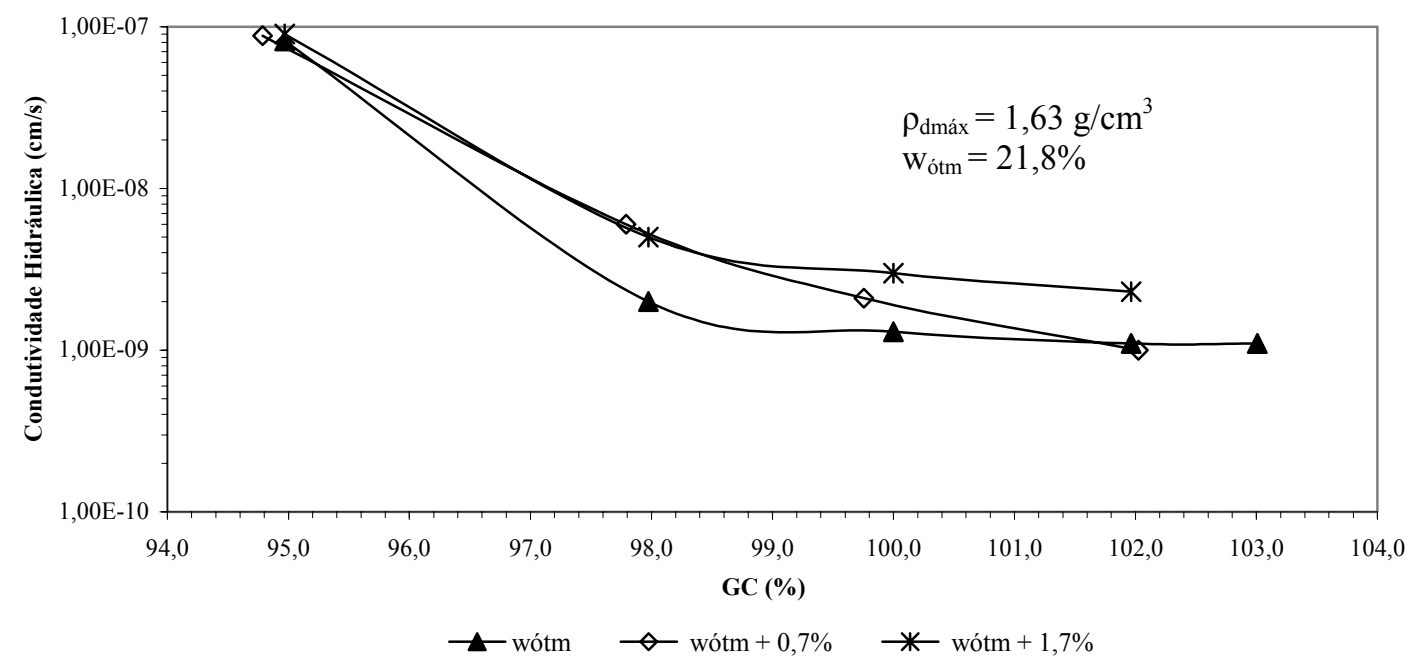

Figura 4.34 - Efeito do grau de compactação na condutividade hidráulica para a mostra k04. 
O comportamento da condutividade hidráulica frente às variações de grau de compactação segue a tendência das amostras anteriores. Graus de compactação acima de $100 \%$ não causam significativas reduções na condutividade hidráulica.

A Figura 4.35 mostra a curva de compactação para o ensaio de Proctor Normal, as condições de compactação dos corpos-de-prova, os valores de condutividade hidráulica, as condições ideais de compactação ( $\mathrm{GC} \geq 95 \%$ e w $\geq 20,0 \%$ ) e a zona admissível, baseados em parâmetros de condutividade hidráulica.

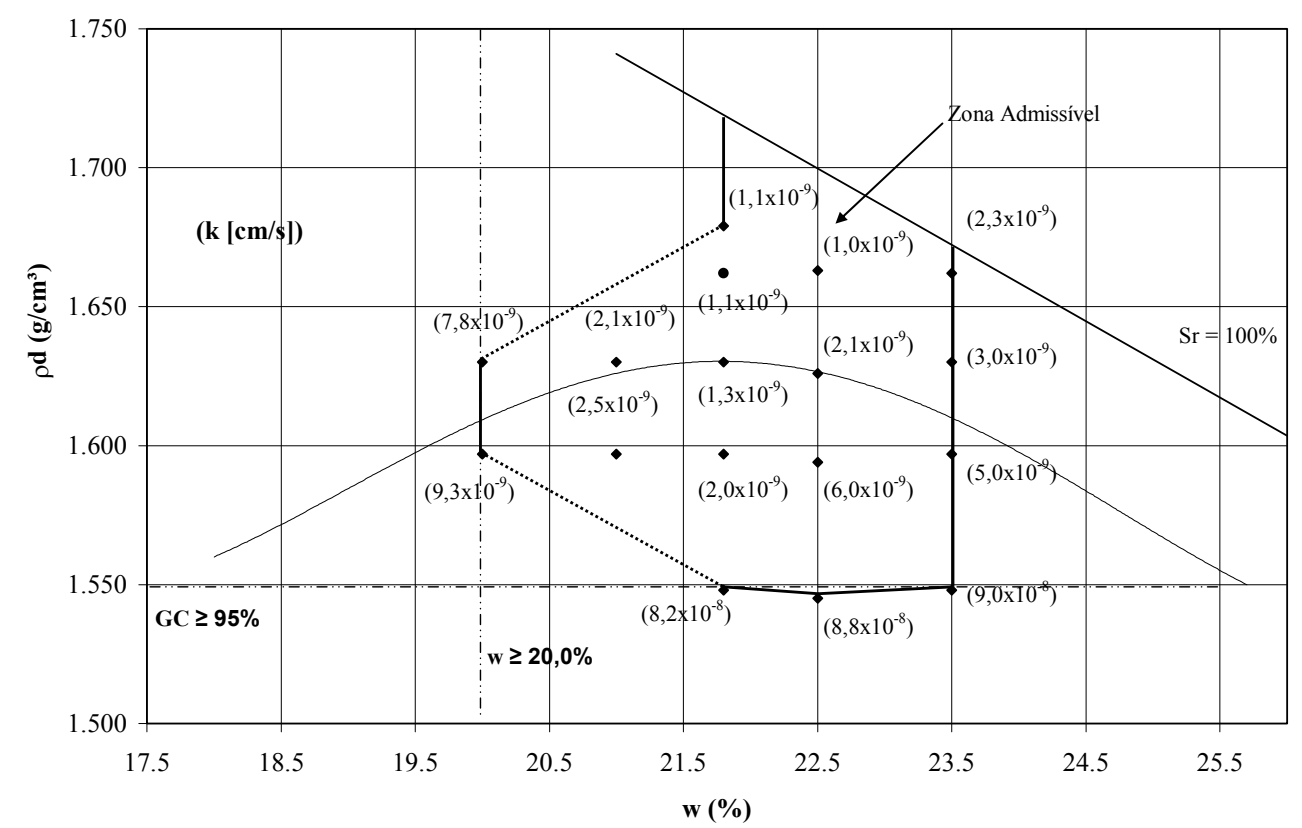

Figura 4.35 - Limitantes inferiores de condições ideais de compactação e zona admissível, baseados em parâmetros de condutividade hidráulica, para a amostra k04.

\subsubsection{Influência do teor de umidade volumétrico}

O comportamento da condutividade hidráulica frente a variação do teor de umidade volumétrico é mostrado na Figura 4.36. 


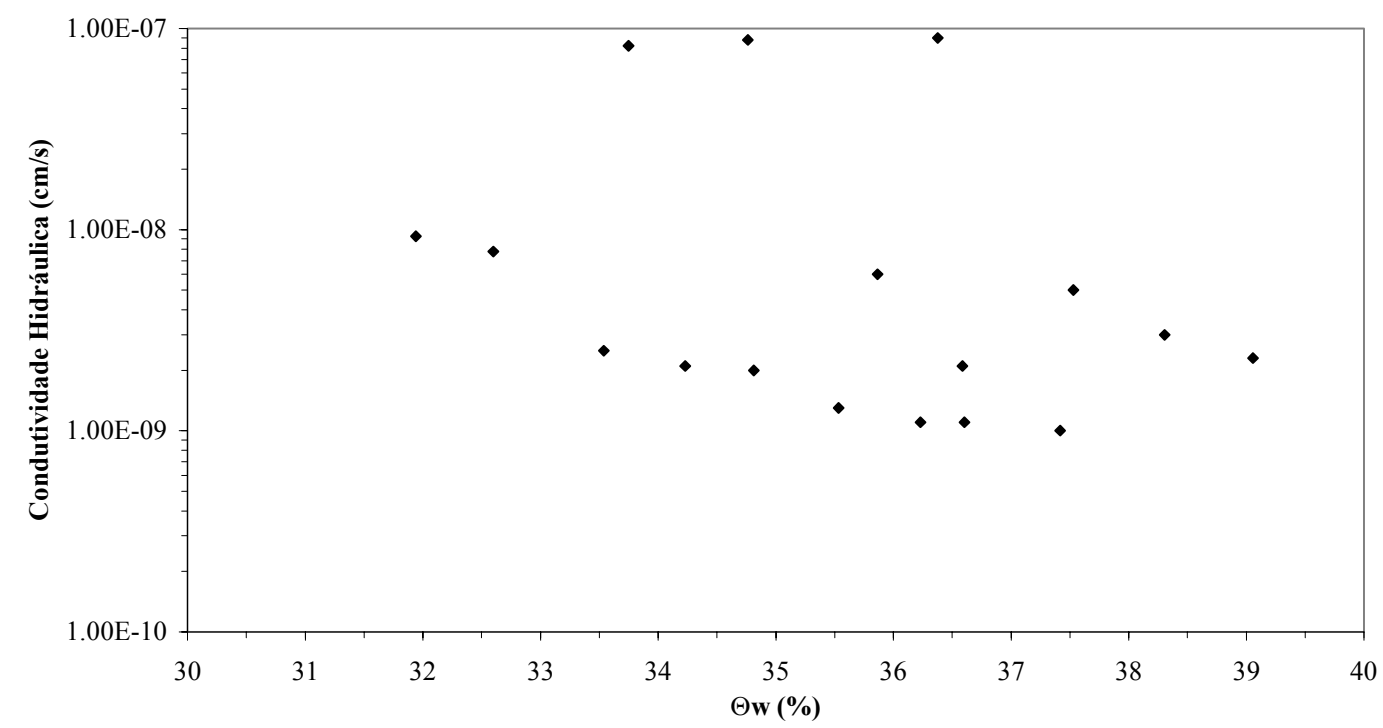

Figura 4.36 - Condutividade hidráulica em função do teor de umidade volumétrico, amostra k04.

Também para esta amostra, pode-se observar uma tendência de diminuição da condutividade hidráulica com o aumento do teor de umidade volumétrico.

\subsubsection{Contração}

Para a observação da contração na secagem foram selecionados os corpos de prova $\mathrm{k} 04-06\left(\mathrm{w}_{\text {mold. }}=22,5 \%, \mathrm{GC}=94,8 \%\right)$, k04-08 ( $\left.\mathrm{w}_{\text {mold. }}=22,5 \%, \mathrm{GC}=99,8 \%\right)$ e k04-09 ( $\mathrm{w}_{\text {mold. }}=$ $22,5 \%, \mathrm{GC}=102,0 \%)$. O ensaio foi realizado como descrito no item 3.3.

A Figura 4.37 mostra o a contração axial e volumétrica em função do tempo para estes corpos-de-prova. 


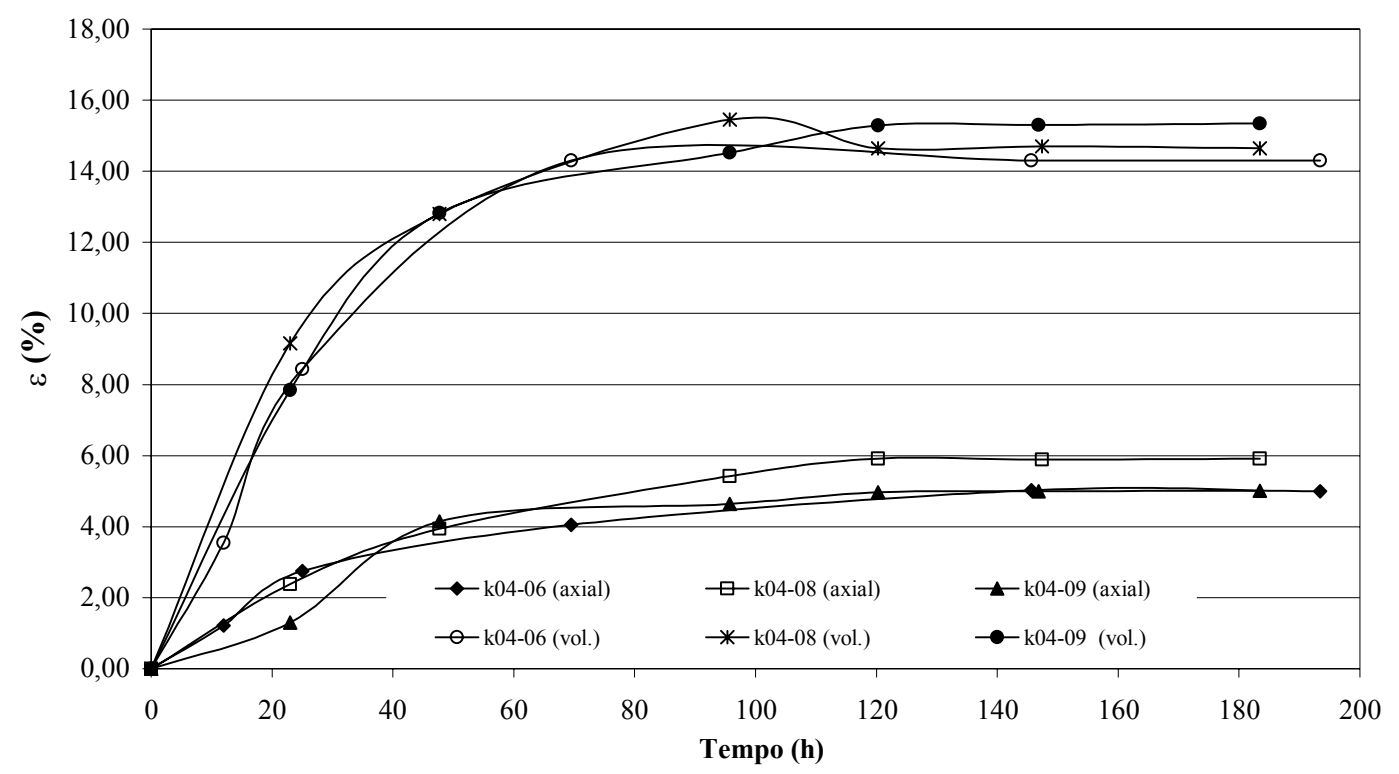

Figura 4.37 - Contração axial e volumétrica em função do tempo para a mostra k04.

A temperatura ambiente e umidade relativa do ar registradas variaram, respectivamente, entre 24 a $26^{\circ} \mathrm{C}$ e 40 a $42 \%$. O grau de compactação não exerceu influência no valor final da contração.

A amostra em questão apresentou os maiores valores de contração axial e volumétrica até aqui estudados.

Os corpos-de-prova foram submetidos a ciclos de umedecimento e secagem para observar o aparecimento de trincas. Seguiu-se o mesmo processo de umedecimento e secagem utilizado para a amostra anterior. A Figura 4.38 mostra a condição final do corpo de prova k04-09 após um ciclo.

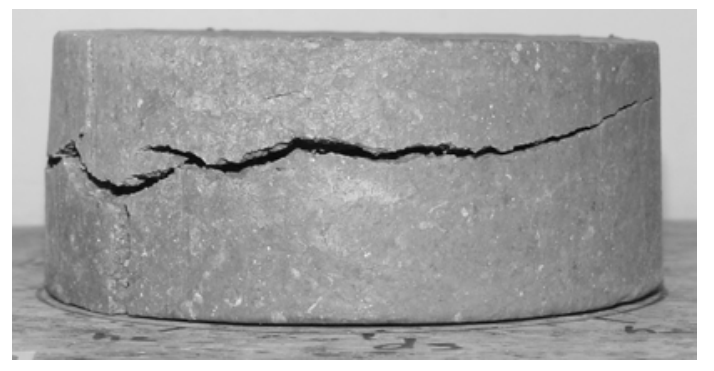

(a)

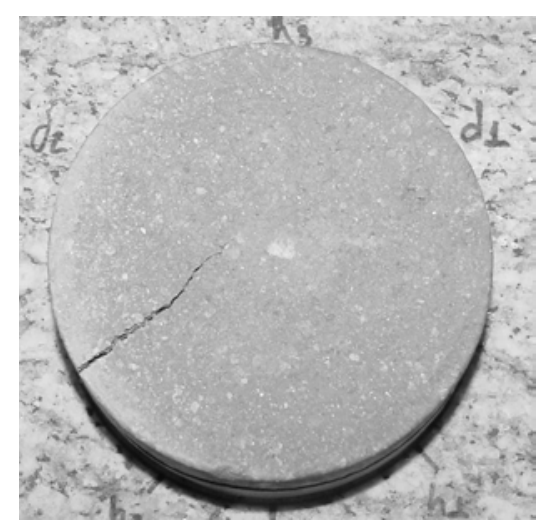

(b)

Figura 4.38 - Condição do Cp k04-09 após 1 ciclo de umedecimento e secagem, (a) vista lateral, (b) vista superior. 
O estado final de trincamento do corpo-de-prova k04-09 foi típico para os três corposde-prova analisados. A secagem foi realizada a sombra e em local com ventilação moderada. Pôde-se observar, durante o processo secagem, o aparecimento de trincas de contração de grandes dimensões, aproximadamente $0,5 \mathrm{~cm}$ de abertura.

Após os ciclos, os corpos-de-prova foram submetidos a ensaios de condutividade hidráulica e os resultados são mostrados na Tabela 4.15.

Tabela 4.15 - Acréscimo da condutividade hidráulica devido a ciclos de umedecimento e secagem, amostra k04.

\begin{tabular}{ccc}
\hline $\mathbf{C p s}$ & $\mathbf{k}_{\text {iníc. }}(\mathbf{c m} / \mathbf{s})$ & $\mathbf{k}_{\text {final. }}(\mathbf{c m} / \mathbf{s})$ \\
\hline $\mathrm{k} 04-06$ & $8,8.10^{-8}$ & $1,2 \cdot 10^{-6}$ \\
\hline $\mathrm{k} 04-08$ & $2,1 \cdot 10^{-9}$ & $5,4 \cdot 10^{-8}$ \\
\hline $\mathrm{k} 04-09$ & $1,0.10^{-9}$ & $4,3 \cdot 10^{-8}$ \\
\hline
\end{tabular}

Apesar do aparecimento de trincas de grandes dimensões durante o processo de secagem, os valores da condutividade hidráulica dos corpos-de-prova após o ciclo aumentaram menos que 4 ordem de grandeza do valor inicial e os corpos-de-prova k04-08 e k04-09 se mantiveram dentro do limite aceitável para barreiras impermeáveis. Este acréscimo no valor da condutividade hidráulica é relativamente pequeno se compararmos ao acréscimo sofrido pela amostra $\mathrm{k} 01$, que apresentou um alto grau de trincamento após a ciclagem. $\mathrm{O}$ desempenho da condutividade hidráulica do solo após a ciclagem pode ser explicado pelo fechamento e/ou a diminuição de abertura das trincas durante o processo de umedecimento do corpo-de-prova. A Figura 4.39 mostra o estado do corpo-de-prova k04-09 após o processo de umedecimento, onde pode ser observada a diminuição e, em alguns pontos, o fechamento completo das trincas existentes. 


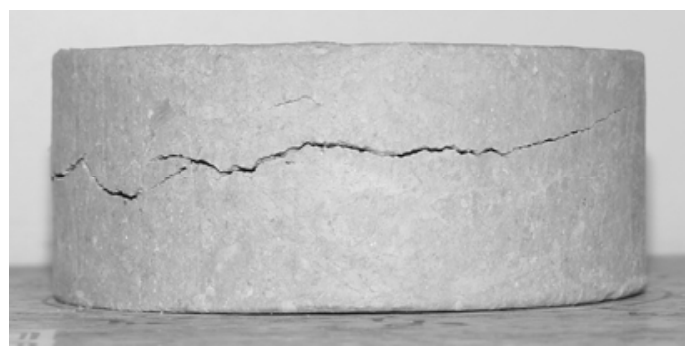

(a)

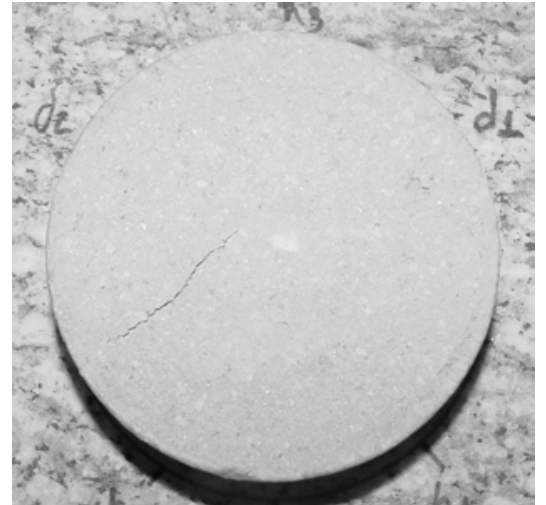

(b)

Figura 4.39 - Condição do Cp k04-09 após o processo de umedecimento, (a) vista lateral, (b) vista superior.

\subsubsection{Ensaios com permeâmetro de parede rígida}

A Tabela 4.16 apresenta as condições de compactação estudadas e os resultados de condutividade hidráulica obtidas em ensaios com permeâmetro de parede rígida. A exemplo das amostras anteriores, o ensaio foi realizado conforme descrito no item 3.2.2.

Tabela 4.16 - Resultados e condições de ensaio em parede rígida para a amostra Dutra k04.

\begin{tabular}{lllcccc}
\hline Amostra & $\begin{array}{l}\mathbf{w}_{\text {mold }} \\
(\%)\end{array}$ & $\rho \mathbf{d}\left(\mathbf{g} / \mathbf{c m}^{\mathbf{3}}\right)$ & $\mathbf{G C}(\mathbf{\%})$ & $\mathbf{e}$ & $\mathbf{S r}(\mathbf{\%})$ & $\mathbf{k}(\mathbf{c m} / \mathbf{s})$ \\
\hline $\mathrm{k} 04-02 \mathrm{r}$ & 21,8 & 1,601 & 98,2 & 0,718 & 83,5 & $5,4.10^{-10}$ \\
\hline $\mathrm{k} 04-03 \mathrm{r}$ & 21,8 & 1,624 & 99,6 & 0,693 & 86,5 & $4,9.10^{-10}$ \\
\hline $\mathrm{k} 04-04 \mathrm{r}$ & 21,8 & 1,660 & 101,8 & 0,657 & 91,3 & $5,1.10^{-10}$ \\
\hline
\end{tabular}

A Figura 4.40 apresenta o comportamento da condutividade hidráulica em função do tempo para os corpos-de-prova citados na Tabela acima. 


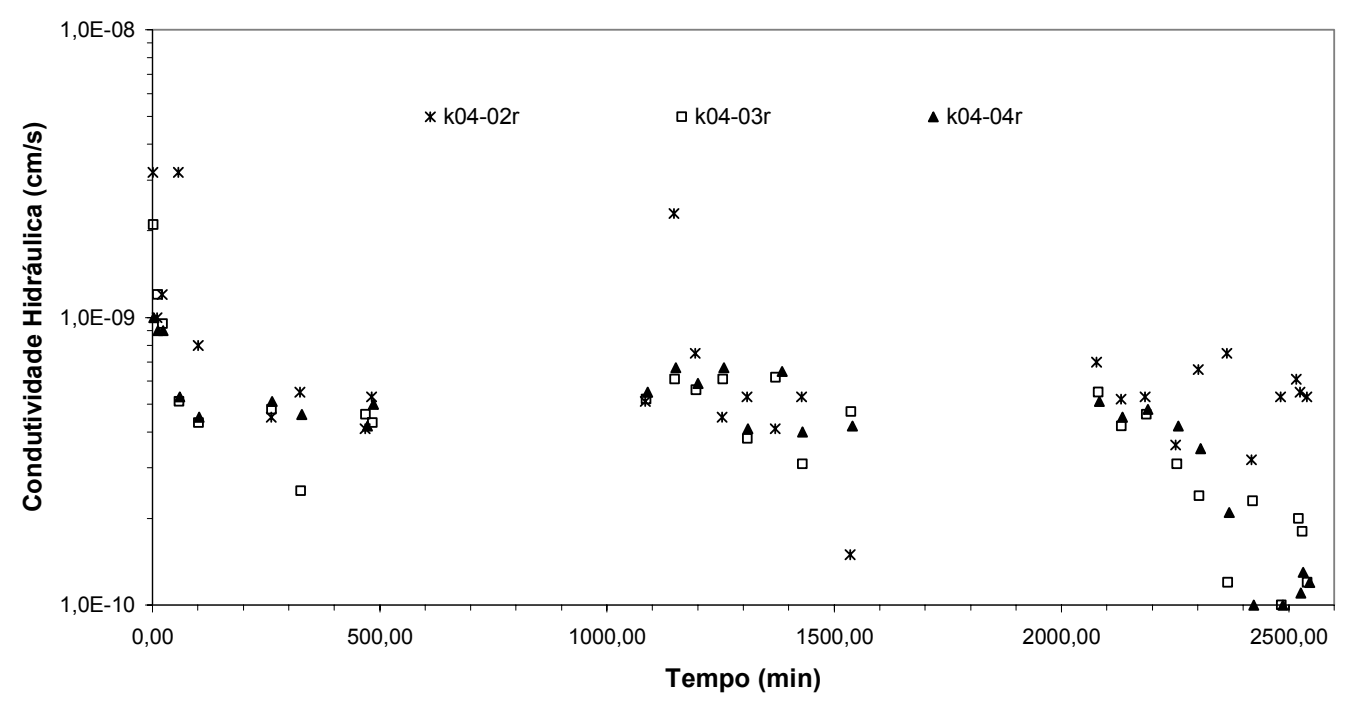

Figura 4.40 - Condutividade hidráulica vs Tempo, ensaios em permeâmetro de parede rígida. Amostra k04, cps moldados com 21,8\% de umidade e com diferentes graus de compactação.

O tempo médio de saturação dos corpos-de-prova ensaiados em permeâmetro de parede rígida foi de duas semanas.

Os resultados de condutividade hidráulica em função do tempo apresentam certa dispersão se comparados com os resultados das outras amostras estudadas. Este comportamento deve-se a dificuldade de quantificar o pequeno volume de líquido percolado durante o grande tempo necessário para realização do ensaio em permeâmetro de parede rígida.

Paras os corpos-de-prova k04-03r e k04-04r pôde-se observar uma brusca redução na condutividade hidráulica após, aproximadamente, 2200 minutos de ensaio. Este comportamento pode indicar a colmatação dos corpos-de-prova.

Estes resultados de condutividade hidráulica apresentados para a amostra em questão podem não retratar a realidade, pois o método de ensaio não é apropriado para mensurar $\mathrm{k}$ desta ordem de grandeza, $10^{-10} \mathrm{~cm} / \mathrm{s}$.

A comparação dos resultados de condutividade hidráulica obtidos em permeâmetros de parede rígida (r) e flexível (f) é apresentada na Tabela 4.17. 
Tabela 4.17 - Comparação dos resultados de condutividade hidráulica obtidos em ensaios com permeâmetros de parede rígida (r) e flexível (f) para a amostra k04.

\begin{tabular}{cccccc}
\hline \multirow{2}{*}{ Amostra } & \multirow{2}{*}{$\mathbf{w}_{\text {mold }}(\%)$} & $\mathbf{e}$ & $\mathbf{S r}(\mathbf{\%})$ & $\mathbf{k}(\mathbf{c m} / \mathbf{s})$ \\
\hline \multirow{2}{*}{$\mathrm{k} 04-02$} & $\mathrm{r}$ & 21,8 & 0,718 & 83,5 & $5,40 \mathrm{E}-10$ \\
\cline { 2 - 6 } & $\mathrm{f}$ & 21,8 & 0,722 & 83,0 & $2,00 \mathrm{E}-09$ \\
\hline \multirow{2}{*}{$\mathrm{k} 04-03$} & $\mathrm{r}$ & 21,8 & 0,693 & 86,5 & $4,90 \mathrm{E}-10$ \\
\cline { 2 - 6 } & $\mathrm{f}$ & 21,8 & 0,687 & 87,2 & $1,30 \mathrm{E}-09$ \\
\hline \multirow{2}{*}{$\mathrm{k} 04-04$} & $\mathrm{r}$ & 21,8 & 0,657 & 91,3 & $5,10 \mathrm{E}-10$ \\
\cline { 2 - 6 } & $\mathrm{f}$ & 21,8 & 0,655 & 91,6 & $1,10 \mathrm{E}-09$ \\
\hline
\end{tabular}

Apesar da pequena diferença dos resultados apresentada pelos dois métodos de ensaio, os valores de condutividade hidráulica obtidos em ensaios com permeâmetro de parede rígida se mantiveram menores se comparados com os resultados de ensaios com permeâmetro de parede flexível, essa diferença pode ser observada na Figura 4.41.

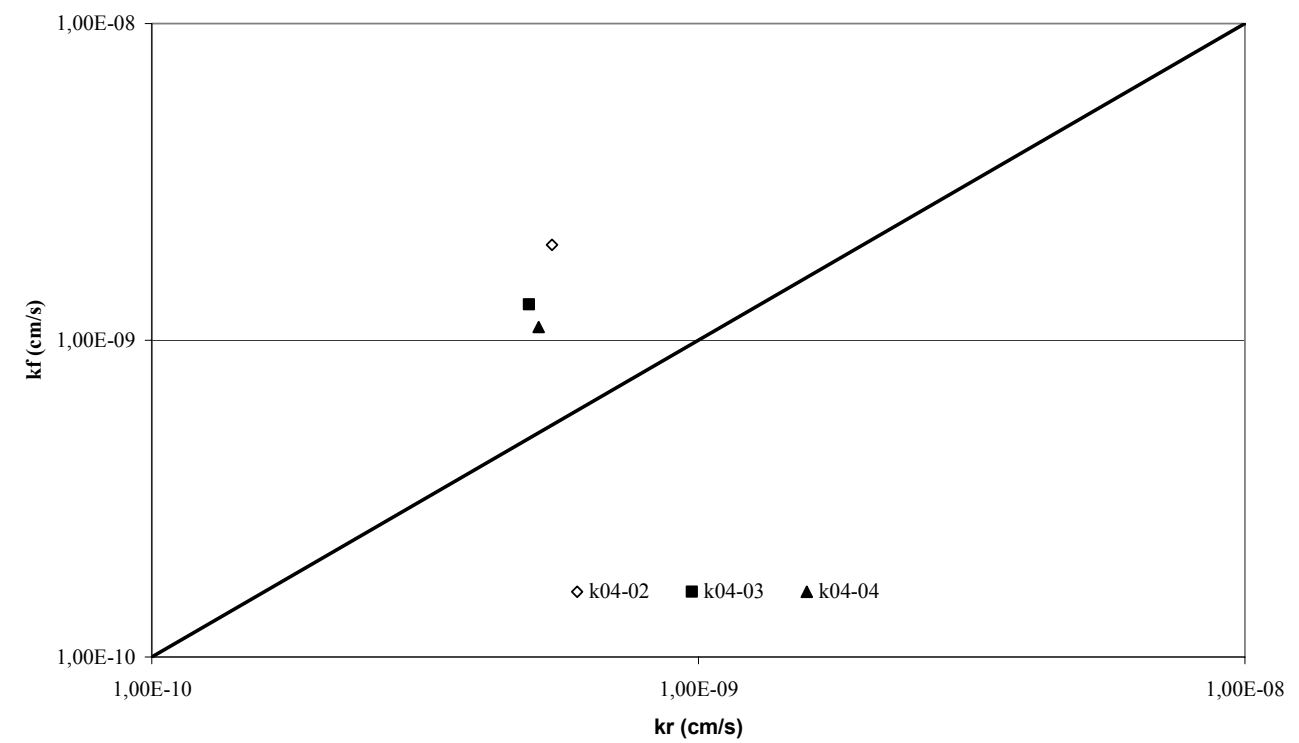

Figura 4.41 - Comparação da condutividade hidráulica em ensaios com permeâmetros de parede flexível e rígida para a amostra k04.

À exemplo das amostras anteriores, a diferença dos resultados obtidos nos dois métodos de ensaio analisados foi reduzida quando se reduzia o índice de vazios dos corposde-prova estudados. 


\subsection{SANTA FELÍCIA - K05}

Trata-se de uma areia argilosa contendo 38,5\% das partículas menores que 0,075 $\mathrm{mm}$. O solo foi classificado como SC, isto é, areia com argila pela Classificação Unificada.

\subsubsection{Condutividade hidráulica}

A Tabela 4.18 mostra as condições de compactação e de ensaio em permeâmetro de parede flexível para cada corpo-de-prova analisado.

Tabela 4.18 - Resultados e condições de ensaio em parede flexível para a amostra Santa Felícia - k05.

\begin{tabular}{|c|c|c|c|c|c|c|c|c|c|}
\hline \multirow[b]{2}{*}{ Amostra } & \multirow{2}{*}{$\begin{array}{c}W_{\text {mold }} \\
(\%)\end{array}$} & \multirow{2}{*}{$\begin{array}{c}\rho d \\
\left(\mathrm{~g} / \mathrm{cm}^{3}\right)\end{array}$} & \multirow{2}{*}{$\begin{array}{l}\text { GC } \\
(\%)\end{array}$} & \multirow[b]{2}{*}{ e } & \multirow[b]{2}{*}{$\operatorname{Sr}(\%)$} & \multicolumn{2}{|c|}{ Saturação (kPa) } & \multirow[b]{2}{*}{ B } & \multirow[b]{2}{*}{$\mathrm{k}(\mathrm{cm} / \mathrm{s})$} \\
\hline & & & & & & $\sigma 3 c$ & C.P. & & \\
\hline $\mathrm{k} 05-01$ & 15,4 & 1,731 & 94,8 & 0,53 & 77,0 & 550 & 510 & 0,98 & $8,30 \mathrm{E}-07$ \\
\hline $\mathrm{k} 05-02$ & 15,4 & 1,788 & 98,0 & 0,48 & 85,0 & 500 & 440 & 0,98 & $5,30 \mathrm{E}-07$ \\
\hline $\mathrm{k} 05-03$ & 15,4 & 1,821 & 99,8 & 0,45 & 89,9 & 500 & 440 & 0,98 & $1,20 \mathrm{E}-07$ \\
\hline $\mathrm{k} 05-04$ & 15,4 & 1,842 & 100,9 & 0,44 & 93,3 & 450 & 410 & 0,99 & $5,70 \mathrm{E}-08$ \\
\hline $\mathrm{k} 05-05$ & 15,4 & 1,859 & 101,9 & 0,42 & 96,2 & 450 & 410 & 0,98 & $6,20 \mathrm{E}-08$ \\
\hline k05-06 & 16,2 & 1,732 & 94,9 & 0,53 & 81,2 & 550 & 510 & 0,99 & $8,50 \mathrm{E}-07$ \\
\hline k05-07 & 16,2 & 1,790 & 98,1 & 0,48 & 89,6 & 550 & 510 & 0,98 & $7,10 \mathrm{E}-07$ \\
\hline k05-08 & 16,2 & 1,825 & 100,0 & 0,45 & 95,2 & 550 & 510 & 0,99 & $3,00 \mathrm{E}-07$ \\
\hline k05-09 & 16,2 & 1,843 & 101,0 & 0,44 & 98,3 & 550 & 510 & 0,97 & $1,10 \mathrm{E}-07$ \\
\hline k05-10 & 17,3 & 1,735 & 95,1 & 0,53 & 87,1 & 550 & 510 & 0,99 & $8,90 \mathrm{E}-07$ \\
\hline k05-11 & 17,3 & 1,791 & 98,1 & 0,48 & 95,8 & 550 & 510 & 0,98 & $7,30 \mathrm{E}-07$ \\
\hline $\mathrm{k} 05-12$ & 17,3 & 1,823 & 99,9 & 0,45 & 101,3 & 550 & 510 & 0,98 & $3,50 \mathrm{E}-07$ \\
\hline k05-13 & 14,9 & 1,788 & 98,0 & 0,48 & 82,1 & 550 & 510 & 0,98 & $5,70 \mathrm{E}-07$ \\
\hline k05-14 & 14,9 & 1,826 & 100,1 & 0,45 & 87,7 & 550 & 510 & 0,98 & $1,60 \mathrm{E}-07$ \\
\hline $\mathrm{k} 05-15$ & 14,0 & 1,787 & 97,9 & 0,48 & 77,0 & 550 & 510 & 0,97 & $1,10 \mathrm{E}-06$ \\
\hline k05-16 & 14,0 & 1,822 & 99,8 & 0,45 & 81,8 & 550 & 510 & 0,98 & $9,20 \mathrm{E}-07$ \\
\hline
\end{tabular}

A Figura 4.42 mostra o comportamento da condutividade hidráulica em função do tempo para corpos de prova moldados com teor de umidade igual a $15,4 \%$ e diferentes graus de compactação, e também para corpos de prova moldados com grau de compactação igual a $100 \%$ e diferentes teores de umidade de moldagem. O comportamento da condutividade em função do tempo foi típico para todos os corpos-de-prova ensaiados. 


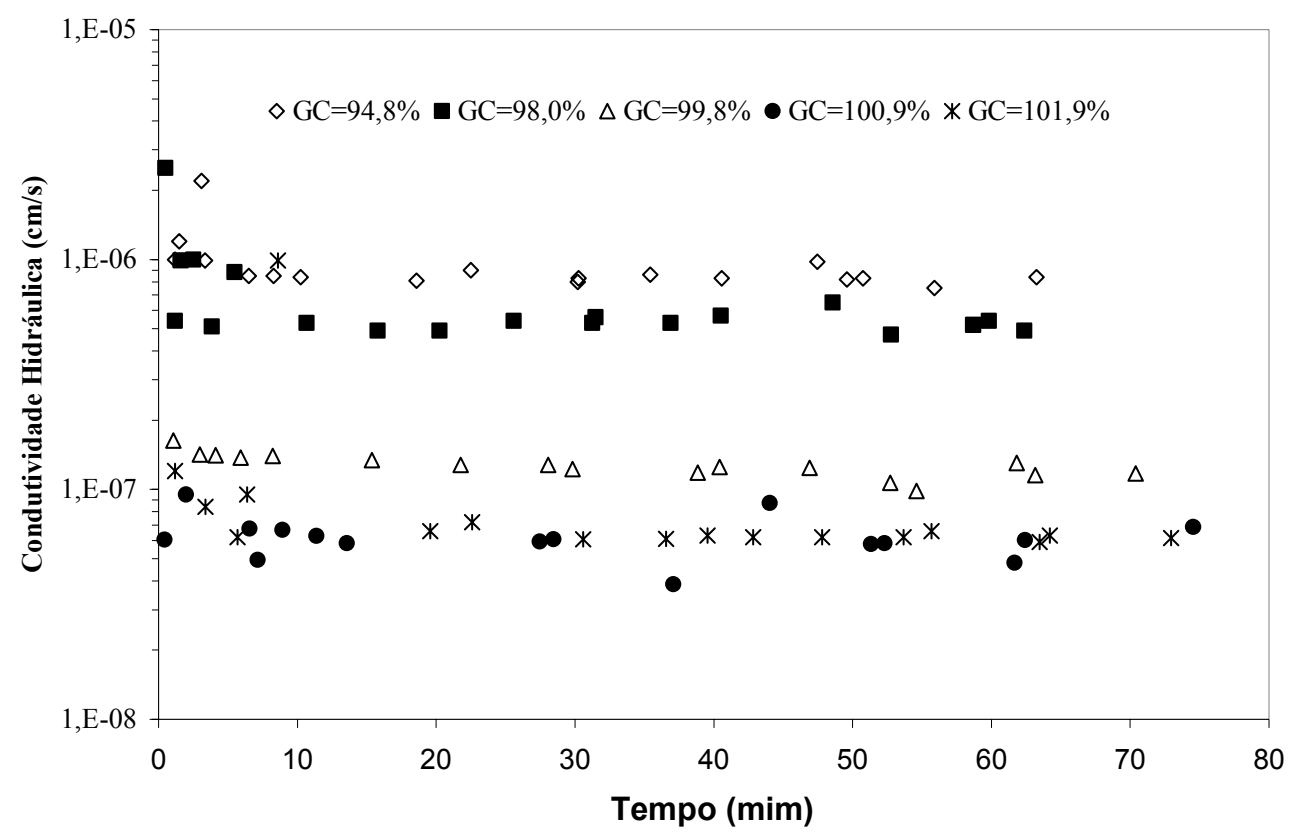

Figura 4.42a - Condutividade hidráulica vs Tempo, amostra k05, CPs moldados com $\mathbf{1 5 , 4 \%}$ de umidade e diferentes graus de compactação.

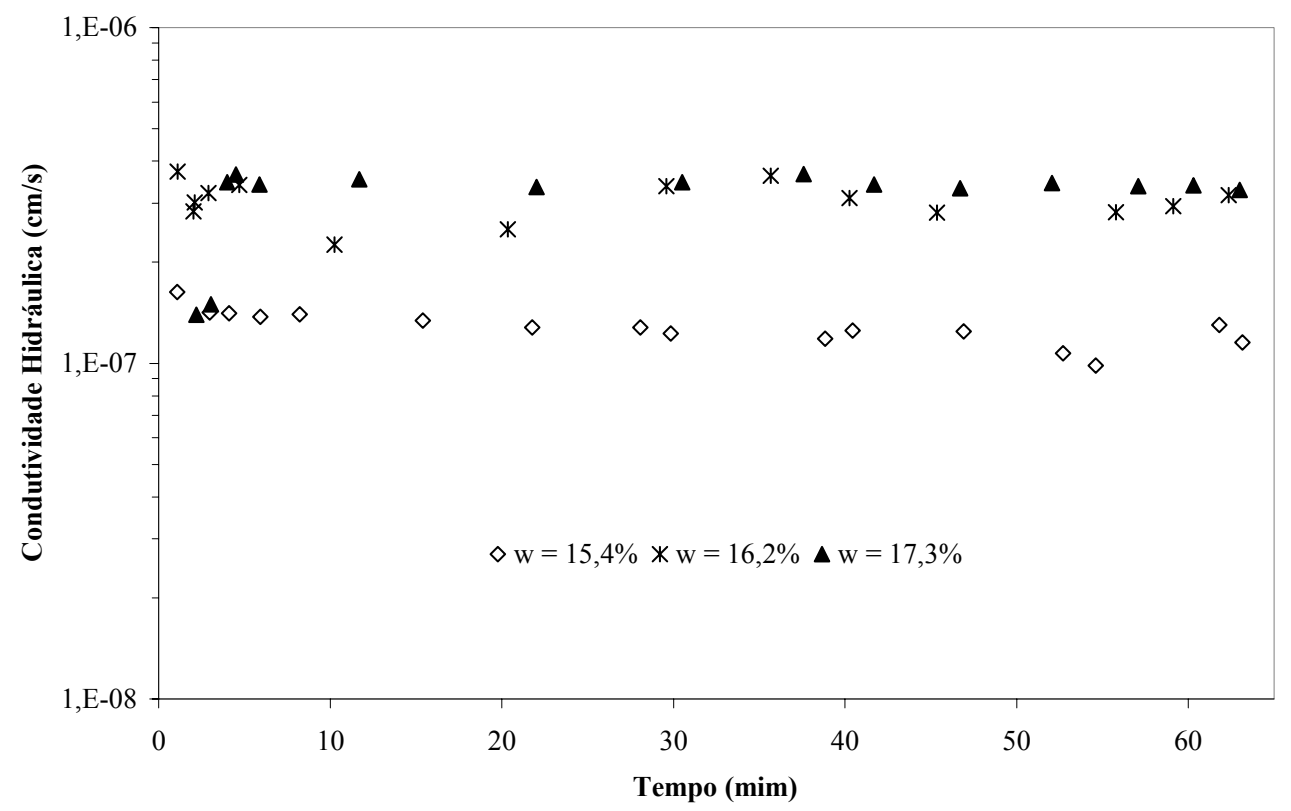

Figura 4.42b - Condutividade hidráulica vs Tempo, amostra k05, CPs moldados com GC $=\mathbf{1 0 0} \%$ e diferentes teores de umidade.

Assim como para as amostras anteriores, o valor da condutividade hidráulica foi determinado a partir de uma reta média dos pontos obtidos no ensaio. O fluxo através dos corpos-de-prova se torna constante, para maioria dos corpos-de-prova ensaiados, a partir dos primeiros 5 minutos de ensaio. O tempo médio de saturação dos corpos-de-prova foi de 24 horas. 
O comportamento da condutividade hidráulica frente à variação de teor de umidade de moldagem para diferentes graus de compactação é mostrado na Figura 4.43.

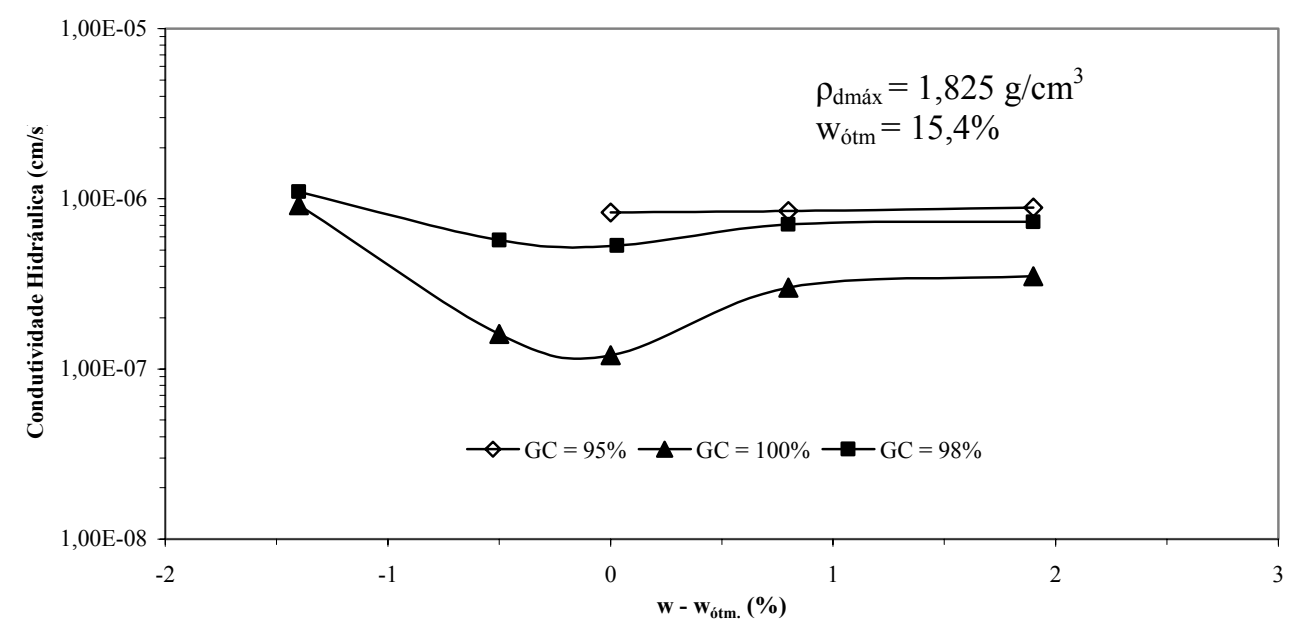

Figura 4.43 - Efeito do desvio de umidade de moldagem na condutividade hidráulica para a amostra k05.

A condutividade hidráulica alcança o mínimo valor quando a compactação é realizada com teor de umidade igual ao teor de umidade ótimo, e apresenta uma tendência de aumento para teores de umidade de moldagem superiores a este.

Para os corpos-de-prova moldados com $\mathrm{GC}=100 \%$ a redução da condutividade hidráulica foi mais pronunciada quando se passa do ramo seco para o ramo úmido. Nos corpos-de-prova moldados com GC = 95 e 98\%, a variação do teor de umidade de moldagem não exerceu grande influência na redução da condutividade hidráulica.

O comportamento da condutividade hidráulica frente à variação do grau de compactação para diferentes teores de umidade de moldagem é mostrado na Figura 4.44.

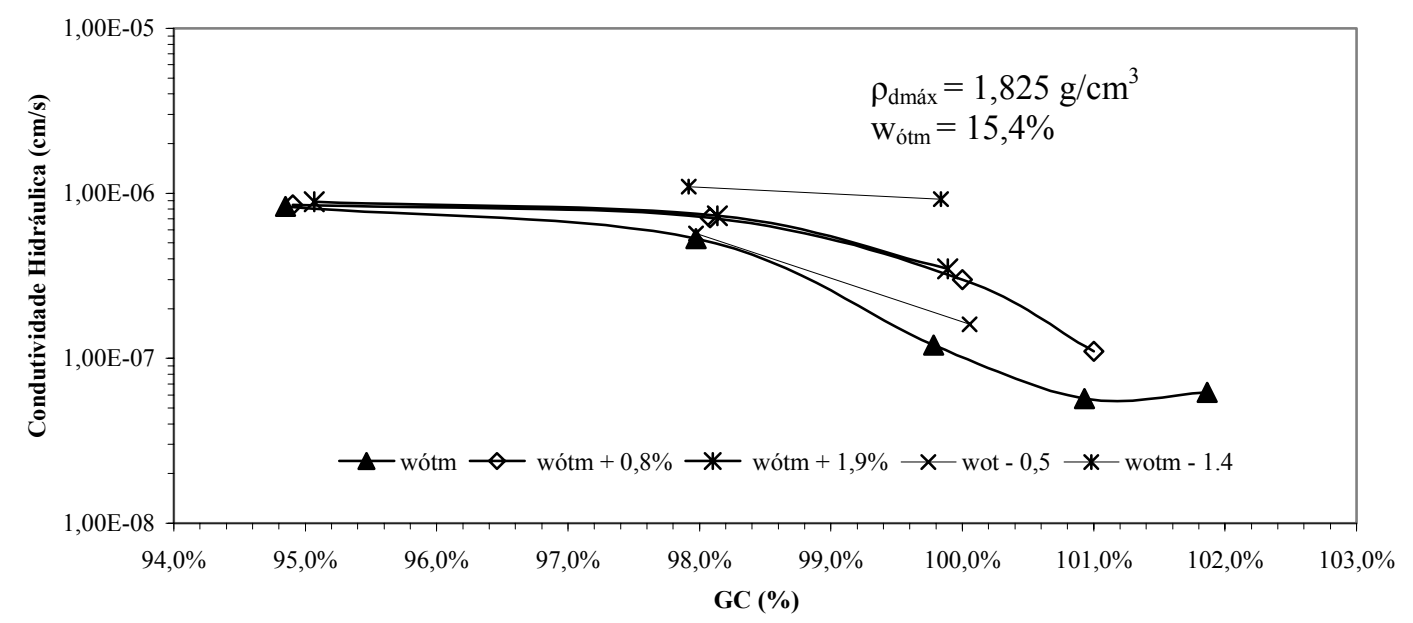

Figura 4.44 - Efeito do grau de compactação na condutividade hidráulica para a mostra k05. 
O comportamento da condutividade hidráulica frente às variações de grau de compactação é semelhante aos apresentados pelos outros solos estudados. Obteve-se maior redução da condutividade hidráulica para graus de compactação superiores a 98\%. Para o teor de umidade igual ao teor ótimo, observou-se uma leve tendência de aumento da condutividade hidráulica para graus de compactação superiores a $101 \%$.

A Figura 4.45 mostra a curva de compactação para o ensaio de Proctor Normal, as condições de compactação dos corpos-de-prova, os valores de condutividade hidráulica. Como o número de corpos-de-prova que se mantiveram com condutividade hidráulica dentro do limite sugerido para barreiras impermeáveis foi muito reduzido, apenas 2 corpos-de-prova, optou-se para esta amostra não determinar condições ideais de compactação e a zona admissível.

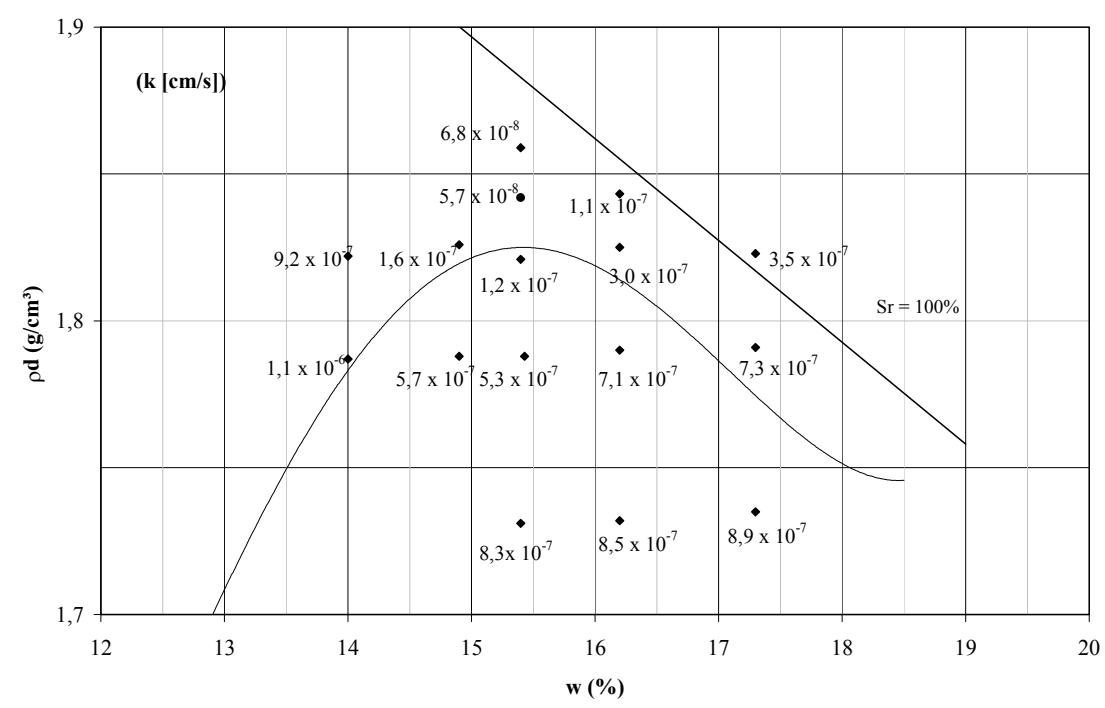

Figura 4.45 - Curva de compactação, condições de compactação dos corpos-de-prova e valores de condutividade hidráulica para a amostra k05. 


\subsubsection{Influência do teor de umidade volumétrico}

A Figura 4.46 mostra a variação da condutividade hidráulica em função do teor de umidade volumétrico é mostrado para a amostra k05.

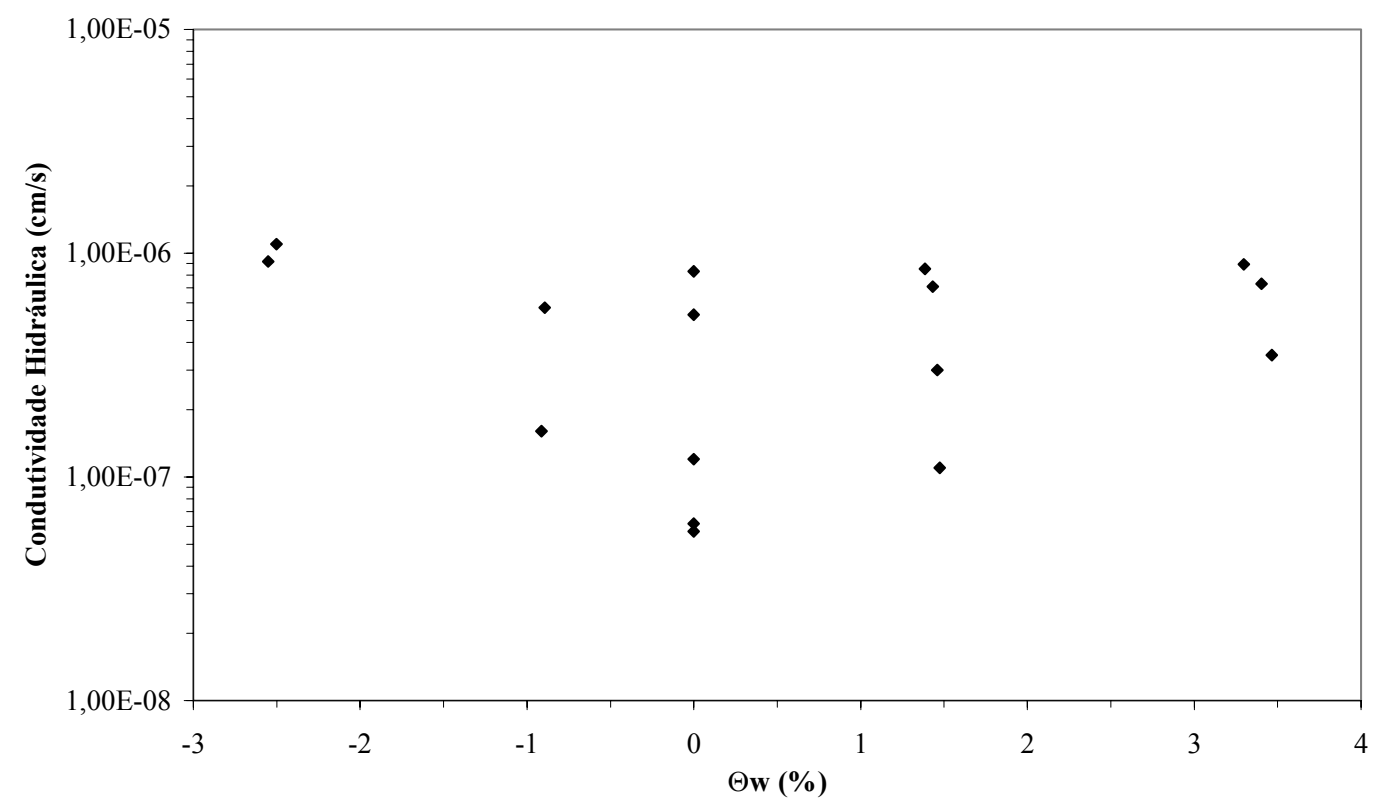

Figura 4.46 - Condutividade hidráulica em função do teor de umidade volumétrico, amostra k05.

Diferentemente dos outros solos estudados, a variação do teor de umidade volumétrico não exerceu grande influência na condutividade hidráulica.

\subsubsection{Contração}

Para a observação da contração na secagem foram selecionados os corpos de prova $\mathrm{k} 05-03\left(\mathrm{w}_{\text {mold. }}=15,4 \%, \mathrm{GC}=99,8 \%\right), \mathrm{k} 05-04\left(\mathrm{w}_{\text {mold. }}=15,4 \%, \mathrm{GC}=100,9 \%\right)$ e k05-14 $\left(\mathrm{w}_{\text {mold }}\right.$. $=14,9 \%, \mathrm{GC}=100,1 \%)$. O ensaio foi realizado como descrito no item 3.3.

A Figura 4.47 mostra o a contração axial e volumétrica em função do tempo para estes corpos-de-prova. 


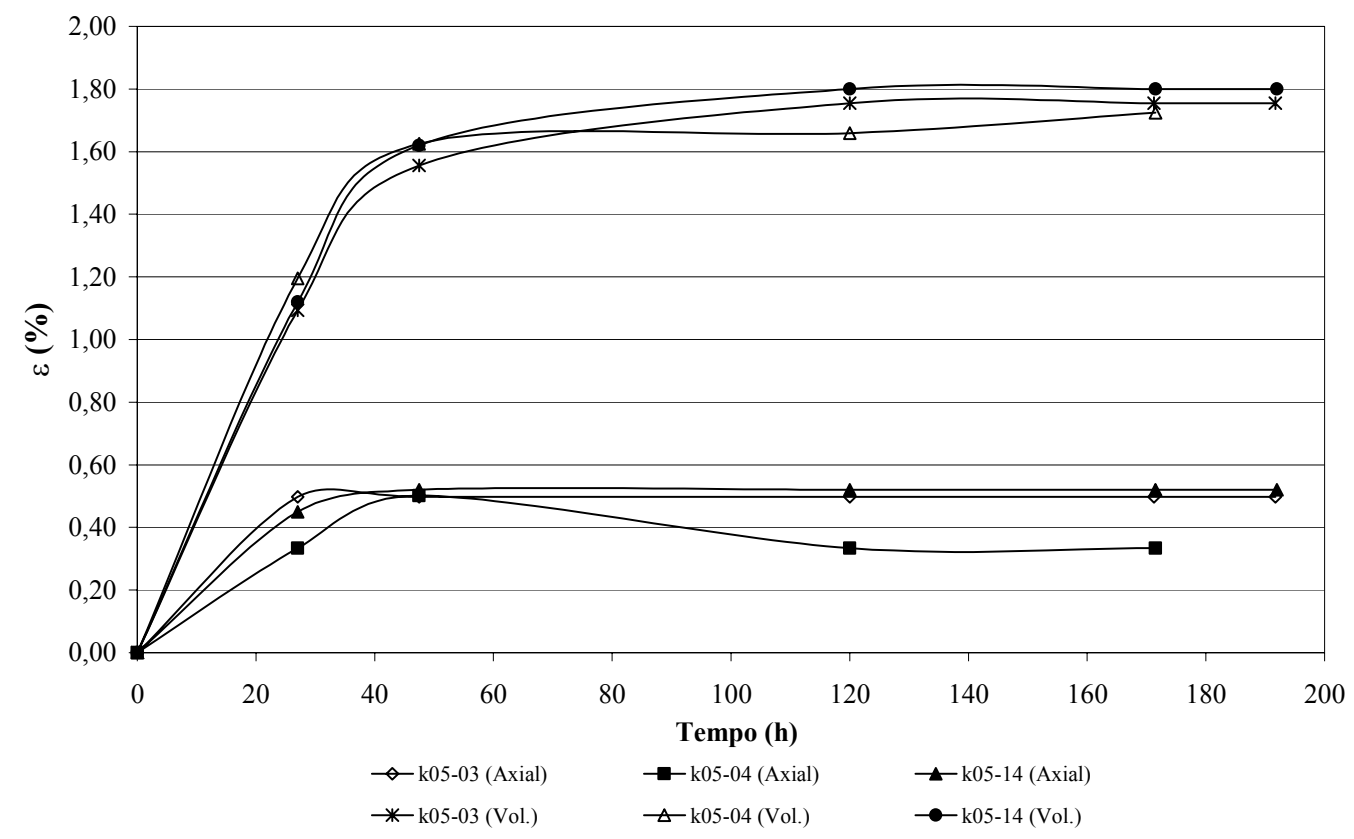

Figura 4.47 - Contração axial e volumétrica em função do tempo para a mostra k05.

Os valores de temperatura ambiente e umidade relativa do ar variaram, respectivamente, entre 26 a $28^{\circ} \mathrm{C}$ e 42 a $53 \%$.

Os valores da contração axial e volumétrica foram relativamente baixos se comparados aos das amostras anteriores e não excederam o limite de $4 \%$ sugerido por Daniel \& $\mathrm{Wu}$ (1993) para barreira impermeável. Para estes corpos-de-prova ensaiados, o teor de umidade de moldagem e o grau de compactação não exerceram influência no valor final da contração.

Como para as amostras anteriores, os corpos-de-prova foram submetidos a ciclos de umedecimento e secagem para observar o aparecimento de trincas. O processo de umedecimento foi realizado por circulação de água destilada dentro da câmara confinante do permeâmetro de parede flexível, a fim de minimizar o efeito do desconfinamento lateral durante o umedecimento. A Figura 4.48 mostra a condição final do corpo de prova k05-03. 


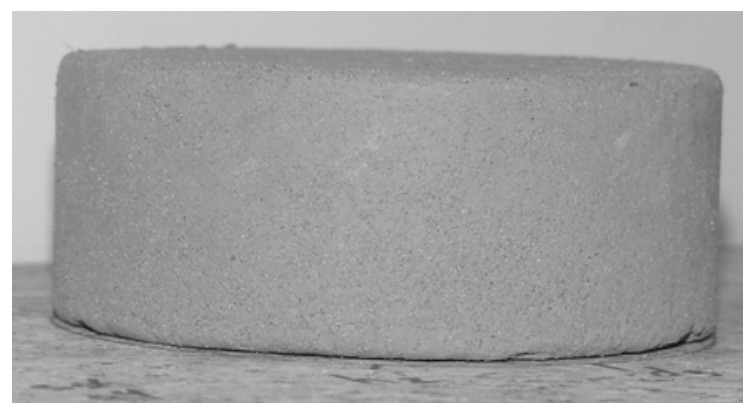

(a)

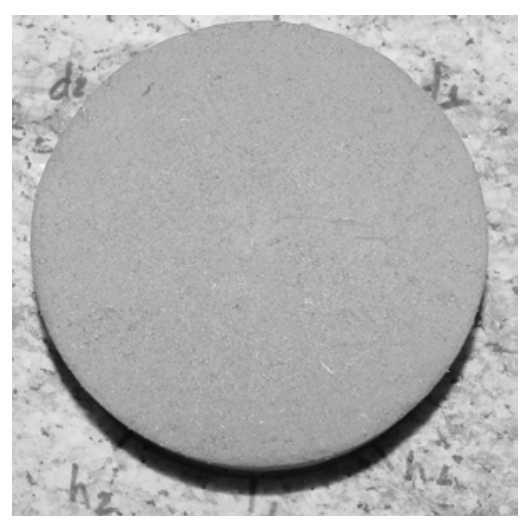

(b)

Figura 4.48 - Condição do Cp k05-03 após três ciclos de umedecimento e secagem, (a) vista lateral, (b) vista superior.

Pode-se observar na Figura 4.48 que, após os ciclos, o corpos-de-prova apresentou boas condições estruturais, não foi notada o surgimento de trincas durante os processos de umedecimento e secagem. Este comportamento foi típico para todos os corpos-de-prova ensaiados.

Após o último ciclo, os corpos-de-prova foram submetidos a ensaios de condutividade hidráulica e os resultados são mostrados na Tabela 4.19.

Tabela 4.19 - Acréscimo da condutividade hidráulica devido a ciclos de umedecimento e secagem, amostra k05.

\begin{tabular}{ccc}
\hline $\mathbf{C p s}$ & $\mathbf{k}_{\text {iníc. }}(\mathbf{c m} / \mathbf{s})$ & $\mathbf{k}_{\text {final. }}(\mathbf{c m} / \mathbf{s})$ \\
\hline $\mathrm{k} 05-03$ & $1,2.10^{-7}$ & $3,1.10^{-7}$ \\
\hline $\mathrm{k} 05-04$ & $5,7.10^{-8}$ & $5,4 \cdot 10^{-7}$ \\
\hline $\mathrm{k} 05-14$ & $1,6.10^{-7}$ & $1,9.10^{-7}$ \\
\hline
\end{tabular}

A variação da condutividade hidráulica devido aos ciclos de umedecimento e secagem foi desprezível para todos os corpos-de-prova ensaiados. 


\subsubsection{Ensaios com permeâmetro de parede rígida}

As condições dos corpos-de-prova ensaiados em permeâmetro de parede rígida estão apresentadas na Tabela 4.20.

Tabela 4.20 - Resultados e condições de compactação para ensaio em permeâmetro de parede rígida para a amostra Araras - k05.

\begin{tabular}{ccccccc}
\hline Amostra & $\begin{array}{c}\mathbf{w}_{\text {mold }} \\
\mathbf{( \% )}\end{array}$ & $\boldsymbol{\rho} \mathbf{d}\left(\mathbf{g} / \mathbf{c m}^{\mathbf{3}}\right)$ & $\begin{array}{c}\mathbf{G C} \\
\mathbf{( \% )}\end{array}$ & $\mathbf{e}$ & $\begin{array}{c}\text { Sr } \\
\mathbf{( \% )}\end{array}$ & $\mathbf{k}(\mathbf{c m} / \mathbf{s})$ \\
\hline $\mathrm{k} 05-01 \mathrm{r}$ & 15,2 & 1,729 & 94,7 & 0,531 & 75,8 & $1,10 \mathrm{E}-07$ \\
\hline $\mathrm{k} 05-02 \mathrm{r}$ & 15,2 & 1,790 & 98,1 & 0,479 & 84,0 & $9,80 \mathrm{E}-08$ \\
\hline $\mathrm{k} 05-03 \mathrm{r}$ & 15,2 & 1,823 & 99,9 & 0,452 & 89,0 & $9,10 \mathrm{E}-08$ \\
\hline
\end{tabular}

O comportamento da condutividade hidráulica em função do tempo para os corpos-deprova apresentados na Tabela 4.20 é mostrado na Figura 4.49.

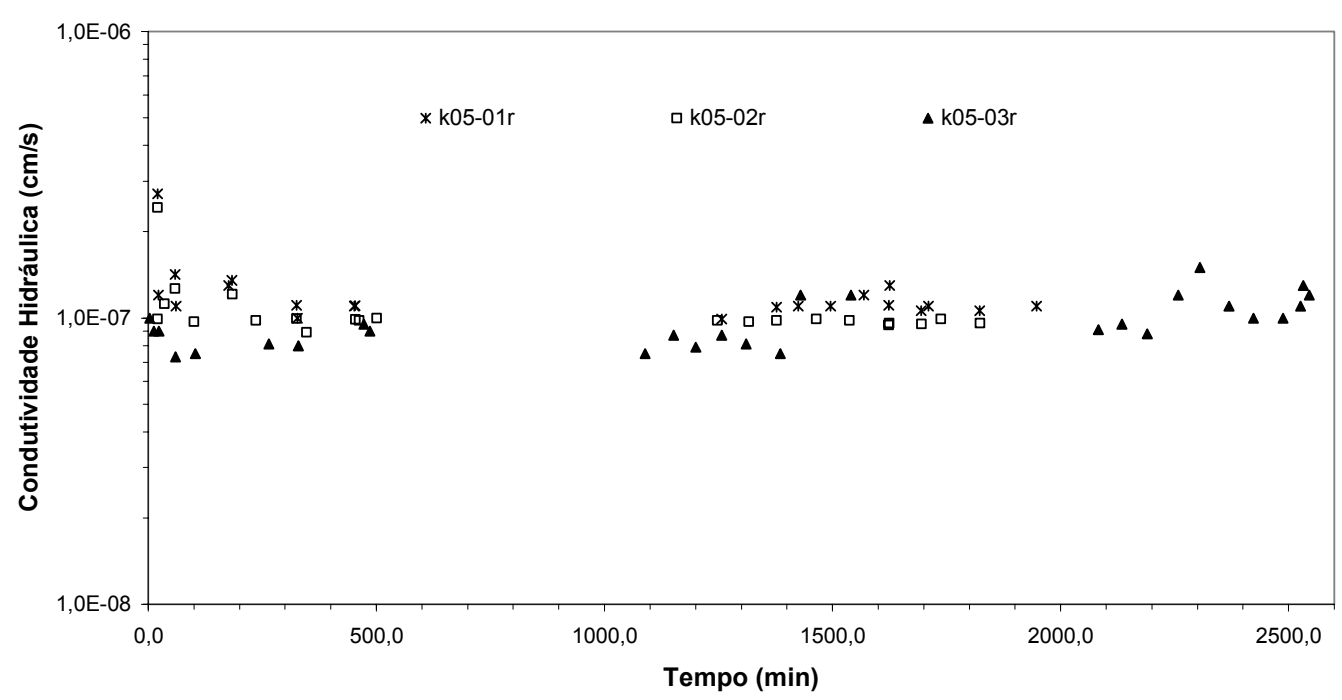

Figura 4.49 - Condutividade hidráulica vs Tempo, ensaios em permeâmetro de parede rígida. Amostra k05, cps moldados com 15,4\% de umidade e com diferentes graus de compactação.

O tempo médio de saturação dos corpos-de-prova ensaiados em permeâmetro de parede rígida foi de 72 horas.

A comparação dos resultados de condutividade hidráulica obtidos em permeâmetros de parede rígida (r) e flexível (f) é apresentada na Tabela 4.21. 
Tabela 4.21 - Comparação dos resultados de condutividade hidráulica obtidos em ensaios com permeâmetros de parede rígida (r) e flexível (f) para a amostra k05.

\begin{tabular}{cccccc}
\hline \multirow{2}{*}{ Amostra } & \multirow{2}{*}{$\mathbf{w}_{\text {mold }}(\%)$} & $\mathbf{e}$ & $\mathbf{S r}(\%)$ & $\mathbf{k}(\mathbf{c m} / \mathbf{s})$ \\
\hline \multirow{2}{*}{$\mathrm{k} 05-01$} & $\mathrm{r}$ & 15,2 & 0,531 & 75,8 & $1,10 \mathrm{E}-07$ \\
\cline { 2 - 6 } & $\mathrm{f}$ & 15,4 & 0,529 & 77,0 & $8,30 \mathrm{E}-07$ \\
\hline \multirow{2}{*}{$\mathrm{k} 05-02$} & $\mathrm{r}$ & 15,2 & 0,479 & 84,0 & $9,80 \mathrm{E}-08$ \\
\cline { 2 - 6 } & $\mathrm{f}$ & 15,4 & 0,480 & 85,0 & $5,30 \mathrm{E}-07$ \\
\hline \multirow{2}{*}{$\mathrm{k} 05-03$} & $\mathrm{r}$ & 15,2 & 0,452 & 89,0 & $9,10 \mathrm{E}-08$ \\
\cline { 2 - 6 } & $\mathrm{f}$ & 15,4 & 0,454 & 89,9 & $1,20 \mathrm{E}-07$ \\
\hline
\end{tabular}

A amostra em questão não apresentou grandes diferenças nos resultados de condutividade hidráulica obtidos nos dois métodos de ensaio estudado, com exceção do corpo-de-prova k02-02, que apresentou a condutividade hidráulica, aproximadamente uma ordem de grandeza maior se comparado ao resultado obtido em ensaio de parede rígida. $\mathrm{Na}$ Figura 4.50 são comparados os resultados obtidos pelos dois métodos de ensaios.

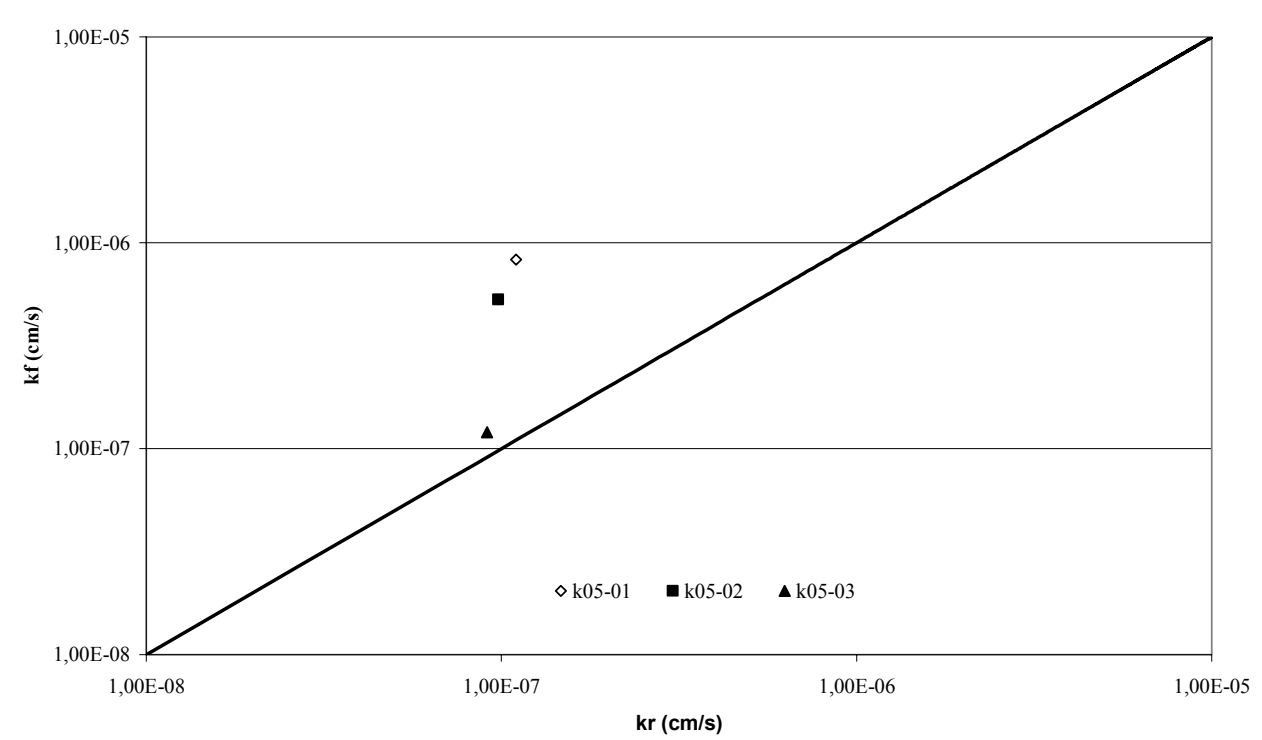

Figura 4.50 - Comparação da condutividade hidráulica em ensaios com permeâmetros de parede flexível e rígida para a mostra k05.

A exemplo das amostras anteriores, a diferença dos resultados obtidos nos dois métodos de ensaio analisados foi reduzida quando se reduzia o índice de vazios dos corposde-prova estudados. 


\section{6 k EM FUNÇÃO DE $\rho_{d}$ E w}

Como apresentado anteriormente, a massa específica seca e o teor umidade de moldagem exercem influência direta no valor da condutividade hidráulica do solo compactado. De posse dos resultados obtidos nesta pesquisa, pode-se sugerir uma área no gráfico $\rho_{\mathrm{d}} v s \mathrm{w}$ em que a condutividade hidráulica de solos, predominantemente argilosos, não exceda valores admissíveis para a construção de barreiras impermeáveis.

A Figura 4.51 apresenta as curvas de compactação dos solos estudados, as condições de compactação dos corpos-de-prova que se mantiveram sob valores desejáveis de condutividade hidráulica, isto é, $\mathrm{k} \leq 10^{-7} \mathrm{~cm} / \mathrm{s}$ e uma região do gráfico onde foi possível obter os valores pretendidos.

A idéia desta carta e das que se seguem é oferecer um processo de identificação expedita, úteis para análises preliminares. Evidentemente ela não pretende substituir uma análise mais completa acerca da condutividade hidráulica de solos compactados e deverá ser aprimorada à medida que outros solos forem sendo ensaiados.

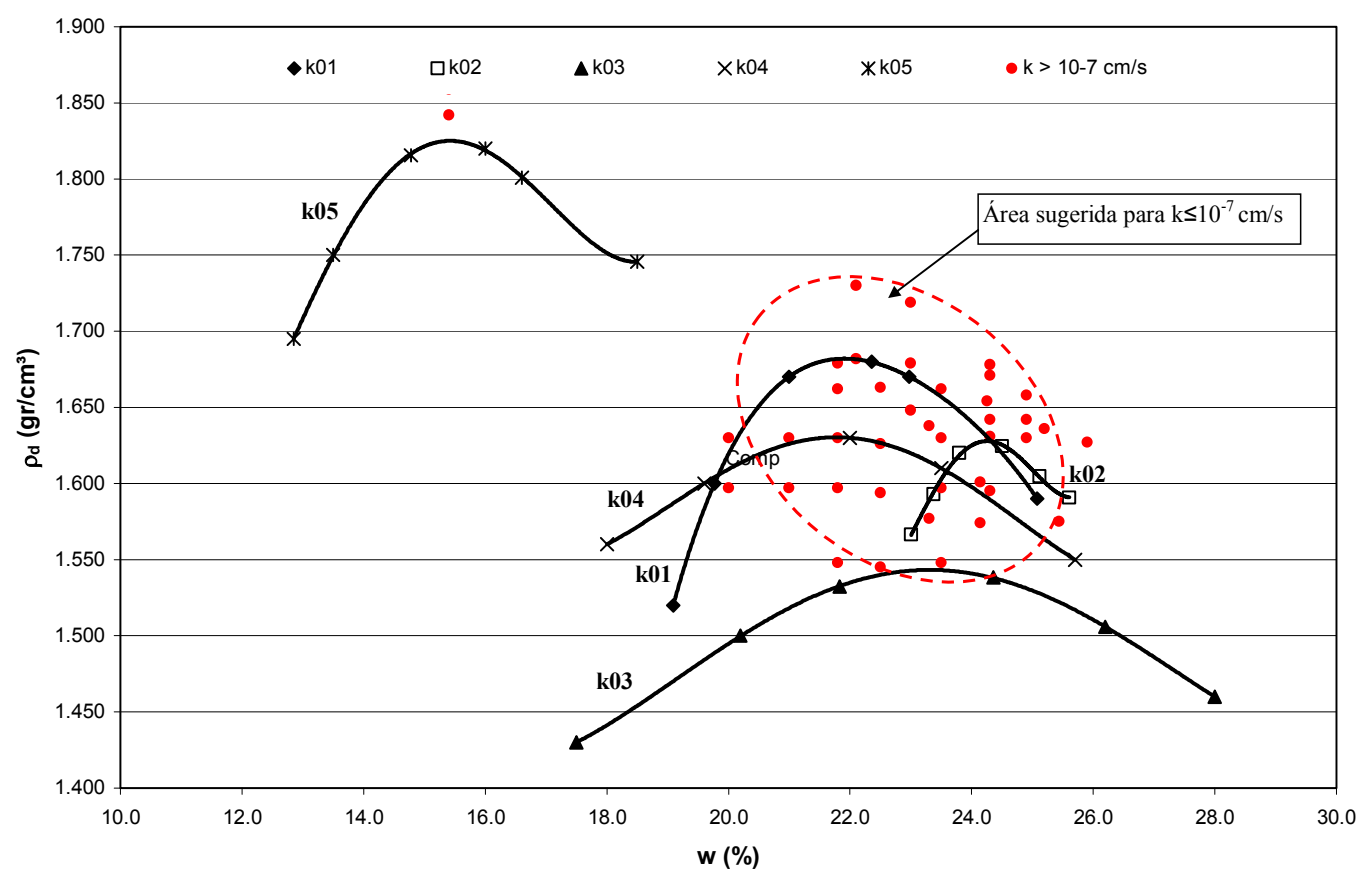

Figura 4.51 - Curvas de compactação dos solos estudados e conjunto de parâmetros de compactação capazes de produzir $k \leq 10^{-7} \mathrm{~cm} / \mathrm{s}$. 


\subsection{CORRELAÇÕES COM OUTRAS CARACTERÍSTICAS DOS SOLOS}

Foi analisada a influência de fatores como o teor de umidade gravimétrico e volumétrico, o grau de compactação e a contração axial e volumétrica. Para verificar se a condutividade hidráulica também é influenciada pelas características intrínsecas dos solos, como a distribuição granulométrica, porcentagem de argila, o índice c' da classificação MCT, o índice de plasticidade (IP), entre outros fatores. Faz-se uma tentativa inicial de correlacionar alguns destes fatores com a condutividade hidráulica obtida em ensaios de permeâmetro de parede flexível para o teor de umidade ótimo e grau de compactação igual a 100\%.

A influência da fração de argila, aqui definida como porcentagem de partículas menores que $0,002 \mathrm{~mm}$, é mostrada na Figura 4.52 .

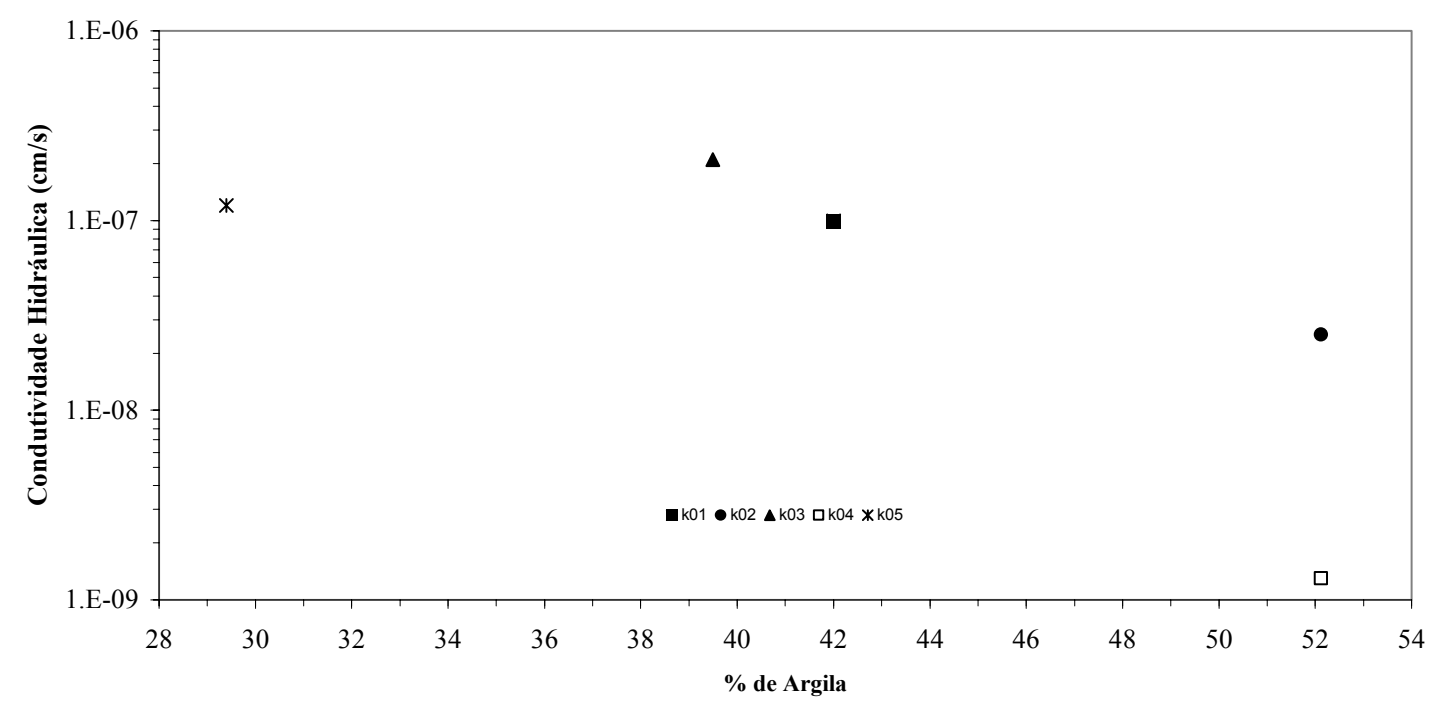

Figura 4.52 - Condutividade hidráulica vs \% de argila, para ensaios em permeâmetro de parede flexível e corpos-de-prova com $w=w_{\text {otm }}$ e GC $=100 \%$.

Pode ser observada uma pequena tendência de diminuição da condutividade hidráulica com o aumento da fração de argila do solo.

Outro fator que se mostrou importante no comportamento da condutividade hidráulica é a distribuição granulométrica das partículas dos solos. Com a análise desta característica pode-se esboçar uma tentativa inicial de delimitar uma região no gráfico de granulometria em que é possível encontrar solos que, quando compactados, apresentam valores de condutividade hidráulica desejáveis para a construção de barreiras impermeáveis. 
A Figura 4.53 mostra uma região delimitada no gráfico de granulometria com base nos resultados de condutividade hidráulica. Solos cujas as curvas granulométricas se encaixem nessa região podem, preliminarmente, serem tomados como capazes de apresentar condutividade hidráulica menor ou igual a $10^{-7} \mathrm{~cm} / \mathrm{s}$, quando compactados. Dada a pequena quantidade de amostras ensaiadas, não se devem excluir de imediato outros solos que caiam fora da região assinalada e esse critério de seleção preliminar poderá ser aprimorado a medida que outros resultados fiquem disponíveis.

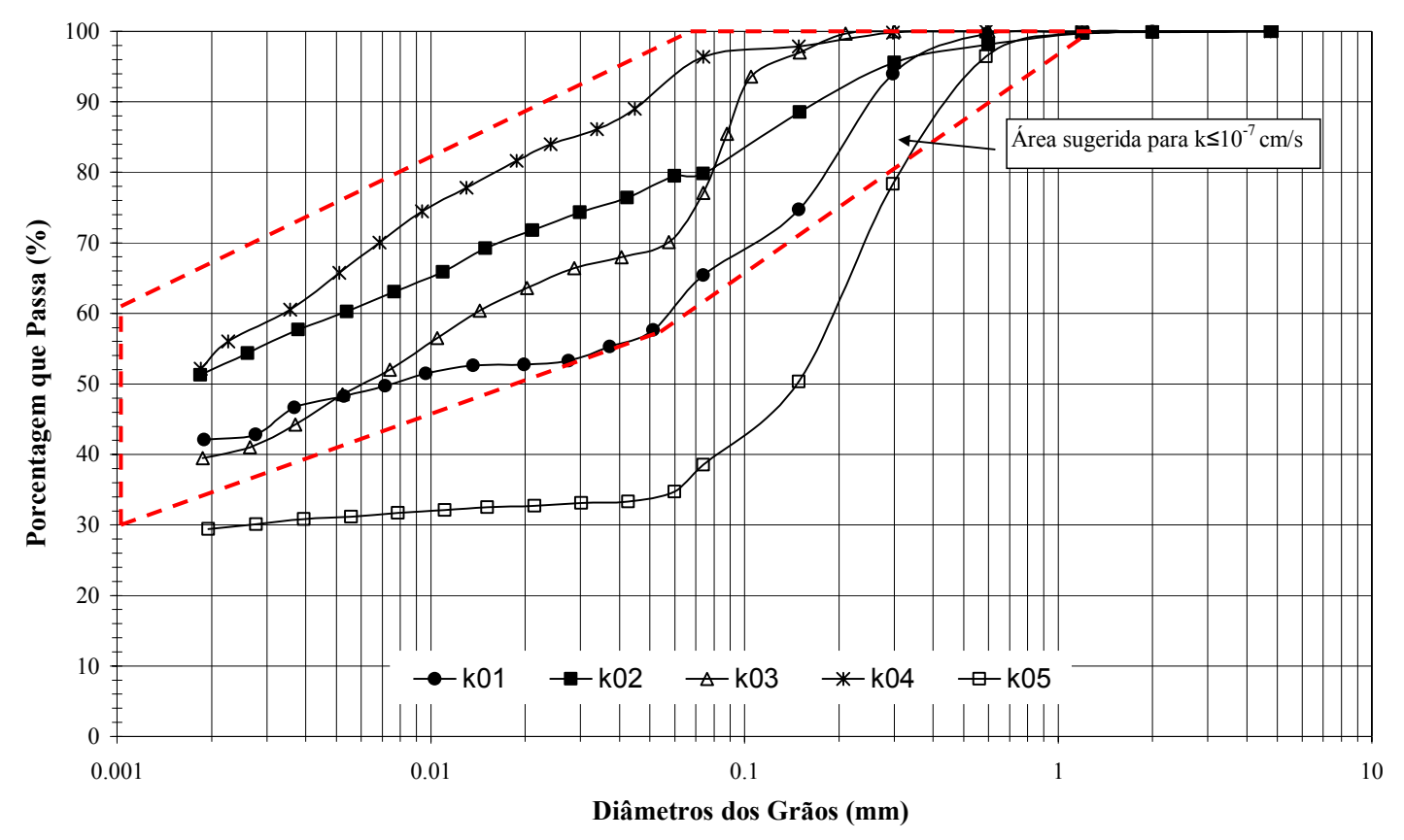

Figura 4.53 - Região onde é possível encontrar solos que, preliminarmente, podem ser tomados com capazes de apresentar $\mathrm{k} \leq 10^{-7} \mathrm{~cm} / \mathrm{s}$.

Além da porcentagem de argila constituinte do solo e a distribuição granulométrica das partículas procura-se na Figura 4.54 apresentar uma tentativa inicial de delimitar uma região na carta de plasticidade, baseada nos resultados de condutividade hidráulica, onde os solos nela enquadrados podem se apresentar adequados para a utilização como barreira impermeável. Também para esta região sugerida na carta de plasticidade, o estudo de novos solos pode aprimorá-la. 


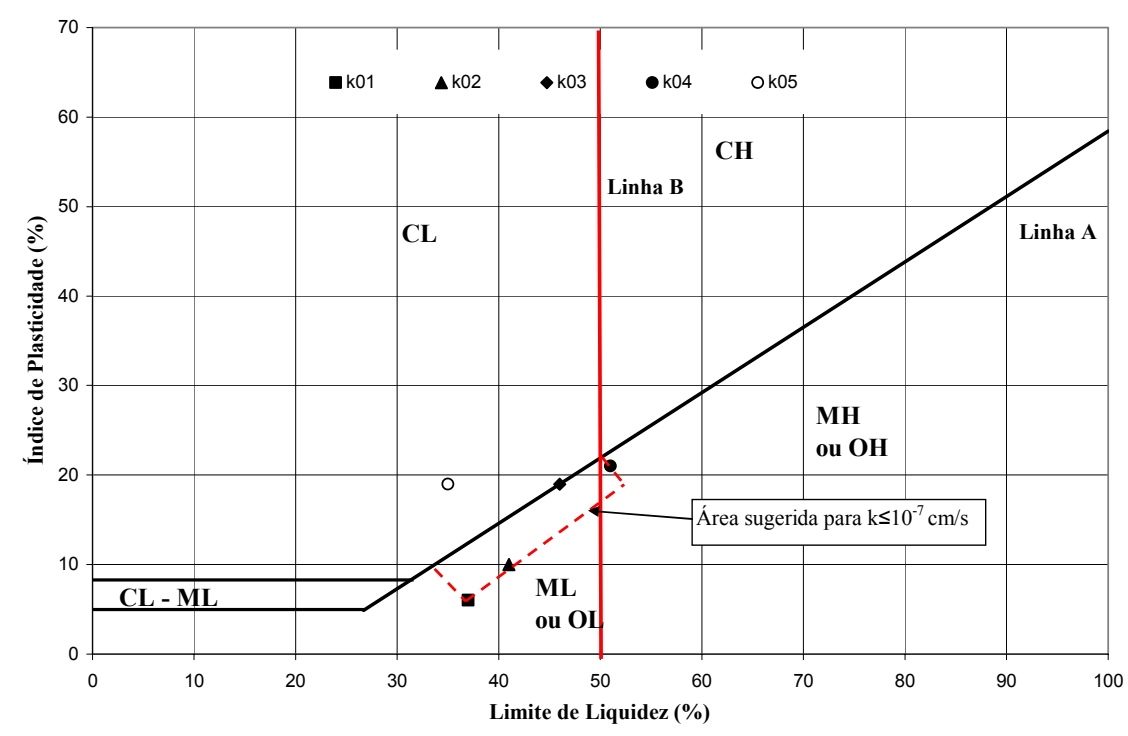

Figura 4.54 - Região onde pode-se encontrar solos que, preliminarmente, podem apresentam condutividade hidráulica desejada quando compactados.

Da junção e do cruzamento dessas informações, baseadas em ensaios simples, pode-se ter então um direcionamento para a escolha de amostras, o que permitirá otimizar as etapas de investigações e o trabalho laboratorial necessário ao projeto e a construção de barreiras impermeabilizantes. 
Nesta dissertação analisaram-se os comportamentos de cinco amostras de solo compactado visando a utilização como barreiras impermeáveis de aterro sanitário. O estudo foi realizado utilizando um permeâmetro de parede flexível e empregando o sistema de controle hidráulico de volume constante (sistema fechado), além do permeâmetro de parede rígida.

Da análise dos resultados obtidos podem-se fazer as seguintes considerações:

a) Quanto ao permeâmetro de parede flexível:

As vantagens deste tipo de ensaio estão na possibilidade de garantir a saturação completa do corpo-de-prova durante o ensaio, eliminar o fluxo preferencial entre o corpo-deprova e a parede do permeâmetro e conhecer o estado de tensões atuantes no corpo-de-prova durante o ensaio.

Foi utilizado o parâmetro B para a verificação da saturação dos corpos-de-prova. Nos ensaios realizados, foi considerado a saturação para corpos-de-prova que apresentavam $B \geq$ 0,96. Porém testes realizados com o permeâmetro de parede flexível mostraram que a condutividade hidráulica não sofre variação para valores do parâmetro B entre 0,91 a 0,98.

b) Quanto à condutividade hidráulica dos solos compactados:

Para todos os solos estudados, a redução da condutividade hidráulica foi mais pronunciada quando as condições de compactação passavam do ramo seco para o ramo úmido. Este comportamento pressupõe a influência da estrutura interna do solo compactado na condutividade hidráulica. As amostras estudadas apresentaram menores valores da condutividade hidráulica quando a compactação é realizada no teor de umidade ótimo ou pouco acima do ótimo. Foi observada uma tendência de aumento na condutividade hidráulica para valores de teor de umidade de moldagem de 1 a 3 pontos percentuais acima do teor de umidade ótimo. 
A condutividade hidráulica foi reduzida com o aumento do grau de compactação do solo para todos os teores de umidade de moldagem estudados. Esta redução é mais significativa até $100 \%$ de grau de compactação; valores do grau de compactação superiores a este não causam grandes ganhos na redução da condutividade hidráulica. Notou-se uma leve tendência da condutividade hidráulica convergir ao mesmo valor para graus de compactação superiores $100 \%$.

A redução da condutividade hidráulica frente as variações de teores de umidade de moldagem e graus de compactação foram mais pronunciadas nas amostras com maiores quantidades de argila. A amostra k05 - Santa Felícia, que contém apenas 30\% das partículas menores que $0,002 \mathrm{~mm}$, sofreu menor redução da condutividade hidráulica frente a variação destes parâmetros.

O valor de condutividade hidráulica menor ou igual a $10^{-7} \mathrm{~cm} / \mathrm{s}$, sugerido por algumas agências reguladoras de meio ambiente para barreiras impermeáveis, foi alcançado por quatro dos cinco solos estudados. Suas condições ideais sugeridas de compactação são k01, GC $\geq$ $99 \%$ e $\mathrm{w} \geq 22,6 \%$; $\mathrm{k} 02, \mathrm{GC} \geq 99 \%$ e w $\geq 24,3 \%$.; $\mathrm{k} 03, \mathrm{GC} \geq 102 \%$ e w $\geq 23,3 \%$; e k04, GC $\geq$ $95 \%$ e w $\geq 20 \%$. Estas condições de compactação sugeridas são limitantes inferiores com base em valores da condutividade hidráulica, porém condições superiores a estas não causam importantes reduções na condutividade hidráulica. Deve-se lembrar que condições muito superiores às sugeridas neste trabalho como ideais podem causar problemas como a laminação, para elevados graus de compactação, e grandes dificuldades de compactação no caso de teor de umidade muito superior ao ótimo.

Para a amostra k05 optou-se por não determinar condições ideais de compactação e a zona admissível, pois apenas dois corpos-de-prova atingiram a valor da condutividade hidráulica sugerida para barreiras impermeáveis.

A amostra k04 apresentou menores valores da condutividade hidráulica para as mesmas condições de compactação, se comparados às outras amostras. Dentre os fatores envolvidos neste comportamento, podem-se destacar a fração de partículas menores que 0,075 mm e altos valores de limites de consistência. Já a amostra k05 apresentou o pior desempenho no tocante à condutividade hidráulica, sendo este solo pouco indicado para a sua utilização como único material de impermeabilização. 
Para a maioria das amostras estudadas, o processo de contração se estabilizou por volta de 48 horas. O teor de umidade e o grau de compactação não influenciaram significativamente os resultados da contração. Um dos fatores condicionantes para este comportamento é o fato dos corpos-de-prova analisados terem sidos compactados no ramo úmido.

Com exceção da amostra k05, para todas as outras amostras estudadas a contração volumétrica excedeu o limite de $4 \%$ sugerido por Daniel \& Wu (1993) para barreira impermeável, porém para a amostra $\mathrm{k} 04$, que excedeu o limite de contração volumétrica em mais que 10 pontos percentuais e apresentou trincas de contração de grandes dimensões, a condutividade hidráulica se manteve dentro do aceitável, isto é, $1.10^{-7} \mathrm{~cm} / \mathrm{s}$. Já a amostra k05 apresentou valores de contração volumétrica aceitáveis, em torno de $1,8 \%$, e o processo de contração não causou variações significativas no valor da condutividade hidráulica.

O aparecimento de trincas durante os ciclos de umedecimento e secagem foi observado para as 5 amostras estudadas. Quando o processo de umedecimento foi realizado sem confinamento lateral, condição imposta à amostra k01, os corpos-de-prova apresentaram um grande números de trincas, o que ocasionou um acréscimo da condutividade hidráulica de 100 ordens de grandeza do valor inicial. Porém, quando o processo de umedecimento foi realizado com confinamento lateral, condição imposta às amostras k02, k03, k04 e k05, as trincas surgiram durante o processo de secagem e o número de trincas foi bruscamente reduzido. O acréscimo máximo da condutividade hidráulica foi de 4 ordens de grandeza do valor inicial. Cabe lembrar que as condições do ensaio de ciclagem, nas duas metodologias empregadas, não retratam exatamente as condições reais de campo.

c) Quanto a comparação dos permeâmetros utilizados:

Para os ensaios em permeâmetro de parede rígida, foram selecionadas condições de compactação semelhantes às ensaiadas em permeâmetro de parede flexível. Para todos os casos analisados, os valores de condutividade hidráulica obtidos em permeâmetro de parede rígida foram menores se comparados aos valores obtidos no outro método de ensaio. Este comportamento pode indicar a condição não saturada dos corpos-de-prova durante o ensaio em permeâmetro de parede rígida, sendo que o solo compactado atinge a maior permeabilidade em condição saturada (condição crítica). 
Os valores de condutividade hidráulica obtidos em ensaios com permeâmetro de parede flexível mostraram-se, aproximadamente, uma ordem de grandeza maior que os obtidos no de parede rígida, para corpos-de-prova compactados com grau de compactação próximo de $98 \%$.

Observou-se que quanto maior o grau de compactação dos corpos-de-prova e, consequentemente, o grau de saturação inicial, menor a diferença nos resultados entre os dois métodos de ensaio analisados.

Os resultados dos ensaios em permeâmetro de parede rígida para as amostras $\mathrm{k} 02 \mathrm{e}$ k04 apresentaram certa dispersão se comparados com as outras amostras ensaiadas. Cabe destacar a grande dificuldade de mensurar valores, de condutividade hidráulica, menores que $10^{-8} \mathrm{~cm} / \mathrm{s}$ em permeâmetros de parede rígida.

Para a fase inicial de saturação dos corpos-de-prova nos ensaios em permeâmetros de parede rígida, foram necessários, em média, quatro dias de percolação. Com exceção dos corpos-deprova da amostra k04 que levaram duas semanas para atingir a saturação considerada. Este tempo é consideravelmente alto se comparado ao tempo médio necessário para a saturação considerada nos ensaios em permeâmetro de parede flexível, que foi de 24 horas. O tempo necessário para a realização das leituras durante o ensaio também foi reduzido quando era utilizado o permeâmetro de parede flexível.

Por fim, sugerem-se neste trabalho características de fácil obtenção que permitem a escolha de solos potencialmente aproveitáveis para a construção de barreiras impermeabilizantes, minimizando assim os custos com investigações preliminares.

Para trabalhos futuros relacionados a este assunto, sugerem-se ensaios de identificação da atividade dos argilomirerais como, por exemplo, o ensaio de absorção de azul de metileno, para correlacionar o comportamento físico químico dos solos com a condutividade hidráulica. Outra análise interessante é a observação da estrutura interna do solo compactado por microscopia ótica e sua correlação com a condutividade hidráulica. 


\section{REFERENCIAS BIBLIOGRÁFICAS}

ALBRECHT, B.A. \& BENSON, C. H., (2001)" Effect of desiccation on compacted natural clays.” J. Geoenvir. Engrg., ASCE, 127(1), 67-75.

BENSON, C.H. \$ DANIEL, D.E., (1990). “ Influence of clods on hydraulic conductivity of compacted clay.” J. Geotech. Engeg., ASCE, 116(8), 1231 - 1248.

BENSON, C., Zhai, H. and Wang, X. (1994). " Estimative the hydraulic conductivity of compacted clay liners.” J. Geotch. Engrg., ASCE, 120(2), 366-387.

BENSON , C. H., ZHAI, H., \& Wang, X. (1994). "Estimating the hydraulic conductivity of compacted clay liners.” J, Geothec. Engrg, ASBE, 120(2), p.366-387

BJERRUM, L. AND HUDER, J. (1957). Measurement of the Permeability of Compacted Clay. Proceeding of the Fourth International Conference on Soil Mechanics and Foundation Engineering, Betterworths, London, Vol. 1, pp.6-8.

BOUTWELL, G. P. \& HEDGES, C., (1989). "Evaluation of waste -retention liners by multivariate statistics”. Proc., Twelfph Int. Conf. On. Soil Mech. And Foudation Engrg., Rio de Janeiro, Brazil, 2, 815-818.

CETESB (1993). Resíduos Sólidos Industriais - 2ª Edição.

CARVALHO, M.F. (1999), “Comportamento Mecânico de Resíduos Sólidos Urbanos”. Tese (doutorado), 300p. Escola de Engenharia de São Carlos - USP, São Carlos-SP.

DANIEL, D. E.; TRAUTWEIN, S. J.; BOYNTON, S. S. AND FOREMAN, D. E. (1984). Permeabylity Testing with Flexible-Wall Permeameters. Geotechnical Testing Journal, GTJODJ, Vol. 7, nº 3, Sept. 1984, pp. 113-122. 
DANIEL, D. E.(1994); State-of-the-Art: Laboratory Hydraulic Conductivity Tests for Saturated Soils. Hydraulic Conductivity and Waste Contaminant Transport in Soil. ASTM STP 1142, David E. Daniel and Stephen j. Trautwein, Eds., American Society for Testing and Materials, Philadelphia.

DANIEL, D.E., (1993). “ Geotechnical practice for waste disposal”. Chapmann \& Hall, 1ed, London, 683p.

DANIEL, D. E. \& BENSON, C. (1990). "Water content-density criteria for compacted soil liners.” J. Geotech. Engrg., ASCE, 116(12), p.1811-1830.

DANIEL, D. E. \& WUY. (1993). "Compacted clay liners and cover for arid sites." J. Geotech. Engrg., ASCE, 119(12), p.223-237.

DOURADO, K. A. (2003). Condutividade hidráulica de materiais de baixa permeabilidade: Desenvolvimento, construção e testes de um sistema de medida. Disertação (mestrado) Escola de Engenharia de São Carlos, USP, São Carlos - SP.

HEAD, K. H. (1986). Manual of soil laboratory testing, Vol 3: effective strs tests, 1 ed, London 1238p.

KLEPPE, J. \& OLSON, R., (1985) - “Desiccation cracking of soil barrier.” Hydraulic barriers in soil and rock, STP 874, ASTM, Philadelphia, p.263-275.

LAMBE, T.W. \& WHITMAN, R.V., (1969) "Soil Mechanics, SI version”. John Wiley \& Sins, Inc.,Singapura, 553p.

LAMBE, T.W., (1958) 'The structure of compacted clay.” J. Soil Mech. And Foud. Engrg. Div., ASCE, 84(8), 1-35.

LIMA, L. M. Q., (1995) “Lixo Tratamento e biorremediação”. Hermus Editora Ltda, São Paulo, SP. 
MACAMBIRA, I. Q. (2002). Comportamento Hidráulico de Alguns Solos Lateríticos para Uso como Barreira Impermeável. Dissertação (Mestrado). São Carlos, 2002. 117 p.

MANUAL DE GERENCIAMENTO INTEGRADO DO LIXO MUNICIPAL (1995). $1^{\mathrm{a}}$ Edição São Paulo: Instituto de Pesquisas Tecnológicas, CEMPRE, 1995, 278p.

McBEAN, E.A.A.; ROVERS, F.A.; FARQUHAR,G.J. (1995). “ Solid Waste Landfill Engeneering and Desing” A Simon \& Schurtr Company, 1ed, Ne Jersey - NY, p 207-250.

MELO, L.G.; VAL, E.C. (1994) - Consideração sobre o revestimento de fundo de áreas de disposição de resíduos à luz das recomendações internacionais atuais. SEMINÁRIO GEOTECNIA DE ATERROS PARA DISPOSIÇÃO DE RESÍDUOS, GEOAMBIENTAL'94. Rio de Janeiro, abril, p.3.1-3.13.

MESRI, G. \& OLSON, R.E., (1971). "Mechanisms Controlling the Permeability of clays." Clays and clays minerals, 19.

MITCHELL, J.K.; HOOPER, D. R. \& CAMPANELLA, R. G. (1965). “ Permeability of compacted clay". J. Soil mechanics and foudation division., ASCE, 91 (4), p. 41-65.

MOLLAMAHMUTOGLU, M., YILMAZ, Y. (2001) - Potential use of fly ash and bentonite mixture as liner or cover at waste disposal areas. ENVIRONMENTAL GEOLOGY, 40 (1112).

NOGAMI, J. S. \& VILLIBOR, D. F., (1995). "Pavimentação de baixo custo com solos lateríticos”. Ed. Villibor, 1 ed, 317p., São Paulo, SP.

OLSON, R. E. AND DANIEL, D. E. (1981). Measurement of the Hydraulic Conductivity of Fine-Grained Soils, Permeability and Graundwater Contaminant Transport, ASTM STP 746, T. F. Zimme and C. O. Riggs, Eds., American Society for Testing and Materials, Philadelphia, pp. 18-64.

SHARMA, H. D. AND LEWIS, S. P. (1994). Waste Containment Systems, Waste Stabilization, and landfills. John Willey \& Sons, INC. 
SEED, H. B. \& CHAN, C.K, (1995) “ Structure and strength characteristics of compacted clays.” J. Soil Mechanics and Foundation Division., 85(5), p.87-128.

TCHOBANOGLOUS, G..; THEISEN, H.; VIGIL, S. (1993) integrated Solid Waste Management Engineering Principles and Management Issues. McGraw-Hill, Inc, 1993, 978p.

TIVERON, V. P. M.; MARQUES, A. C. M.; NAHAS, C. M.; FRANCISCO, N.C.T. \& GODOI, M.O. (1995). Disposição de resíduos Sólidos no Município de Sã Paulo. Aterros sanitários. I Seminário Luso-Brasileiro de Geotecnia Ambiental, Lisboa, 1995. 15p.

WANG, X. AND BENSON, C. H. (1999). Hydraulic Conductivity Testing of Geosynthetic Clay Liners (GCLs) Using the Constant Volume Method. Geotechnical Testing Journal, GTJODJ, Vol. 22, $\mathrm{N}^{\mathrm{0}}$ 4,

December 1999, pp 277-283.

WATABE Y, LEROUEIL S, LE BIHAN JP. "Influence of compaction conditions on poresize distribution and saturated hydraulic conductivity of a glacial till" Canadian Geotechnical Journal, Quebec, 37(6).

ZUQUETTE, L.V; PEJON, O.J.; SINELLI, O. GANDOLFI, N. (1995). Carta de Zoneamento Específico para Disposição de Resíduos de Região de Ribeirão Preto-SP. III SIMPÓSIO SOBRE BARRAGENS DE REJEITOS E DISPOSIÇÃO DE RESÍDUOS - REGEO'95, v.II, Ouro Preto/MG, p. 5535-548. 


\section{Apêndice}

\section{Ensaio em Permeâmetro de Parede Flexível}

O permeâmetro de parede flexível e o sistema de controle hidráulico fechado são apresentados na Figura A1.

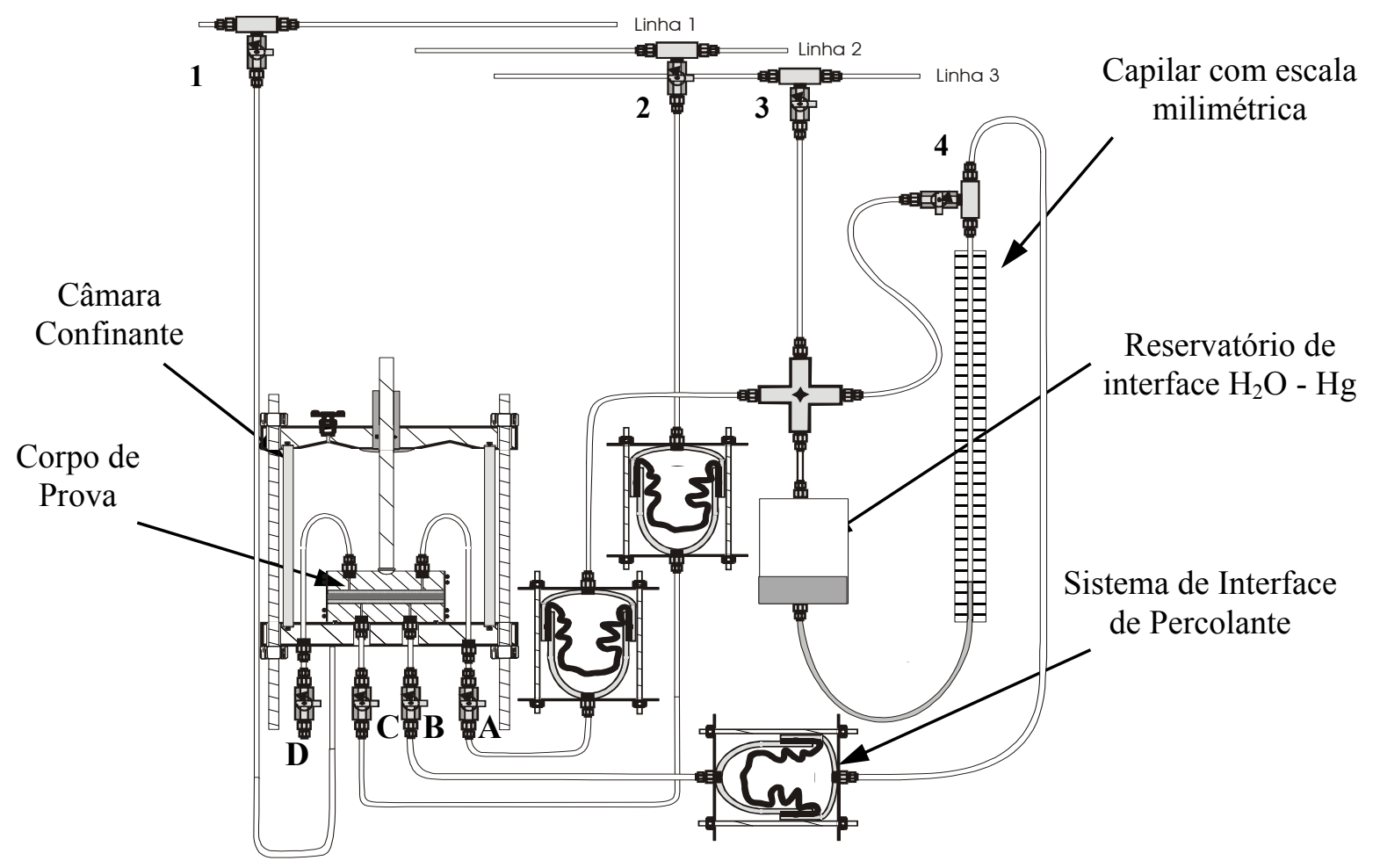

Figura A1 - Esquema do sistema de controle hidráulico fechado, Dourado (2003).

Registro 1: Acesso à câmara confinante.

Registro 2 :Acesso à base do corpo-de-prova.

Registro 3 :Acesso ao sistema hidráulico fechado (topo e base do C.P.).

Registro 4: Quando aberto equilibra as pressões entre o reservatório $\left(\mathrm{H}_{2} \mathrm{O}-\mathrm{Hg}\right)$ e o tubo capilar

Registro A: Acesso ao topo do C.P. pelo Sistema Hidráulico Fechado.

Registro B: Acesso à base do $\mathrm{CP}$ pelo Sistema Hidráulico fechado.

Registro C: Acesso à base do CP pela linha 2.

Registro D: Acesso do topo do CP à atmosfera. 


\section{- Montagem do ensaio:}

A seqüência de montagem dos corpos-de-prova no permeâmetro não depende do tipo de material a ser ensaiado. Sobre o pedestal e de forma concêntrica, coloca-se em ordem seqüencial, pedra porosa (previamente saturada), papel filtro, corpo-de-prova, papel filtro e pedra porosa (previamente saturada), como ilustrado na Figura A2a. O cabeçote é posto sobre a pedra porosa superior e o corpo-de-prova é envolvido por uma membrana flexível, fixandoa no pedestal e no cabeçote com o'ring ou elásticos, como é ilustrado na Figura A2b. Em seguida encaixa-se a parede lateral sobre a base, Figura A3a, e a tampa sobre a parede lateral, prendendo todo o conjunto com porcas e borboleta, Figura A3b.

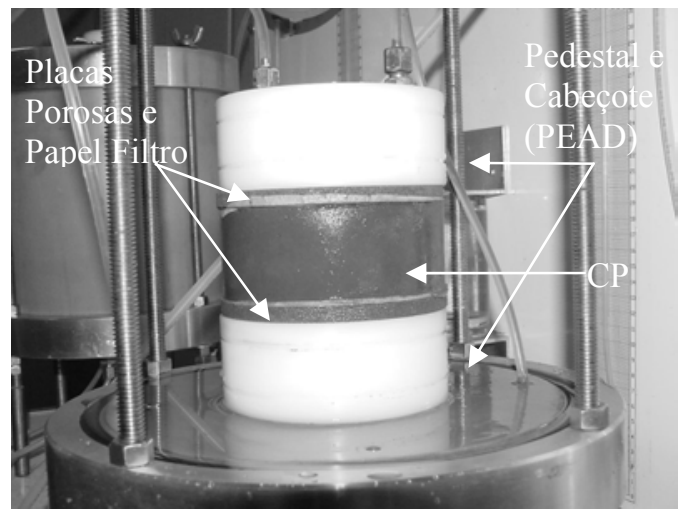

(a)

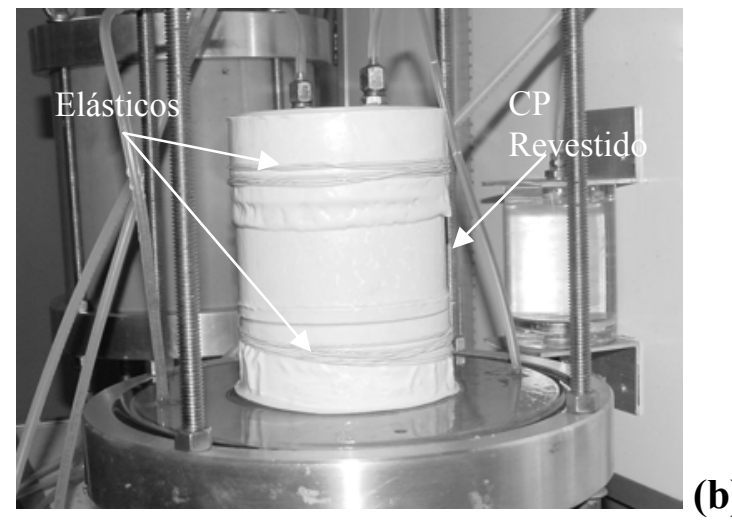

(b)

Figura A2 a, b - Seqüência de montagem do ensaio em permeâmetro de parede flexível.

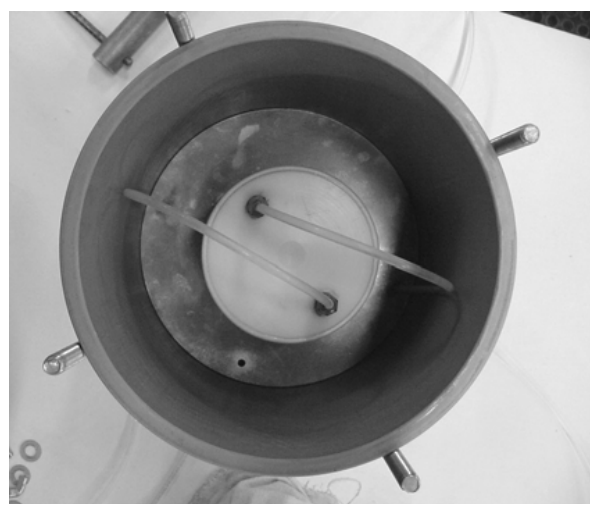

(a)

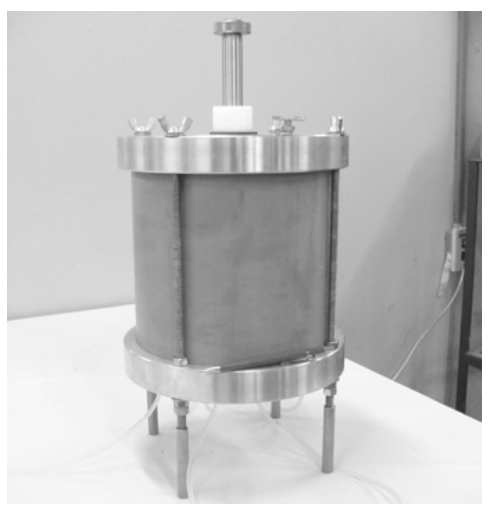

(b)

Figura A3 a,b - Detalhe de fechamento da câmera confinate, Dourado (2003).

Após o fechamento da câmara confinante, deve-se abrir o registro 1 (Figiura A1) para que o fluido confinante ocupe lentamente a câmara, a medida em que o ar presente no seu interior é drenado pela válvula de acento da tampa. 


\section{- Saturação do sistema:}

Após o enchimento e antes de submeter o corpo-de-prova à saturação por contra-pressão, aplica-se uma baixa pressão de confinamento, entre 7 e $35 \mathrm{kPa}$ (linha 1). Faz-se circular água, com pressão inferior à pressão confinante pelo cabeçote e pedestal, com o objetivo de eliminar o ar retido nos tubos e pedras porosas.

Para a circulação de água pelo cabeçote uma pressão inferior a pressão confinante deve ser aplicada na linha 3, os registros 3, A e D devem ser abertos na seqüência citada. O fluxo de água deve ser mantido até que não se observe saída de bolhas de ar pelo registro D (aproximadamente 10 mim para corpos-de-prova de solo compactado). Após a eliminação das bolhas deve-se fechar os registros $\mathbf{D}, \mathbf{A}$ e 3 na seqüência citada.

Para a circulação de água pelo pedestal, deve-se aplicar uma pressão inferior a pressão confinante na linha 3 , a mangueira do registro $\mathrm{C}$ deve ser desconectada, os registros 3,4 , B e C devem ser abertos na seqüência citada. O fluxo deve ser mantido até que não se observe saída de bolhas de ar pelo registro $\mathbf{C}$ (aproximadamente $10 \mathrm{mim}$ para corpos-de-prova de solo compactado). Após a eliminação das bolhas deve-se saturar a mangueira da linha 2 e conectar ao registro $\mathbf{C}$, os registros $\mathbf{C}$, B e $\mathbf{4}$ devem ser fechados na seqüência citada.

\section{- Saturação do corpo-de-prova:}

A saturação do corpo-de-prova é obtida pelo incremento da pressão confinante e contrapressão, sendo que a pressão confinante deve ser maior do que a contra-pressão. Deve-se proceder da seguinte maneira: ajusta-se a pressão desejada para a linha 1 (confinante), e para a linha 3 (contra-pressão); deve-se abrir os registros 1, 3, 4, A e B na seqüência citada. Neste momento deve-se observar se a diferença de pressão entre a pressão confinante e a contrapressão é mantida. A saturação é atingida por incrementos de pressão confinante e contra pressão como é proposto por Head (1986), e verificada pelo parâmetro B. 


\section{- Verificação do Parâmetro B}

Após o processo de saturação descrito acima, para a verificação do parâmetro B deve-se proceder da seguinte maneira:

Tomemos como exemplo a seguintes condições de pressão:

Linha 1 ajustada para pressão confinante igual a $600 \mathrm{kPa}$.

Linha 3 ajustada para contra pressão igual a $560 \mathrm{kPa}$.

$11^{0}$ Passo: Fechar o registro 1 e fazer um incremento de pressão na linha 1 (pressão confinante): ex. pressão inicial na linha $1=600 \mathrm{kPa}$, pressão final $=650 \mathrm{kPa}$, incremento $=$ $50 \mathrm{kPa}$.

$2^{\circ}$ Passo: Fechar os registros A, B, C, D, 2 e 3 e fazer um incremento na contra pressão da mesma magnitude do incremento realizado na pressão confinante: ex. pressão na linha 2 e 3 inicial $=560 \mathrm{kPa}$, pressão final na linha 2 e $3=610 \mathrm{kPa}$.

$3^{\circ}$ Passo: Mantendo o registro $\mathbf{C}$ fechado, abrir o registro 2 para que a pressão de contra pressão pressurize a mangueira até o registro C. Isso deve ser feito para que não haja perda de carga devido a pressurização das mangueiras.

$4^{\mathbf{0}}$ Passo: Cortar a alimentação da contra pressão (linha 2 e 3 ) e monitorar a pressão da linha 2 por meio do atuador servo controlado.

$5^{\circ}$ Passo: Abrir o registro 1 para impor na câmara confinante o incremento de pressão (ex. $650 \mathrm{kPa}$ ). Neste momento deve-se abrir o registro $\mathbf{C}$ para medir a pressão axial do corpo-deprova por meio do atuador servo controlado.

$6^{0}$ Passo: Esperar para que a pressão axial do corpo-de-prova (medida pelo atuador servo controlado) se estabilize. A pressão medida no atuador menos a contra pressão inicial de contra pressão é igual a variação de pressão sofrida no corpo-de-prova axialmente. Essa variação de pressão representa a variação de pressão neutra do corpo-de-prova, sendo o parâmetro B definido como: 
$B=\frac{\Delta u}{\Delta \sigma_{3}}$

Em que:

$\Delta \mathrm{u}$ - variação da pressão neutra;

$\Delta \sigma_{3}-$ variação da pressão confinante.

Exemplo:

Variação de pressão confinante (incremento), $\Delta \sigma_{3}=50 \mathrm{kPa}$;

Contra pressão inicial $=560 \mathrm{kPa}$;

Pressão medida pelo atuador na linha $2=608 \mathrm{kPa}$;

Variação de pressão neutra do corpo-de-prova, $\Delta \mathrm{u}=608-560=48 \mathrm{kPa}$.

$B=\frac{\Delta u}{\Delta \sigma_{3}}=\frac{48 k P a}{50 k P a}=0,96$

\section{- Imposição do Gradiente Hidráulico}

Para que ocorra fluxo através do corpo-de-prova é necessária a imposição de um gradiente de pressão entre o topo e a base, portanto, neste instante o sistema encontra-se pressurizado sob o valor ajustado na linha 2 e 3 para a contra-pressão e na linha 1 para pressão confinante. Antes da aplicação do gradiente hidráulico, com o registro 4 aberto, deve ser realizada a leitura da posição de equilíbrio da coluna de $\mathrm{Hg}$ no tubo capilar. $\mathrm{O}$ gradiente é imposto por um atuador servo-controlado na linha 3, sendo nele programada a pressão de contra-pressão mais o incremento de pressão responsável pela aplicação do gradiente hidráulico inicial desejado. Nesta etapa o registro 4 é mantido fechado, os registros 2 e 3 do sistema são mantidos abertos, bem como os registros A, B e C da câmara. Ocorrerá fluxo como mostra a Figura A4, ascendendo uma coluna de $\mathrm{Hg}$ no tubo capilar, até que haja equilíbrio entre as colunas do reservatório e do tubo capilar; atingido o equilíbrio nas colunas, tem-se um gradiente de pressão entre a base e o topo do $\mathrm{CP}$ que é proporcional à diferença entre as pressões das fontes 3 e 2 . 


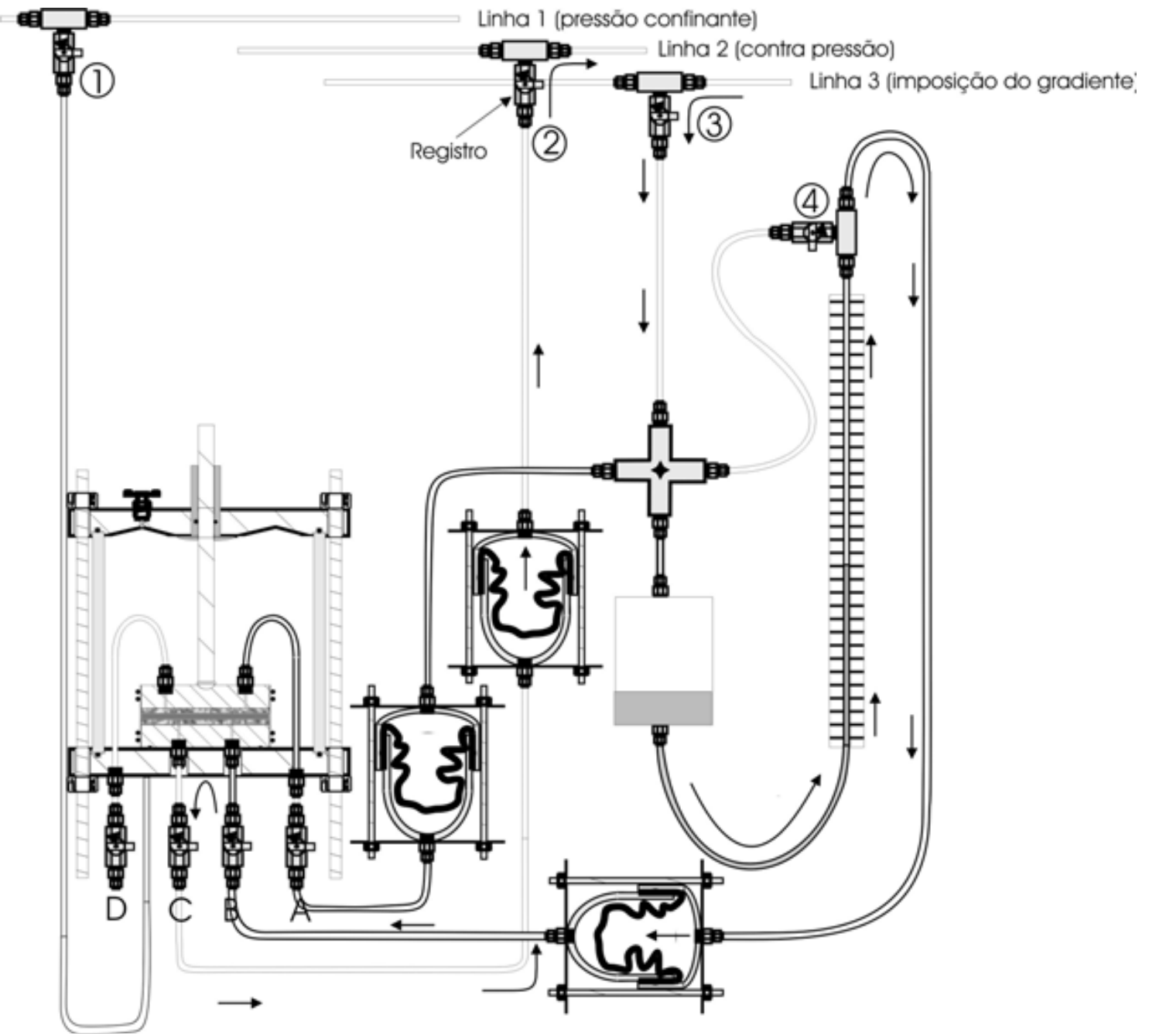

Figura A4 - Fluxo de imposição do gradiente de pressão no sistema fechado, Dourado (2003).

\section{- Percolação do Corpo-de-Prova}

Nesta fase, a fase de ensaio, se inicia com a leitura da posição inicial da coluna de $\mathrm{Hg}$ do tubo capilar, em seguida deve-se fechar os registros 2 e 3, simultaneamente com ínicio da contagem do tempo. Corta-se o acesso das linhas 2 e 3, a coluna de $\mathrm{Hg}$ no tubo capilar que estava compensando a diferença de pressão entre as linhas 2 e 3 tenderá a voltar ao equilíbrio, forçando fluxo através do corpo-de-prova conforme ilustrado na Figura A5. 


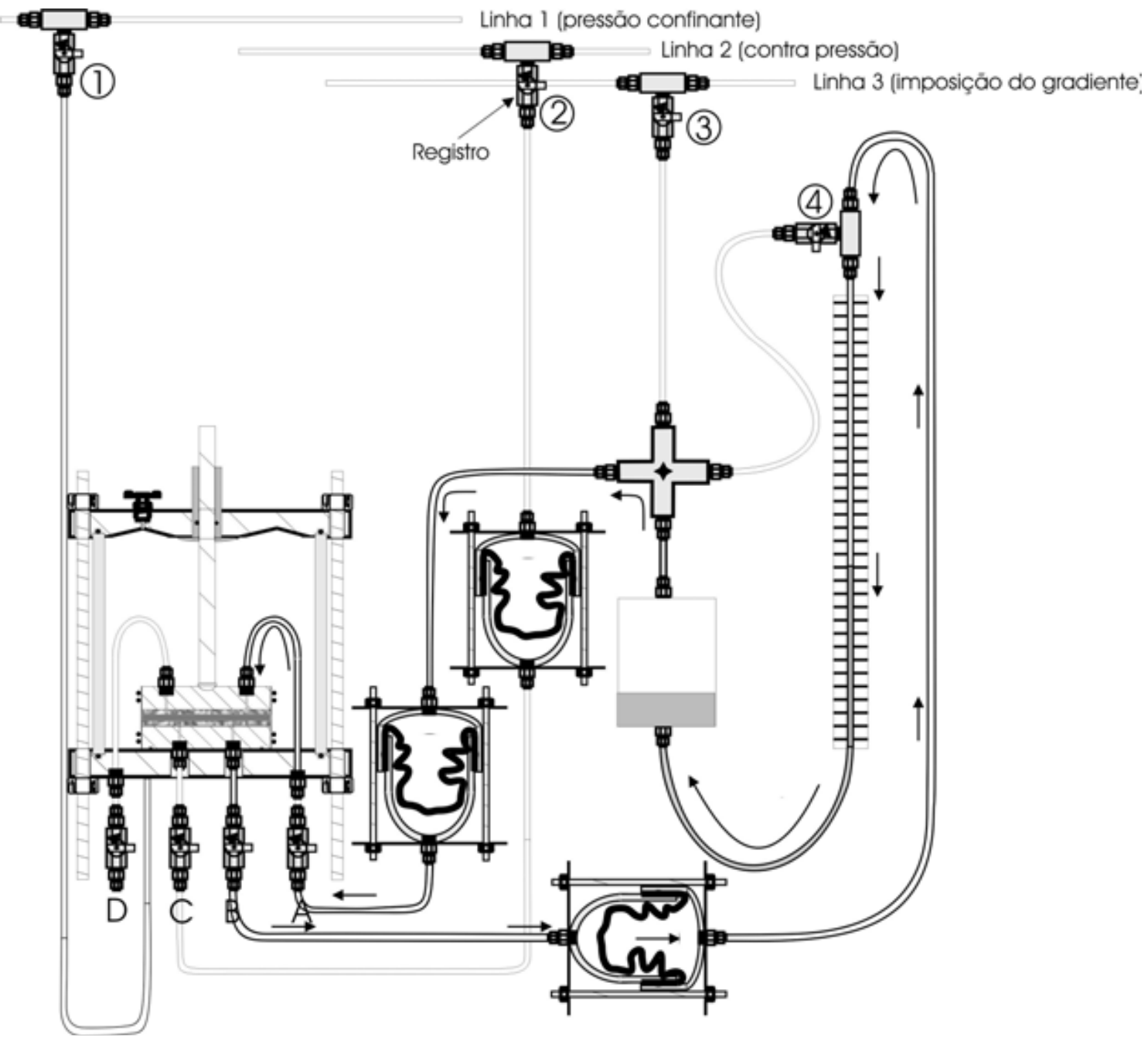

Figura A5 - Fluxo durante o ensaio com o sistema fechado, Dourado (2003).

Deve-se realizar leituras da posição da coluna de $\mathrm{Hg}$ no tubo capilar, tempo percorrido de ensaio e temperatura, até que cesse o fluxo através do corpo-de-prova.

- Cálculo da condutividade hidráulica:

O cálculo da condutividade hidráulica é realizado com a Equação A1.

$k=\frac{a \cdot A}{(a+A) \cdot\left(G_{H g}-G_{H_{2} O}\right)} \cdot \frac{L}{S \cdot \Delta t} \cdot \ln \left(\frac{Y_{i}}{Y_{i+1}}\right)$ 
Em que:

$\mathrm{k}$ : $\quad$ condutividade hidráulica entre as leituras i e i +1 ;

a : área do tubo capilar;

A: $\quad$ área da caneca de mercúrio;

L: $\quad$ altura do CP;

$\mathrm{S}: \quad$ área do $\mathrm{CP}$;

$\mathrm{Y}_{\mathrm{i}, \mathrm{i}+1}$ : altura da coluna de mercúrio do capilar no tempo i e $\mathrm{i}+1$;

$\Delta \mathrm{t}: \quad$ diferença de tempo entre as leituras $\mathrm{Y}_{\mathrm{i}}$ e $\mathrm{Y}_{\mathrm{i}+1}$;

$\mathrm{G}_{\mathrm{Hg}}$ : densidade relativa do mercúrio;

$\mathrm{G}_{\mathrm{H} 2 \mathrm{O}}$ : densidade da água.

\section{- Dimensões do equipamento:}

As dimensões dos tubos capilares e canecas de interface $\mathrm{Hg}-\mathrm{H}_{2} \mathrm{O}$ dos sistemas de controle hidráulico fechado são apresentadas na Tabela A1. Detalhes da construção do equipamento podem ser encontrados em Dourado (2003).

Tabela 1 - Área da seção transversal do tubo capilar e caneca de interface $\mathrm{Hg}-\mathrm{H}_{2} \mathrm{O}$, adaptado de Dourado (2003).

\begin{tabular}{ccccc}
\hline Sistema & $\mathbf{1}$ & $\mathbf{2}$ & $\mathbf{3}$ & $\mathbf{4}^{\mathbf{*}}$ \\
\hline "a", Área Tubo Capilar $\left(\mathrm{cm}^{2}\right)$ & 0,059923 & 0,064374 & 0,057256 & 0,7112 \\
\hline "A", Área Caneca $\left(\mathrm{cm}^{2}\right)$ & 32,16991 & 32,16991 & 32,16991 & 32,16991
\end{tabular}

*As dimensões do sistema 4 foram modificadas para a adaptação do equipamento para ensaios com materiais mais permeáveis, $\leq 10^{-7} \mathrm{~cm} / \mathrm{s}$.

A diferença de ascensão capilar de $\mathrm{Hg}$ entre o tubo capilar e a caneca de interface é compensada no cálculo de $\mathrm{k}$ quando de considera a posição de equilíbrio da coluna de $\mathrm{Hg}$ no tubo capilar. 